\title{
United abominations:
}

Density functional studies of heavy metal chemistry

by

\section{George Schoendorff}

A dissertation submitted to the graduate faculty

in partial fulfillment of the requirements for the degree of

DOCTOR OF PHILOSOPHY

\author{
Major: Physical Chemistry \\ Program of Study Committee: \\ Mark Gordon, Co-major Professor \\ Theresa Windus, Co-major Professor \\ Andreja Bakac \\ William Jenks \\ Gordon Miller \\ Aaron Sadow
}

Iowa State University

Ames, Iowa State University 


\section{Graduate College \\ Iowa State University}

This is to certify that the doctoral dissertation of

George Emil Schoendorff

has met the dissertation requirements of Iowa State University

Co-major Professor

Co-major Professor

For the Major Program 
TABLE OF CONTENTS

ACKNOWLEDGEMENTS vi

CHAPTER 1. GENERAL INTRODUCTION 1

General Overview 1

Dissertation Organization 2

Theoretical Background 2

$\begin{array}{ll}\text { References } & 21\end{array}$

CHAPTER 2. DENSITY FUNCTIONAL STUDIES ON THE COMPLEXATION AND SPECTROSCOPY OF URANYL LIGANTED WITH ACETONITRILE AND ACETONE DERIVATIVES

Abstract $\quad 24$

Introduction 25

Details of the Calculations 27

Results and Discussion $\quad 28$

Conclusion $\quad 36$

Acknowledgements $\quad 37$

Tables and Figures $\quad 38$

References $\quad 49$

CHAPTER 3. GAS PHASE COMPUTATIONAL STUDIES ON THE COMPETITION BETWEEN NITRILE AND WATER LIGANDS IN URANYL COMPLEXES

Abstract 52

Introduction 53

Details of the Calculations $\quad 55$

Results and Discussion $\quad 56$

$\begin{array}{ll}\text { Conclusion } & 67\end{array}$

Acknowledgements 69

Tables and Figures $\quad 71$

References $\quad 84$

CHAPTER 4. ON THE FORMATION OF "HYPERCOORDINATED” URANYL COMPLEXES

Abstract 86

Introduction $\quad 87$

$\begin{array}{ll}\text { Details of the Calculations } & 87\end{array}$

Discussion $\quad 88$

Conclusions $\quad 92$

Acknowledgements $\quad 94$

Tables and Figures $\quad 95$

References $\quad 99$ 
CHAPTER 5. SOLVING THE RIDDLES OF URANYL ACETONE COMPLEXES: WATER-ELIMINATION AND "HYPERCOORDINATION"

Abstract 101

Introduction 102

Experimental Details 103

Computational Details 105

Results and Discussion 106

$\begin{array}{ll}\text { Conclusion } & 119\end{array}$

Acknowledgements 120

$\begin{array}{ll}\text { Tables and Figures } & 121\end{array}$

References 128

CHAPTER 6. STRUCTURE, BONDING, AND LIGAND-BASED REACTIONS OF ZWITTERIONIC BORATOIRIDIUM(I) COMPLEXES WITH OXAZOLINE-BASED SCORPIONATE LIGANDS

Abstract 130

Introduction 131

Results and Discussion 132

Concluding Remarks $\quad 143$

Acknowledgement 144

Experimental - General Procedures 145

Details of the Density Functional Theory Calculations 151

Tables and Figures $\quad 153$

References 159

CHAPTER 7. CATALYTIC HYDROAMINATION/CYCLIZATION OF

$\mathrm{PhB}\left(\mathrm{C}_{5} \mathrm{H}_{4}\right)\left(\mathrm{Ox}^{\mathrm{R}_{2}}\right)_{2} \mathrm{Zr}\left(\mathrm{NR}^{\prime}\right)\left(\mathrm{NR}{ }^{\prime \prime}\right)$

Abstract 163

Introduction 163

Computational Details 165

Results and Discussion 167

Conclusion 171

Acknowledgements 172

Tables and Figures 173

$\begin{array}{ll}\text { References } & 179\end{array}$

CHAPTER 8. AN OVERVIEW OF GPU CODING TECHNIQUES WITH PGI FORTRAN

Introduction 181

Fermi Architecture 183

Explicit Model 184

Directives 190

Restrictions 194

Libraries 196

Specific Issues 197

Conclusion 199 
$\begin{array}{lr}\text { Acknowledgements } & 200\end{array}$

Additional Information $\quad 200$

$\begin{array}{ll}\text { Glossary } & 201\end{array}$

Figures

202

$\begin{array}{lr}\text { References } & 210\end{array}$

CHAPTER 9. GENERAL CONCLUSIONS

$\begin{array}{ll}\text { Uranyl Complexes } & 213\end{array}$

$\begin{array}{ll}\text { Boratoiridium(I) Complexes } & 218\end{array}$

$\begin{array}{ll}\text { Catalytic Hydroamination/Cyclization } & 219\end{array}$

PGI Fortran for Graphical Processors $\quad 220$

$\begin{array}{ll}\text { References } & 221\end{array}$ 


\section{ACKNOWLEDGEMENTS}

I would like to thank my advisors, Mark Gordon and Theresa Windus, for their support throughout my graduate career. I would also like to thank Mike Schmidt for answering a multitude of questions ranging from how to use GAMESS to the meaning of life; John Gibson, Mike van Stipdonk, and Wibe de Jong for their assistance with the actinide studies; and Aaron Sadow for letting me meddle in his projects. I also want to thank Jie Song for convincing me to go to graduate school and helping me choose ISU, and Charles Stewart for being the first to show me that chemistry is interesting. Finally, I would like to dedicate this dissertation to the memory of Benjamin Baird, without whom chapter 6 would not have been possible.

This work was performed at the Ames Laboratory under contract number DE-AC0207CH11358 with the U. S. Department of Energy. The document number assigned to this dissertation is IS-T 3047. 


\section{CHAPTER 1. GENERAL INTRODUCTION}

\section{General Overview}

The study of chemical systems that contain heavy elements is a particularly challenging branch of computational chemistry. Such studies require correlation of a large number of electrons, use of high angular momentum basis functions, and treatment of relativistic effects. Ideally, one would like to achieve a full configuration interaction (CI) calculation 4-component relativistic calculation with a complete basis set. This goal is unattainable for all but the smallest chemical systems, but a number of approximate methods can be used to make the study of heavy element chemistry computationally feasible. The methods employed in the study of the chemical systems presented in this dissertation are described in Section 3 of this chapter.

Computational chemistry is useful particularly when studying chemical systems that are difficult to work with experimentally due to safety, economic, or other concerns. Frequently, this is the case when it comes to the study of actinides, primarily due to their radioactive nature and regulations concerning their safe use. In cases where experimental work is feasible, computational chemistry can help explain experimental results as well as provide direction for new experiments. To this end, sizeable collaborative effort between experimentalists and theorists has aided in the advancement of our studies of gas phase actinide chemistry. Experimental results have been the driving forces behind most of the computational studies presented in later chapters, but computational results have recently inspired new experiments. A separate collaboration with the Sadow group has also enabled a deeper understanding of some transition metal and main group chemistry. Currently, computational methods are being used to help interpret experimental 
observations, but it is conceivable that computational studies may prompt new experiments in the future.

\section{Dissertation Organization}

The present work consists of chapters that are either in press, in preparation for submission, or previously unpublished. Chapter 2 is a study of carbonyl and nitrile addition to uranyl $\left(\mathrm{UO}_{2}{ }^{2+}\right)$. Chapter 3 investigates the competition between nitrile and water ligands in the formation of uranyl complexes. Chapter 4 examines the possibility of hypercoordinated uranyl with acetone ligands. Chapter 5 is a study of uranyl with diactone alcohol ligands as a means to explain the apparent hypercoordinated uranyl. A Discussion of the formation of mesityl oxide ligands is also included in chapter 5. Chapter 6 is a joint theory/experimental study of reactions of zwitterionic boratoiridium(I) complexes with oxazoline-based scorpionate ligands. Chapter 7 is a computational study of the catalytic hydroamination/cyclization of aminoalkenes with zirconium-based catalysts. Chapter 8 is a survey of techniques for programming for graphical processing units (GPUs) using Fortran. Chapter 9 is a discussion of the general conclusions drawn from the work presented in this dissertation.

\section{Theoretical Background}

Quantum mechanical systems are described by the time-dependent Schrödinger

equation $^{1}$ (Eq. 1). In Eq. $1 i=\sqrt{-1}, \hbar$ is Plank's constant (h) divided by $2 \pi, \hat{H}$ is the Hamiltonian operator, and $\Psi(r, R, t)$ is the wave function as a function of electronic coordinates, nuclear coordinates, and time, respectively. 
$-i \hbar \frac{\partial}{\partial t} \Psi(r, R, t)=\hat{H} \Psi(r, R, t)$

Most information of interest to a chemist can be obtained by solving for stationary state solutions of the Schrödinger equation. The stationary state subset of solutions to Eq. 1 can be obtained by solving the time independent Schrödinger equation (Eq. 2). Eq. 2 is a second order differential equation that depends only on electronic and nuclear coordinates. Eq. 2 is also an eigenvalue equation with the eigenfunction $\Psi(r, R)$ corresponding to the stationary state solutions of the Schrödinger equation. The corresponding eigenvalue, E, is the energy associated with a stationary state solution.

$\hat{H} \Psi(r, R)=E \Psi(r, R)$

The Hamiltonian operator from Eq. 2 in atomic units is given in Eq. 3. The first two terms are the electronic $\left(\hat{T}_{e}\right)$ and nuclear $\left(\hat{T}_{n}\right)$ kinetic energy operators, respectively. $\nabla_{i}$ is the Laplacian of electron $\mathrm{i}, \nabla_{A}$ is the Laplacian of nucleus $\mathrm{A}, \mathrm{m}_{\mathrm{A}}$ is the mass of nucleus A, and the sums run over all electrons and all nuclei. The final three terms are potential energy operators that correspond to electron-nuclear attraction $\left(\hat{V}_{e n}\right)$, electronelectron repulsion $\left(\hat{V}_{e e}\right)$, and nuclear-nuclear repulsion $\left(\hat{V}_{n n}\right) . \mathrm{Z}_{\mathrm{A}}$ is the charge of nucleus $A ; R_{A}$ is the position of nucleus $A ; r_{i}$ is the position of electron $i$. 


$$
\hat{H}=\underbrace{-\frac{1}{2} \sum_{i=1}^{\text {electrons }} \nabla_{i}^{2}}_{\hat{T}_{e}}-\underbrace{\frac{1}{2} \sum_{A=1}^{\text {nuclei }} \frac{\nabla_{A}^{2}}{m_{A}}}_{\hat{T}_{n}}-\underbrace{\sum_{A=1}^{\text {nuclei electrons }} \sum_{i=1}^{\left|R_{A}-r_{i}\right|}}_{\hat{V}_{e n}}+\underbrace{\sum_{i>j}^{\text {electrons }} \frac{1}{\left|r_{i}-r_{j}\right|}}_{\hat{V}_{e e}}+\underbrace{\sum_{A>B}^{\text {nuclei }} \frac{Z_{A} Z_{B}}{\left|R_{A}-R_{B}\right|}}_{\hat{V}_{n n}}
$$

The motion of the nuclei and electrons is coupled in term 3 of Eq. $3\left(\hat{V}_{e n}\right)$. This results in a total wave function as a function of $3 \mathrm{n}$ electronic coordinates and $3 \mathrm{~N}$ nuclear coordinates in a Cartesian representation. An approximation can be made that effectively decouples the electronic and nuclear motions. The relative motion of the electrons is much faster than the motion of the nuclei due to the large difference in their masses. From the point of view of an electron, the nuclei are essentially stationary and electrons will "instantaneously" adjust to any change in nuclear positions. This is the essence of the Born-Oppenheimer approximation ${ }^{2}$. Since the Born-Oppenheimer approximation allows for the separation of electronic and nuclear coordinates, the electronic Schrödinger equation can be solved for fixed nuclear positions. When the Born-Oppenheimer approximation is made, the nuclear kinetic energy term $\left(\hat{T}_{n}\right)$ is zero and the nuclearnuclear repulsion $\left(\hat{V}_{n n}\right)$ becomes a constant. The resulting electronic Hamiltonian is given in Eq. 4. The electronic Hamiltonian acts on a wave function independent of nuclear coordinates in the electronic Schrödinger equation (Eq. 5).

$$
\begin{aligned}
& \hat{H}_{e l}=-\frac{1}{2} \sum_{i=1}^{\text {electrons }} \nabla_{i}^{2}-\sum_{A=1}^{\text {nucle electrons }} \sum_{i=1}^{\mid} \frac{Z_{A}}{\left|R_{A}-r_{i}\right|}+\sum_{i>j}^{\text {electrons }} \frac{1}{\left|r_{i}-r_{j}\right|} \\
& \hat{H}_{e l} \psi_{e l}(r)=E_{e l} \psi_{e l}(r)
\end{aligned}
$$


Eq. 5 produces the electronic energy of a molecule with a fixed nuclear configuration. The total energy $\mathrm{U}(\mathrm{R})$ (Eq. 6) can be recovered by addition of $\hat{V}_{n n}$ to the electronic energy. The nuclear-nuclear repulsion term is treated with classical point charges, since the nuclei are assumed to be stationary within the Born-Oppenheimer approximation. Repeating this process for a range of nuclear configurations allows one to construct a potential energy surface from which chemically relevant information such as minima and barrier heights can be obtained.

$U(R)=E_{e l}+\sum_{A>B}^{\text {nuclei }} \frac{Z_{A} Z_{B}}{\left|R_{A}-R_{B}\right|}$

The exact wave function is a complicated function of electronic and nuclear coordinates. In general, the exact wave function is not known. Since the Hamiltonian is additive with respect to the indices for each electron or nucleus, it is reasonable to construct an initial wave function as a product of one-particle functions. A Hartreeproduct (HP) wave function (Eq. 7) is a wave function in which each $\phi$ is a one-electron function. Each $\phi$ can be thought of as a molecular orbital.

$\Psi_{H P}=\phi_{1} \phi_{2} \ldots \phi_{N}$

The Hartree-product wave function is a symmetric function, but fermions (e.g., electrons) are described by antisymmetric functions. So the sign of the wave function must change if the indices of the electrons are swapped. This can be achieved by 
constructing a Slater determinant (Eq. 8) ${ }^{3}$. The Hartree-Fock (HF) wave function can be written as such a determinant.

$\Psi_{H F}=\left|\phi_{1} \phi_{2} \ldots \phi_{N}\right|$

The Hartree-Fock method is an ab initio approach to treat many electron systems and is generally a starting point for more advanced methods ${ }^{4}$. The difficulty involved in solving many electron systems arises from the $\hat{V}_{e e}$ term in the Hamiltonian. This term couples electronic coordinates. Electronic coupling is not present in the Hartree-Fock wave function, but it is accounted for in the Hamiltonian. In order to deal with the coupling of electronic coordinates, the Hartree-Fock method uses a one electron Fock operator that treats $\hat{V}_{e e}$ as one-electron potentials in the field of the other electrons (Eq. 9). In Eq. 9, the first term is the kinetic energy of electron n, the second term is the electron-nuclear repulsion energy of electron $\mathrm{n}$ with all the nuclei, and the final term is an approximate electron-electron repulsion of electron $\mathrm{n}$ in the mean field of the other electrons.

$\hat{f}(n)=-\frac{1}{2} \nabla_{n}^{2}-\sum_{A=1}^{\text {nuclei }} \frac{Z_{A}}{\left|R_{A}-r_{n}\right|}+\hat{V}_{H F}(n)$

Because the last term of Eq. 9 requires knowledge of the other electrons, the HF equations must be solved iteratively to obtain optimized orbitals and orbital energies. This iterative process is the self-consistent field (SCF) method. For each electron, n, $\hat{V}_{H F}$ 
can be separated into the sum of a Coulomb $(\hat{J})$ term and an exchange $(\hat{K})$ term (Eq. 10$)$. The Coulomb term is defined in Eq. 11 and the exchange term is defined in Eq. 12. The $i, j$ indices denote molecular orbitals or basis functions and the 1,2 indices denote electrons.

$$
\begin{aligned}
& \hat{V}_{H F}(n)=\sum_{i} \hat{J}_{i}(n)+\sum_{i} \hat{K}_{i}(n) \\
& \hat{J}_{i}(1) \phi_{j}(1)=\left[\int d \tau_{2} \phi_{i}^{*}(2) \frac{1}{r_{12}} \phi_{i}(2)\right] \phi_{j}(1) \\
& \hat{K}_{i}(1) \phi_{j}(1)=\left[\int d \tau_{2} \phi_{i}^{*}(2) \frac{1}{r_{12}} \phi_{j}(2)\right] \phi_{i}(1)
\end{aligned}
$$

Solutions to the HF equations are optimized sets of molecular orbitals. The orbital energies are given in Eq. 13 where $\varepsilon_{i}$ is the energy of orbital $\phi_{i}$. For closed shells, the Fock operator $\hat{f}(n)$ is defined in Eq. 14. The first two terms are $\hat{T}_{e}$ and $\hat{V}_{e n}$ for electron $n$. The last term, $\hat{V}_{\mathrm{HF}}(n)$, is the average potential of electron $\mathrm{n}$ in the field of the other electrons. These orbitals are optimized variationally such that the energy is minimized. The variational principle provides a lower bound for the energy that corresponds to the exact solution. Any improvement on the HF method will approach the exact solution from above.

$\hat{f}(n) \phi_{i}(n)=\varepsilon_{i} \phi_{i}(n)$ 
$\hat{f}(n)=-\frac{1}{2} \nabla_{n}^{2}-\sum_{A=1}^{\text {nuclei }} \frac{Z_{A}}{\left|r_{n}-R_{A}\right|}+\underbrace{\sum_{i=1}^{\text {electrons }}\left(2 \hat{J}_{i}(n)-\hat{K}_{i}(n)\right)}_{\hat{V}_{\mathrm{HF}}(n)}$

The Hartree-Fock method describes electronic motion in a mean field of the other electrons. The electrons are not explicitly correlated. The correlation energy is defined as the difference in energy between the exact energy and the Hartree-Fock energy (Eq. 15), ignoring relativistic effects. This energy difference is the energy due to correlation effects that are not accounted for by the mean field approximation made in the HartreeFock method. The correlation energy is usually a small fraction of the total energy, but a small fraction of the total energy still can be on the order of tens or even hundreds of $\mathrm{kcal} / \mathrm{mol}$, depending on the size of the system. It is frequently necessary to recover some of the correlation energy to achieve chemical accuracy.

$E_{\text {corr }}=E_{\text {exact }}-E_{H F}$

Many body perturbation theory (MBPT) is a method that can recover much of the correlation energy. The total Hamiltonian is treated as a sum of a one-particle Hamiltonian $\left(\hat{H}_{0}\right)$ plus a perturbation $\left(\hat{H}^{\prime}\right)$. Both the Hamiltonian and the wave function are expanded in terms of the perturbation (Eqs. 17 and 18) $)^{5,6}$.

$$
\begin{aligned}
& \hat{H}=\hat{H}_{0}+\lambda \hat{H}^{\prime} \\
& \Psi=\Psi_{0}+\sum_{i=1}^{n} \lambda^{i} \Psi_{i}
\end{aligned}
$$




$$
E=E_{0}+\sum_{i=1}^{n} \lambda^{i} E_{i}
$$

A common implementation of perturbation theory is Møller-Plesset perturbation theory ${ }^{7}$. Møller-Plesset perturbation theory is not variational, so there is no lower bound to the energy. It is, however, size consistent ${ }^{1}$ and size extensive ${ }^{2}$, which makes it an attractive alternative to truncated configuration interaction (CI) $)^{3}$. Møller-Plesset perturbation theory is performed to second order. The zeroth order solution recovers Hartree-Fock solutions, since the Hartree-Fock wave function and Hamiltonian are used as the reference. The first order correction to the energy is zero, so that the second order energy correction alone contributes to the correlation energy Eq. 19 (Eq. 19a in Dirac notation). The a and $\mathrm{b}$ subscripts denote occupied orbitals, the $\mathrm{r}$ and s subscripts denote virtual orbitals, and 1 and 2 are electron labels. Therefore, MP2 includes double excitations. Use of MP2 usually recovers $\sim 80-90 \%$ of the correlation energy.

$$
\begin{aligned}
& E_{\mathrm{MP} 2}=E_{\mathrm{HF}}+\sum_{\substack{a<b \\
r<s}} \frac{\left|\iint \phi_{a}^{*}(1) \phi_{b}^{*}(2) \frac{1}{r_{12}} \phi_{r}(1) \phi_{s}(2) d \tau_{1} d \tau_{2}-\iint \phi_{a}^{*}(1) \phi_{b}^{*}(2) \frac{1}{r_{12}} \phi_{s}(1) \phi_{r}(2) d \tau_{1} d \tau_{2}\right|^{2}}{\varepsilon_{a}+\varepsilon_{b}-\varepsilon_{r}-\varepsilon_{s}} \\
& E_{\mathrm{MP} 2}=E_{\mathrm{HF}}+\sum_{\substack{a<b \\
r<s}} \frac{\left|\left\langle\phi_{a} \phi_{b}|| \phi_{r} \phi_{s}\right\rangle\right|}{\varepsilon_{a}+\varepsilon_{b}-\varepsilon_{r}-\varepsilon_{s}}
\end{aligned}
$$

\footnotetext{
${ }^{1}$ Size consistent indicates that the method has the correct fragmentation limit as $r$, the distance between the two fragments, goes to infinity. For example, a size consistent method would give the same energy for $\mathrm{A}+\mathrm{B}$ if $\mathrm{A}$ and $\mathrm{B}$ are calculated together or separately.

${ }^{2}$ Size extensive indicates that the method has the correct scaling with respect to the number of electrons.

${ }^{3}$ Full CI is size consistent and size extensive as well as prohibitively expensive for most chemical systems. A truncated CI expansion is neither size consistent nor size extensive.
} 
The MBPT formalism is used beyond second order. However, the perturbation expansion is not guaranteed to converge, and the cost of higher order energy correction grows. Other correlated methods frequently are used instead of MP3 and beyond.

Density functional theory (DFT) is another method for recovering electron correlation effects for many-electron systems. It can be shown that the ground state energy of a chemical system is uniquely defined by its density ${ }^{8}$. Solving for the density, then, provides an indirect way of capturing electron correlation. The amount of electron correlation recovered depends on the functional used. Use of hybrid functionals has roughly the same computational cost as Hartree-Fock, which has led to DFT being a popular method used in the study of many transition metal systems, actinide systems, and other chemical systems that are otherwise prohibitively computationally expensive.

The most common implementation of DFT used by chemists is the Kohn-Sham approach $^{9}$. The Kohn-Sham method uses a one-electron operator (Eq. 20) to describe electrons moving in an external potential of the other electrons.

$$
\hat{h}_{\mathrm{KS}}=-\frac{1}{2} \nabla^{2}+\sum_{A}^{\text {nuclei }} \frac{Z_{A}}{\left|r-r_{A}\right|}+\int \frac{\rho\left(r^{\prime}\right)}{\left|r-r^{\prime}\right|} d r^{\prime}+\hat{V}_{\mathrm{XC}}(r)
$$

In Eq. 20, $\rho$ is the electron density and correlation effects are contained in the exchangecorrelation functional, $\hat{V}_{\mathrm{XC}}(r)$. The exact functional is unknown, so a plethora of functionals have been devised that are fitted to either experimental data or high-level computational results. No single functional works well for every system, though, so a benchmark study is generally required to validate the choice of a functional for a 
particular chemical system. The need to benchmark functionals is necessary, especially for chemical systems that contain transition metals, lanthanides, or actinides, since DFT functionals are generally not parameterized for use with these elements.

An early attempt to find a suitable exchange-correlation functional resulted in the development of the local density approximation (LDA). A homogeneous non-interacting electron gas model was used to develop the LDA functional. Eq. 21 gives the LDA exchange-correlation functional. $\varepsilon_{\mathrm{XC}}$ can be split into an exchange term $\left(\varepsilon_{\mathrm{X}}\right)^{10}$ and a correlation term $\left(\varepsilon_{\mathrm{C}}\right)^{11}$.

$\hat{V}_{\mathrm{XC}}^{\mathrm{LDA}}=\frac{\partial E_{\mathrm{XC}}^{\mathrm{LDA}}}{\partial \rho}=\varepsilon_{\mathrm{XC}}(\rho(r))+\rho(r) \frac{\partial \varepsilon_{\mathrm{XC}}(\rho)}{\partial \rho}$

The LDA functional contains only local information about the density. More advanced functionals include additional corrections such as the gradient of the density (GGA functionals) or a fraction of Hartree-Fock exchange (hybrid functionals). One of the most widely used functionals is the B3LYP functional. This functional uses $20 \%$ Slater exchange ${ }^{10}$ and $80 \% \mathrm{LYP}^{12}$ exchange in the $\varepsilon_{\mathrm{X}}$ term. The correlation functional $\left(\varepsilon_{\mathrm{C}}\right)$ is constructed using $19 \% \mathrm{VWN}^{11}$ correlation and $81 \%$ Becke 88 correlation ${ }^{13}$. A variation on B3LYP is the Coulomb-attenuating method B3LYP (CAM-B3LYP) functional ${ }^{14}$. At short range, exchange is determined via the B3 DFT exchange functional while longrange exchange uses $100 \%$ Hartree-Fock exchange. Intermediate ranges incorporate a mixture of B3 and HF exchange. Eq. 22 shows how the exchange term is broken down into fractions of other exchange functionals. $\alpha$ is a distance-dependant parameter, $\mathrm{c}^{\mathrm{B} 88}$ is 
a constant parameter determined to be 0.72 by a least-squares fit to experimental data ${ }^{15}$, and $\Delta \varepsilon_{\mathrm{X}}^{\mathrm{B} 88}$ is Becke's gradient-correction for exchange ${ }^{16}$.

$\varepsilon_{\mathrm{X}}=(1-\alpha) \varepsilon_{\mathrm{X}}^{\text {Slater }}+\alpha \varepsilon_{\mathrm{X}}^{\mathrm{HF}}+\mathrm{c}^{\mathrm{B} 88} \Delta \varepsilon_{\mathrm{X}}^{\mathrm{B} 88}$

Just as HF exchange is included in hybrid functionals, a fraction of MP2 correlation also can be incorporated. One such functional that includes MP2 correlation is the B2PLYP functiona $1^{17}$. The correlation functional used with B2PLYP includes 73\% LYP correlation and 27\% MP2 correlation. The drawback to this functional is that the MP2 energy is required, so the computational cost is on the order of $\mathrm{N}^{5}(\mathrm{~N}=$ number of basis functions) as opposed to the formal $\mathrm{N}^{4}$ scaling for other DFT hybrid functionals. Dispersion corrected functionals can also be used to handle weak and long-range interactions. The SSB-D functional ${ }^{18,19}$ was designed to reproduce PBE results for weak interactions and includes a dispersion correction.

Chemical systems that include heavy elements such as transition metals, lanthanides, or actinides require inclusion of relativistic effects. Special relativity was incorporated into quantum mechanics by Dirac in 1928 for fermions ${ }^{20}$. The Schrödinger equation (Eq. 1) is incompatible with special relativity because it is not Lorentz invariant. Examination of Eq. 1 makes this readily apparent. The left hand side of the equation has a first derivative with respect to time and the right hand side of the equation has a second derivative with respect to position. Consequently, time and space are not treated equally.

Eq. 23 is a Lorentz invariant relativistic relationship between energy and momentum. 
$(E-q \varphi)^{2}=m^{2} c^{4}+c^{2} \vec{\pi}^{2}$

$E$ is the total energy, $q \varphi$ is the potential energy as a product of charge and a scalar potential, $m$ is the mass, $c$ is the speed of light, and $\pi$ is the mechanical momentum. The mechanical momentum is related to the more familiar canonical momentum $(\vec{p}=m \vec{v})$ by the principle of minimal electromagnetic coupling.

$\vec{\pi}=\vec{p}-q \vec{A}$

In Eq. $24 \vec{p}$ is the canonical momentum, q is a charge, and $\vec{A}$ is a vector potential. Substituting the Hamiltonian for the total energy in Eq. 23 leads to Eq. 25.

$(\hat{H}-q \varphi)^{2}=m^{2} c^{4}+c^{2} \vec{\pi}^{2}$

The right hand side of Eq. 25 is assumed to be a perfect square. Completing the square produces the Dirac Hamiltonian.

$\hat{H}=\beta m c^{2}+c \vec{\alpha} \cdot \overrightarrow{\hat{\pi}}+q \vec{\varphi}$

In Eq. $26 \vec{\alpha}$ and $\beta$ must be chosen to satisfy the following conditions.

$\left[\alpha_{i}, \alpha_{j}\right]=2 \delta_{i j},\left[\alpha_{i}, \beta\right]=0$, and $\beta^{2}=1$ 
Suitable coefficients are $4 x 4$ matrices composed of the $2 x 2$ Pauli matrices $\left(\sigma_{x}, \sigma_{y}\right.$, and $\left.\sigma_{z}\right)$ and the identity matrix (Eq. 28).

$\alpha_{x}=\left(\begin{array}{cc}0 & \sigma_{x} \\ \sigma_{x} & 0\end{array}\right), \alpha_{y}=\left(\begin{array}{cc}0 & \sigma_{y} \\ \sigma_{y} & 0\end{array}\right), \alpha_{z}=\left(\begin{array}{cc}0 & \sigma_{z} \\ \sigma_{z} & 0\end{array}\right)$, and $\beta=\left(\begin{array}{cc}\mathrm{I} & 0 \\ 0 & \mathrm{I}\end{array}\right)$

Thus, the electronic time dependent Dirac equation is Eq. 29, where the wave function $\Psi(r, t)$ is now a four-component vector.

$-i \hbar \frac{\partial}{\partial t} \Psi(r, t)=\left(\beta m c^{2}+c \vec{\alpha} \cdot \overrightarrow{\hat{\pi}}+q \hat{\varphi}\right) \Psi(r, t)$

As with the Schrödinger equation, there is also a time independent form of the Dirac equation that produces stationary state solutions (Eq. 30).

$\left(\beta m c^{2}+c \vec{\alpha} \cdot \overrightarrow{\hat{\pi}}+q \hat{\varphi}\right) \Psi=E \Psi$

Equations 29 and 30 are exact treatments of relativity as long as the assumption that Eq. 26 is a perfect square is valid. This assumption implies that the Dirac equation may produce only a subset of the possible solutions. One implication of Eq. 26 is that the Dirac equation predicts the existence of antimatter, since both positive and negative energy solutions exist ${ }^{21}-$ a prediction that was later confirmed ${ }^{22}$. 
The Dirac equation can be solved in a manner similar to solving the Schrödinger equation. Methods such as Dirac Hartree-Fock (DHF) ${ }^{23}$, Dirac MP2 ${ }^{24}$, Dirac coupledcluster $^{25,26}$, etc. exist, though they are largely impractical for all but the smallest chemical systems due to the size of the relativistic basis sets and the large number of integral evaluations necessary when the four-component wave function is expressed as four onecomponent spin orbitals (spinors).

The four-component wave function is composed of two spinors that have a large contribution to the electron density and two spinors that have a small local contribution to the electron density. These are the large and small components, respectively. Different basis sets for the large and small components are required such that Eq. 31 is satisfied. In Eq. $31 \psi_{i}(r)$ is a relativistic spinor, $\chi_{\mu}^{L}(r)$ and $\chi_{v}^{S}(r)$ are basis functions for the large and small components, $c_{\mu i}^{L}$ and $c_{v i}^{S}$ are coefficients of the large and small component basis functions, and $\mathrm{N}^{\mathrm{L}}$ and $\mathrm{N}^{\mathrm{S}}$ are the number of large and small component basis functions in the expansion.

$\psi_{i}(r)=\sum_{\mu=1}^{N^{L}}\left(\begin{array}{c}\chi_{\mu}^{L}(r) \\ 0\end{array}\right) c_{\mu i}^{L}+\sum_{v=1}^{N^{S}}\left(\begin{array}{c}0 \\ \chi_{v}^{S}(r)\end{array}\right) c_{v i}^{S}$

The large and small component basis functions are related by the kinetic balance condition (Eq. 32) ${ }^{27}$.

$\chi^{S}(r)=\frac{\hat{\vec{\sigma}} \cdot \hat{\vec{p}}}{2 m c} \chi^{L}(r)$ and $(\hat{\vec{\sigma}} \cdot \hat{\vec{p}})(\hat{\vec{\sigma}} \cdot \hat{\vec{p}})=\hat{\vec{p}}^{2}$ 
In Eq. 32, $\hat{\vec{\sigma}}$ is the spin operator and $\hat{\vec{p}}$ is the momentum operator. As c approaches infinity, the small component goes to zero, and non-relativistic solutions are obtained. Use of Eq. 32 to generate a small component basis set of one-component spinors results in a small component basis set that is almost twice as large as the large component basis set. This is because a large component function with angular momentum $l$ corresponds to small component functions of angular moment $l-1$ and $l+1$. Such a large increase in the number of basis functions makes use of the Dirac equation impractical for most chemical systems, so approximate methods are usually necessary.

One approach would be to decouple the large and small components. Decoupling can be achieved by use of a Foldy-Wouthuysen transformation ${ }^{28}$. The FoldyWouthuysen transformation is an energy independent unitary transformation illustrated in Eq. 33. The Dirac wave function is a four-component vector, so the Dirac Hamiltonian $\hat{\mathbf{H}}^{\mathbf{D}}$ must be a $4 \times 4$ tensor. Likewise, the unitary matrix $\hat{\mathbf{U}}$ and its inverse $\hat{\mathbf{U}}^{-1}$ are also $4 \times 4$ matrices. The resulting Hamiltonian is composed of two $2 \times 2$ Hamiltonian matrices in block diagonal form corresponding to the decoupled positive $\left(\hat{\mathbf{H}}_{+}\right)$and negative $\left(\hat{\mathbf{H}}_{-}\right)$ energy states (matter and antimatter states, respectively).

$$
\hat{\mathbf{U}} \hat{\mathbf{H}}^{\mathrm{D}} \hat{\mathbf{U}}^{-1}=\left(\begin{array}{cc}
\hat{\mathbf{H}}_{+} & \mathbf{0} \\
\mathbf{0} & \hat{\mathbf{H}}_{-}
\end{array}\right)
$$

The Hamiltonian for the positive energy states is given in Eq. $34 . \mathrm{V}$ is the potential, $\vec{\sigma}$ is the spin operator, $\vec{p}$ is the momentum operator, and $\hat{X}$ and $\hat{X}^{\dagger}$ are operators defined in 
Eq. 35. The operator $(\vec{\sigma} \cdot \vec{p})$ does not commute with the potential, so the order of $\hat{X}$ and $\hat{X}^{\dagger}$ must be maintained as written in Eq. 34 .

$$
\begin{aligned}
& \hat{H}_{+}=\frac{1}{\sqrt{1+\hat{X}^{\dagger} \hat{X}}}\left[V+c(\vec{\sigma} \cdot \vec{p}) \hat{X}+c \hat{X}^{\dagger}(\vec{\sigma} \cdot \vec{p})+\hat{X}^{\dagger}\left(V-2 m c^{2}\right) \hat{X} \frac{1}{\sqrt{1+\hat{X}^{\dagger} \hat{X}}}\right. \\
& \hat{X}=\left(2 m c^{2}+E-V\right)^{-1} c(\vec{\sigma} \cdot \vec{p}), \hat{X}^{\dagger}=c(\vec{\sigma} \cdot \vec{p})\left(2 m c^{2}+E-V\right)^{-1}
\end{aligned}
$$

For a particle with a constant potential (i.e. a free particle), $\hat{X}$ can be determined exactly. An exact decoupling of the large and small components then can be achieved. If the potential is not constant, as is the case for a bound electron, then an approximation must be made. The usual approximation is the Douglas-Kroll approximation ${ }^{29,30}$.

Douglas-Kroll is an iterative approximation that achieves exact decoupling of the large and small components when performed to infinite order ${ }^{31}$. In practice, the twoelectron relativistic corrections are neglected, though this introduces only a small error (usually $<5 \%$ of the relativistic energy correction) compared to a four-component relativistic calculation. The number of matrix multiplications required for most implementations of the Douglas-Kroll method increases roughly exponentially with the order of the transformation. Also, in practice, second or third order approximations frequently are performed, as these are usually a reasonable compromise between accuracy and computational cost. However, convergence is reached between tenth and thirty-fifth order depending on the nuclear charge ${ }^{32}$. Larger nuclear charges require higher order transformations to reach convergence. 
The Douglas-Kroll method begins with a Foldy-Wouthuysen transformation of the Hamiltonian operator Eq. 36. $\hat{E}_{p}$ is the positive energy root (Eq. 37), $\hat{\varepsilon}$ is an even operator (Eq. 38), and $\hat{O}$ is an odd operator (Eq. 39). Due to the prevalence of the momentum operator in the Foldy-Wouthuysen transformation, this transformation is most often performed in momentum space.

$\hat{U} \hat{H}^{D} \hat{U}^{\dagger}=\beta \hat{E}_{p}+\hat{\varepsilon}+\hat{O}=\hat{H}^{D}$

$\hat{E}_{p}=\left(\vec{p}^{2}+m^{2}\right)^{1 / 2}$

$\hat{\varepsilon}=\hat{A}_{p}\left(V+\hat{R}_{p} B \hat{R}_{p}\right) \hat{A}_{p}$

$\hat{O}=\beta \hat{A}_{p}\left[\hat{R}_{p}, V\right]$

In Eq. 38 and Eq. $39 \hat{A}_{p}$ and $\hat{R}_{p}$ are defined in Eqs. 40 and 41, respectively.

$$
\begin{aligned}
& \hat{A}_{p}=\left(\frac{\hat{E}_{p}+m}{2 \hat{E}_{p}}\right)^{1 / 2} \\
& \hat{R}_{p}=\frac{\vec{\alpha} \cdot \vec{p}}{\hat{E}_{p}+m}
\end{aligned}
$$

Up to this point, an approximate Foldy-Wouthusen transformation for a bound particle has been presented. Introduction of a second unitary transformation refines the approximation. The new unitary operator is given in Eq. 42 , and the $\hat{W}_{1}$ operator that appears in Eq. 42 is defined in Eq. 43. 


$$
\begin{aligned}
& \hat{U}^{\prime}=\left(1+\hat{W}_{1}^{2}\right)^{1 / 2}+\hat{W}_{1} \\
& \hat{W}_{1}\left(p, p^{\prime}\right)=\hat{A}_{p^{\prime}} \hat{A}_{p}\left(\hat{R}_{p}-\hat{R}_{p}^{\prime}\right) \frac{V\left(p, p^{\prime}\right)}{\hat{E}_{p^{\prime}}+\hat{E}_{p}}
\end{aligned}
$$

Higher order refinements to the Douglas-Kroll approximation can be made using recursively according to Eq. 44.

$\hat{U}_{n}=\left(1+\hat{W}_{n}^{2}\right)^{1 / 2}+\hat{W}_{n}$

The Douglas-Kroll method is a variational method (as opposed to other relativistic approximations such as the $\mathrm{N}$-order relativistic approximation). Higher order corrections (beyond third order), are uncommon since the transformation becomes unwieldy and the added accuracy is minimal. Furthermore, many implementations of the Douglas-Kroll approximation include only the one-electron terms. The two-electron terms often are ignored due to the difficulty of the $\vec{p} \hat{V} \vec{p}$ integrals. Nevertheless, third order DouglasKroll is usually sufficient to capture the bulk of the relativistic effects.

Another method of incorporating relativistic effects into quantum chemistry is through the use of relativistic pseudopotentials on the heavy atoms. Pseudopotentials start with a frozen core approximation. The frozen core approximation partitions the Fock operator into core and valence orbitals (Eq. 45). A modified nuclear charge $\left(Z_{A}^{*}=Z_{A}-Z_{\text {core }}\right)$ corresponding to the number of valence electrons is introduced (Eq. 
46). The core orbitals are then frozen and only the valence orbitals are allowed to vary during an energy optimization.

$$
\begin{aligned}
& \hat{f}=\hat{h}^{\text {kinetic }}-\sum_{Z}^{\text {Nuclei }} \frac{Z_{A}}{r_{A}}+\sum_{A}^{\text {Nucleicore }} \underbrace{\sum_{c}\left(\hat{J}_{c}^{A}-\hat{K}_{c}^{A}\right)}_{\text {core }}+\underbrace{\sum_{v}^{\text {valence }}\left(\hat{J}_{v}-\hat{K}_{v}\right)}_{\text {valence }} \\
& \hat{f}=\hat{h}^{\text {kinetic }}-\underbrace{\sum_{A}^{\text {Nuclei }} \frac{Z_{A}^{*}}{r_{A}}+\sum_{v}^{\text {valence }}\left(\hat{J}_{v}-\hat{K}_{v}\right)}_{\text {valence }}+\underbrace{\sum_{A}^{\text {Nuclei }}\left(-\frac{Z_{A}^{\text {core }}}{r_{A}}+\sum_{c}^{\text {core }} \hat{J}_{c}^{A}\right)-\sum_{A}^{\text {Nucleicore }} \sum_{c} \hat{K}_{c}^{A}}_{\text {core }}
\end{aligned}
$$

The core orbitals in Eq. 46 can be fit to create nodeless pseudo-orbitals. The pseudoorbitals can be replaced with a potential to create an Effective Core Potential (ECP). When the potential is fit to relativistic orbitals, then a relativistic ECP (RECP) is generated. RECP's include scalar relativistic effects (mass-velocity and Darwin).

ECP's are generally fit in one of two ways. Shape consistent ECP's such as the LANL $^{33}$ ECP's are fit to reproduce the shape of the original core orbital. However, the short-range region is not a perfect fit since the nodes are smoothed out. Energy consistent ECP's such as the Stuttgart ${ }^{34}$ ECP's are fit such that the difference in energy between the pseudopotential and the original orbital is minimized. Energy consistent ECP's also smooth out the radial nodes. 


\section{References}

${ }^{1}$ Schrödinger, E., Phys. Rev. 1926, 28, 1049. Schrödinger, E. Ann. Phys. 1926, 79, 361.

Schrödinger, E. Ann. Phys. 1926, 79, 489. Schrödinger, E. Ann. Phys. 1926, 79, 734.

Schrödinger, E. Ann. Phys. 1926, 80, 437. Schrödinger, E. Ann. Phys. 1926, 81, 109.

Schrödinger, E. Die Naturwißenscheften 1926, 14, 664.

${ }^{2}$ Born, M.; Oppenheimer, R. Ann. Phys. 1927, 84, 457.

${ }^{3}$ Slater, J. C. Phys. Rev. 1929, 34, 1293.

${ }^{4}$ Hartree, D. R. Proc. Cambridge Philos. Soc. 1928, 24, 89. Hartree, D. R. Proc.

Cambridge Philos. Soc. 1928, 24, 111. Hartree, D. R. Proc. Cambridge Philos. Soc.

1928, 24, 426. Fock, V. Z. Phys. 1930, 61, 126. Fock, V. Z. Phys. 1930, 62, 795.

${ }^{5}$ Pople, J. A.; Binkley, S.; Seeger, R. Int. J. Quant. Chem. 1976, 10, 1.

${ }^{6}$ Löwdin, P. O. J. Chem. Phys. 1951, 19, 1396.

${ }^{7}$ Møller, C.; Plesset, M. S. Phys. Rev. 1934, 46, 618.

${ }^{8}$ Hohenberg, P.; Kohn, W. Phys. Rev. 1964, 136, B864.

${ }^{9}$ Kohn, W.; Sham, L. J. Phys. Rev. 1965, 140, A1133.

${ }^{10}$ Slater, J.C. Phys. Rev. 1951, 81 (3), 1287.

${ }^{11}$ Vosko, S.H.; Wilk, L.; Nusiar, M. Can. J. Phys. 1980, 58 (8), 1200.

${ }^{12}$ Lee, C.; Yang, W.; Parr, R.G. Phys. Rev. B 1988, 37, 785.

${ }^{13}$ Becke, A.D. J. Chem. Phys. 1993, 98, 5648.

${ }^{14}$ Yanai, T.; Tew, D.; Handy, N., Chem. Phys. Lett. 2004, 393, 51.

${ }^{15}$ Becke, A. D. J. Chem. Phys. 1993, 98, 5648.

${ }^{16}$ Becke, A. D. Phys. Rev. A 1988, 38, 3098.

${ }^{17}$ Grimme, S. J. Chem. Phys. 2006, 124, 034108. 
${ }^{18}$ Swart, M.; Solà, M.; Bickelhaupt, F. M. J. Chem. Phys. 2009, 131, 094103.

${ }^{19}$ Swart, M.; Solà, M.; Bickelhaupt, F. M. J. Comp. Meth. Sci. Engin. 2009, 9, 69.

${ }^{20}$ Dirac, P. A. M. Proc. Roy. Soc. A 1928, 117 (778), 610.

${ }^{21}$ Dirac, P. A. M. Proc. Roy. Soc. A 1930, 126, 360. Dirac, P. A. M. Proc. Camb. Phil.

Soc. 1930, 26, 361.

${ }^{22}$ Anderson, C. D. Phys. Rev. 1933, 43 (6), 491.

${ }^{23}$ Saue, R.; Fægri, K.; Helgaker, T.; Gropen, O. Mol. Phys.1997, 91, 937.

${ }^{24}$ Lærdahl, J. L.; Saue, T.; Fægri, K Theor. Chem. Acc. 1997, 97, 177.

${ }^{25}$ Visscher, L.; Lee, T. J.; Dyall, K. G. J. Chem. Phys. 1996, 105, 8769.

${ }^{26}$ Visscher, L.; Eliav, E.; Kaldor, U. J. Chem. Phys. 2001, 115, 9720.

${ }^{27}$ Stanton, R. E.; Havriliak, S. J. Chem. Phys. 1984, 81, 1920.

${ }^{28}$ Eriksen, E. Phys. Rev. 1958, 111, 1011.

${ }^{29}$ Douglas, M; Kroll, N. M. Ann. Phys. 1974, 8289.

${ }^{30}$ Jansen, G.; Hess, B. A. Phys. Rev. A 1989, 39, 6016.

${ }^{31}$ Barysz, M.; Sadlej, A. J. J. Chem. Phys. 2002, 116, 2696. Barysz, M. Progress in Theoretical Chemistry and Physics, Kluwer Academic Publishers, 2002, 349. Kedziera, D.; Barysz, M.; Sadlej, A. J. Struct. Chem. 2004, 369. Kedziera, D.; Barysz, M. J. Chem. Phys. 2004, 121, 6719. Barysz, M.; Mentel, L. Leszczynski, J. J. Chem. Phys. 2009, 130, 164114.

${ }^{32}$ Peng, D.; Hirao, K. J. Chem. Phys. 2009, 130, 044102.

${ }^{33}$ Wadt, W. R.; Hay, P. J. J. Chem. Phys. 1985, 82, 270. 
${ }^{34}$ Bergner, A.; Dolg, M.; Küchle, W.; Stoll, H.; Preuss, H. Mol. Phys. 1993, 80 (6), 1431.

Küchle, W.; Dolg, M.; Stoll, H. Mol. Phys. 1991, 74 (6), 1245. Godbout, N.; Salahub, D.R.; Andzelm, J.; Wimmer, E. Can. J. Chem. 1992, 70 (2), 560. 
[Reprinted with permission from Schoendorff, G.; Windus, T. L.; de Jong, W. A. J. Phys.

Chem. 2009, 113 (45), 12525. Copyright 2009 American Chemical Society.]

\title{
Density Functional Studies on the Complexation and Spectroscopy of Uranyl
}

Ligated with Acetonitrile and Acetone Derivatives

George Schoendorff ${ }^{1}$, Theresa L. Windus ${ }^{* 1}$, Wibe A. de Jong ${ }^{\dagger^{2}}$

1. Department of Chemistry, Iowa State University and Ames Laboratory, Ames IA

50011

2. Environmental Molecular Sciences Laboratory, Pacific Northwest National

Laboratory, P.O. Box 999, Richland, Washington 99352

\begin{abstract}
The coordination of nitrile (acetonitrile, propionitrile, and benzonitrile) and carbonyl (formaldehyde, acetaldehyde, and acetone) ligands to the uranyl dication $\left(\mathrm{UO}_{2}{ }^{2+}\right)$ has been examined using density functional theory (DFT) utilizing relativistic effective core potentials (RECPs). Complexes containing up to six ligands have been modeled in the gas phase for all ligands except formaldehyde, for which no minimum could be found. A comparison of relative binding energies indicates that five coordinate complexes are predominant while a six coordinate complex involving propionitrile ligands might be possible. Additionally, the relative binding energy and the weakening
\end{abstract}

\footnotetext{
*Email: twindus@iastate.edu

†Email: bert.dejong@pnl.gov
} 
of the uranyl bond is related to the size of the ligand and, in general, nitriles bind more strongly to uranyl than carbonyls.

\section{Introduction}

Understanding the chemical properties of uranium species in the environment is a key issue for the U.S. Department of Energy -- to understand speciation in waste tanks at nuclear weapons productions sites, and to understand the transport of actinides in the subsurface environment. Uranium generally exists as a uranyl dication $\left(\mathrm{UO}_{2}{ }^{2+}\right)$ that can readily form complexes with various anions. The uranyl chemistry is dependent on $\mathrm{pH}$ and available anions, and multiple species can often exist in equilibrium. Uranyl species can also interact with mineral surfaces and form new species, or undergo redox processes. This complex chemistry complicates the interpretation of experimental measurements.

Molecular scale modeling using computational chemistry methodologies, combined with experimental observations, has been demonstrated to provide a fundamental understanding of the complex chemistry of actinides in the condensed phase. Over the years various computational studies on model systems, with or without the inclusion of an approximate description of the molecule's environment, have been reported in the

literature. ${ }^{1,2,3,4,5,6,7}$ For example, in our recent computational modeling study of gas-phase uranyl carbonate, nitrate and acetate complexes ${ }^{8}$ we showed that the calculated structures and vibrational frequencies are in generally good agreement with experimental data obtained in the solution and solid state environment. 
One of the key issues in computational chemistry is the validation of the basic methodologies and calculated results for molecules. For uranyl complexes, we have relied on highly accurate benchmark calculations on the free uranyl in lieu of available experimental data., ${ }^{9,11}$ Over the last couple of years, Groenewold, Van Stipdonk, and coworkers published results of measurements on various uranyl complexes in the gas phase. $^{12,13,14,15,16,17}$ These experiments provide the computational chemistry community with a wealth of experimental benchmark data that can be used as a proving ground for the current computational methodologies, and to improve upon them. In a series of joint experimental and computational papers ${ }^{13,18,19,20,21}$ it was shown that vibrational stretching frequencies of actinide species and relative energetics calculated with density functional theory (DFT) are in good agreement with experimental data.

This paper reports the results of $a b$ initio calculations on acetonitrile and its derivatives propionitrile and benzonitrile, and acetone and its derivatives acetaldehyde and formaldehyde. In their gas-phase experiments of the nitrile series, Van Stipdonk et $a l{ }^{12}$ were able to isolate the $\left[\mathrm{UO}_{2}(\mathrm{~L})_{\mathrm{n}}\right]^{2+}$ complexes (with $\mathrm{n}=1-5$ for acetonitrile, and $\mathrm{n}=2$ 5 for propionitrile and benzonitrile), and they studied the intrinsic reactions with water molecules. From acetonitrile to benzonitrile, the ligands have an increased capability to donate electron density to the uranyl. Similarly, by eliminating the methyl groups on acetone the electron donating capability is reduced, which should be reflected in the structure and vibrational spectroscopy of uranyl. The vibrational spectra of the uranyl acetone complexes in the gas-phase have been measured, whereas those of the acetaldehyde and formaldehyde complexes have not. The reaction of formaldehyde with uranium has been studied experimentally by Gibson et al., ${ }^{22}$ while Senanayake et al. 
studied the reaction on the surface of $\mathrm{UO}_{2}$ crystals. ${ }^{23}$ We will present the coordination, vibrational frequencies, and the binding and dissociation energetics of the $\left[\mathrm{UO}_{2}(\mathrm{~L})_{\mathrm{n}}\right]^{2+}(\mathrm{n}$ $=1-6, \mathrm{~L}=$ formaldehyde $($ Form), acetaldehyde (Aca), acetone (Ace), acetonitrile (Acn), propionitrile $(\mathrm{Pn})$, and benzonitrile (Bzn)) complexes. These results provide the ground work for a subsequent study on the reaction of water molecules with these species, which will enable the direct comparison of our calculations with the previous mentioned gasphase experiments.

\section{Details of the Calculations}

All calculations were performed with the NWChem software suite ${ }^{24,25}$ using density functional theory (DFT). The choice of functional and basis sets is based on a previous systematic study where fully relativistic $\operatorname{CCSD}(\mathrm{T})$ benchmark calculations on $\mathrm{UO}_{2}{ }^{2+}$ were compared to various DFT functionals and basis set choices. ${ }^{10}$ The local density approximation (LDA) ${ }^{26,27}$ was used to determine the structures and frequencies, and energies were calculated using the B3LYP ${ }^{28,29}$ functional at the LDA optimized geometry. For uranium the small core Stuttgart RECP and associated Stuttgart orbital basis set ${ }^{30,31,32}$ was employed, whereas for all other atoms $(\mathrm{O}, \mathrm{C}, \mathrm{H}, \mathrm{N})$ the valence triple$\zeta$ plus polarization $(\mathrm{TZVP})^{33}$ DFT optimized basis sets were used. In all cases, spherical functions were employed. Hessian calculations were performed for each optimized structure to verify the structures as minima and to obtain zero point energies and frequencies. Molecular orbital pictures were obtained from canonical orbitals calculated at the LDA optimized geometry using the B3LYP functional. All molecular orbitals were 
plotted with an isovalue of 0.0178. Molecular and orbital analysis as well as image production was performed using Ecce ${ }^{34}$ and MacMolPlt. ${ }^{35}$

\section{Results and Discussion}

In this study, complexation of $\mathrm{UO}_{2}{ }^{2+}$ with nitrile and carbonyl ligands was examined with the coordination number ranging from 1 through 6 . A few of the key geometrical parameters and frequencies are given in Table 1, and full information is available as Supplementary Information. In general, the nitrogens of the nitrile ligands tend to lie in the equatorial plane. When the ligand is not linear, it tends to lie parallel to the O-U-O axis. The smallest of the nitrile ligands studied, acetonitrile, experiences little distortion from this arrangement when multiple ligands are present. When there are 5 or fewer ligands, the N-U-O bond angle is always nearly $90^{\circ}$ and the N-C-C backbone of acetonitrile lies in the equatorial plane. The N-U-N angles are always evenly spaced with the 3 coordinate complex having a N-U-N angle of $120^{\circ}$, the 4 coordinate complex $90^{\circ}$, and the 5 coordinate complex $72^{\circ}$. The two coordinate complex, however, is an exception with a N-U-N angle of $104^{\circ}$. This arrangement of acetonitrile in the 2coordinate complexes allows both the $\mathrm{p}_{\mathrm{x}}$ and the $\mathrm{p}_{\mathrm{y}}$ orbitals on uranium to effectively bind with both $\mathrm{N}$ s orbitals (Figure 1).

Like acetonitrile, propionitrile and benzonitrile also form $90^{\circ} \mathrm{N}-\mathrm{U}-\mathrm{O}$ bond angles. Likewise, the 2-coordinate complexes also exhibit a N-U-N angle less than $180^{\circ}$. The ethyl groups on propionitrile are free to rotate about the single bond between nitrogen and the $\alpha$ carbon. This rotation is essentially a free rotor with energy differences of $<1$ $\mathrm{kcal} / \mathrm{mol}$ between the ethyl group pointing up or down for each propionitrile. 
Additionally, while the benzonitriles' nitrogens lie in the equatorial plane, the plane of the phenyl groups lies parallel to $\mathrm{UO}_{2}{ }^{2+}$.

When there are six nitrile ligands present, the structures exhibit significant differences from the smaller complexes. The ligands of these complexes no longer lie in the equatorial plane. Rather, repulsion between adjacent ligands forces acetonitrile and propionitrile to deviate from the equatorial plane by $11^{\circ}$, with ligands lying alternately above and below the equatorial plane. The complex containing 6 benzonitriles also exhibits a similar distortion. However, the deviation from the equatorial plane is slightly less pronounced and ranges from $9^{\circ}$ to $10^{\circ}$.

Since the nitrogen in the ligands has a lone pair of electrons capable of donation to the electron deficient uranium, it is not surprising that the nitrile ligands have an affinity for uranium and, indeed, electron donation to the metal center does occur. The evidence for this is apparent in the molecular orbitals as well as in the changes in the structure of uranyl. The 3-coordinate acetonitrile complex provides a characteristic example of such a U-N bond (Figure 2). Here, electron density is donated from the C-N $\pi_{\mathrm{z}}$ to the $\mathrm{U} 5 \mathrm{f}_{\mathrm{z}^{3}}$ orbital. This bonding scheme recurs with all the nitrile complexes studied. Addition of ligands to uranyl and the associated electron donation causes an increase in the uranium-oxygen bond length in $\mathrm{UO}_{2}{ }^{2+}$. It can be seen in Table 1 that the addition of nitrile ligands to uranyl red-shifts both the symmetric and asymmetric stretching frequencies for $\mathrm{UO}_{2}{ }^{2+}$ by nearly $136-145 \mathrm{~cm}^{-1}$ and by $154-163 \mathrm{~cm}^{-1}$ respectively by the sixth ligand addition. The red-shift in the $\mathrm{UO}_{2}{ }^{2+}$ stretching frequencies and the increase in the U-O bond lengths are an indication of a weakening of the U-O bond strength, in agreement with the observations of McGlynn et al. ${ }^{36}$ These 
effects become more pronounced as the size of the ligand increases. This phenomenon is a result of the nitriles' ability to shift electron density to stabilize donation of electron density from nitrogen to uranium and the conjugated $\pi$ system in benzonitrile has the greatest ability to facilitate such a shift in electron density. Additionally, the strength of the $\mathrm{CN}$ bond in the ligands is reduced upon addition to uranyl. There is a noticeable change in the $\mathrm{CN}$ bond length upon the first addition of a ligand (increases by $0.014 \AA$ for acetonitrile, $0.016 \AA$ for propionitrile, and by $0.019 \AA$ for benzonitrile). Likewise, the $\mathrm{CN}$ stretching frequencies decrease by $104-168 \mathrm{~cm}^{-1}$ upon the first ligand addition. The changes in both the $\mathrm{CN}$ bond length and stretching frequencies reflect the fact that the ligand donates electrons to uranium, thereby diminishing the strength of the $\mathrm{CN}$ bonds. As with the $\mathrm{UO}_{2}{ }^{2+}$ stretching frequencies, the change is greater for the larger ligands. This effect diminishes as the number of ligands increases until the sixth addition when the $\mathrm{CN}$ bond length recovers to within $0.002 \AA$ of its bond length in the bare nitrile molecule, indicating a reduction in electron donation per ligand to uranyl from the individual ligands as more ligands are added.

There are also two other notable bonding interactions that frequently occur in these nitrile species. In these cases an additional bonding interaction occurs between a $p$ orbital on the nitrogen and the p orbitals on the uranyl oxygens (Figure 3). Additionally, the $\mathrm{p}$ orbitals on adjacent nitrogens exhibit a substantial overlap resulting in a ring of electron density around uranium. Generally, this molecular orbital is antibonding with uranium (Figure 4).

The HOMOs of the nitrile complexes resemble the HOMOs of the bare ligands. Likewise, most of the other higher energy occupied orbitals are localized on the ligands. 
Thus, these orbitals are not responsible for bonding between uranyl and the ligands. The bonding interactions noted above tend to be the result of lower-lying orbitals.

The other class of ligands in this study is carbonyls, in particular formaldehyde, acetaldehyde, and acetone. These exhibit much the same characteristics as the nitrile ligands with selected information given in Table 2. As with the nitrile complexes, the bonding interactions result from lower lying orbitals, and the highest energy orbitals tend to be localized on the ligands. In general, the oxygens from the carbonyl ligands lie in the equatorial plane. However, the ligands themselves are oriented perpendicular to $\mathrm{UO}_{2}{ }^{2+}$. This is in contrast to the tendency of the nitriles to lie parallel to the O-U-O axis.

The smallest of the carbonyls studied is formaldehyde. In most cases formaldehyde is oriented such that the U-O-C angle is $180^{\circ}$. The 5-coordinate complex, however, has a U-O-C angle of $141^{\circ}$ in the equatorial plane The Mulliken charge on the hydrogen nearest the adjacent ligand's oxygen is $0.016 \mathrm{e}$ less positive than the other hydrogen. This, together with the structural features, suggests that hydrogen bonding may occur (Figure 5). Unlike the other systems studied, no six coordinate complex containing formaldehyde ligands could be found. If a sixth formaldehyde is placed in the equatorial plane with the plane of formaldehyde perpendicular to $\mathrm{UO}_{2}{ }^{2+}$, it is moved outside of the coordination sphere during the geometry optimization. Also, if a sixth formaldehyde is added with the plane of formaldehyde parallel to $\mathrm{UO}_{2}{ }^{2+}$, it remains in the coordination sphere. However, a Hessian calculation on this complex produces an imaginary frequency corresponding to motion of this formaldehyde out of the coordination sphere. 
The structures of the acetaldehyde and acetone complexes are similar to the formaldehyde complexes. While formaldehyde generally is oriented with a U-O-C angle of $180^{\circ}$, acetaldehyde and acetone deviate from this angle by up to $5^{\circ}$ when there are 3 or fewer ligands. With four ligands, the U-O-C angle decreases to $169^{\circ}$ for acetaldehyde and $155^{\circ}$ for acetone, and the addition of a fifth ligand decreases this angle further to $139^{\circ}$ for acetaldehyde. These ligands tend to arrange such that the oxygens and carbon backbone lie in the equatorial plane, and the methyl groups in acetaldehyde point either all clockwise or all counterclockwise. Likewise, acetone's two methyl groups also lie in the equatorial plane.

The remaining complexes are the 5 coordinate acetone complex and the 6 coordinate acetaldehyde and acetone complexes. The proximity of these ligands' methyl groups to the oxygen causes distortions in the geometry due to steric effects. With five acetones, the plane of each ligand is rotated $7^{\circ}-26^{\circ}$ from the equatorial plane (Figure 6). The acetones in $\left[\mathrm{UO}_{2}(\text { Ace })_{6}\right]^{2+}$ cannot all lie in the equatorial plane (Figure 7 ). The oxygens deviate from this plane by $9^{\circ}$ and alternate above and below the equatorial plane. Additionally, the carbon backbone of acetone alternates between $41^{\circ}$ and $-41^{\circ}$ relative to $\mathrm{UO}_{2}{ }^{2+}$. Another notable feature of this complex is that a methyl group from each acetone is oriented such that one of the hydrogens points towards an axial oxygen on $\mathrm{UO}_{2}{ }^{2+}$ with an O-H distance of $2.245 \AA$... Similarly, 6 acetaldehydes are too bulky to lie in the equatorial plane. Thus, they orient themselves $20.0^{\circ} \pm 0.6^{\circ}$ relative to $\mathrm{UO}_{2}{ }^{2+}$ (the U-O-CC dihedral angle) and alternate pointing up and down (Figure 8).

The bonding in the carbonyl complexes is akin to the nitriles. For example all the 2-coordinate carbonyls, especially formaldehyde and acetaldehyde, bond in a similar 
manner to that depicted in Figure 1, resulting in an angle of $<120^{\circ}$ between adjacent ligands. Additionally, when there are 4 or 5 ligands, the $\mathrm{CO}$ groups on adjacent ligands are sufficiently close that they exhibit a significant overlap leading to a ring of electron density around uranium. The resulting molecular orbital resembles the one in Figure 4. Primarily, bonding interactions with uranium occur via electron donation from the $\mathrm{CO}$ group to a $\mathrm{p}$ orbital on uranium and by overlap of a carbonyl $\mathrm{O} p$ orbital with a $\mathrm{U} s$ orbital. These two bonding scenarios lead to a decrease in the uranyl U-O bond strength. This can be seen in the increase in U-O bond length and the decrease in the U-O stretching frequencies (Table 2). The changes in the $\mathrm{UO}_{2}{ }^{2+}$ stretching frequencies are more pronounced with carbonyl ligands than with nitriles. Here, the symmetric stretch is red-shifted by $113-205 \mathrm{~cm}^{-1}$ and the asymmetric stretch is red-shifted by $127-222 \mathrm{~cm}^{-}$

1. The largest changes occur with acetone, the largest carbonyl studied. As with the C-N stretches earlier, the $\mathrm{C}-\mathrm{O}$ stretching frequencies exhibit a substantial red shift of up to 312 $\mathrm{cm}^{-1}$ upon addition of the first ligand. Unlike the nitriles, however, the C-O stretch never fully recovers - even after addition of a sixth ligand.

Optimized geometries have been obtained for all complexes (both nitrile and carbonyls) with up to six ligands with the exception of formaldehyde complexes. Examination of the relative binding energies, however, indicates that some of these structures are not energetically favorable (Tables 3 and 4). Addition of all ligands is exothermic up to the fifth ligand addition. This is in agreement with other experimental and computational results. , $^{1,4,6}$ For most ligands, however, the sixth addition is endothermic. The exception here is propionitrile, which has a relative binding energy of $1.8 \mathrm{kcal} / \mathrm{mol}$ for the sixth addition. Additionally, the sixth benzonitrile addition is 
predicted to be endothermic by $0.8 \mathrm{kcal} / \mathrm{mol}$. This value is quite small and does not necessarily prohibit the formation of $\left[\mathrm{UO}_{2}(\mathrm{Bzn})_{6}\right]^{2+}$ considering the accuracy of the energetics coming from the DFT methodology used in this work. The process by which these complexes are formed in the experiments is energetic, and considering the weak binding energy it is not surprising that these two complexes were not observed. ${ }^{4}$

The changes in the $\mathrm{UO}_{2}{ }^{2+}$ stretching frequencies for the carbonyl and nitrile ligands seem to indicate that carbonyls are more capable of donating electrons to uranyl. One might expect, then, that they would bind more strongly to uranyl than the nitrile ligands. This, however, is not the case. Examination of the relative binding energies for the first ligand addition indicates the overall relative strength of the ligands is formaldehyde $<$ acetonitrile $<$ acetaldehyde $<$ propionitrile $<$ acetone $<$ benzonitrile. Thus, the nitrile ligands generally have a greater affinity for uranyl. Additionally, the relative binding energies indicate that a ligand's strength is directly related to its size for both the carbonyl series and the nitrile series. In general, addition of a methyl group to a ligand increases its capacity to donate electrons to uranyl, and the addition of large delocalized systems, as in benzonitrile, has an even greater effect on the ligand's affinity for uranyl.

Mulliken charges offer additional insight into the changes in electronic structure. Normally, one would expect the charge on uranium to largely decrease as ligands are added. While this reduction in charge occurs, it is not as dramatic as expected. The change in charge on uranium from the bare uranyl ion to a complexed ion with $5-6$ ligands is less than $0.5 \mathrm{e}^{-}$. Thus, uranium maintains roughly a +2 charge. The electron density donated from the ligands tends to reside on the axial oxygens, each changing by - 
$0.2 \mathrm{e}^{-}$to $-0.3 \mathrm{e}^{-}$from the bare uranyl ion to a fully complexed ion. Additionally, while the nitriles' nitrogens and the carbonyls' oxygens conduct this transfer of electron density to uranyl, their Mulliken charges are relatively unaffected. These atom's charges change by $<-0.1 \mathrm{e}^{-}$throughout the additions. The bulk of the donated electron density comes from the carbon backbone of the ligands. While the charge on each carbon changes by about $0.1 \mathrm{e}^{-}-0.2 \mathrm{e}^{-}$, this adds up to a significant capacity to donate electron density as the number of carbons increases. Thus the role of the uranium and the ligands' nitrogens or oxygens is simply to conduct a shift in electron density from the ligands' carbon backbone to uranyl's axial oxygens.

Some of the complexes with acetone and acetonitrile have been experimentally observed by Groenewold et al. and their vibrational frequencies have been measured. ${ }^{13}$ The trends in the calculated frequencies is in agreement with their results for both the acetone and acetonitrile series. However, some of the larger complexes presented here have not been observed. Uranyl ligated with up to 4 acetones and up to 5 acetonitriles has been observed, while the complexes with 5 and 6 acetones and 6 acetonitriles were not observed in the aforementioned study. This is a result of the weak binding energy of the larger complexes. The binding energy for the fourth addition of acetone is 30.8 $\mathrm{kcal} / \mathrm{mol}$ and the binding energy for the fifth addition of acetonitrile is $25.7 \mathrm{kcal} / \mathrm{mol}$, while the binding energy for the next addition drops to $12.7 \mathrm{kcal} / \mathrm{mol}$ for acetone and -3.9 $\mathrm{kcal} / \mathrm{mol}$ for acetonitrile. In another study by van Stipdonk et al., complexes containing up to five propionitrile ligands and up to five benzonitrile ligands have also been isolated. $^{12}$ The binding energies for these complexes are $26.5 \mathrm{kcal} / \mathrm{mol}$ and 23.7 $\mathrm{kcal} / \mathrm{mol}$, respectively. This suggests that a ligand addition with a binding energy greater 
than $23.7 \mathrm{kcal} / \mathrm{mol}$ should be observable in mass spectroscopic studies. Due to the roughly $10 \mathrm{kcal} / \mathrm{mol}$ difference between the fifth and sixth ligand additions for the complexes studies, a minimum value of the binding energy necessary for experimental observation cannot be exactly determined. However, since the binding energy of the fifth addition of formaldehyde and acetaldehyde are within $3 \mathrm{kcal} / \mathrm{mol}$ of that for the fifth addition of benzonitrile, it is possible that these may be isolated in future mass spectrometric studies.

\section{Conclusion}

The complexation of gas phase $\mathrm{UO}_{2}{ }^{2+}$ with nitrile and carbonyl ligands has been examined. Both types of ligands bind to uranyl with the nitrogen or oxygen lying in the equatorial plane. However, complexes containing six ligands, as well as the five coordinate acetone complex, experience distortions due to steric effects that force them to deviate from the equatorial plane. Additionally, the plane of the nitrile ligands is parallel to $\mathrm{UO}_{2}{ }^{2+}$, while the plane of the carbonyl ligands is generally perpendicular to $\mathrm{UO}_{2}{ }^{2+}$. The carbonyls, however, have side groups closer to uranium than do the nitrile. This forces the plane of the carbonyl ligands to deviate from a $90^{\circ}$ angle with $\mathrm{UO}_{2}{ }^{2+}$ when 5 or 6 ligands are present. Additionally, while the nitrile series binds to uranyl with a U-N-C angle of $180^{\circ}$, the carbonyl series binds with a U-O-C angle less than $180^{\circ}$ in the equatorial plane when 4 or more ligands are present. Notably, formaldehyde is the only ligands studied that does not form a 6 coordinate complex with uranyl.

Both classes of ligands exhibit a strong affinity for uranyl; however, the nitrile ligands tend to bind more strongly than the carbonyls. The strength of the uranyl-ligand 
bonds are also influenced by the size of the ligands. Larger ligands more easily stabilize a shift in electron density, and thus are more capable of donation to the metal center. This effect is most noteworthy for the first ligand addition, and it diminishes as more ligands are added. Complexes containing up to six ligands have been modeled, and the relative binding energies predict all complexes to have five ligands with the exception of complexes containing either propionitrile or acetone ligands. This is similar to experimental results obtained van Stipdonk et al. in their ESI-MS study of nitrile containing complexes ${ }^{12}$. However, in their experimental work, no complexes with six ligands were found.

\section{Acknowledgements}

This research was performed in part using the Molecular Science Computing Facility (MSCF) in the William R. Wiley Environmental Molecular Sciences Laboratory, a national scientific user facility sponsored by the U.S. Department of Energy's Office of Biological and Environmental Research and located at the Pacific Northwest National Laboratory, operated for the Department of Energy by Battelle. Funding has been provided by Iowa State University and an NSF grant in petascale applications to T. L. Windus.

Supporting Information Available: The atomic coordinates for the optimized geometries, the complete set of vibrational frequencies (and their descriptions) in the $800-2500 \mathrm{~cm}^{-1}$ range, and the raw calculated energies are available. This material is available free of charge via the Internet at http://pubs.acs.org. 
Table 1. Calculated uranyl $\mathrm{U}=\mathrm{O}$ and $\mathrm{C}=\mathrm{N}$ bond lengths (in $\AA$ ) and associated stretching frequencies (in $\mathrm{cm}^{-1}$ ) of the acetonitrile, propionitrile, and benzonitrile complexes.

\begin{tabular}{|c|c|c|c|c|c|}
\hline $\begin{array}{l}\text { Molecular } \\
\text { complex }\end{array}$ & $\begin{array}{c}\mathrm{U}=\mathrm{O} \text { bond } \\
\text { length }\end{array}$ & $\begin{array}{c}\mathrm{UO}_{2} \\
\text { symmetric } \\
\text { stretch }\end{array}$ & $\begin{array}{c}\mathrm{UO}_{2} \\
\text { asymmetric } \\
\text { stretch }\end{array}$ & $\begin{array}{c}\mathrm{C}=\mathrm{N} \text { bond } \\
\text { length }\end{array}$ & $\mathrm{C}=\mathrm{N}$ stretch \\
\hline$\left[\mathrm{UO}_{2}\right]^{2+}$ & 1.702 & 1028 & 1131 & --- & --- \\
\hline Acetonitrile & --- & --- & --- & 1.161 & 2320 \\
\hline 1 -acn & 1.722 & 986 & 1084 & 1.175 & 2216 \\
\hline 2 -acn & 1.735 & 960 & 1053 & 1.168 & 2253(a), 2271(s) \\
\hline 3-acn & 1.745 & 941 & 1031 & 1.164 & 2284(a), 2284(a), 2299(s) \\
\hline 4-acn & 1.754 & 923 & 1011 & 1.162 & 2301(a), 2302(a), 2302(a), 2314(s) \\
\hline 5 -acn & 1.759 & 914 & 1001 & 1.160 & 2319(a), 2319(a), 2321(a), 2321(a), 2330(s) \\
\hline 6-acn & 1.761 & 892 & 977 & 1.159 & 2329(a), 2330(a), 2330(a), 2331(a), 2331(a), 2337(s) \\
\hline Propionitrile & --- & --- & --- & 1.161 & 2309 \\
\hline $1-\mathrm{pn}$ & 1.724 & 974 & 1078 & 1.177 & 2171 \\
\hline 2-pn & 1.737 & 955 & 1048 & 1.170 & 2225(a), 2244(s) \\
\hline 3-pn & 1.747 & 938 & 1027 & 1.166 & 2261(a), 2261(a), 2278(s) \\
\hline 4-pn & 1.756 & 922 & 1007 & 1.163 & 2281(a), 2282(a), 2282(a), 2295(s) \\
\hline 5-pn & 1.760 & 913 & 997 & 1.161 & 2302(a), 2302(a), 2304(a), 2304(a), 2314(s) \\
\hline 6-pn & 1.767 & 891 & 974 & 1.160 & 2315(a), 2315(a), 2315(a), 2316(a), 2316(a), 2322(s) \\
\hline Benzonitrile & --- & --- & --- & 1.164 & 2289 \\
\hline $1-\mathrm{bzn}$ & 1.733 & 958 & 1058 & 1.183 & 2121 \\
\hline 2-bzn & 1.747 & 931 & 1027 & 1.177 & 2182(a), 2196(s) \\
\hline 3-bzn & 1.755 & 916 & 1010 & 1.172 & 2221(a), 2221(a), 2241(s) \\
\hline 4-bzn & 1.763 & 905 & 993 & 1.169 & 2241(a), 2245(a), 2245(a), 2266(s) \\
\hline $5-b z n$ & 1.766 & 898 & 984 & 1.165 & 2267(a), 2267(a), 2272(a), 2272(a), 2287(s) \\
\hline 6-bzn & 1.770 & 883 & 968 & 1.163 & 2286(a), 2287(a), 2287(a), 2289(a), 2289(a), 2297(s) \\
\hline
\end{tabular}


Table 2. Calculated uranyl $\mathrm{U}=\mathrm{O}$ and $\mathrm{C}=\mathrm{O}$ bond lengths (in $\AA$ ) and associated stretching frequencies (in $\mathrm{cm}^{-1}$ ) of the acetone, acetaldehyde, and formaldehyde complexes. Multiple $\mathrm{UO}_{2}$ symmetric stretches observed for $3-5$ acetaldehydes and 5 acetones are the result of coupling to $\mathrm{C}-\mathrm{C}$ stretches in the acetaldehyde and acetone ligands.

\begin{tabular}{|c|c|c|c|c|c|}
\hline $\begin{array}{l}\text { Molecular } \\
\text { complex }\end{array}$ & $\begin{array}{c}\mathrm{U}=\mathrm{O} \text { bond } \\
\text { length }\end{array}$ & $\begin{array}{c}\mathrm{UO}_{2} \text { symmetric } \\
\text { stretch }\end{array}$ & $\begin{array}{c}\mathrm{UO}_{2} \\
\text { asymmetric } \\
\text { stretch }\end{array}$ & $\mathrm{C}=\mathrm{O}$ bond length & $\mathrm{C}=\mathrm{O}$ stretch \\
\hline$\left[\mathrm{UO}_{2}\right]^{2+}$ & 1.702 & 1028 & 1131 & --- & --- \\
\hline Formaldehyde & --- & --- & --- & 1.206 & 1780 \\
\hline 1 -for & 1.721 & 988 & 1087 & 1.240 & 1615 \\
\hline 2-for & 1.735 & 960 & 1054 & 1.236 & 1655(a), 1663(s) \\
\hline 5 -for & 1.758 & 915 & 1004 & 1.227 & 1710(a), 1710(a), 1710(a), 1710(a), 1719(s) \\
\hline Acetaldehyde & --- & --- & --- & 1.212 & 1790 \\
\hline 1 -aca & 1.725 & 980 & 1077 & 1.269 & 1533 \\
\hline 2-aca & 1.740 & 948 & 1042 & 1.256 & $1597(a), 1614(s)$ \\
\hline 3-aca & 1.752 & 914,928 & 1016 & 1.248 & 1640(a), 1640(a), 1663(s) \\
\hline Acetone & --- & --- & --- & 1.219 & 1767 \\
\hline 1 -ace & 1.728 & 972 & 1070 & 1.290 & 1455 \\
\hline 2-ace & 1.745 & 938 & 1033 & 1.271 & $1536(\mathrm{a}), 1560(\mathrm{~s})$ \\
\hline 3-ace & 1.757 & 915 & 1005 & 1.259 & 1593(a), 1593(a), 1623(s) \\
\hline 4-ace & 1.766 & 899 & 986 & 1.252 & 1626(a), 1631(a), 1631(a), 1660(s) \\
\hline 5 -ace & 1.779 & $858,859,860,867$ & 948 & 1.249 & 1625(a), 1629(a), 1638(a), 1648(a), 1672(s) \\
\hline 6-ace & 1.792 & 823 & 909 & 1.247 & 1641(a), 1642(a), 1642(a), 1649(a), 1650(a), 1671(s) \\
\hline
\end{tabular}


Table 3. B3LYP dissociation and relative binding energies (in $\mathrm{kcal} / \mathrm{mol}$ ) for the uranyl acetonitrile, propionitrile, and benzonitrile complexes. Energies include the zero-point energy correction.

\begin{tabular}{|c|c|c|c|c|c|c|}
\hline $\mathrm{n}$ & \multicolumn{2}{|c|}{ Acetonitrile } & \multicolumn{2}{c|}{ Propionitrile } & \multicolumn{2}{c|}{ Benzonitrile } \\
\hline \multirow{2}{*}{} & $\begin{array}{c}\text { Relative } \\
\text { binding } \\
\text { energy }\end{array}$ & $\begin{array}{c}\text { Absolute } \\
\text { binding } \\
\text { energy }\end{array}$ & $\begin{array}{c}\text { Relative } \\
\text { binding } \\
\text { energy }\end{array}$ & $\begin{array}{c}\text { Absolute } \\
\text { binding } \\
\text { energy }\end{array}$ & $\begin{array}{c}\text { Relative } \\
\text { binding } \\
\text { energy }^{\mathrm{a}}\end{array}$ & $\begin{array}{c}\text { Absolute } \\
\text { binding } \\
\text { energy }^{\mathrm{b}}\end{array}$ \\
\hline 1 & 92.8 & -92.8 & 98.4 & -98.4 & 119.4 & -119.4 \\
2 & 71.2 & -164.1 & 72.7 & -171.0 & 73.8 & -193.2 \\
3 & 57.9 & -221.9 & 58.6 & -229.7 & 57.6 & -250.8 \\
4 & 41.7 & -263.6 & 41.8 & -271.5 & 40.4 & -291.1 \\
5 & 25.7 & -261.8 & 26.5 & -296.7 & 23.7 & -314.8 \\
6 & -3.9 & -282.1 & 1.8 & -298.5 & -0.8 & -314.0 \\
\hline
\end{tabular}

${ }^{\mathrm{a}}$ : Relative binding energy: $\mathrm{UO}_{2}[\mathrm{~L}]_{\mathrm{n}}{ }^{2+} \rightarrow \mathrm{UO}_{2}[\mathrm{~L}]_{\mathrm{n}-1}{ }^{2+}+[\mathrm{L}]$

${ }^{\mathrm{b}}:$ Absolute binding energy: $\left[\mathrm{UO}_{2}\right]^{2+}+\mathrm{n}[\mathrm{L}] \rightarrow \mathrm{UO}_{2}[\mathrm{~L}]_{\mathrm{n}}{ }^{2+}$ 
Table 4. B3LYP dissociation and relative binding energies (in $\mathrm{kcal} / \mathrm{mol}$ ) for the uranyl acetone, acetaldehyde, and formaldehyde complexes. Energies include the zero-point energy correction.

\begin{tabular}{|c|c|c|c|c|c|c|}
\hline $\mathrm{n}$ & \multicolumn{2}{|c|}{ Formaldehyde } & \multicolumn{2}{c|}{ Acetaldehyde } & \multicolumn{2}{c|}{ Acetone } \\
\hline & $\begin{array}{c}\text { Relative } \\
\text { binding } \\
\text { energy }^{\mathrm{a}}\end{array}$ & $\begin{array}{c}\text { Absolute } \\
\text { binding } \\
\text { energy }^{\mathrm{b}}\end{array}$ & $\begin{array}{c}\text { Relative } \\
\text { binding } \\
\text { energy }^{\mathrm{a}}\end{array}$ & $\begin{array}{c}\text { Absolute } \\
\text { binding } \\
\text { energy }^{\mathrm{b}}\end{array}$ & $\begin{array}{c}\text { Relative } \\
\text { binding } \\
\text { energy }^{\mathrm{a}}\end{array}$ & $\begin{array}{c}\text { Absolute } \\
\text { binding } \\
\text { energy }^{\mathrm{b}}\end{array}$ \\
\hline 1 & 77.8 & -77.8 & 95.7 & -95.7 & 108.1 & -108.1 \\
2 & 60.2 & -137.9 & 69.5 & -165.2 & 75.0 & -183.1 \\
3 & 39.8 & -187.7 & 55.1 & -220.3 & 57.8 & -240.9 \\
4 & 35.5 & -223.2 & 37.3 & -257.7 & 30.8 & -271.7 \\
5 & 20.8 & -241.8 & 20.8 & -278.5 & 12.7 & -280.2 \\
6 & --- & --- & -5.4 & -273.2 & 2.7 & -282.9 \\
\hline
\end{tabular}

${ }^{\mathrm{a}}$ : Relative binding energy: $\mathrm{UO}_{2}[\mathrm{~L}]_{\mathrm{n}}{ }^{2+} \rightarrow \mathrm{UO}_{2}[\mathrm{~L}]_{\mathrm{n}-1}{ }^{2+}+[\mathrm{L}]$

${ }^{\mathrm{b}}$ : Absolute binding energy: $\left[\mathrm{UO}_{2}\right]^{2+}+\mathrm{n}[\mathrm{L}] \rightarrow \mathrm{UO}_{2}[\mathrm{~L}]_{\mathrm{n}}{ }^{2+}$ 
Figure 1. $\mathrm{U}-\mathrm{N} \sigma$ bonds in $\left[\mathrm{UO}_{2}(\mathrm{Acn})_{2}\right]^{2+}$ between $\mathrm{U} \mathrm{p}_{\mathrm{x}}$ and $\mathrm{N}$ s orbitals (HOMO-24) (A) and $\mathrm{U} \mathrm{p}_{\mathrm{y}}$ and $\mathrm{N}$ s orbitals (HOMO-25) (B). Uranium is colored gold, oxygen is red, nitrogen is blue, carbon is gray, and hydrogen is white.
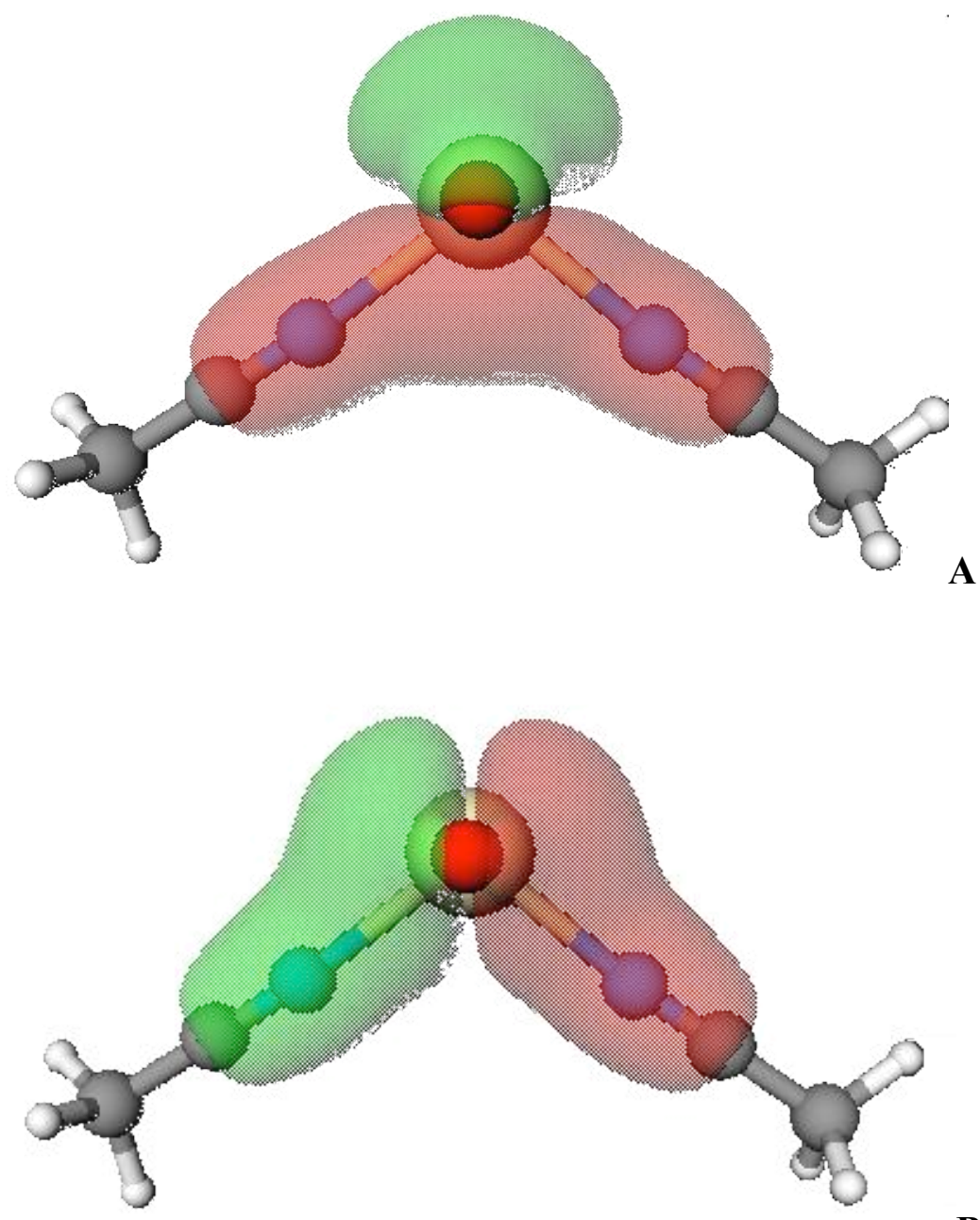

B 
Figure 2. $\mathrm{U}-\mathrm{N}$ bond in $\left[\mathrm{UO} 2(\mathrm{Acn})_{3}\right]^{2+}(\mathrm{HOMO}-6)$ via $\mathrm{N} \mathrm{p}_{\mathrm{z}}$ donation to $\mathrm{U} \mathrm{f}_{\mathrm{z}^{3}}$.

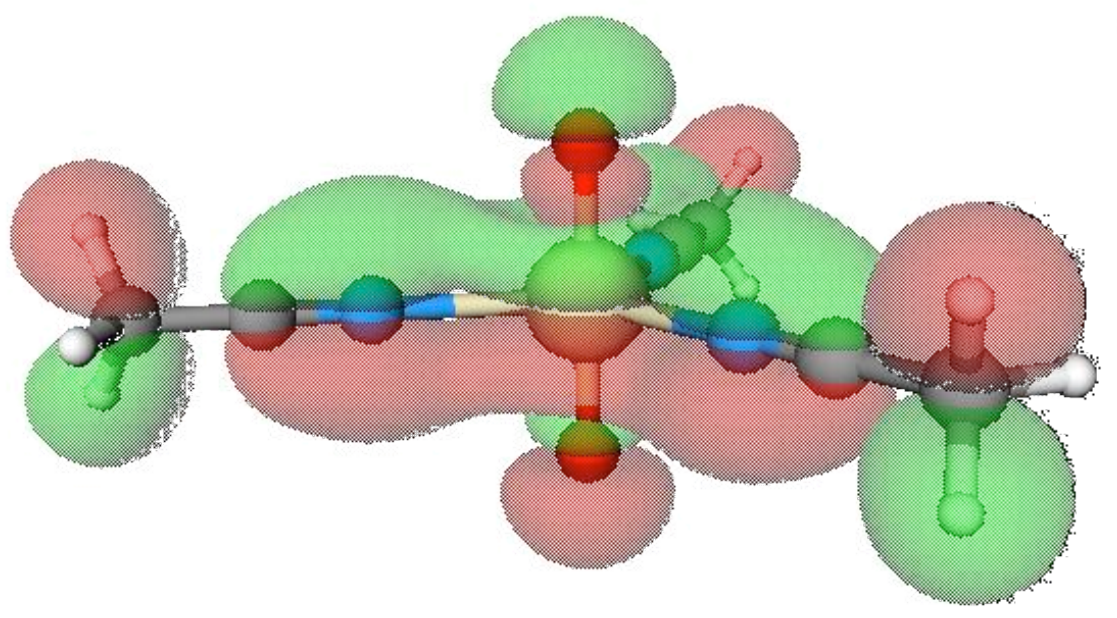

Figure 3. Bond between $\mathrm{N} p$ and $\mathrm{O} p$ orbitals on uranyl in $\left[\mathrm{UO}_{2}(\mathrm{Acn})\right]^{2+}(\mathrm{HOMO}-3)$.

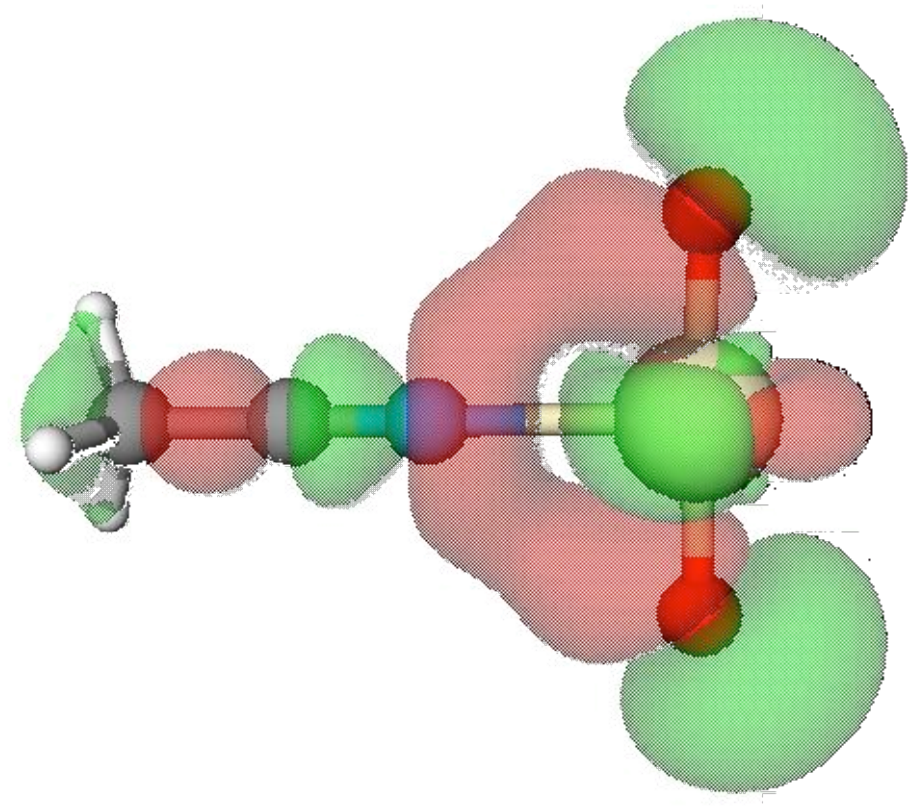


Figure 4. Bonding interaction of adjacent ligands via $\mathrm{N} \mathrm{s}$ orbitals and antibonding to $\mathrm{U} \mathrm{s}$ in $\left[\mathrm{UO}_{2}(\mathrm{Pn})_{5}\right]^{2+}(\mathrm{HOMO}-45)$.

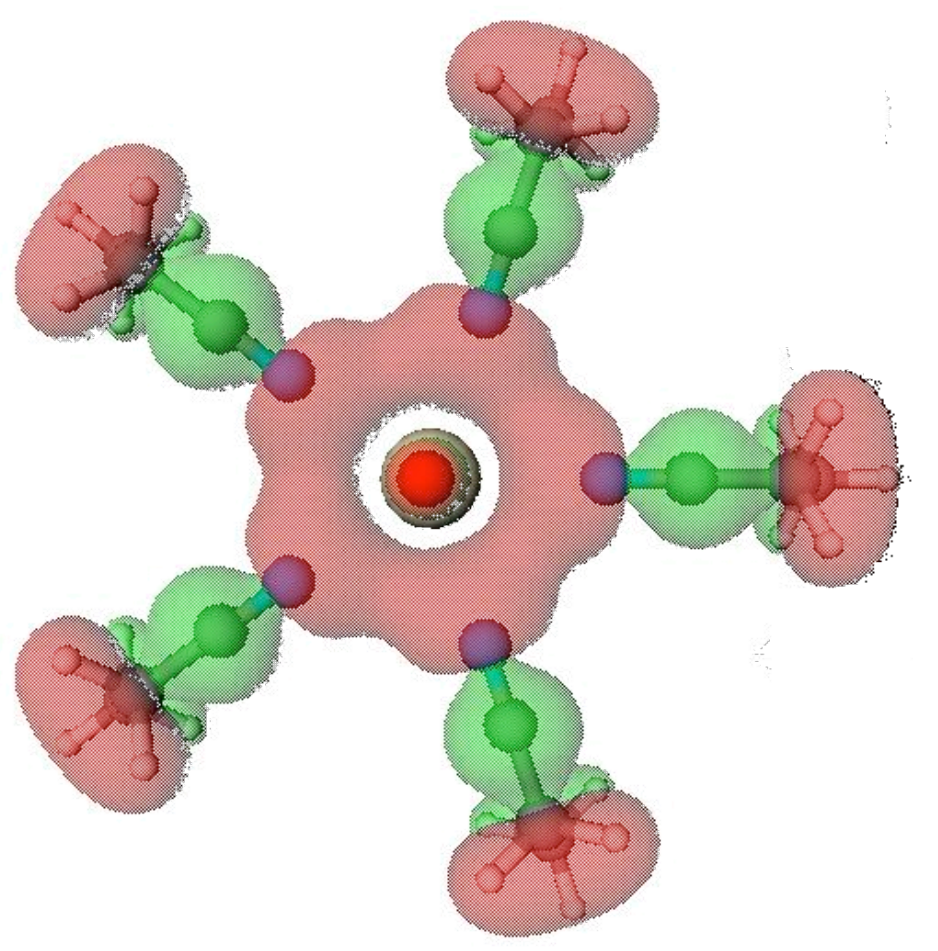


Figure 5. Formaldehydes in $\left[\mathrm{UO}_{2}\left(\mathrm{CH}_{2} \mathrm{O}\right)_{5}\right]^{2+}$ form $141.1^{\circ} \mathrm{U}-\mathrm{O}-\mathrm{C}$ angles. The $\mathrm{H}-\mathrm{O}$ distance between adjacent formaldehydes is $2.478 \AA$ and the $\mathrm{C}-\mathrm{H}-\mathrm{O}$ angle is $108.4^{\circ}$ suggesting the possibility of hydrogen bond formation.

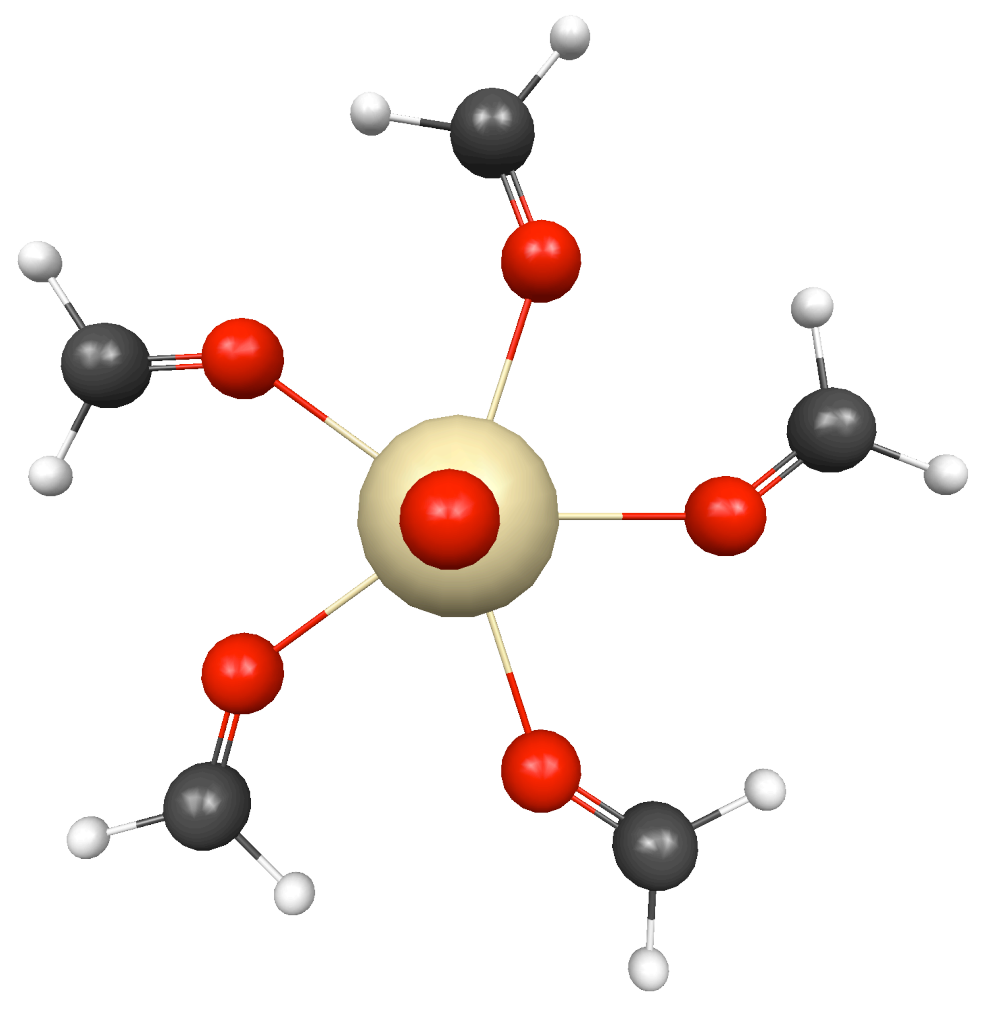


Figure 6. $\left[\mathrm{UO}_{2}(\text { Ace })_{5}\right]^{2+}$ perspective view. While acetones' oxygens remain in the equatorial plane, the plane of the acetones is rotated $7^{\circ}-26^{\circ}$ with respect to the equatorial plane.

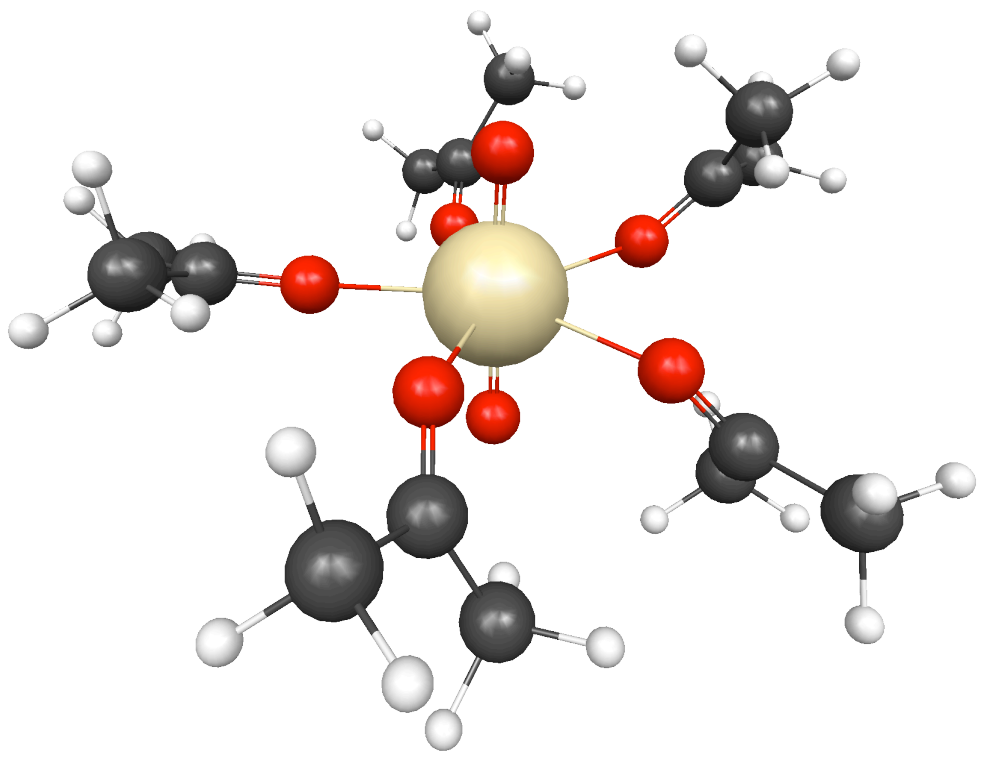


Figure 7. $\left[\mathrm{UO}_{2}(\text { Ace })_{6}\right]^{2+}$ perspective view (A) and top view (B). The acetones' oxygens alternate $9^{\circ}$ above and below the equatorial plane, and the plane of acetone's carbon backbone is rotated $\pm 40.9^{\circ}$ relative to the $\mathrm{UO}_{2}{ }^{2+}$ axis. Methyl groups on each acetone are oriented such that one of the hydrogens points toward an axial oxygen in $\mathrm{UO}_{2}{ }^{2+}$. This $\mathrm{O}-$ $\mathrm{H}$ distance is $2.245 \AA$ suggesting hydrogen bonding.

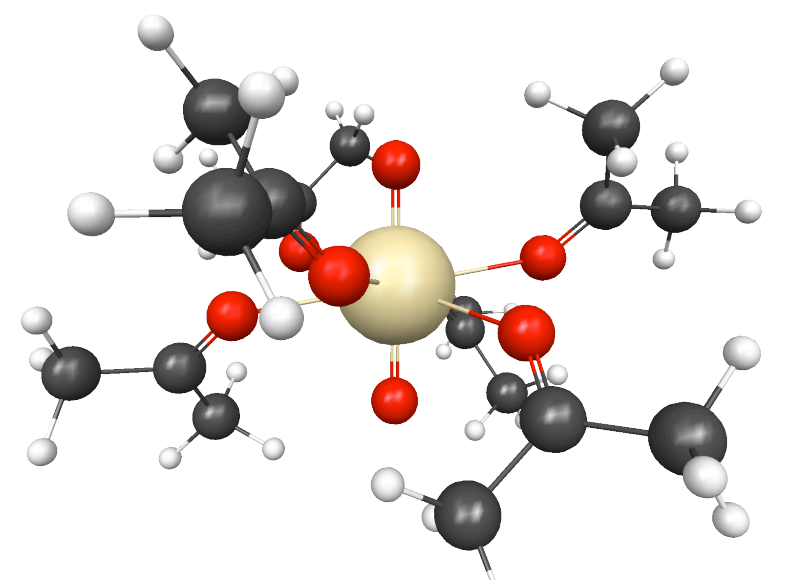

A

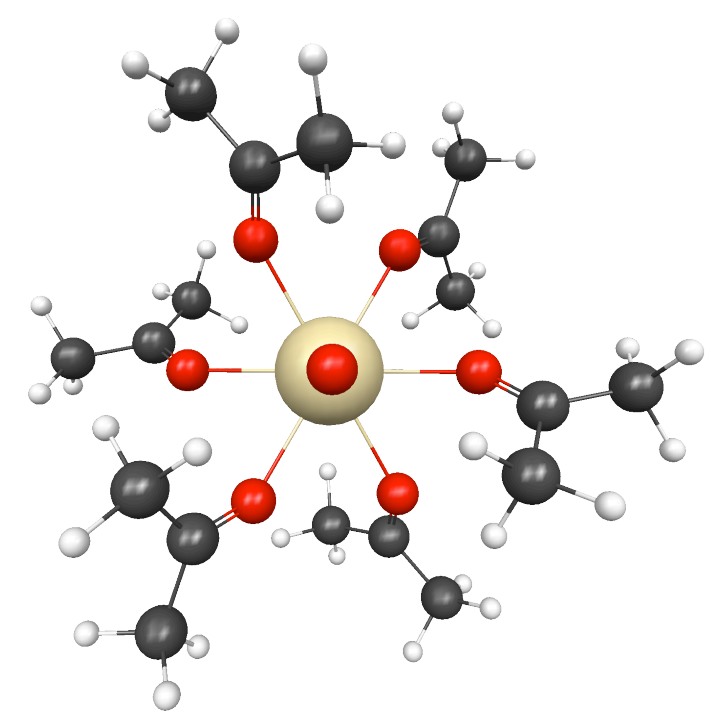


Figure 8. $\left[\mathrm{UO}_{2}(\mathrm{Aca})_{6}\right]^{2+}$ perspective view. Acetaldehyde ligands alternate pointing up and down. The U-O-C-C dihedral angle is $20.0^{\circ} \pm 0.6^{\circ}$.

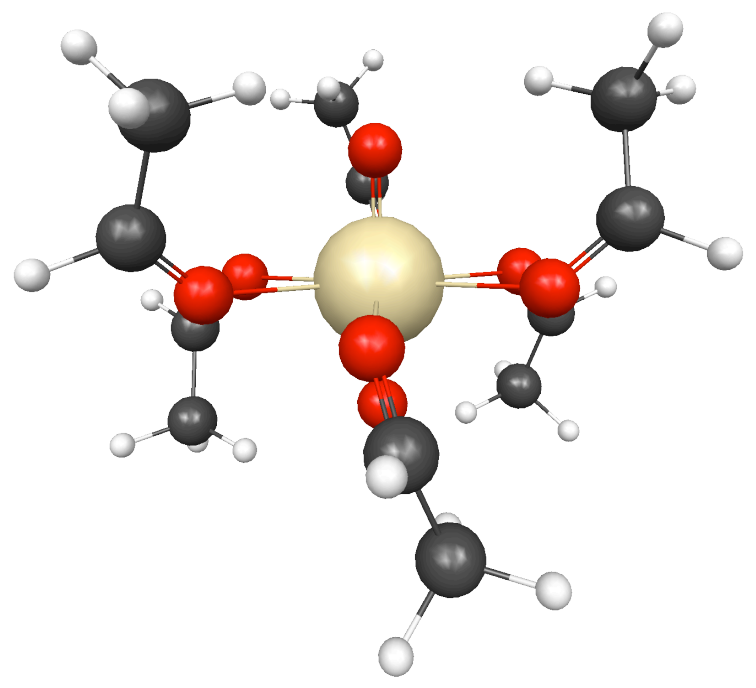




\section{References}

${ }^{1}$ Hay, P.J.; Martin R.L.; Schreckenbach, G. J. Phys. Chem. A 2000, 104, 6259

${ }^{2}$ Vallet, V.; Wahlgren, U.; Schimmelpfennig, B.; Moll, H.; Szabo, Z.; Grenthe, I. Inorg.

Chem. 2001, 40, 3516

${ }^{3}$ Moskaleva, L.V.; Krüger, S.; Spörl, A.; Rösch, N. Inorg. Chem. 2004, 43, 4080

${ }^{4}$ Spencer, S.; Gagliardi, L.; Handy, N.C.; Ioannou, A.G.; Skylaris, C.K.; Willetts, A.;

Simper, A.M. J. Phys. Chem. A 1999, 103, 1831

${ }^{5}$ Tsushima, S.; Yang, T.X.; Suzuki, A. Chem. Phys. Lett. 2001, 334, 365

${ }^{6}$ Sonnenberg, J.L.; Hay, P.J.; Martin, R.L.; Bursten, B.E. Inorg. Chem. 2005, 44, 2255.

${ }^{7}$ Nichols,P.; Bylaska, E.J.; Schenter, G.K.; de Jong, W.A. J. Chem Phys., 2008, 128, 124507

${ }^{8}$ De Jong, W.A.; Aprà, E.;Windus, T.L.; Nichols, J.A.; Harrison, R.J.; Gutowksi, K.E.;

Dixon, D.A. J. Phys. Chem. A. 2005, 109, 11568.

${ }^{9}$ de Jong, W.A.; Visscher, L.; Nieuwpoort, W.C. J. Mol. Struct. (THEOCHEM) 1999, 41.

${ }^{10}$ de Jong, W.A.; Harrison, R.J.; Nichols, J.A.; Dixon, D.A. Theor. Chem. Acc. 2001, 107, 22.

${ }^{11}$ Jackson, V.E.; Craciun, R.N.; Dixon, D.A.; Peterson, K.A.; de Jong, W.A. J. Phys. Chem. A 2008, 112, 4095

${ }^{12}$ Van Stipdonk, M.J.; Chien, W.; Bulleigh, K.; Wu, Q.; Groenewold, G.S. J. Phys. Chem. A. 2006, 110, 959.

${ }^{13}$ Groenewold, G.S.; Gianotto, A.K.; Cossel, K.C.; Van Stipdonk, M.J.; Moore, D.T.; Pofler, N.; Oomens, J.; de Jong, W.A.; Visscher, L. J. Am. Chem. Soc. 2006, 128, 4802.

${ }^{14}$ Van Stipdonk, M.J.; Chien, W.; Anbalagan, V.; Bulleigh, K.; Hanna, D.; Groenewold, 
G.S. J. Phys. Chem. A 2004, 108, 10448.

${ }^{15}$ Van Stipdonk, M.J.; Anbalagan, V.; Chien, W.; Gresham, G.; Groenewold, G.S.;

Hanna, D. J. Am. Soc. Mass. Spectrom. 2003, 14, 1205.

${ }^{16}$ Gresham, G.; Gianotto, A.K.; Harrington, P.B.; Cao, L.; Scott, J.R.; Olson, J.E.;

Appelhans, A.D.; Van Stipdonk, M.J.; Groenewold, G.S. J. Phys. Chem. A 2003, 107, 8530.

${ }^{17}$ Van Stipdonk, M.J.; Chien, W.; Anbalagan, V.; Gresham, G.; Groenewold, G.S. Int. J. Mass. Spectrom. 2004, 237, 175.

${ }^{18}$ Gary S. Groenewold, G.S.; Van Stipdonk, M.J.; de Jong, W.A.; Oomens, J.; Gresham, G.L.; McIlwain, M.E.; Gao, D; Siboulet, B.; Visscher, L.; Kullman, M.; Polfer, N. ChemPhysChem, 2008, 9, 1278.

${ }^{19}$ Bryantsev, V.S.; de Jong, W.A.; Cossel, K.C.; Diallo, M.S.; Goddard III, W.A.;

Groenewold, G.S.; Chien, W.; Van Stipdonk, M.J. J. Phys Chem A, 2008, 112, 5777

${ }^{20}$ Groenewold, G.S.; Gianotto, A.K.; Cossel, K.C.; Van Stipdonk, M.J.; Moore, D.T.;

Polfer, N.; Oomens, J.; de Jong, W.A.; Visscher, L. J. Am. Chem. Soc., 2006, 128, 4802

${ }^{21}$ Groenewold, G.S.; Gianotto, A.K.; Cossel, K.C.; Van Stipdonk, M.J.; Oomens, J.;

Polfer, N.; Moore, D.T.; de Jong, W.A. Phys. Chem. Chem. Phys. 2007, 9, 596

${ }^{22}$ Gibson, J.K.; Haire, R.G.; Santos, M.; Marçalo, J. ; Pires de Matos, A. J. Phys. Chem. A, 2005, 109, 2768.

${ }^{23}$ Senanayake, S.D.; Chong, S.V.; Idriss, H. Cat. Today 2003, 85, 311.

${ }^{24}$ Aprà, E.; et al. NWChem, A Computational Chemistry Package for Parallel Computers, Version 4.7, Pacific Northwest National Laboratory, Richland, Washington, 2005. 
${ }^{25}$ Kendall, R.A.; Apra, E.; Bernholdt, D.E.; Bylaska, E.J.; Dupuis, M.; Fann, G.I.;

Harrison, R.J.; Ju, J.; Nichols, J.A.; Nieplocha, J.; Straatsma, T.P.; Windus, T.L.; Wong,

A.T. Computer Phys. Comm. 2000, 128, 260.

${ }^{26}$ Slater, J.C. Phys. Rev. 1951, 81 (3), 1287.

${ }^{27}$ Vosko, S.H.; Wilk, L.; Nusiar, M. Can. J. Phys. 1980, 58 (8), 1200.

${ }^{28}$ Becke, A.D. J. Chem. Phys. 1993, 98, 5648.

${ }^{29}$ Lee, C.; Yang, W.; Parr, R.G. Phys. Rev. B 1988, 37, 785.

${ }^{30}$ Bergner, A.; Dolg, M.; Küchle, W.; Stoll, H.; Preuss, H. Mol. Phys. 1993, 80 (6), 1431.

${ }^{31}$ Küchle, W.; Dolg, M.; Stoll, H. Mol. Phys. 1991, 74 (6), 1245.

${ }^{32}$ Küchle, W.; Dolg, M.; Stoll, H. ; Preuss, H. J. Chem. Phys. 1994, 100 (10), 7535.

${ }^{33}$ Godbout, N.; Salahub, D.R.; Andzelm, J.; Wimmer, E. Can. J. Chem. 1992, 70 (2), 560.

${ }^{34}$ Black, G.; Daily, J.; Elsethagen, T.; Feller, D.; Gracio, D.; Jones, D.; Keller, T.;

Matsumoto, S.; Palmer, B.; Peterson, M.; Schuchardt, K.; Stephan, E.; Sun, L.; Swanson, K.; Taylor, H.; Vorpagel, E.; Windus, T.; Winters, C.; "ECCE, A Problem Solving Environment for Computational Chemistry, Software Version 5.1", Pacific Northwest National Laboratory, Richland, Washington 99352-0999, USA, 2009.

${ }^{35}$ Bode, B. M. and Gordon, M. S. J. Mol. Graphics Mod., 1998, 16, 133-138.

${ }^{36}$ McGlynn, S.P.; Smith, J.K.; Neely, W.C. J. Chem. Phys. 1961, 35 (1), 105 - 116. 
[Reprinted with permission from Schoendorff, G.; de Jong, W. A.; Gordon, M. S.;

Windus, T. L. J. Phys. Chem. A 2010, 114 (33), 8902. Copyright 2010 American

Chemical Society.]

\title{
Gas Phase Computational Studies on the Competition Between Nitrile and Water Ligands in Uranyl Complexes
}

George Schoendorff , Wibe A. de Jong ${ }^{1,2}$, Mark S. Gordon ${ }^{1}$, and Theresa L. Windus ${ }^{2,1}$

1. Department of Chemistry, Iowa State University and Ames Laboratory, Ames IA 50011

2. Environmental Molecular Sciences Laboratory, Pacific Northwest National Laboratory, P.O. Box 999, Richland, Washington 99352

\begin{abstract}
The gas phase formation of uranyl dicationic complexes containing water and nitrile (acetonitrile, propionitrile, and benzonitrile) ligands, $\left[\mathrm{UO}_{2}\left(\mathrm{H}_{2} \mathrm{O}\right)_{\mathrm{m}}(\mathrm{RCN})_{\mathrm{n}}\right]^{2+}$, has been studied using density functional theory with a relativistic effective core potential to account for scalar relativistic effects on uranium. It is shown that nitrile addition is favored over the addition of water ligands. Decomposition of these complexes to $\left[\mathrm{UO}_{2} \mathrm{OH}\left(\mathrm{H}_{2} \mathrm{O}\right)_{\mathrm{m}}(\mathrm{RCN})_{\mathrm{n}}\right]^{+}$by the loss of either $\mathrm{H}_{3} \mathrm{O}^{+}$or $(\mathrm{RCN}+\mathrm{H})^{+}$is also examined. It is found that this reaction is competitive with the ligand addition when the coordination sphere of uranyl is unsaturated. Additionally, this reaction is influenced by the size of the
\end{abstract}

\footnotetext{
† Email: twindus@iastate.edu

*Email: bert.dejong@pnl.gov
} 
nitrile ligand with reactions involving acetonitrile being the most prevalent. Finally, ligand addition to the monocation shows similar trends to that of the dication with energetic differences being smaller for the addition to the monocation.

\section{Introduction}

Advances in nuclear technology over the last seven decades have alleviated some of the need for fossil fuels. However, nuclear power does come with a significant environmental cost, primarily in the accumulation, treatment, and storage of nuclear waste. Due to the renewed interest in nuclear technology, there has been a resurgence of interest in the chemical reactivity of uranium. In particular, the uranyl dication has received particular attention due to its prevalence in uranium containing species. For these reasons, the chemistry of the uranyl dication, particularly its interaction with water, has been the subject of intense investigation. ${ }^{1,2,3,4,5,6,7}$ However, other ligands, such as acetone and acetonitrile derivatives ${ }^{8}$ also exhibit a substantial affinity for uranyl and compete with water for coordination sites.

While much of the nuclear waste chemistry happens in the solution or solid phase, gas phase reactions are also being explored to understand the fundamental uranium chemistry. These gas phase studies also provide an excellent source for direct comparison with computation, which can help to validate the computational approach and give insight into the bonding characteristics of these systems. Notably, complexes with both water and acetonitrile derivatives as ligands have been studied experimentally using electrospray ionization mass spectroscopy (ESI-MS) and multiple-stage collision induced dissociation (CID). ${ }^{9}$ In the course of the experimental study, two types of reactions were 
observed. The first of these is a simple ligand addition reaction whereby either water or RCN (acetonitrile, propionitrile, or benzonitrile) is added sequentially to build up a complex with uranyl (e.g. $\left.\left[\mathrm{UO}_{2}\left(\mathrm{H}_{2} \mathrm{O}\right)_{\mathrm{m}}(\mathrm{RCN})_{\mathrm{n}}\right]^{2+}\right)$. The other reaction involves the decomposition of the aforementioned complex via a charge-exchange (hydrolysis) reaction to produce $\left[\mathrm{UO}_{2} \mathrm{OH}\left(\mathrm{H}_{2} \mathrm{O}\right)_{\mathrm{m}}(\mathrm{RCN})_{\mathrm{n}}\right]^{+}$and either $\mathrm{H}_{3} \mathrm{O}^{+}$or $(\mathrm{H}+\mathrm{RCN})^{+}$. While both reactions occurred in the ion trap before analysis by mass spectrometry, short isolation times $(30 \mathrm{~ms})$ yielded only dicationic species and longer isolation times $(100-1000 \mathrm{~ms})$ led to the formation of the monocationic species. Due to the long isolation times involved in these experiments, the dominant chemistry occurs under equilibrium conditions.

The present computational work seeks to understand these gas phase experimental results and is an extension of a previous study of the coordination of water, carbonyl ligands (formaldehyde, acetaldehyde, and acetone), and nitrile ligands (acetonitrile, propionitrile, and benzonitrile) to the uranyl dication. ${ }^{8}$ In that study, the complexes modeled contained only one type of ligand (eg. all water ligands, all acetonitrile ligands, etc.). It was found that the ligands' affinity for uranyl followed the general trend RCN > $\mathrm{RCO}>\mathrm{H}_{2} \mathrm{O}$, and larger ligands were shown to bind more strongly to uranyl due to an increased capacity to delocalize charge. The present study proceeds to examine the influence of the coordination of water ligands in competition with the coordination of nitrile ligands in the gas phase, allowing for comparison with the aforementioned gas phase experimental study. By examining a complete set of data as a function of coordination number, number of nitrile ligands, and size of the nitrile ligands, general observations of the effects of the coordination of nitrile ligands with uranyl in the 
presence of water are presented with the aim of elucidating why formation of some of these complexes are favored over the formation of others. First the growth of dicationic uranyl complexes by subsequent ligand additions is examined. The coordination number is varied from $1-6$ equatorial ligands, and for each equatorial coordination number, $\mathrm{N}$, both the number of water ligands and nitrile ligands are also allowed to vary from $1-\mathrm{N}$ while keeping the total equatorial coordination number constant. Finally, the discussion will move on to model the charge-exchange (hydrolysis) reactions that were experimentally observed. These reactions were shown to be thermodynamically competitive with the ligand addition reactions when the coordination sphere of $\mathrm{UO}_{2}{ }^{2+}$ is unsaturated. ${ }^{9}$

\section{Details of the Calculations}

All calculations were performed using the NWChem software suite. ${ }^{10,11}$ The choice of functional and basis set for this research was based on a previous systematic study in which fully relativistic coupled cluster theory, (specifically, $\operatorname{CCSD}(\mathrm{T})$ ) benchmark calculations on $\mathrm{UO}_{2}{ }^{2+}$ were compared to various levels of theory, DFT functionals, and basis set choices. ${ }^{12}$ That study showed that the best agreement was obtained by employing the local density approximation (LDA) $)^{13,14}$ to determine optimized geometries and frequencies and the B3LYP ${ }^{15,16}$ functional at the LDA optimized geometries for energetics. Accordingly, all geometry optimizations and Hessians were obtained using LDA, and all energies reported were obtained with the B3LYP functional using the LDA optimized geometry. While DFT energies can introduce some error in calculated energies, the aforementioned benchmark study 
examined this effect for various functionals and found that in cases with uranyl, the B3LYP functional provided the most consistently accurate energies. All reported energies in this paper include the zero-point energy correction at $0 \mathrm{~K}$. While Gibbs free energies at other temperatures could certainly be calculated to make a more definitive comparison with experiment, many of these molecules have high amplitude/low frequency modes that make a harmonic approach unreasonable. As shown by one of the authors, ${ }^{17,18}$ anharmonic methods are required which are well beyond the scope of this work. Due to this issue, the terms "exoergic" and "exoergicity" are used for the reaction energetics represented in this work.

The small core Stuttgart relativistic effective core potential (RECP) and associated Stuttgart orbital basis set ${ }^{19,20,21}$ was employed for uranium, while valence triple- $\zeta$ plus polarization $(\mathrm{TZVP})^{22}$ DFT optimized basis sets were used for all other atoms $(\mathrm{H}, \mathrm{C}, \mathrm{N}$, and $\mathrm{O})$. In all cases, spherical primitive Gaussian functions were used. Hessian (energy second derivative) calculations were performed with the LDA functional at the optimized geometries to obtain zero point energies and frequencies and to ensure that the optimized structures are potential energy minima. Molecular images were produced using MacMolPlt. $^{23}$

\section{Results and Discussion}

Three types of reactions have been modeled in this study. The first is a ligand addition reaction of the form

$$
\left[\mathrm{UO}_{2}\left(\mathrm{H}_{2} \mathrm{O}\right)_{m}(\mathrm{RCN})_{\mathrm{n}}\right]^{2+}+\mathrm{H}_{2} \mathrm{O} \rightarrow\left[\mathrm{UO}_{2}\left(\mathrm{H}_{2} \mathrm{O}\right)_{m+1}(\mathrm{RCN})_{n}\right]^{2+}
$$

and 


$$
\left[\mathrm{UO}_{2}\left(\mathrm{H}_{2} \mathrm{O}\right)_{\mathrm{m}}(\mathrm{RCN})_{\mathrm{n}}\right]^{2+}+\mathrm{RCN} \rightarrow\left[\mathrm{UO}_{2}\left(\mathrm{H}_{2} \mathrm{O}\right)_{\mathrm{m}}(\mathrm{RCN})_{\mathrm{n}+1}\right]^{2+}
$$

where the total equatorial coordination number $(n+m+1)$ is constrained to be less than or equal to six and RCN is acetonitrile (Acn), propionitrile (Pn), or benzonitrile (Bzn). Another type of reaction is a charge-exchange (hydrolysis) reaction that follows either

$$
\left[\mathrm{UO}_{2}\left(\mathrm{H}_{2} \mathrm{O}\right)_{\mathrm{m}}(\mathrm{RCN})_{\mathrm{n}}\right]^{2+} \rightarrow\left[\mathrm{UO}_{2} \mathrm{OH}\left(\mathrm{H}_{2} \mathrm{O}\right)_{\mathrm{m}-2}(\mathrm{RCN})_{\mathrm{n}}\right]^{+}+\mathrm{H}_{3} \mathrm{O}^{+}
$$

if a protonated water ligand dissociates, or

$$
\left[\mathrm{UO}_{2}\left(\mathrm{H}_{2} \mathrm{O}\right)_{\mathrm{m}}(\mathrm{RCN})_{\mathrm{n}}\right]^{2+} \rightarrow\left[\mathrm{UO}_{2} \mathrm{OH}\left(\mathrm{H}_{2} \mathrm{O}\right)_{\mathrm{m}-1}(\mathrm{RCN})_{\mathrm{n}-1}\right]^{+}+(\mathrm{H}+\mathrm{RCN})^{+}
$$

if a protonated nitrile ligand dissociates. Finally, the monocationic complexes can undergo further ligand additions according to the following reactions

$$
\left[\mathrm{UO}_{2} \mathrm{OH}\left(\mathrm{H}_{2} \mathrm{O}\right)_{\mathrm{m}}(\mathrm{RCN})_{\mathrm{n}}\right]^{+}+\mathrm{H}_{2} \mathrm{O} \rightarrow\left[\mathrm{UO}_{2} \mathrm{OH}\left(\mathrm{H}_{2} \mathrm{O}\right)_{\mathrm{m}+1}(\mathrm{RCN})_{\mathrm{n}}\right]^{+}
$$

and

$$
\left[\mathrm{UO}_{2} \mathrm{OH}\left(\mathrm{H}_{2} \mathrm{O}\right)_{\mathrm{m}}(\mathrm{RCN})_{\mathrm{n}}\right]^{+}+\mathrm{RCN} \rightarrow\left[\mathrm{UO}_{2} \mathrm{OH}\left(\mathrm{H}_{2} \mathrm{O}\right)_{\mathrm{m}}(\mathrm{RCN})_{\mathrm{n}+1}\right]^{+} .
$$

We first will address the ligand addition reactions involving dicationic complexes before moving on to the charge-exchange reactions and ligand additions to monocationic species.

\section{Ligand Addition Reactions}

The successive addition of nitrile ligands to uranyl dication was previously examined by this group. ${ }^{8}$ The present work builds upon the previous results by allowing water, as well as nitrile ligands, to bind to uranyl.

The trends observed in the ligand addition products are similar to those observed

earlier ${ }^{8}$ for nitrile ligand addition. Data reflecting this observation can be found in the supplementary material. In general, when the equatorial coordination number is held 
constant, there is a red shift in the $\mathrm{UO}_{2}{ }^{2+}$ symmetric and antisymmetric stretching frequencies as the number of nitrile ligands increases and the number of water ligands decreases. This is accompanied by an increase in both the $\mathrm{U}-\mathrm{O}_{\text {axial }}$ bond lengths and the U-ligand bond lengths. Additionally, increasing the number of nitrile ligands also causes blue shifts in the C-N stretching frequencies with concomitant decreases in the C-N bond lengths. Increasing the total number of ligands results in similar trends. Thus, as noted in our previous paper ${ }^{8}$, ligand addition weakens the $\mathrm{U}-\mathrm{O}_{\text {axial }}$ bond in $\mathrm{UO}_{2}{ }^{2+}$ and the $\mathrm{U}$ ligand bond within the complex while strengthening the C-N bond in the nitrile ligands. However, increasing the number of ligands has a greater impact on these structural changes than does replacing water ligands with nitrile ligands. Changes in bond lengths and vibrational frequencies caused by ligand addition can be up to an order of magnitude larger than changes associated with substituting a water ligand for a nitrile. For example, the U-O $\mathrm{O}_{\text {axial }}$ bond length increases by approximately $0.01 \AA$ when each successive ligand is added. However, if the coordination number is held fixed and water ligands are substituted with benzonitrile, then the $\mathrm{U}-\mathrm{O}_{\text {axial }}$ bond length increases by approximately $0.005 \AA$ for each successive substitution.

One limitation of current mass-spectroscopy studies is that one cannot distinguish between isomers; however, a comparison of isomers can be performed straightforwardly using computations. Conformational isomers can occur when the equatorial coordination number exceeds three. With four ligands, $\left[\mathrm{UO}_{2}(\mathrm{RCN})_{2}\left(\mathrm{H}_{2} \mathrm{O}\right)_{2}\right]^{2+}$ can take either of the isomeric forms depicted in Figure 1. In this case, the ligand arrangement in isomer 1A (referred to as trans in this paper) always has the lowest energy, regardless of whether the nitrile is acetonitrile, propionitrile, or benzonitrile. The largest energy difference between 
isomers with four equatorial ligands occurs when the nitriles are acetonitrile $(1.5 \mathrm{kcal} / \mathrm{mol})$. This value decreases as the size of the nitrile ligand increases, so that the energy difference is $0.4 \mathrm{kcal} / \mathrm{mol}$ for propionitrile ligands and $0.1 \mathrm{kcal} / \mathrm{mol}$ for benzonitrile ligands. Obviously, at this level of theory, the latter two should be considered isoenergetic.

Figure 2 gives examples of the isomers that can occur when five equatorial ligands are present. Structures $2 \mathrm{~A}$ and $2 \mathrm{~B}$ are complexes with two nitrile ligands, and structures $2 \mathrm{C}$ and $2 \mathrm{D}$ are complexes with three nitrile ligands. The energy differences among these isomers are less than $1 \mathrm{kcal} / \mathrm{mol}$, regardless of whether the nitrile is acetonitrile, propionitrile, or benzonitrile. Therefore all isomers with five equatorial ligands are also nearly isoenergetic.

The isomers associated with six equatorial ligands are not as straightforward as are those for smaller numbers of ligands. As noted in previous work ${ }^{8}$, the sixth ligand can be a direct ligand (although weakly bound), or it can add to the first solvent shell. There are three possibilities when 2, 3, and 4 nitrile ligands are present. Repulsion between adjacent ligands distorts their arrangement around $\mathrm{UO}_{2}{ }^{2+}$ so that the ligands lie above and below the equatorial plane. Furthermore, during the geometry optimization, one ligand frequently moves out of the coordination sphere. Nonetheless, some isomers with all six ligands directly bound to uranyl can be found. The isomers of complexes containing acetonitrile are shown in Figure 3, while those that contain propionitrile and benzonitrile are shown in Figures 4 and 5, respectively. The energy difference for the isomers with acetonitrile ligands is only $0.1 \mathrm{kcal} / \mathrm{mol}$. However, energy differences for isomers involving propionitrile ligands and benzonitrile ligands can be as large as $3.8 \mathrm{kcal} / \mathrm{mol}$. In the case of propionitrile, $4 \mathrm{~A}$ and $4 \mathrm{~B}$ are isoenergetic while $4 \mathrm{D}$ is $3.8 \mathrm{kcal} / \mathrm{mol}$ 
lower in energy than 4E. The energy difference between $\mathbf{5 A}$ and $\mathbf{5 B}$ is $3.3 \mathrm{kcal} / \mathrm{mol}$, with $\mathbf{5 B}$ being lower in energy. In general, the lowest energy structures exhibit the greatest deviation of the ligands from the equatorial plane, indicating that steric effects may contribute to the energy differences.

Figures 6 displays the relative binding energies for acetonitrile and water additions, with water additions associated with arrows pointing toward the right and nitrile additions with those pointing to the left. In those cases where there is a choice of isomers, average values of the isomer energies have been used since these isomers tend to be isoenergetic. Average values were also used in the case of $\left[\mathrm{UO}_{2}(\mathrm{Pn})_{4}\left(\mathrm{H}_{2} \mathrm{O}\right)_{2}\right]^{2+}$ and $\left[\mathrm{UO}_{2}(\mathrm{Bzn})_{2}\left(\mathrm{H}_{2} \mathrm{O}\right)_{4}\right]^{2+}$ since the trends are clear even though the binding energies for each isomer varies by up to $2 \mathrm{kcal} / \mathrm{mol}$ from the reported values when these complexes are involved. Likewise, Figures 7 and 8 display relative binding energies for the propionitrile and benzonitrile systems, respectively. It is clear that addition of a nitrile ligand is favored over water addition in all cases. Furthermore, as shown previously ${ }^{8}$, large nitrile ligands bind more strongly to uranyl than small nitrile ligands. This trend holds whether or not water ligands are present and is consistent with the experimental observations that complexes with an abundance of nitrile ligands are favored over those with primarily water ligands. For example, the complexes with acetonitrile ligands that have been experimentally observed are $\left[\mathrm{UO}_{2}(\mathrm{Acn})\right]^{2+}, \quad\left[\mathrm{UO}_{2}(\mathrm{Acn})_{2}\right]^{2+}$, $\left[\mathrm{UO}_{2}(\mathrm{Acn})_{2}\left(\mathrm{H}_{2} \mathrm{O}\right)\right]^{2+}, \quad\left[\mathrm{UO}_{2}(\mathrm{Acn})_{2}\left(\mathrm{H}_{2} \mathrm{O}\right)_{2}\right]^{2+}, \quad\left[\mathrm{UO}_{2}(\mathrm{Acn})_{2}\left(\mathrm{H}_{2} \mathrm{O}\right)_{3}\right]^{2+}, \quad\left[\mathrm{UO}_{2}(\mathrm{Acn})_{3}\right]^{2+}$, $\left[\mathrm{UO}_{2}(\mathrm{Acn})_{3}\left(\mathrm{H}_{2} \mathrm{O}\right)\right]^{2+}, \quad\left[\mathrm{UO}_{2}(\mathrm{Acn})_{3}\left(\mathrm{H}_{2} \mathrm{O}\right)_{2}\right]^{2+}, \quad\left[\mathrm{UO}_{2}(\mathrm{Acn})_{4}\right]^{2+}$, $\left[\mathrm{UO}_{2}(\mathrm{Acn})_{4}\left(\mathrm{H}_{2} \mathrm{O}\right)\right]^{2+}$, and $\left[\mathrm{UO}_{2}(\mathrm{Acn})_{5}\right]^{2+} .9$ Of these eleven complexes, five do not have water ligands and only one of the six remaining complexes has more water than acetonitrile. Similarly, the 
experimentally observed complexes with propionitrile and benzonitrile ligands are $\left[\mathrm{UO}_{2}(\mathrm{Pn})_{2}\right]^{2+}, \quad\left[\mathrm{UO}_{2}(\mathrm{Pn})_{2}\left(\mathrm{H}_{2} \mathrm{O}\right)\right]^{2+}, \quad\left[\mathrm{UO}_{2}(\mathrm{Pn})_{2}\left(\mathrm{H}_{2} \mathrm{O}\right)_{2}\right]^{2+}, \quad\left[\mathrm{UO}_{2}(\mathrm{Pn})_{2}\left(\mathrm{H}_{2} \mathrm{O}\right)_{3}\right]^{2+}$, $\left[\mathrm{UO}_{2}(\mathrm{Pn})_{3}\right]^{2+},\left[\mathrm{UO}_{2}(\mathrm{Pn})_{3}\left(\mathrm{H}_{2} \mathrm{O}\right)\right]^{2+},\left[\mathrm{UO}_{2}(\mathrm{Pn})_{3}\left(\mathrm{H}_{2} \mathrm{O}\right)_{2}\right]^{2+},\left[\mathrm{UO}_{2}(\mathrm{Pn})_{4}\right]^{2+},\left[\mathrm{UO}_{2}(\mathrm{Pn})_{4}\left(\mathrm{H}_{2} \mathrm{O}\right)\right]^{2+}$, $\left[\mathrm{UO}_{2}(\mathrm{Pn})_{5}\right]^{2+},\left[\mathrm{UO}_{2}(\mathrm{Bzn})_{2}\right]^{2+},\left[\mathrm{UO}_{2}(\mathrm{Bzn})_{3}\right]^{2+},\left[\mathrm{UO}_{2}(\mathrm{Bzn})_{3}\left(\mathrm{H}_{2} \mathrm{O}\right)\right]^{2+},\left[\mathrm{UO}_{2}(\mathrm{Bzn})_{4}\right]^{2+}$, and $\left[\mathrm{UO}_{2}(\mathrm{Bzn})_{5}\right]^{2+}{ }^{9}$ Again, there is only one instance for which the water ligands outnumber the nitrile ligands.

For complexes with four or fewer ligands, it is likely that the ligand addition reactions are primarily driven by thermodynamics. However, the binding energies for successive ligand additions decrease as the number of ligands increases. This is a result of saturating uranyl with electrons donated from each ligand. When more ligands are present, each ligand donates a smaller amount of electron density to uranyl. Examination of Mulliken charges confirms this. As more ligands are added, the change in the charges on the water ligands' oxygens and the nitrile ligands' nitrogens relative to those of the bare ligands are smaller than is observed for the first ligands that are added. Additionally, the binding energies indicate that nitrile addition is always favored over water addition. This is not surprising since water is clearly a weaker electron donor than the nitriles. Even though there is a preference for nitrile addition over water addition, the difference in the binding energy of these two ligands relative to each other decreases as the size of the complex grows. For example, the binding energy of the first ligand addition to $\mathrm{UO}_{2}{ }^{2+}$ differs by $53.8 \mathrm{kcal} / \mathrm{mol}$ for benzonitrile vs. water addition. This difference decreases to $29.3 \mathrm{kcal} / \mathrm{mol}$ if the parent complex is $\left[\mathrm{UO}_{2} \mathrm{Bzn}\right]^{2+}$ and to $41.9^{\mathrm{kcal} / \mathrm{mol}}$ if the parent complex is $\left[\mathrm{UO}_{2} \mathrm{H}_{2} \mathrm{O}\right]^{2+}$. By the fifth ligand addition, the preference for benzonitrile over water is less than $20 \mathrm{kcal} / \mathrm{mol}$. In all cases, addition of benzonitrile leads to 
a larger (more negative) binding energy. This trend also can be observed for complexes with acetonitrile and propionitrile, although the difference in the binding energies is less pronounced. Thus, there is greater competition between water and the nitriles when the size of the nitrile ligand is reduced. In general, it can be seen that water addition becomes competitive with nitrile addition when the difference in binding energies for these additions is within $17 \mathrm{kcal} / \mathrm{mol}$. Only when the differences in binding energy drops below this threshold are water additions observed experimentally. Since the acetonitrile and propionitrile do not bind to uranyl as strongly as benzonitrile, water additions become competitive after the second ligand addition when acetonitrile and propionitrile are involved. However, water does not become competitive with benzonitrile addition until three benzonitrile ligands have been added. Because water addition is more competitive with acetonitrile and propionitrile than with benzonitrile, more complexes with water ligands are observed experimentally for complexes containing the smaller nitrile ligands. This allows water ligands the possibility of outnumbering nitrile ligands in the case of $\left[\mathrm{UO}_{2}(\mathrm{Acn})_{2}\left(\mathrm{H}_{2} \mathrm{O}\right)_{3}\right]^{2+}$ and $\left[\mathrm{UO}_{2}(\mathrm{Pn})_{2}\left(\mathrm{H}_{2} \mathrm{O}\right)_{3}\right]^{2+}$.

Examination of the binding energies also reveals that the number of nitrile ligands vs. the number of water ligands influences the binding energy of the next ligand addition. As the number of water ligands increases (the number of nitrile ligands decreases), the magnitude of the binding energy for the next ligand addition also increases. Generally, the increase in binding energy is greater for addition of a nitrile than for water addition. This observation is true regardless of which nitrile ligand is involved, though it is more pronounced as the size of the nitrile ligands grows. Therefore, if a water does happen to add first, formation of complexes with a mixture of both nitriles and water ligands is 
favored (i.e. nitriles are favored for subsequent additions). However, this effect can be overshadowed by the relatively large magnitude of the binding energies for the first $1-3$ nitrile additions. Therefore, nitrile addition is favored initially, while water addition becomes more competitive as the size of the complex grows.

\section{Charge-Exchange Reactions}

In addition to ligand additions to dicationic species, it has been observed that some of these complexes can undergo charge-exchange (hydrolysis) reactions of the form given in equations 3 and 4 . Reactions of this type have been experimentally observed in the gas phase for complexes involving all three of the nitrile ligands considered here? These observations come from the same ESI-MS experiments that produced the ligand addition products discussed earlier.

The experimentally observed products involving acetonitrile ligands are $\left[\mathrm{UO}_{2} \mathrm{OH}(\mathrm{Acn})\right]^{+},\left[\mathrm{UO}_{2} \mathrm{OH}(\mathrm{Acn})\left(\mathrm{H}_{2} \mathrm{O}\right)\right]^{+},\left[\mathrm{UO}_{2} \mathrm{OH}(\mathrm{Acn})_{2}\right]^{+}$, and $\left[\mathrm{UO}_{2} \mathrm{OH}(\mathrm{Acn})\left(\mathrm{H}_{2} \mathrm{O}\right)_{2}\right]^{+}$. Likewise, complexes with the same $\mathrm{RCN}: \mathrm{H}_{2} \mathrm{O}$ ratio involving propionitrile and benzonitrile have also been experimentally observed with the exception of $\left[\mathrm{UO}_{2} \mathrm{OH}(\mathrm{Bzn})_{2}\right]^{+}$. As was the case for some of the dicationic complexes, isomers exist for $\left[\mathrm{UO}_{2} \mathrm{OH}(\mathrm{RCN})\left(\mathrm{H}_{2} \mathrm{O}\right)_{2}\right]^{+}$and $\left[\mathrm{UO}_{2} \mathrm{OH}(\mathrm{RCN})_{2}\left(\mathrm{H}_{2} \mathrm{O}\right)\right]^{+}$. The energy differences $\left(\mathrm{E}_{\text {trans }}\right.$ $-\mathrm{E}_{\mathrm{cis}}$ ) between these isomers are given in Table 1. All energy differences are less than 1 kcal $/$ mol with the exception of $\left[\mathrm{UO}_{2} \mathrm{OH}(\mathrm{Pn})_{2}\left(\mathrm{H}_{2} \mathrm{O}\right)\right]^{+}$which has a $\Delta \mathrm{E}$ of $-1.2 \mathrm{kcal} / \mathrm{mol}$ (a negative energy means that the trans isomer is lower in energy). While these isomers are essentially isoenergetic, note that when two nitrile ligands are involved, a trans arrangement of the nitriles is favored. Due to the bulky nature of the nitrile ligands, this 
should be expected. However, when the complex contains two water ligands, the cis arrangement is favored.

Reaction energies for the charge-exchange reactions are given in Table 2. For any of these reactions to proceed, uranyl first must have two ligands bound to it, at least one of which must be water. Thus two ligand additions must occur before a charge-exchange reaction is possible. The reaction energies of the charge exchange reactions tend to be 10 - $25 \mathrm{kcal} / \mathrm{mol}$ less exoergic than the alternative ligand addition reactions. (For example, formation of $\left[\mathrm{UO}_{2} \mathrm{OH}\right]^{+}$compared to the third ligand addition.) Additionally, the exoergicity of the reaction decreases as the size of the nitrile ligand increases. Thus, observation of these monocationic species requires a longer isolation time as the size of the nitrile ligands is increased, as was noted by van Stipdonk et al. ${ }^{9}$ Moreover, since the exoergicity of ligand addition reactions increases with the size of the ligand and the exoergicity of charge-exchange reactions decreases with increasing ligand size, there is a preference for the formation of monocationic uranyl complexes from dicationic complexes that contain acetonitrile ligands over dicationic complexes containing propionitrile or benzonitrile.

Charge-exchange reactions can proceed via two likely pathways. When the dicationic precursor contains no nitrile ligands, $\mathrm{H}_{3} \mathrm{O}^{+}$is lost leading to the monocationic complex (equation 3 is the only possible pathway). When two water ligands are present in the precursor, the charge-exchange reaction can be competitive with the ligand addition reaction. As for ligand additions, an increase in the size of the precursor ion leads to a decrease in the exoergicity of the charge-exchange reaction. When $\mathrm{H}_{3} \mathrm{O}^{+}$is lost in the charge-exchange reaction (equation 3), the reaction energy becomes endoergic 
when four or more ligands are present in the precursor ion. This endoergicity then increases as the size of the precursor ion grows. A more thermodynamically favorable pathway involves the loss of a protonated nitrile (equation 4). The reaction energy of protonated nitrile elimination reactions is more competitive than the equation 3 pathway with ligand addition reactions. The reaction energy for the loss of $(\mathrm{H}+\mathrm{RCN})^{+}$is approximately $15 \mathrm{kcal} / \mathrm{mol}$ lower than the reaction energy for the loss of $\mathrm{H}_{3} \mathrm{O}^{+}$. This makes the charge-exchange reaction via loss of $(\mathrm{H}+\mathrm{RCN})^{+}$sufficiently exoergic for chargeexchange reactions to be competitive with ligand addition reactions. Despite this, the reaction energy of ligand additions is always more exoergic than the energy of chargeexchange reactions. Additionally, while pathways that lose $\mathrm{H}_{3} \mathrm{O}^{+}$become endoergic when the precursor ion has four or more ligands, the pathway that loses $(\mathrm{H}+\mathrm{RCN})^{+}$is still exoergic even when the precursor ion has five ligands (with the exception of $\left[\mathrm{UO}_{2}\left(\mathrm{H}_{2} \mathrm{O}\right)(\mathrm{Bzn})_{4}\right]^{2+}$ and $\left.\left[\mathrm{UO}_{2}\left(\mathrm{H}_{2} \mathrm{O}\right)_{3}(\mathrm{Bzn})_{2}\right]^{2+}\right)$.

The fact that hydrated uranyl complexes can undergo hydrolysis reactions should come as no surprise. It is well known that metal cations are acidic species. Unfortunately, experimental and theoretical data for uranyl induced hydrolysis is scarce. Hydrolysis of one water ligand from uranyl(VI) hydrate has previously been studied with QM/MM simulations, ${ }^{24}$ and hydrolysis products with multiple hydroxide ligands have also been examined in both the gas phase and with a polarizable continuum. ${ }^{6}$ However, hydrolysis studies of a single uranyl dication with an unsaturated coordination sphere are lacking, though the current results are consistent with trends noted for main group and transition metals. ${ }^{25,26}$ These reactions have been experimentally observed in the gas phase rather than in solution, though hydrolysis of only one water ligand has been 
observed in these cases. ${ }^{9}$ While the reactions modeled here represent gas phase results, microsolvation via inclusion of water ligands can account for some of the solvation effects. Thus, these results can be used to predict general trends in solution, though variation of the $\mathrm{pH}$ will also have a substantial influence.

Once a monocationic complex is formed, it can undergo further ligand addition reactions. Binding energies for these reactions can be found in Figures 9, 10, and 11. In general, ligand additions to monocationic complexes exhibit the same trends as the ligand additions to dicationic complexes. Addition of a nitrile ligand is always thermodynamically favored over water addition, and the exoergicity of the nitrile addition increases with increasing size (Acn $<\mathrm{Pn}<$ Bzn). Unlike the previous ligand addition reactions, though, water is much more competitive with nitrile additions to a monocationic species. The largest difference occurs with the first addition of benzonitrile to $\left[\mathrm{UO}_{2} \mathrm{OH}\right]^{+}$compared to the first addition of water. In this case the addition of benzonitrile is favored by $11.4 \mathrm{kcal} / \mathrm{mol}$, whereas the first addition of benzonitrile to $\mathrm{UO}_{2}{ }^{2+}$ is $53.8 \mathrm{kcal} / \mathrm{mol}$ more exoergic than the first water addition. The difference in binding energy between addition of acetonitrile or proprionitrile is $\sim 3 \mathrm{kcal} / \mathrm{mol}$, while the difference in binding energy between the addition of acetonitrile or benzonitrile is up to $6 \mathrm{kcal} / \mathrm{mol}$. As with ligand additions to dicationic complexes, the exoergicity of the addition increases according to Acn $<$ Pn $<$ Bzn. Since the difference in binding energies of monocationic ligand additions is much smaller than it is with ligand additions to dicationic complexes, the type of nitrile ligand should have a minimal impact on the reactions observed. However, experimental observations show that formation of monocationic complexes with acetonitrile are favored over those with propionitrile which, in turn, are favored over 
those with benzonitrile. The reason for this is apparent from the charge-exchange reaction energies. The propensity of a precursor ion to undergo charge-exchange is related to the type of nitrile ligands present in the precursor according to Acn $>\mathrm{Pn}>$ Bzn, eg. complexes with smaller nitrile ligands are more likely to undergo charge-exchange reactions. Once the charge-exchange process is completed, ligand addition to the monocationic species can occur just as it does with dicationic complexes. As with the dicationic ligand addition reactions, the ratio of nitrile ligands to water ligands influences the binding energy of subsequent ligand additions. In nearly all cases, more water ligands in the precursor will increase the tendency of the next ligand added to be a nitrile.

\section{Conclusion}

Reactions involving dicationic uranyl complexes with both water and nitrile (acetonitrile, propionitrile, and benzonitrile) ligands have been examined. These include charge-exchange reactions, whereby a dicationic complex is reduced to a monocationic complex, addition of ligands to the dicationic complexes, and addition of ligands to the monocationic complexes. While most of the complexes presented here have been experimentally observed, the inclusion of all the other possible products has enabled a thorough study of the processes observed experimentally. These results help shed light on some of the possible products of those reactions that have not been observed. Additionally, mass spectrometry studies are unable to distinguish between isomers. In some cases this may be a significant disadvantage. However, the computational results presented here show that, in general, the possible isomers of interest are isoenergetic. Therefore, it is expected that they would be formed in nearly equal proportions. 
The predominant reaction pathway in this study is ligand addition. It has been shown that ligand addition reactions are always thermodynamically favored as long as the equatorial coordination number is less than five for dicationic complexes and less than 4 for monocationic complexes. Addition of more ligands is generally either endoergic or the exoergicity of the reaction is small enough that thermodynamics alone is not enough to drive the reaction forward. The addition of a water ligand versus a nitrile ligand is influenced by the ratio of nitrile ligands to water ligands in the precursor ion. When there is a predominance of water ligands, the binding energy for the next ligand addition becomes more exoergic than if the precursor ion contains primarily nitrile ligands. This has a greater effect on the binding energies of nitrile additions than it does on water additions. Therefore, the tendency to add a nitrile ligand is enhanced when the precursor ion contains predominantly water ligands. This effect occurs for ligand additions to both the dicationic and the monocationic species and can explain the large number of dicationic complexes with mainly nitrile ligands observed experimentally. ${ }^{9}$

In addition to ligand addition reactions, charge-exchange or hydrolysis reactions of the form of equations $\mathbf{3}$ and $\mathbf{4}$ have been examined. These reactions involve at least two ligands, and water must be one of them. While it is not clear if both ligands must be bound to $\mathrm{UO}_{2}{ }^{2+}$, the energies of the endpoints of the reactions are unchanged. The reaction energies of the charge-exchange reactions indicate that they are thermodynamically competitive with the third ligand addition to dicationic precursor ions, although they are less exoergic than the third ligand addition. Charge-exchange reactions are still exoergic when the precursor ion has many ligands, but only if the reaction proceeds via equation 4 (loss of $\left.(\mathrm{H}+\mathrm{RCN})^{+}\right)$rather than by equation 3 (loss of 
$\mathrm{H}_{3} \mathrm{O}^{+}$). Once the complex is reduced to a monocation, it then can proceed with subsequent ligand additions. As with ligand additions to dicationic complexes, nitrile addition is favored when ligands are added to monocationic complexes. However, the difference in binding energies between a nitrile and water - and even among the nitriles themselves - is diminished when adding to monocationic species. Thus, water becomes more competitive when adding to monocationic complexes than it is when adding to dicationic complexes. This tendency, along with the initial depletion of dicationic complexes that contain water through the charge-exchange process, helps explain the tendency of monocationic species to be observed with a larger proportion of water ligands than are observed with dicationic species. ${ }^{9}$

\section{Acknowledgements}

This research was performed in part using the Molecular Science Computing Facility (MSCF) in the William R. Wiley Environmental Molecular Sciences Laboratory, a national scientific user facility sponsored by the U.S. Department of Energy's Office of Biological and Environmental Research and located at the Pacific Northwest National Laboratory, operated for the Department of Energy by Battelle. Funding has been provided by Iowa State University and an NSF grant in petascale applications (MSG and TLW).

Supporting Information Available: The atomic coordinates for the optimized geometries, the complete set of vibrational frequencies (and their descriptions) in the 
$800-2500 \mathrm{~cm}^{-1}$ range, and the raw calculated energies are available. This material is available free of charge via the Internet at http://pubs.acs.org. 
Figure 1. Isomers of $\left.\left[\mathrm{UO}_{2}(\mathrm{Acn})_{2}\left(\mathrm{H}_{2} \mathrm{O}\right)_{2}\right)\right]^{2+}$. Uranium is shown in yellow, oxygen is red, nitrogen is blue, carbon is black, and hydrogen is white. Isomers with similar arrangements of the ligands have been found with propionitrile and benzonitrile ligands in the positions that acetonitrile is shown to occupy.
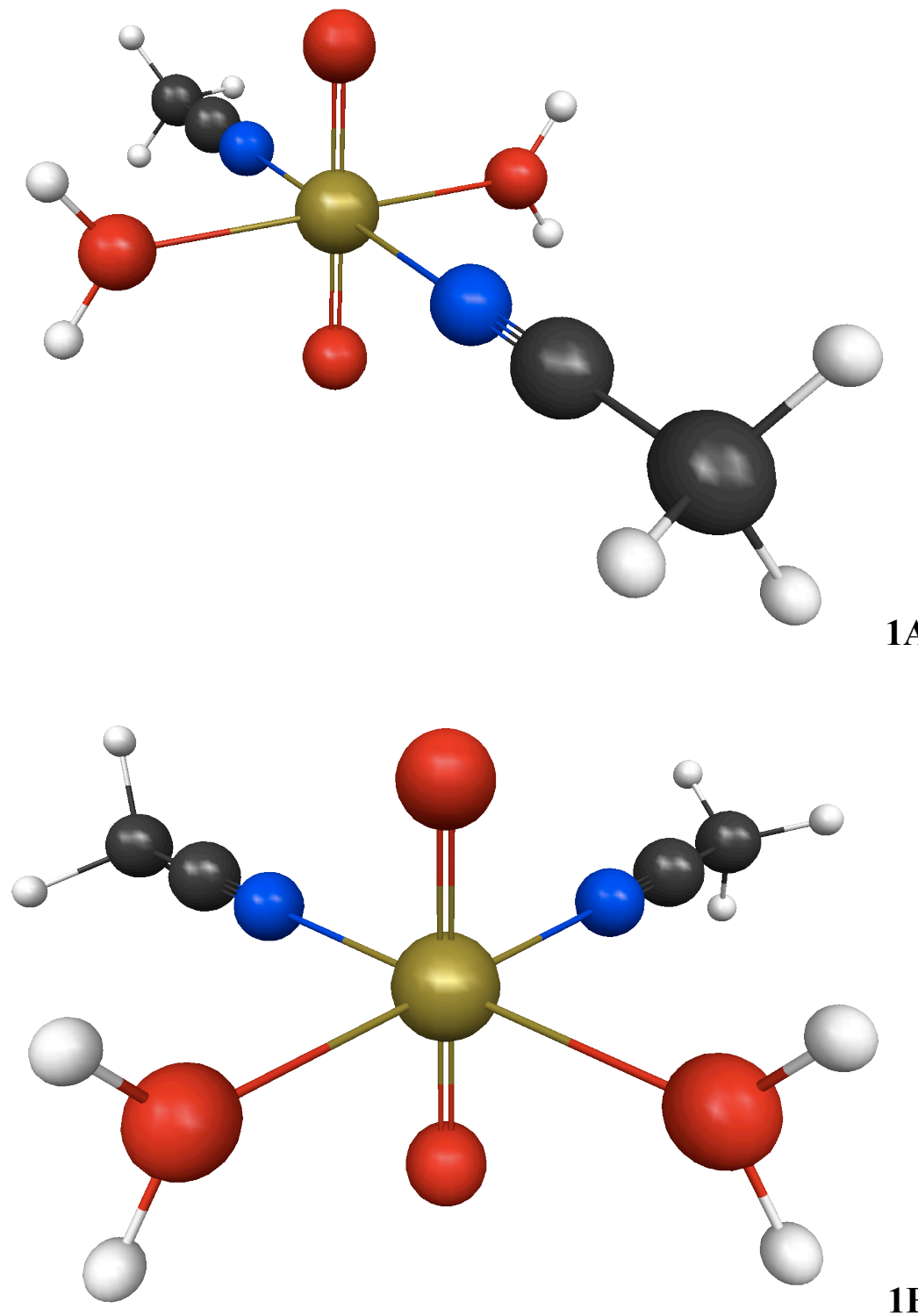
Figure 2. Isomers of $\left[\mathrm{UO}_{2}(\mathrm{Acn})_{2}\left(\mathrm{H}_{2} \mathrm{O}\right)_{3}\right]^{2+}(\mathbf{2} \mathrm{A}$ and $\mathbf{2 B})$ and $\left[\mathrm{UO}_{2}(\mathrm{Acn})_{3}\left(\mathrm{H}_{2} \mathrm{O}\right)_{2}\right]^{2+}(\mathbf{2} \mathbf{C}$ and 2D). Isomers with similar arrangements of the ligands have been found with propionitrile and benzonitrile ligands in the positions that acetonitrile is shown to occupy.
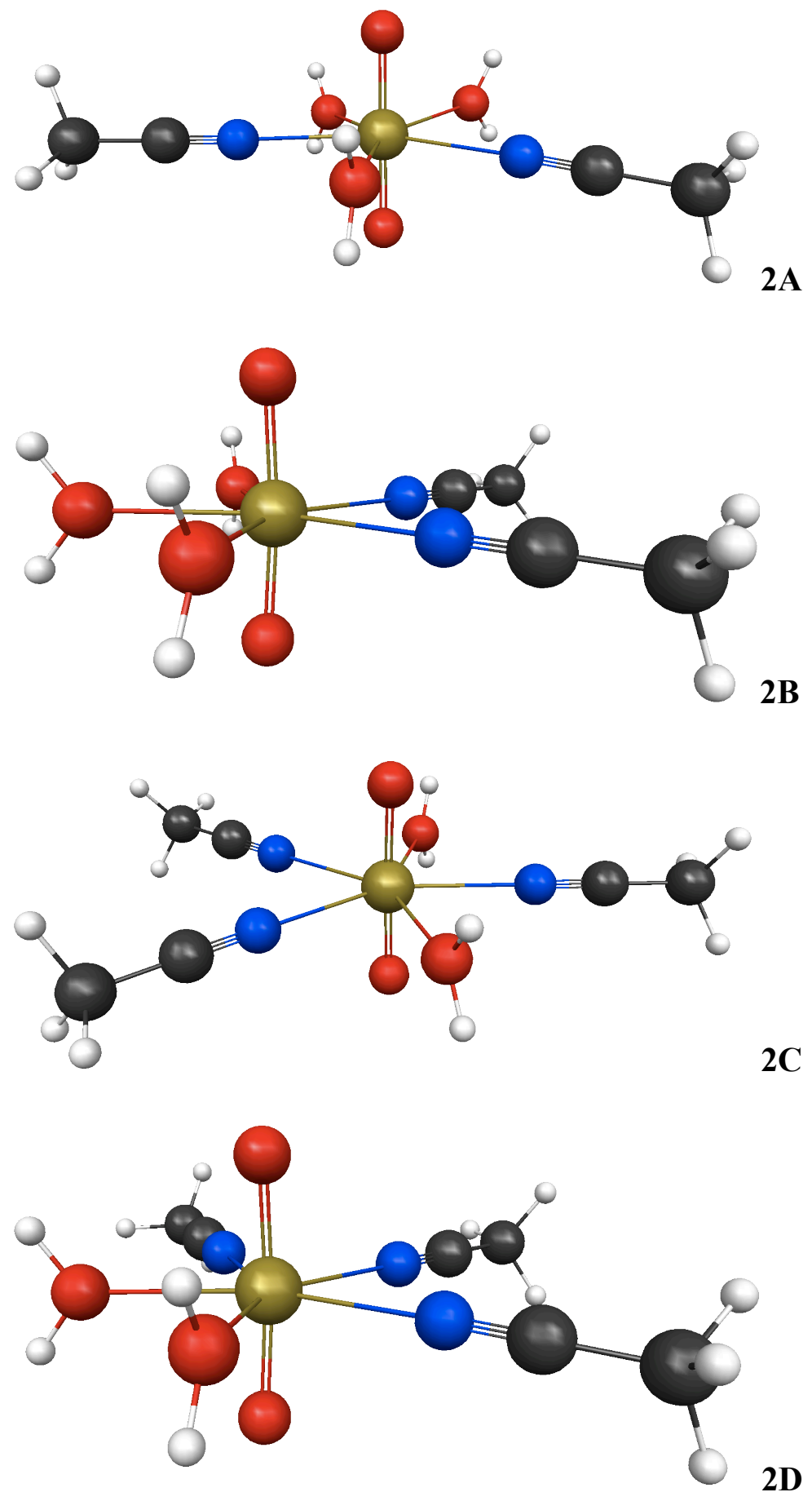
Figure 3. Complexes with six equatorial ligands that contain acetonitrile ligands. Two isomers have been found when two acetonitriles are present (3A and $\mathbf{3 B}$ ), while only one potential isomer could be found when three (3C) and four (3D) acetonitriles are present.
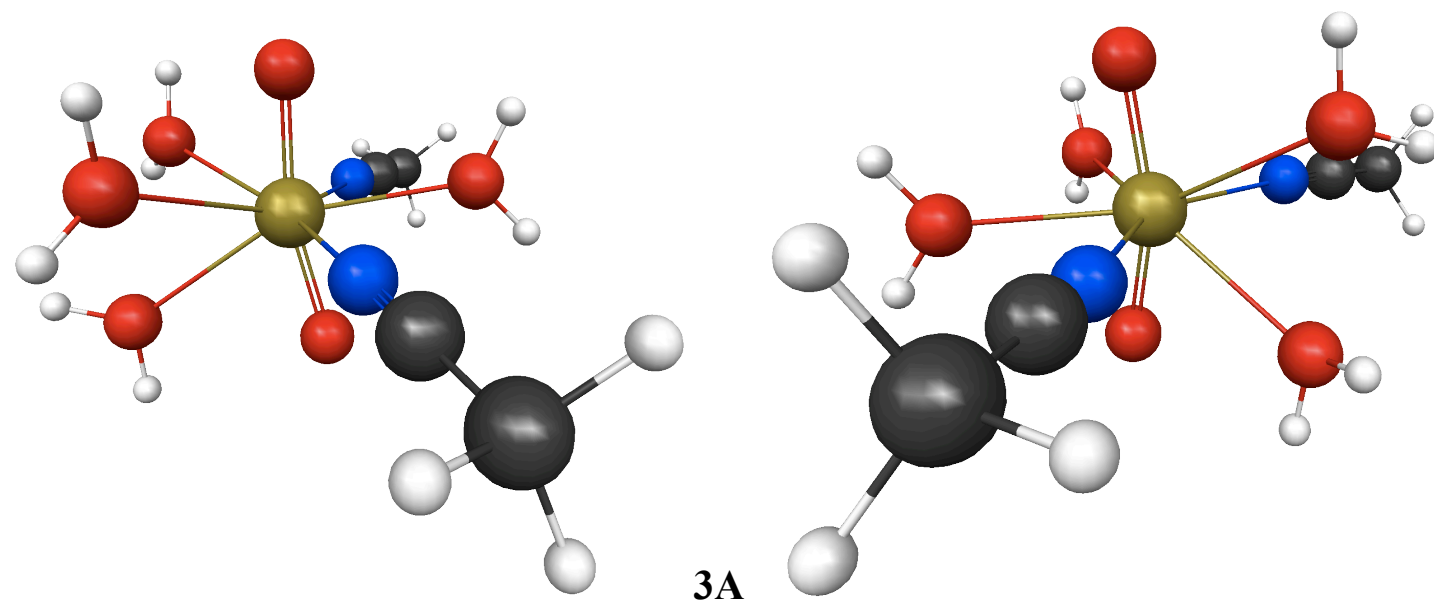

3B

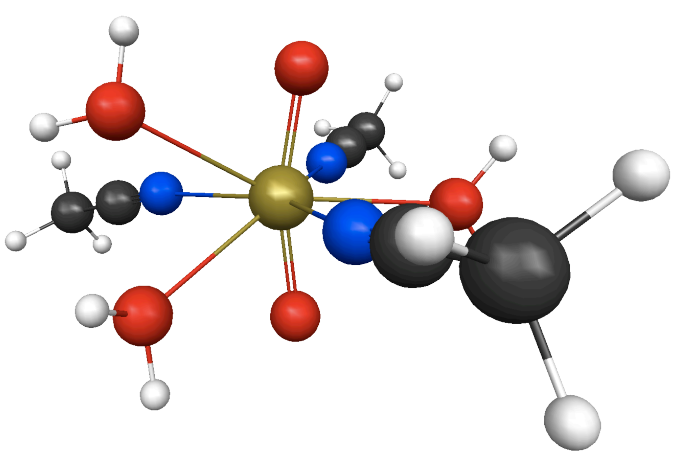

$3 \mathrm{C}$

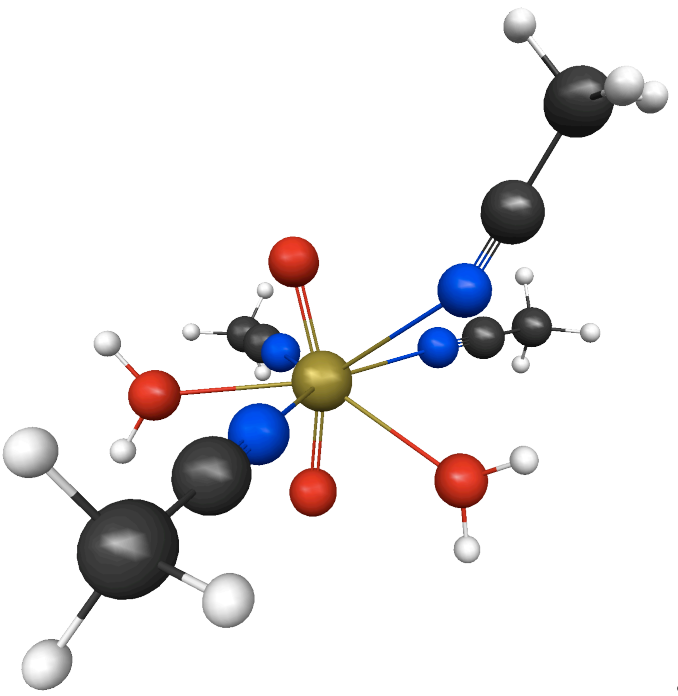


Figure 4. Complexes with six equatorial ligands that contain propionitrile. $\mathbf{4 C}$ is the only complex found that has three propionitrile ligands bound to uranium.

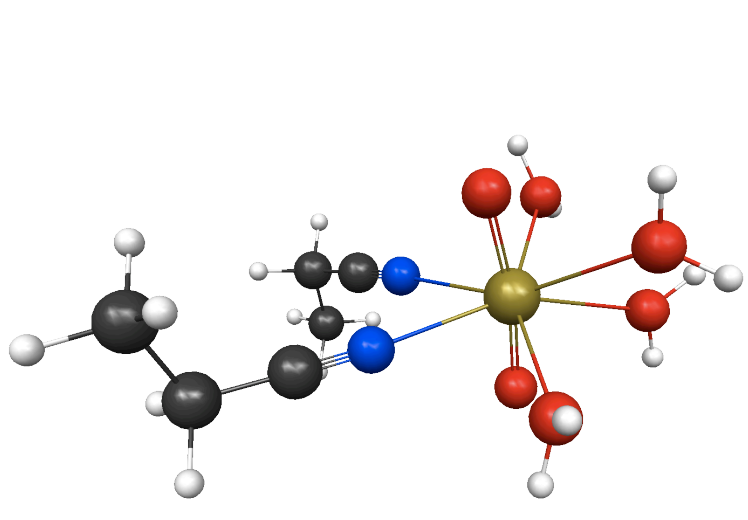

4A
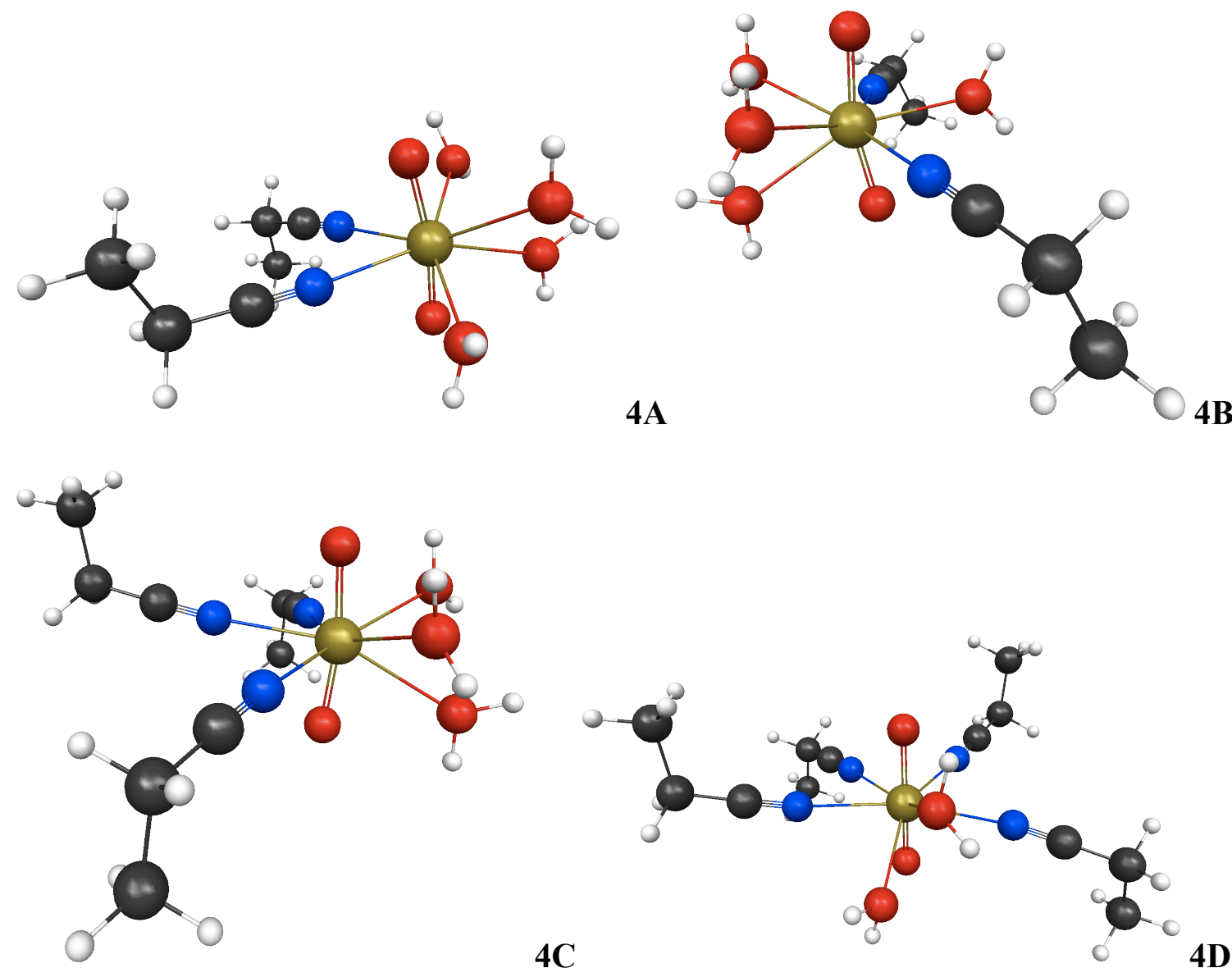

$4 \mathrm{C}$
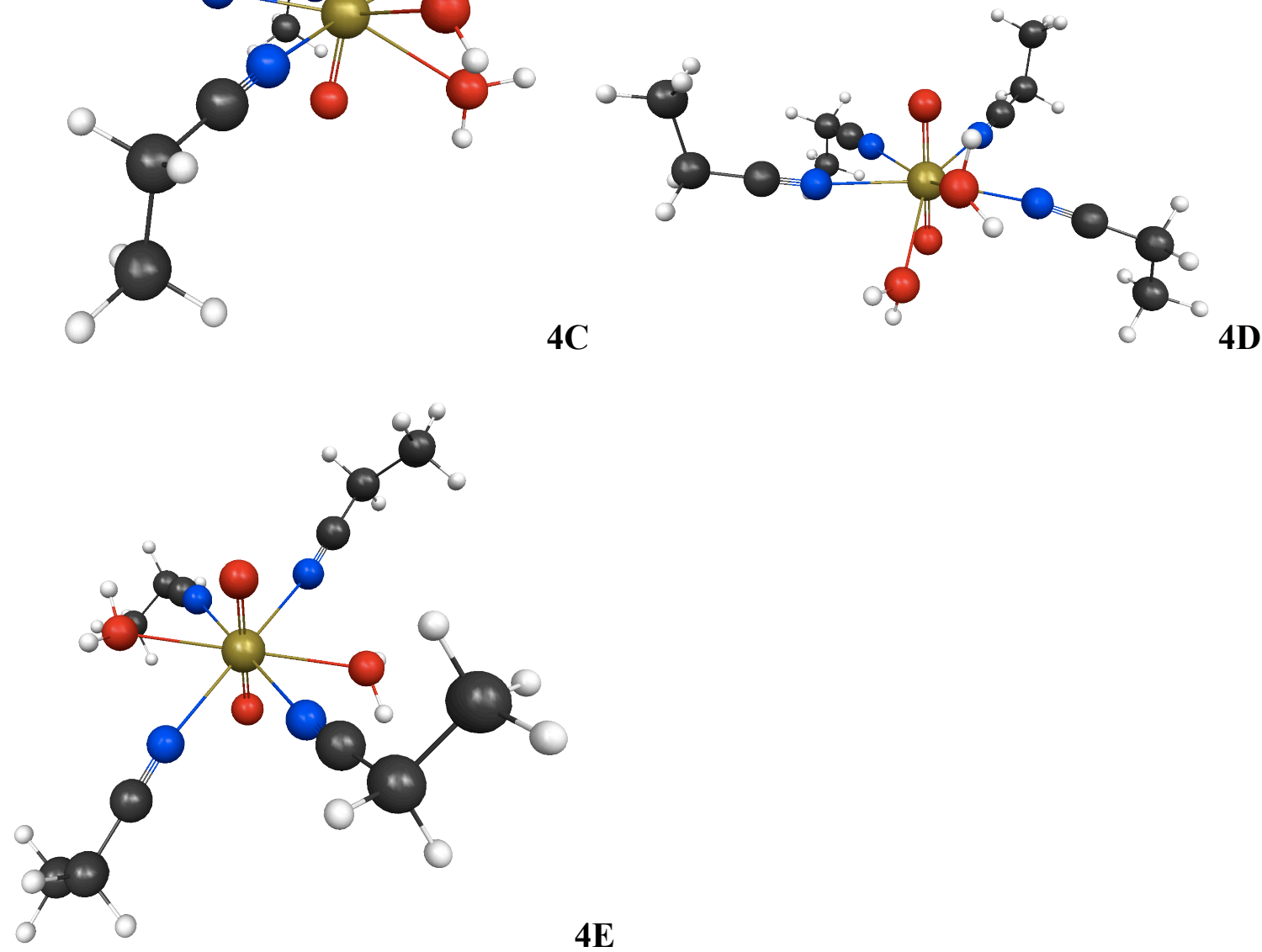

$4 E$ 
Figure 5. Complexes with six equatorial ligands that contain benzonitrile. No complexes with six equatorial ligands could be found that contain three benzonitrile ligands. Complex 5C is the only complex with six equatorial ligands that has four benzonitrile ligands.
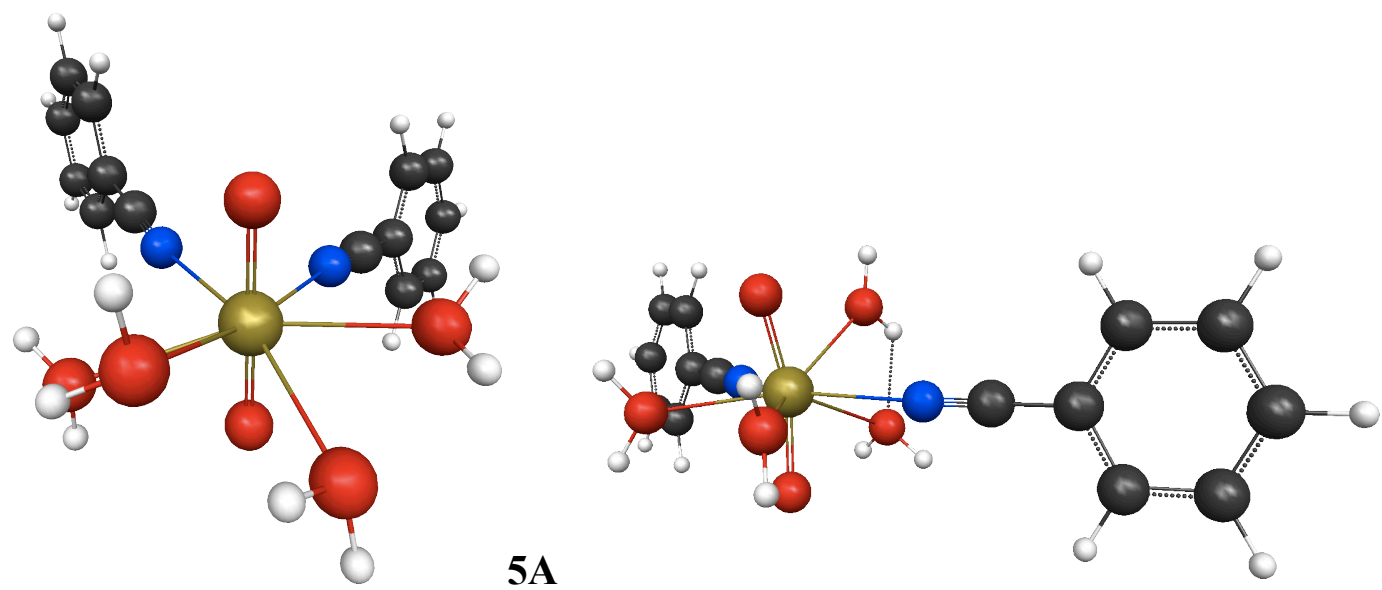

5B

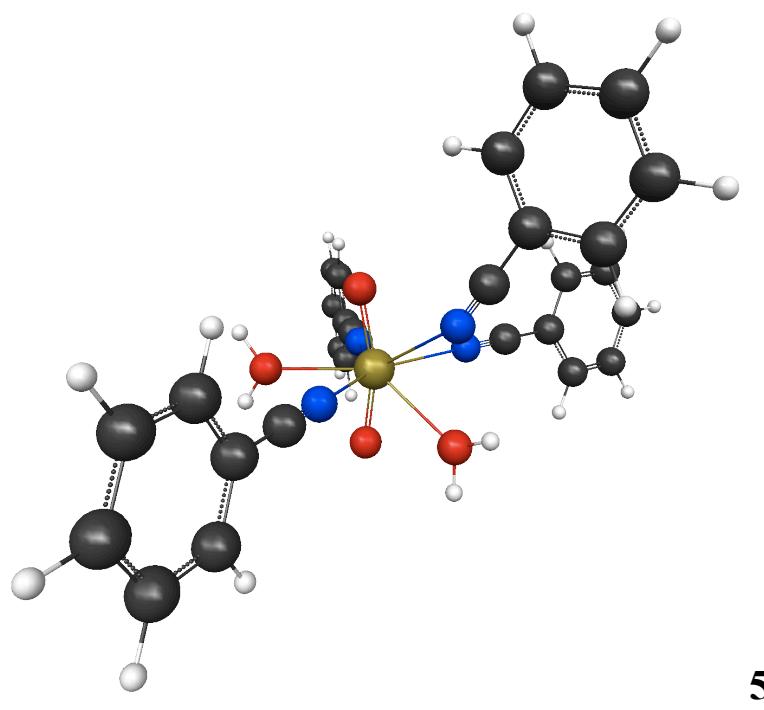

$5 \mathrm{C}$ 
Figure 6. Relative binding energies (kcal/mol) with the zero-point energy correction for acetonitrile (left arrow) and water (right arrow) additions according to $\left[\mathrm{UO}_{2}(\mathrm{Acn})_{\mathrm{n}}\left(\mathrm{H}_{2} \mathrm{O}\right)_{\mathrm{m}}\right]^{2+}+\mathrm{Acn} \rightarrow\left[\mathrm{UO}_{2}(\mathrm{Acn})_{\mathrm{n}+1}\left(\mathrm{H}_{2} \mathrm{O}\right)_{\mathrm{m}}\right]^{2+} \quad$ and $\left[\mathrm{UO}_{2}(\mathrm{Acn})_{\mathrm{n}}\left(\mathrm{H}_{2} \mathrm{O}\right)_{\mathrm{m}}\right]^{2+}+\mathrm{H}_{2} \mathrm{O} \rightarrow\left[\mathrm{UO}_{2}(\mathrm{Acn})_{\mathrm{n}}\left(\mathrm{H}_{2} \mathrm{O}\right)_{\mathrm{m}+1}\right]^{2+}$. Complexes observed in ESIMS experiments are $\mathrm{UO}_{2}{ }^{2+}, \quad\left[\mathrm{UO}_{2}(\mathrm{Acn})\right]^{2+}, \quad\left[\mathrm{UO}_{2}(\mathrm{Acn})_{2}\right]^{2+}, \quad\left[\mathrm{UO}_{2}(\mathrm{Acn})_{2}\left(\mathrm{H}_{2} \mathrm{O}\right)\right]^{2+}$, $\left[\mathrm{UO}_{2}(\mathrm{Acn})_{2}\left(\mathrm{H}_{2} \mathrm{O}\right)_{2}\right]^{2+}, \quad\left[\mathrm{UO}_{2}(\mathrm{Acn})_{2}\left(\mathrm{H}_{2} \mathrm{O}\right)_{3}\right]^{2+}, \quad\left[\mathrm{UO}_{2}(\mathrm{Acn})_{3}\right]^{2+}, \quad\left[\mathrm{UO}_{2}(\mathrm{Acn})_{3}\left(\mathrm{H}_{2} \mathrm{O}\right)\right]^{2+}$, $\left[\mathrm{UO}_{2}(\mathrm{Acn})_{3}\left(\mathrm{H}_{2} \mathrm{O}\right)_{2}\right]^{2+},\left[\mathrm{UO}_{2}(\mathrm{Acn})_{4}\right]^{2+},\left[\mathrm{UO}_{2}(\mathrm{Acn})_{4}\left(\mathrm{H}_{2} \mathrm{O}\right)\right]^{2+}$, and $\left[\mathrm{UO}_{2}(\mathrm{Acn})_{5}\right]^{2+}$.

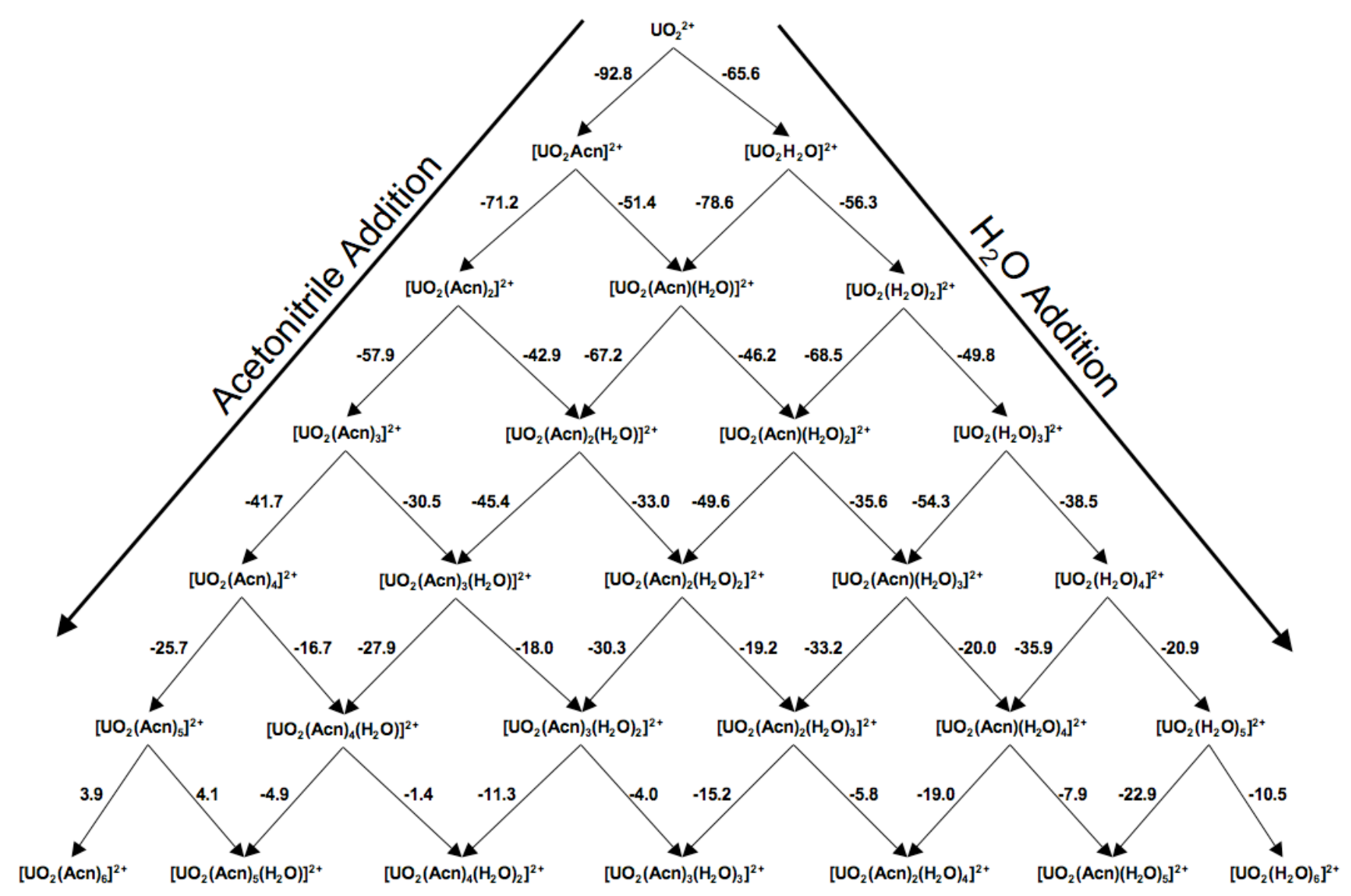


Figure 7. Relative binding energies (kcal/mol) with the zero-point energy correction for propionitrile (left arrow) and water (right arrow) additions according to $\left[\mathrm{UO}_{2}(\mathrm{Pn})_{\mathrm{n}}\left(\mathrm{H}_{2} \mathrm{O}\right)_{\mathrm{m}}\right]^{2+}+\mathrm{Pn} \rightarrow\left[\mathrm{UO}_{2}(\mathrm{Pn})_{\mathrm{n}+1}\left(\mathrm{H}_{2} \mathrm{O}\right)_{\mathrm{m}}\right]^{2+} \quad$ and $\left[\mathrm{UO}_{2}(\mathrm{Pn})_{\mathrm{n}}\left(\mathrm{H}_{2} \mathrm{O}\right)_{\mathrm{m}}\right]^{2+}+\mathrm{H}_{2} \mathrm{O} \rightarrow\left[\mathrm{UO}_{2}(\mathrm{Pn})_{\mathrm{n}}\left(\mathrm{H}_{2} \mathrm{O}\right)_{\mathrm{m}+1}\right]^{2+}$. Complexes observed in ESI-MS experiments are $\quad\left[\mathrm{UO}_{2}(\mathrm{Pn})_{2}\right]^{2+}, \quad\left[\mathrm{UO}_{2}(\mathrm{Pn})_{2}\left(\mathrm{H}_{2} \mathrm{O}\right)\right]^{2+}, \quad\left[\mathrm{UO}_{2}(\mathrm{Pn})_{2}\left(\mathrm{H}_{2} \mathrm{O}\right)_{2}\right]^{2+}$, $\left[\mathrm{UO}_{2}(\mathrm{Pn})_{2}\left(\mathrm{H}_{2} \mathrm{O}\right)_{3}\right]^{2+}, \quad\left[\mathrm{UO}_{2}(\mathrm{Pn})_{3}\right]^{2+}, \quad\left[\mathrm{UO}_{2}(\mathrm{Pn})_{3}\left(\mathrm{H}_{2} \mathrm{O}\right)\right]^{2+}, \quad\left[\mathrm{UO}_{2}(\mathrm{Pn})_{3}\left(\mathrm{H}_{2} \mathrm{O}\right)_{2}\right]^{2+}$, $\left[\mathrm{UO}_{2}(\mathrm{Pn})_{4}\right]^{2+},\left[\mathrm{UO}_{2}(\mathrm{Pn})_{4}\left(\mathrm{H}_{2} \mathrm{O}\right)\right]^{2+}$, and $\left[\mathrm{UO}_{2}(\mathrm{Pn})_{5}\right]^{2+}$.

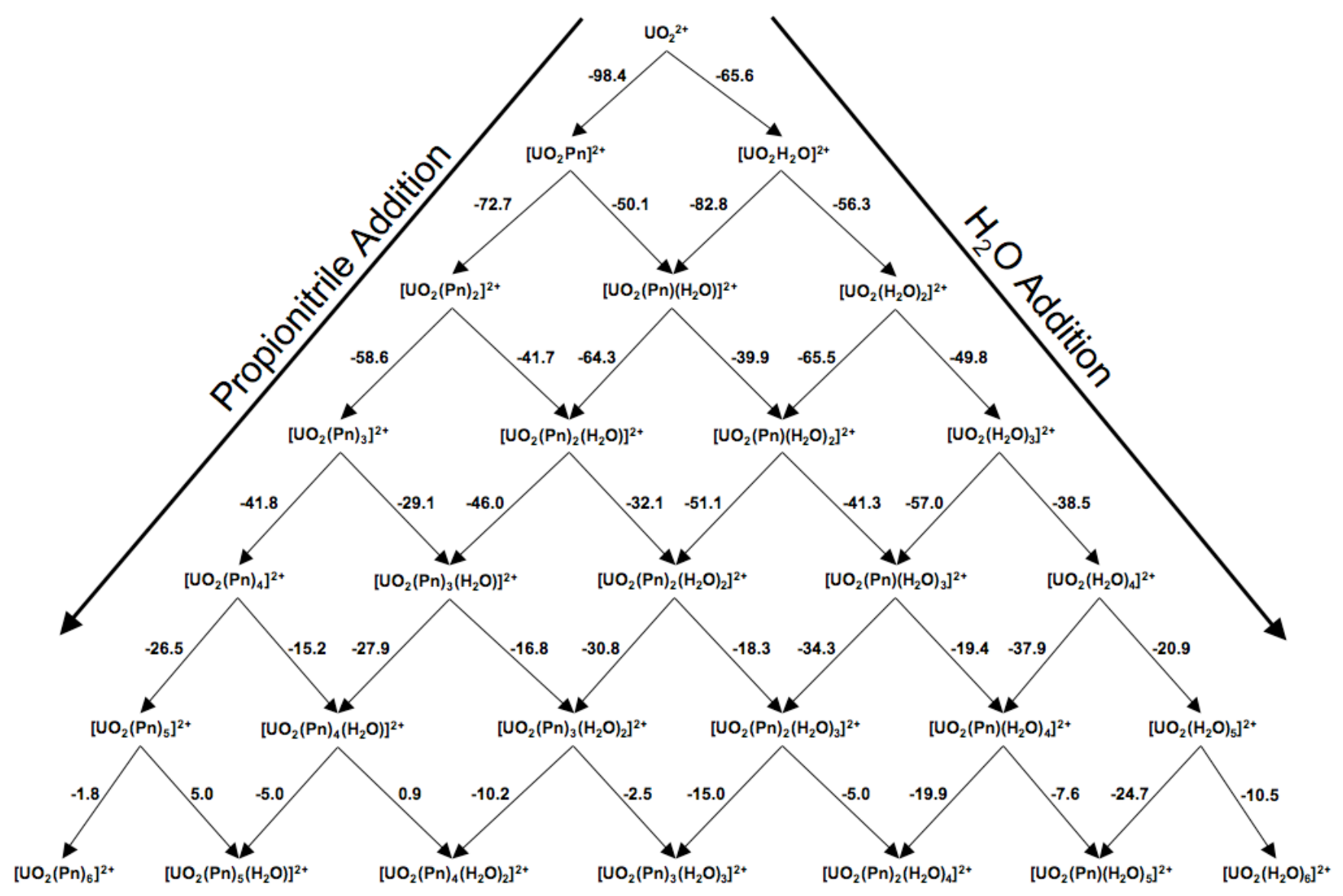


Figure 8. Relative binding energies ( $\mathrm{kcal} / \mathrm{mol}$ ) with the zero-point energy correction for benzonitrile (left arrow) and water (right arrow) additions according to $\left[\mathrm{UO}_{2}(\mathrm{Bzn})_{\mathrm{n}}\left(\mathrm{H}_{2} \mathrm{O}\right)_{\mathrm{m}}\right]^{2+}+\mathrm{Bzn} \rightarrow\left[\mathrm{UO}_{2}(\mathrm{Bzn})_{\mathrm{n}+1}\left(\mathrm{H}_{2} \mathrm{O}\right)_{\mathrm{m}}\right]^{2+} \quad$ and $\left[\mathrm{UO}_{2}(\mathrm{Bzn})_{\mathrm{n}}\left(\mathrm{H}_{2} \mathrm{O}\right)_{\mathrm{m}}\right]^{2+}+\mathrm{H}_{2} \mathrm{O} \rightarrow\left[\mathrm{UO}_{2}(\mathrm{Bzn})_{\mathrm{n}}\left(\mathrm{H}_{2} \mathrm{O}\right)_{\mathrm{m}+1}\right]^{2+}$. Complexes observed in ESIMS experiments are $\left[\mathrm{UO}_{2}(\mathrm{Bzn})_{2}\right]^{2+},\left[\mathrm{UO}_{2}(\mathrm{Bzn})_{3}\right]^{2+},\left[\mathrm{UO}_{2}(\mathrm{Bzn})_{3}\left(\mathrm{H}_{2} \mathrm{O}\right)\right]^{2+},\left[\mathrm{UO}_{2}(\mathrm{Bzn})_{4}\right]^{2+}$, and $\left[\mathrm{UO}_{2}(\mathrm{Bzn})_{5}\right]^{2+9}$

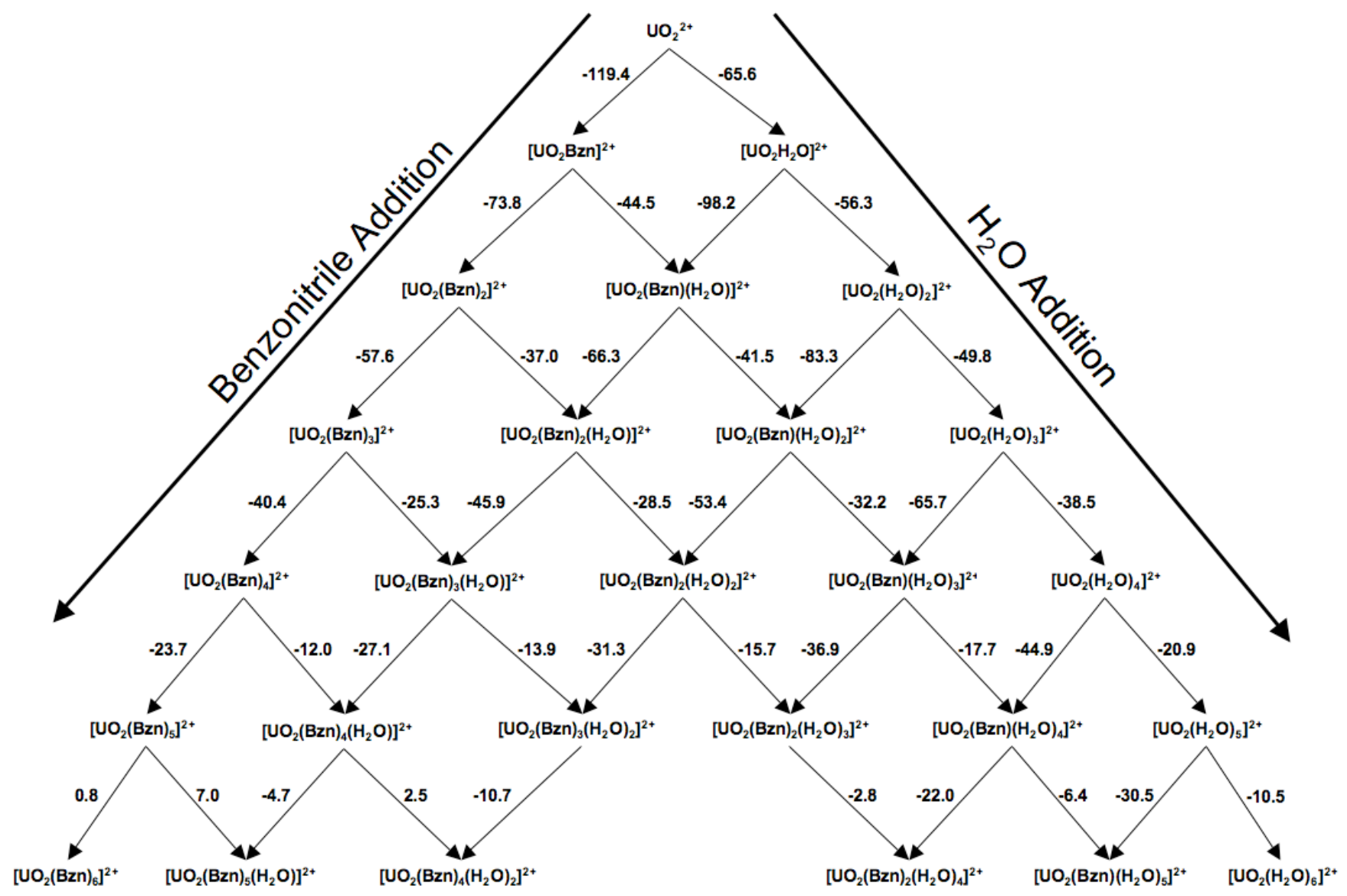


Table 1. Relative energies of the isomers of $\left[\mathrm{UO}_{2} \mathrm{OH}(\mathrm{RCN})\left(\mathrm{H}_{2} \mathrm{O}\right)_{2}\right]^{+}$and $\left[\mathrm{UO}_{2} \mathrm{OH}(\mathrm{RCN})_{2}\left(\mathrm{H}_{2} \mathrm{O}\right)\right]^{+} . \mathrm{E}_{\text {trans }}-\mathrm{E}_{\text {cis }}<0$ indicates that the lowest energy structure is the trans isomer. Energies are given in $\mathrm{kcal} / \mathrm{mol}$ and include the zero-point energy correction.

\begin{tabular}{|c|c|}
\hline & $\mathbf{E}_{\text {trans }}-\mathbf{E}_{\text {cis }}$ \\
\hline$\left[\mathrm{UO}_{2} \mathrm{OH}(\mathrm{Acn})\left(\mathrm{H}_{2} \mathrm{O}\right)_{2}\right]^{+}$ & 0.85 \\
\hline$\left[\mathrm{UO}_{2} \mathrm{OH}(\mathrm{Acn})_{2}\left(\mathrm{H}_{2} \mathrm{O}\right)\right]^{+}$ & -0.99 \\
\hline$\left[\mathrm{UO}_{2} \mathrm{OH}(\mathrm{Pn})\left(\mathrm{H}_{2} \mathrm{O}\right)_{2}\right]^{+}$ & 0.87 \\
\hline$\left[\mathrm{UO}_{2} \mathrm{OH}(\mathrm{Pn})_{2}\left(\mathrm{H}_{2} \mathrm{O}\right)\right]^{+}$ & -1.21 \\
\hline$\left[\mathrm{UO}_{2} \mathrm{OH}(\mathrm{Bzn})\left(\mathrm{H}_{2} \mathrm{O}\right)_{2}\right]^{+}$ & 0.75 \\
\hline$\left[\mathrm{UO}_{2} \mathrm{OH}(\mathrm{Bzn})_{2}\left(\mathrm{H}_{2} \mathrm{O}\right)\right]^{+}$ & -0.72 \\
\hline
\end{tabular}


Table 2. Decomposition of dicationic complexes by charge-exchange reactions.

Reaction energies are given in $\mathrm{kcal} / \mathrm{mol}$ and include the zero-point energy correction.

\begin{tabular}{|c|c|c|c|}
\hline Reaction proceeds according to equation 3 & \multicolumn{3}{|c|}{ Reaction Energies ( kcal/mol) } \\
\hline$\left[\mathrm{UO}_{2}\left(\mathrm{H}_{2} \mathrm{O}\right)_{2}\right]^{2+} \rightarrow\left[\mathrm{UO}_{2} \mathrm{OH}\right]^{+}+\mathrm{H}_{3} \mathrm{O}^{+}$ & \multicolumn{3}{|c|}{-36.3} \\
\hline$\left[\mathrm{UO}_{2}\left(\mathrm{H}_{2} \mathrm{O}\right)_{3}\right]^{2+} \rightarrow\left[\mathrm{UO}_{2} \mathrm{OH}\left(\mathrm{H}_{2} \mathrm{O}\right)\right]^{+}+\mathrm{H}_{3} \mathrm{O}^{+}$ & \multicolumn{3}{|c|}{-20.7} \\
\hline$\left[\mathrm{UO}_{2}\left(\mathrm{H}_{2} \mathrm{O}\right)_{4}\right]^{2+} \rightarrow\left[\mathrm{UO}_{2} \mathrm{OH}\left(\mathrm{H}_{2} \mathrm{O}\right)_{2}\right]^{+}+\mathrm{H}_{3} \mathrm{O}^{+}$ & \multicolumn{3}{|c|}{-12.8} \\
\hline$\left[\mathrm{UO}_{2}\left(\mathrm{H}_{2} \mathrm{O}\right)_{5}\right]^{2+} \rightarrow\left[\mathrm{UO}_{2} \mathrm{OH}\left(\mathrm{H}_{2} \mathrm{O}\right)_{3}\right]^{+}+\mathrm{H}_{3} \mathrm{O}^{+}$ & \multicolumn{3}{|c|}{-14.5} \\
\hline ----- & $\mathbf{L}=\mathbf{A c n}$ & $\mathbf{L}=\mathbf{P n}$ & $\mathbf{L}=\mathbf{B z n}$ \\
\hline$\left[\mathrm{UO}_{2}\left(\mathrm{H}_{2} \mathrm{O}\right)_{2}(\mathrm{~L})\right]^{2+} \rightarrow\left[\mathrm{UO}_{2} \mathrm{OH}(\mathrm{L})\right]^{+}+\mathrm{H}_{3} \mathrm{O}^{+}$ & -11.2 & -9.7 & -1.6 \\
\hline$\left[\mathrm{UO}_{2}\left(\mathrm{H}_{2} \mathrm{O}\right)_{2}(\mathrm{~L})_{2}\right]^{2+} \rightarrow\left[\mathrm{UO}_{2} \mathrm{OH}(\mathrm{L})_{2}\right]^{+}+\mathrm{H}_{3} \mathrm{O}^{+}$ & 4.1 & 6.0 & 14.8 \\
\hline$\left[\mathrm{UO}_{2}\left(\mathrm{H}_{2} \mathrm{O}\right)_{3}(\mathrm{~L})_{2}\right]^{2+} \rightarrow\left[\mathrm{UO}_{2} \mathrm{OH}\left(\mathrm{H}_{2} \mathrm{O}\right)(\mathrm{L})_{2}\right]^{+}+\mathrm{H}_{3} \mathrm{O}^{+}$ & 2.3 & 3.9 & 11.9 \\
\hline$\left[\mathrm{UO}_{2}\left(\mathrm{H}_{2} \mathrm{O}\right)_{2}(\mathrm{~L})_{3}\right]^{2+} \rightarrow\left[\mathrm{UO}_{2} \mathrm{OH}(\mathrm{L})_{3}\right]^{+}+\mathrm{H}_{3} \mathrm{O}^{+}$ & 9.1 & 11.4 & 21.5 \\
\hline Reaction proceeds according to equation 4 & --- & --- & --- \\
\hline$\left[\mathrm{UO}_{2}\left(\mathrm{H}_{2} \mathrm{O}\right)(\mathrm{L})\right]^{2+} \rightarrow\left[\mathrm{UO}_{2} \mathrm{OH}\right]^{+}+(\mathrm{H}+\mathrm{L})^{+}$ & -37.7 & -36.9 & -26.6 \\
\hline$\left[\mathrm{UO}_{2}\left(\mathrm{H}_{2} \mathrm{O}\right)_{2}(\mathrm{~L})\right]^{2+} \rightarrow\left[\mathrm{UO}_{2} \mathrm{OH}\left(\mathrm{H}_{2} \mathrm{O}\right)\right]^{+}+(\mathrm{H}+\mathrm{L})^{+}$ & -25.7 & -25.8 & -21.0 \\
\hline$\left[\mathrm{UO}_{2}\left(\mathrm{H}_{2} \mathrm{O}\right)(\mathrm{L})_{2}\right]^{2+} \rightarrow\left[\mathrm{UO}_{2} \mathrm{OH}(\mathrm{L})\right]^{+}+(\mathrm{H}+\mathrm{L})^{+}$ & -18.4 & -17.7 & -10.5 \\
\hline$\left[\mathrm{UO}_{2}\left(\mathrm{H}_{2} \mathrm{O}\right)_{2}(\mathrm{~L})_{2}\right]^{2+} \rightarrow\left[\mathrm{UO}_{2} \mathrm{OH}\left(\mathrm{H}_{2} \mathrm{O}\right)(\mathrm{L})\right]^{+}+(\mathrm{H}+\mathrm{L})^{+}$ & -13.0 & -13.7 & -9.6 \\
\hline$\left[\mathrm{UO}_{2}\left(\mathrm{H}_{2} \mathrm{O}\right)_{3}(\mathrm{~L})_{2}\right]^{2+} \rightarrow\left[\mathrm{UO}_{2} \mathrm{OH}\left(\mathrm{H}_{2} \mathrm{O}\right)_{2}(\mathrm{~L})\right]^{+}+(\mathrm{H}+\mathrm{L})^{+}$ & -15.9 & -16.4 & 1.7 \\
\hline$\left[\mathrm{UO}_{2}\left(\mathrm{H}_{2} \mathrm{O}\right)_{2}(\mathrm{~L})_{3}\right]^{2+} \rightarrow\left[\mathrm{UO}_{2} \mathrm{OH}\left(\mathrm{H}_{2} \mathrm{O}\right)(\mathrm{L})_{2}\right]^{+}+(\mathrm{H}+\mathrm{L})^{+}$ & -10.3 & -10.5 & -6.2 \\
\hline$\left[\mathrm{UO}_{2}\left(\mathrm{H}_{2} \mathrm{O}\right)(\mathrm{L})_{4}\right]^{2+} \rightarrow\left[\mathrm{UO}_{2} \mathrm{OH}(\mathrm{L})_{3}\right]^{+}+(\mathrm{H}+\mathrm{L})^{+}$ & -4.7 & -4.5 & 0.9 \\
\hline
\end{tabular}


Figure 9. Relative binding energies ( $\mathrm{kcal} / \mathrm{mol}$ ) with the zero-point energy correction for acetonitrile (left arrow) and water (right arrow) additions according to

$\left[\mathrm{UO}_{2} \mathrm{OH}(\mathrm{Acn})_{\mathrm{n}}\left(\mathrm{H}_{2} \mathrm{O}\right)_{\mathrm{m}}\right]^{+}+\mathrm{Acn} \rightarrow\left[\mathrm{UO}_{2} \mathrm{OH}(\mathrm{Acn})_{\mathrm{n}+1}\left(\mathrm{H}_{2} \mathrm{O}\right)_{\mathrm{m}}\right]^{+}$and

$\left[\mathrm{UO}_{2} \mathrm{OH}(\mathrm{Acn})_{\mathrm{n}}\left(\mathrm{H}_{2} \mathrm{O}\right)_{\mathrm{m}}\right]^{+}+\mathrm{H}_{2} \mathrm{O} \rightarrow\left[\mathrm{UO}_{2} \mathrm{OH}(\mathrm{Acn})_{\mathrm{n}}\left(\mathrm{H}_{2} \mathrm{O}\right)_{\mathrm{m}+1}\right]^{+}$. Complexes observed in ESI-MS experiments are $\left[\mathrm{UO}_{2} \mathrm{OH}\right]^{+},\left[\mathrm{UO}_{2} \mathrm{OH}\left(\mathrm{H}_{2} \mathrm{O}\right)\right]^{+},\left[\mathrm{UO}_{2} \mathrm{OH}\left(\mathrm{H}_{2} \mathrm{O}\right)_{2}\right]^{+}$,

$\left[\mathrm{UO}_{2} \mathrm{OH}(\mathrm{Acn})\right]^{+},\left[\mathrm{UO}_{2} \mathrm{OH}(\mathrm{Acn})_{2}\right]^{+}$, and $\left[\mathrm{UO}_{2} \mathrm{OH}(\mathrm{Acn})\left(\mathrm{H}_{2} \mathrm{O}\right)\right]^{+}$.

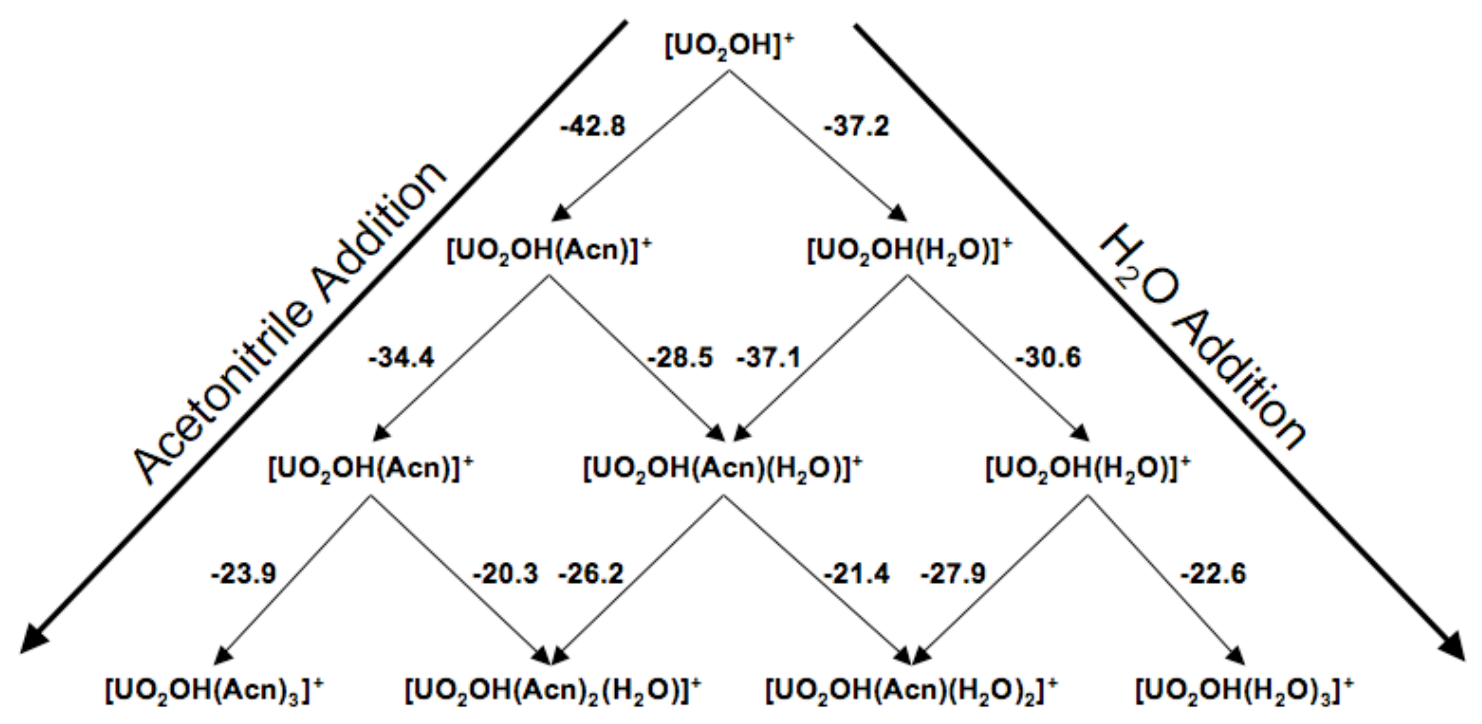


Figure 10. Relative binding energies ( $\mathrm{kcal} / \mathrm{mol}$ ) with the zero-point energy correction for propionitrile (left arrow) and water (right arrow) additions according to

$\left[\mathrm{UO}_{2} \mathrm{OH}(\mathrm{Pn})_{\mathrm{n}}\left(\mathrm{H}_{2} \mathrm{O}\right)_{\mathrm{m}}\right]^{+}+\mathrm{Pn} \rightarrow\left[\mathrm{UO}_{2} \mathrm{OH}(\mathrm{Pn})_{\mathrm{n}+1}\left(\mathrm{H}_{2} \mathrm{O}\right)_{\mathrm{m}}\right]^{+}$and

$\left[\mathrm{UO}_{2} \mathrm{OH}(\mathrm{Pn})_{\mathrm{n}}\left(\mathrm{H}_{2} \mathrm{O}\right)_{\mathrm{m}}\right]^{+}+\mathrm{H}_{2} \mathrm{O} \rightarrow\left[\mathrm{UO}_{2} \mathrm{OH}(\mathrm{Pn})_{\mathrm{n}}\left(\mathrm{H}_{2} \mathrm{O}\right)_{\mathrm{m}+1}\right]^{+}$. Complexes observed in ESIMS experiments are $\left[\mathrm{UO}_{2} \mathrm{OH}(\mathrm{Pn})\right]^{+}, \quad\left[\mathrm{UO}_{2} \mathrm{OH}(\mathrm{Pn})_{2}\right]^{+}, \quad\left[\mathrm{UO}_{2} \mathrm{OH}(\mathrm{Pn})\left(\mathrm{H}_{2} \mathrm{O}\right)\right]^{+}$, and $\left[\mathrm{UO}_{2} \mathrm{OH}(\mathrm{Pn})\left(\mathrm{H}_{2} \mathrm{O}\right)_{2}\right]^{+}$.

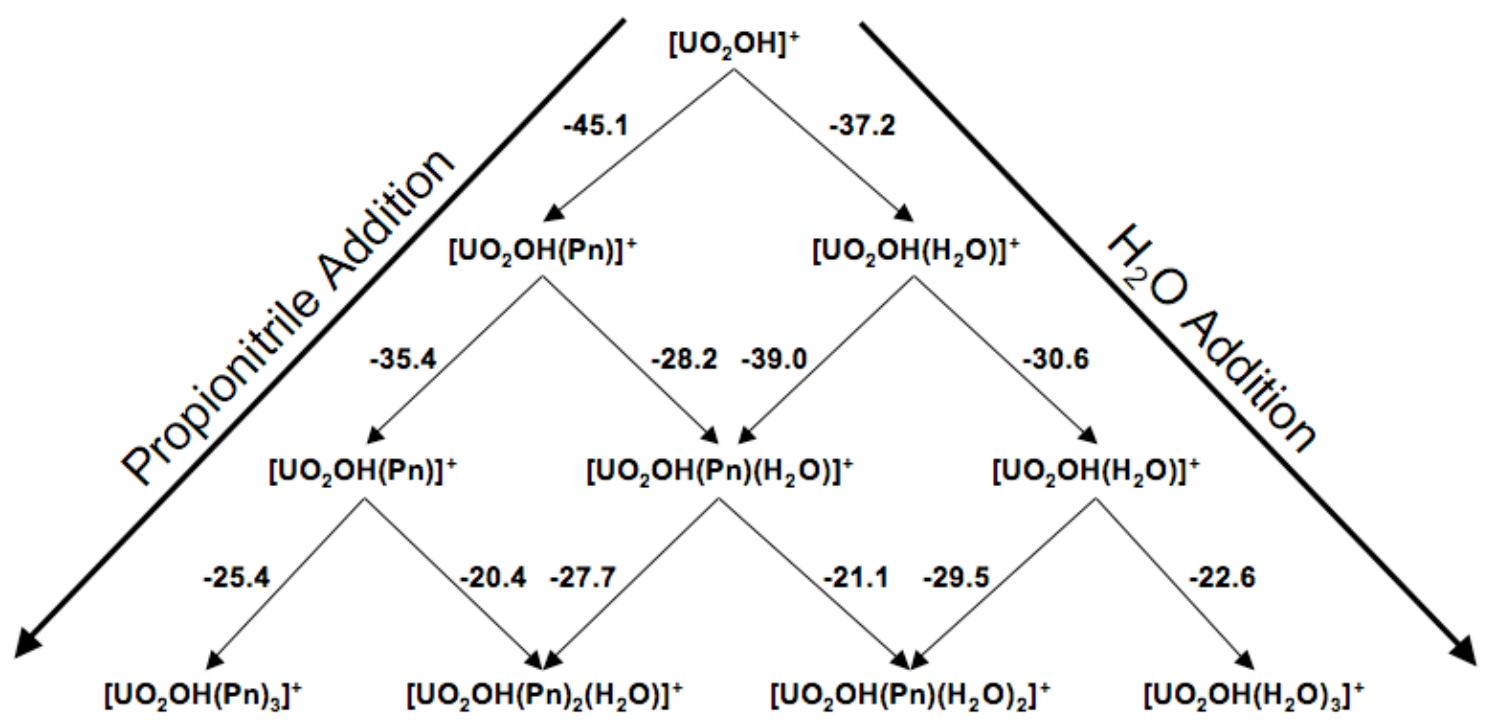


Figure 11. Relative binding energies ( $\mathrm{kcal} / \mathrm{mol}$ ) with the zero-point energy correction for benzonitrile (left arrow) and water (right arrow) additions according to

$\left[\mathrm{UO}_{2} \mathrm{OH}(\mathrm{Bzn})_{\mathrm{n}}\left(\mathrm{H}_{2} \mathrm{O}\right)_{\mathrm{m}}\right]^{+}+\mathrm{Bzn} \rightarrow\left[\mathrm{UO}_{2} \mathrm{OH}(\mathrm{Bzn})_{\mathrm{n}+1}\left(\mathrm{H}_{2} \mathrm{O}\right)_{\mathrm{m}}\right]^{+}$and

$\left[\mathrm{UO}_{2} \mathrm{OH}(\mathrm{Bzn})_{\mathrm{n}}\left(\mathrm{H}_{2} \mathrm{O}\right)_{\mathrm{m}}\right]^{+}+\mathrm{H}_{2} \mathrm{O} \rightarrow\left[\mathrm{UO}_{2} \mathrm{OH}(\mathrm{Bzn})_{\mathrm{n}}\left(\mathrm{H}_{2} \mathrm{O}\right)_{\mathrm{m}+1}\right]^{+}$. Complexes observed in ESI-MS experiments are $\quad\left[\mathrm{UO}_{2} \mathrm{OH}(\mathrm{Bzn})\right]^{+}, \quad\left[\mathrm{UO}_{2} \mathrm{OH}(\mathrm{Bzn})\left(\mathrm{H}_{2} \mathrm{O}\right)\right]^{+}, \quad$ and $\left[\mathrm{UO}_{2} \mathrm{OH}(\mathrm{Bzn})\left(\mathrm{H}_{2} \mathrm{O}\right)_{2}\right]^{+}$.

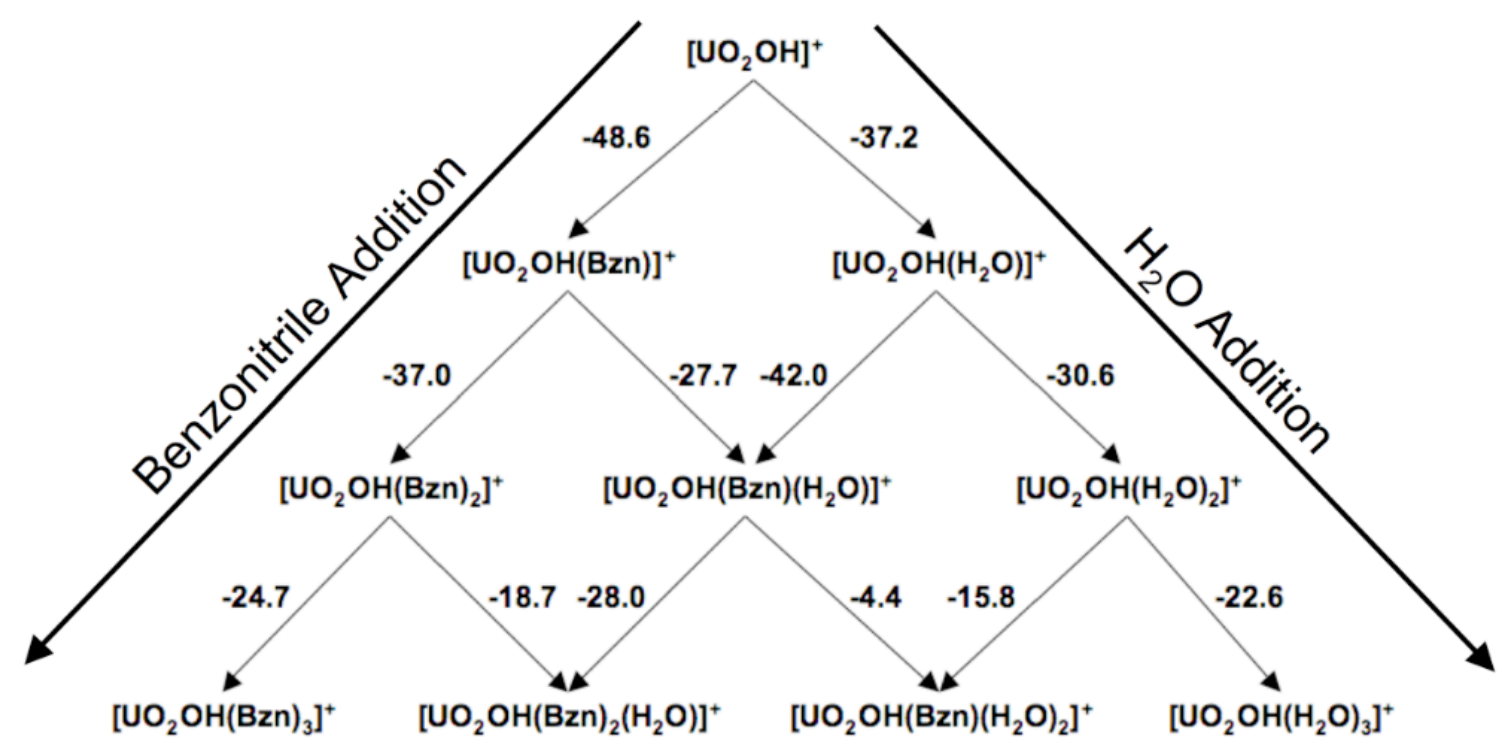




\section{References}

${ }^{1}$ Allen, P. C.; Bucher, J. J.; Shuh, D. K.; Edelstein, N. M.; Reich, T. Inorg. Chem. 1997, $38,4676$.

${ }^{2}$ Clark, D. L.; Conradson, S. D.; Donohoe, R. J.; Keogh, D. W.; Morris, D. E.; Palmer, P.

D.; Rogers, R. D.; Tait, C. D. Inorg. Chem. 1999, 38, 1456.

${ }^{3}$ Hagberg, D.; Karlström, G.; Roos, B. O.; Gagliard, L. JACS 2005, 127, 14250.

${ }^{4}$ Moskaleva, L. V.; Krüger, S.; Spörl, A.; Rösch, N. Inorg. Chem. 2004, 43 (13), 4080.

${ }^{5}$ Tsushima, S.; Yang, T.; Suzuki, A. Chem. Phys. Lett. 2001, 334, 365.

${ }^{6}$ Vallet, V.; Wahlgren, U.; Schimmelpfennig, B.; Szabó, Z.; Grenthe, I. J. Am. Chem.

Soc. 2001, 123, 11999.

${ }^{7}$ Vallet, V.; Szabó, Z.; Grenthe, I. Dalton Transactions 2004, 22, 3799.

${ }^{8}$ Schoendorff, G.; Windus, T. L.; de Jong, W. A. J. Phys. Chem. A, 2009, 113, 12525.

${ }^{9}$ Van Stipdonk, M. J.; Chien, W.; Bulleigh, K.; Wu, Q.; Groenewold, G. S. J. Phys.

Chem. A. 2006, 110, 959.

${ }^{10}$ Bylaska, E. J.; et al. NWChem, A Computational Chemistry Package for Parallel

Computers, Version 5.1.1, Pacific Northwest National Laboratory, Richland,

Washington, 2009.

${ }^{11}$ Kendall, R. A.; Aprà, E.; Bernholdt, D. E.; Bylaska, E. J.; Dupuis, M.; Fann, G. I.;

Harrison, R. J.; Ju, J.; Nichols, J. A.; Nieplocha, J.; Straatsma, T. P.; Windus, T. L.;

Wong, A. T. Computer Phys. Comm. 2000, 128, 260.

12 de Jong, W. A.; Harrison, R. J.; Nichols, J. A.; Dixon, D. A. Theor. Chem. Acc. 2001, $107,22$.

${ }^{13}$ Slater, J. C. Phys. Rev. 1951, 81 (3), 1287. 
${ }^{14}$ Vosko, S. H.; Wilk, L.; Nusiar, M. Can. J. Phys. 1980, 58 (8), 1200.

${ }^{15}$ Becke, A. D. J. Chem. Phys. 1993, 98, 5648.

${ }^{16}$ Lee, C.; Yang, W.; Parr, R. G. Phys. Rev. B 1988, 37, 785.

${ }^{17}$ Njegic, B.; Gordon, M. S. J. Chem. Phys., 2006, 125, 224102.

${ }^{18}$ Njegic, B.; Gordon, M. S. J. Chem. Phys., 2008, 129, 164107.

${ }^{19}$ Bergner, A.; Dolg, M.; Küchle, W.; Stoll, H.; Preuss, H. Mol. Phys. 1993, 80 (6), 1431.

${ }^{20}$ Küchle, W.; Dolg, M.; Stoll, H. Mol. Phys. 1991, 74 (6), 1245.

${ }^{21}$ Küchle, W.; Dolg, M.; Stoll, H.; Preuss, H. J. Chem. Phys. 1994, 100 (10), 7535.

${ }^{22}$ Godbout, N.; Salahub, D. R.; Andzelm, J.; Wimmer, E. Can. J. Chem. 1992, 70 (2), 560.

${ }^{23}$ Bode, B. M.; Gordon, M. S. J. Mol. Graphics Modell. 1998, 16, 133.

${ }^{24}$ Bühl, M.; Kabrede, H. Chem. Phys. Chem. 2006, 7, 2290.

${ }^{25}$ Chang, C. M.; Wang, M. K. Chem. Phys. Lett. 1998, 286, 46.

${ }^{26}$ George, P.; Glusker, J. P.; Trachtman, M.; Bock, C. W. Chem. Phys. Lett. 2002, 351, 454. 
[Reprinted with permission from Schoendorff, G.; de Jong, W. A.; Van Stipdonk, M. J.;

Gibson, J. K.; Rios, D.; Gordon, M. S.; Windus, T. L. Inorg. Chem. 2011, 50 (17), 8490. Copyright 2011 American Chemical Society.]

\title{
On the Formation of "Hypercoordinated" Uranyl Complexes
}

George Schoendorff $f^{*}$, Wibe A. de Jong ${ }^{t}$, Michael J. Van Stipdonk ${ }^{\S}$, John K. Gibson ${ }^{* *}$, Daniel Rios $^{* *}$, Mark S. Gordon ${ }^{\dagger}$, Theresa L. Windus ${ }^{\dagger}$

${ }^{\dagger}$ Department of Chemistry, Iowa State University and Ames Laboratory, Ames, IA 50011

${ }^{* *}$ Environmental Molecular Sciences Laboratory, Pacific Northwest National Laboratory, P.O. Box 999, Richland, WA 99352

${ }^{\S}$ Department of Chemistry, Wichita State University, Wichita, KS 67260-0051

** Chemical Sciences Division, The Glenn T. Seaborg Center, Lawrence Berkeley National Laboratory, Berkeley, CA 94720

\begin{abstract}
Recent gas phase experimental studies suggest the presence of hypercoordinated uranyl complexes. Coordination of acetone (Ace) to uranyl to form hypercoordinated species is examined using density functional theory (DFT) with a range of functionals and second order perturbation theory (MP2). Complexes with up to eight acetones were studied. It is shown that no more than six acetones can bind directly to uranium and that the observed uranyl complexes are not hypercoordinated.
\end{abstract}

\footnotetext{
*Email: twindus@iastate.edu
} 


\section{Introduction}

Actinide chemistry is essential to the development of technologies related to nuclear power and nuclear waste management and speciation. Of particular interest is the chemistry of the early actinides, Th through Am, and the hexavalent actinyl ion $[\mathrm{O}=\mathrm{An}=\mathrm{O}]^{2+}$ is a frequent subject of study. In particular the uranyl dication $\left(\mathrm{UO}_{2}{ }^{2+}\right)$. Uranyl dication coordinated with up to five acetone ligands has been experimentally observed in the gas phase ${ }^{1}$. Density functional theory (DFT) has been used to study the formation of dicationic uranyl complexes with acetone and predicts stable species with up to six acetone ligands in the gas phase ${ }^{2}$. A recent experimental study has verified the existence of the hexacoordinated uranyl species, and suggests hypercoordinated species with up to eight acetones ${ }^{3}$. Possible mechanisms for the binding of the seventh and eighth acetones are examined in the present work, as well as a comparison of the binding energies obtained using various DFT functionals and second order perturbation theory (MP2). The choice of initial structures was based on the mechanisms proposed in reference 3 .

\section{Details of the Calculations}

All calculations were performed using the NWChem software suite ${ }^{4,5}$. The choice of functional and basis set used for the structure optimizations was based on a previous systematic study in which fully relativistic coupled cluster theory (four-component $\operatorname{CCSD}(\mathrm{T}))$ benchmark calculations on $\mathrm{UO}_{2}{ }^{2+}$ were compared to various levels of theory,

DFT functionals, and basis set choices ${ }^{6}$. That study showed that the best agreement using DFT was obtained with the local density approximation (LDA) $)^{7,8}$ to determine optimized 
structures and Hessians and the $\mathrm{B} 3 \mathrm{LYP}^{9,10}$ functional at the LDA optimized structures for energies. MP2 also performed well in the benchmark study, but the computational cost is an order of magnitude greater than it is for the DFT functionals that were used. Accordingly, all structure optimizations and Hessians were obtained using LDA, and all energies reported were obtained with the B3LYP functional using the LDA optimized structure. Since long-range effects may be important in structures with ligands in the second solvation shell of $\mathrm{UO}_{2}^{2+}$, binding energies were also calculated using the B2PLYP $^{11}$, CAM-B3LYP ${ }^{12}$, and SSB-D ${ }^{13,14}$ functionals at the LDA optimized structures. These functionals were chosen because they are the most commonly used functionals to address long range effects. MP2 binding energies are also reported, to provide an $a b$ initio method that includes electron correlation for comparison. All reported energies include the vibrational zero point energy correction.

The small core Stuttgart relativistic effective core potential (RECP) and associated Stuttgart orbital basis set ${ }^{15,16,17}$ were employed for uranium, while valence triple- $\zeta$ plus polarization (TZVP) ${ }^{18}$ DFT optimized basis sets were used for all other atoms $(\mathrm{H}, \mathrm{C}$, and $\mathrm{O})$. In all cases, spherical Gaussian functions were used. Molecular images were produced using MacMolPlt ${ }^{19}$.

\section{Discussion}

Complexes of acetone coordinated to dicationic uranyl have been studied previously for systems involving up to six acetone ligands ${ }^{2}$. Table 1 contains the binding energies for first five acetone additions. The values of the binding energies obtained with the B3LYP functional have been previously reported along with a description of the 
bonding for each of the complexes ${ }^{2}$. This earlier study indicated evidence of donation of electron density into the empty f orbitals with some degree of backbonding into the pi* orbitals on the carbonyl group. However, a Mulliken charge analysis indicated that the primary bonding interaction in these complexes is driven by electrostatics. The energies of these structures have been recalculated using the B2PLYP, CAM-B3LYP, and SSB-D functionals as well as MP2. The LDA and B2PLYP trend in the binding energies is similar to the binding energies predicted by MP2 and the other functionals. In general, the binding energies decrease with increasing coordination number. All the DFT functionals in this study over-bind the first acetone addition with respect to MP2. LDA over-binds all of the subsequent acetone additions. The fact that LDA over-binds is well documented $^{20,21}$. Accordingly, while LDA can provide reasonable structures, the relative energies of these complexes are not reliable when the LDA functional is used. However, existing benchmark studies on the quality of DFT functionals frequently neglect molecules containing actinides.

The remaining functionals - B2PLYP, B3LYP, CAM-B3LYP, and SSB-D - yield binding energies that are in much closer agreement with MP2 than either LDA or B2PLYP for 2-3 ligands. While the trend in the B3LYP binding energies is the same as MP2, B3LYP tends to under-bind the ligands. The CAM-B3LYP functional tends to be more binding than B3LYP, and the SSB-D functional matches the MP2 binding energies better than any of the functionals examined. It is expected that the CAM-B3LYP and SSB-D functionals could continue to provide energies that closely agree with MP2 when additional acetones are added to the system due to their ability to account for long-range interactions. The difference in binding energies between B3LYP and CAM-B3LYP is 
primarily the result of how the functional includes HF exchange. The HF contribution to CAM-B3LYP is local and varies from one region of the molecule to another, while B3LYP employs a "global" HF contribution that is not dependent on position ${ }^{22}$.

Uranyl complexes with six acetones are shown in Figure 1. Complex 1A has all six acetone ligands bound directly to uranyl, while complex 1B has five acetone ligands bound directly to uranyl with the sixth acetone in the second solvation sphere. The sixth acetone in complex $\mathbf{1 B}$ is bound non-covalently to two of the acetone ligands on uranyl.

Uranyl complexes with seven bound species are shown in Figure 2. Structure 2A optimized to a complex with six acetones occupying equatorial sites on uranyl with the seventh acetone in the second solvation shell. Structure 2B is a five coordinate complex with two acetones in the second solvation shell. Additional species consistent with the experimental results have been proposed that involve proton transfer between acetones as well as complexes involving acetone as the enol tautomer ${ }^{3}$. Complex $\mathbf{2 C}$ has five acetone ligands bound directly to uranyl in the equatorial positions. A sixth equatorial ligand is a deprotonated acetone. The proton from this ligand has been transferred to the seventh acetone to produce an alcohol. This alcohol is bound via a hydrogen bond to one of the axial oxygens from uranyl. The final complex with seven acetones involves the enol tautomer of acetone. As with complex 2C, complex 2D involves a hydrogen bonding interaction between an axial oxygen from uranyl and the alcohol hydrogen from the enol tautomer of acetone. The remaining six acetones are directly bound to equatorial positions on uranyl.

Optimized structures of complexes containing eight bound species are presented in Figure 3. Structure 3A has five acetones bound directly to uranyl in the equatorial 
plane. The remaining three acetones are not directly bound to uranyl and lie above the equatorial plane. Structure 3B has four acetone ligands directly bound to uranyl. The fifth equatorial coordination site is occupied by a deprotonated acetone. One protonated acetone is bound via a hydrogen bond to one of the axial oxygens from uranyl. One enol tautomer of acetone is in the second solvation shell between the deprotonated ligand and the hydrogen-bonded protonated acetone (far left of 3B). The final acetone is in the second solvation shell. Structure $\mathbf{3 C}$ has six acetones directly bound to uranyl with enol tautomers of acetone bound via hydrogen bonds to each of the axial oxygens on uranyl.

Table 2 shows the binding energies for the complexes containing six, seven, and eight acetones for the various functionals employed and compares them with the MP2 binding energies. Binding energies for the complexes with seven acetones are calculated with the precursors 1A and 1B (values from 1B are in parentheses). MP2 and LDA both predict complex $\mathbf{1 A}$ to be the more stable product by approximately $3 \mathrm{kcal} / \mathrm{mol}$, while the B2PLYP, B3LYP, CAM-B3LYP, and SSB-D functional all show complex $\mathbf{1 B}$ to be lower in energy. The difference in energy between complexes $\mathbf{1 A}$ and $\mathbf{1 B}$ is $7.6 \mathrm{kcal} / \mathrm{mol}$ or less at all levels of theory with the B3LYP functional producing the largest energy difference. At the fifth acetone addition, uranyl is nearly saturated and addition of a sixth ligand leads to weak binding. Thus the difference in energy for a 6 coordinate complex versus a five coordinate complex with one acetone in the second solvation sphere will be small. For complexes with seven or more acetones, LDA binding energies differ significantly from the MP2 binding energies. B2PLYP is in much closer agreement with MP2 for the large species, but the deviation from MP2 remains unpredictable (significantly over-binding in some cases and under-binding in others). The remaining 
functionals also do not perform well compared with MP2. In some cases the DFT binding energy sign differs from the MP2 sign (for example, $2 \mathrm{~A}$ and $\mathbf{2 C}$ binding energies for SSB-D vs. MP2). Furthermore, the lowest vibrational frequencies predicted for each

of these structures ranges from $6 \mathrm{~cm}^{-1}$ (3B) to $20 \mathrm{~cm}^{-1}$ (2B). Since the LDA Hessian for each of these structures is positive definite, they are all shallow minima on the LDA potential energy surface. This indicates that these are floppy, weakly bound structures. If each structure in Table 2 that has a positive binding energy is optimized using the corresponding method, these species may spontaneously dissociate. Because these structures exist in shallow minima, there may be other local minima on the potential energy surface with comparable energies.

\section{Conclusions}

There are some important details that can be elucidated from the data presented here. It has been shown that care must be taken when choosing a density functional for these systems. The results of this study suggest that the SSB-D functional provides the best binding energies compared with MP2 for complexes that have acetone directly bound to uranyl, and CAM-B3LYP provides the best agreement with MP2 for complexes that have acetones that are not directly bound to uranyl. With six acetones, only LDA gave the correct trend (although it significantly over-binds compared to MP2).

More significantly, the hypercoordinated species previously reported ${ }^{3}$ do not simply involve coordination of acetone ligands to uranyl. The seventh and eighth, and in some computational approaches even the sixth, acetone generally does not bind directly to uranyl. There simply is not sufficient room in the equatorial plane to accommodate so 
many bulky ligands. However, the structures with additional acetones in the second solvation sphere do appear to be possible from the binding energies. Other more exotic species involving proton transfer between acetones and species involving enol tautomers of acetone are high-energy species that are unlikely to form. Additionally, the complexes obtained exist in very shallow potential energy wells suggesting that numerous geometries might be possible, although the last few acetones will necessarily be in the second solvation shell.

The experimental conditions under which the apparently "hypercoordinated" complexes, $\left[\mathrm{UO}_{2}(\text { Ace })_{6,7,8}\right]^{2+}$, were observed have been described. ${ }^{2,23}$ An ion trap gasphase hydration study under similar conditions resulted in monopositive metal ion complexes coordinated by inner-shell waters but not second-shell waters. ${ }^{23}$ DFT computations of $\left[\mathrm{Yb}(\mathrm{OH})_{2}\left(\mathrm{H}_{2} \mathrm{O}\right)_{n}\right]^{+}(\mathrm{n}=1-5)$, for example, demonstrated that the first four waters are directly bound to the $\mathrm{Yb}$ metal center. Addition of a fifth water to the second shell was computed to be both exothermic and exoergic, but was not observed under the experimental conditions, $\mathrm{P}\left[\mathrm{H}_{2} \mathrm{O}\right] \approx 300 \mathrm{~K}$. As second shell acetones should generally be less strongly bound than hydrogen-bonded second shell waters, and the acetone pressure in the ion trap is less than that of water, experimental observations of weakly-bound second shell acetones such as in structure $\mathbf{3 A}$ are not expected. From the experimental observation of the $\left[\mathrm{UO}_{2}(\text { Ace })_{6,7,8}\right]^{2+}$ complexes, and the theory results that their energetically favored structures have outer sphere acetones, it can be concluded that the observed complexes most probably do not comprise only acetone ligands and that uranyl is not necessarily "hypercoordinated." Among alternative ligands that will be considered in future theory and experimental studies of these enigmatic complexes is diacetone 
alcohol, $\mathrm{CH}_{3} \mathrm{C}(\mathrm{O}) \mathrm{CH}_{2} \mathrm{C}(\mathrm{OH})\left(\mathrm{CH}_{3}\right)_{2}$, which is an acetone dimer that is not readily discernible from two acetones by simple mass spectrometry.

\section{Acknowledgements}

This research was performed in part using the Molecular Science Computing Facility (MSCF) in the William R. Wiley Environmental Molecular Sciences Laboratory, a National scientific user facility sponsored by the U.S. Department of Energy's Office of Biological and Environmental Research and located at the Pacific Northwest National Laboratory, operated for the Department of Energy by Battelle. Funding has been provided by Iowa State University and an NSF grant for petascale applications. WdJ's, JKG's, and DR's work was supported by the BES Heavy Element Chemistry program of the U.S. Department of Energy, Office of Science. Work at LBNL was supported by the Director, Office of Science, Office of Basic Energy Sciences, Division of Chemical Sciences, Geosciences and Biosciences of the U.S. Department of Energy, under Contract No. DE-AC02-05CH11231.

\section{Supporting Information}

The atomic coordinates for the optimized structures are available. This material is available free of charge via the Internet at http://pubs.acs.org. 
Table 1. Binding energies $(\mathrm{kcal} / \mathrm{mol})$ for the first five acetone additions including zero point energy. Binding energies are computed for the reactions

$$
\left[\mathrm{UO}_{2}(\text { Ace })_{\mathrm{n}-1}\right]^{2+}+\mathrm{Ace} \rightarrow\left[\mathrm{UO}_{2}(\text { Ace })_{\mathrm{n}}\right]^{2+} .
$$

\begin{tabular}{|c|c|c|c|c|c|c|}
\hline \multirow{2}{*}{ \# of Ace } & \multicolumn{5}{|c|}{ DFT } & \multirow{2}{*}{ MP2 } \\
\cline { 2 - 6 } & LDA & B2PLYP & B3LYP & CAM-B3LYP & SSB-D & \\
\hline 1 & -129.4 & -107.1 & -108.1 & -107.3 & -110.3 & -92.0 \\
\hline 2 & -87.8 & -76.2 & -75.0 & -76.7 & -72.4 & -72.3 \\
\hline 3 & -66.7 & -60.1 & -57.8 & -60.2 & -54.5 & -49.5 \\
\hline 4 & -46.9 & -35.5 & -30.8 & -34.4 & -37.0 & -37.0 \\
\hline 5 & -29.6 & -19.9 & -12.7 & -17.3 & -21.5 & -26.3 \\
\hline
\end{tabular}

Figure 1. Complexes of $\mathrm{UO}_{2}{ }^{2+}$ with six acetones. Complex 1A has six acetone ligands directly bound to uranyl, and complex 1B has five acetone ligands directly bound to uranyl with the sixth acetone in the second solvation sphere.
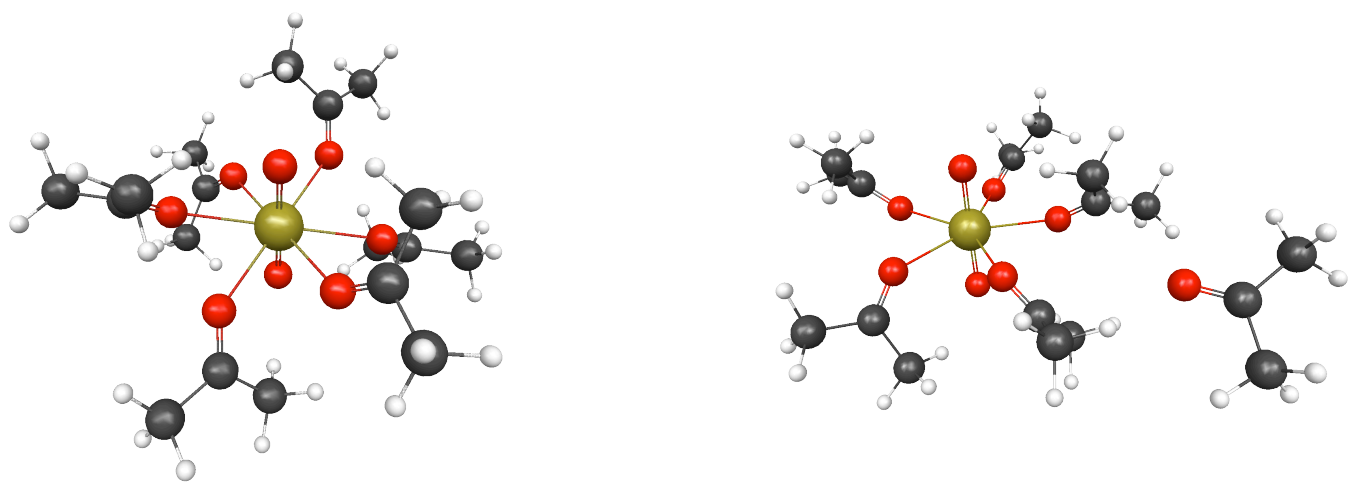

$1 \mathrm{~A}$

1B 
Figure 2. Complexes of $\mathrm{UO}_{2}{ }^{2+}$ with seven bound species. Complexes $\mathbf{2 A}$ and $\mathbf{2 B}$ have seven acetones, complex $\mathbf{2 C}$ involves proton transfer between acetone ligands, and complex 2D has an enol tautomer of acetone bound to an axial oxygen from uranyl via a hydrogen bond.
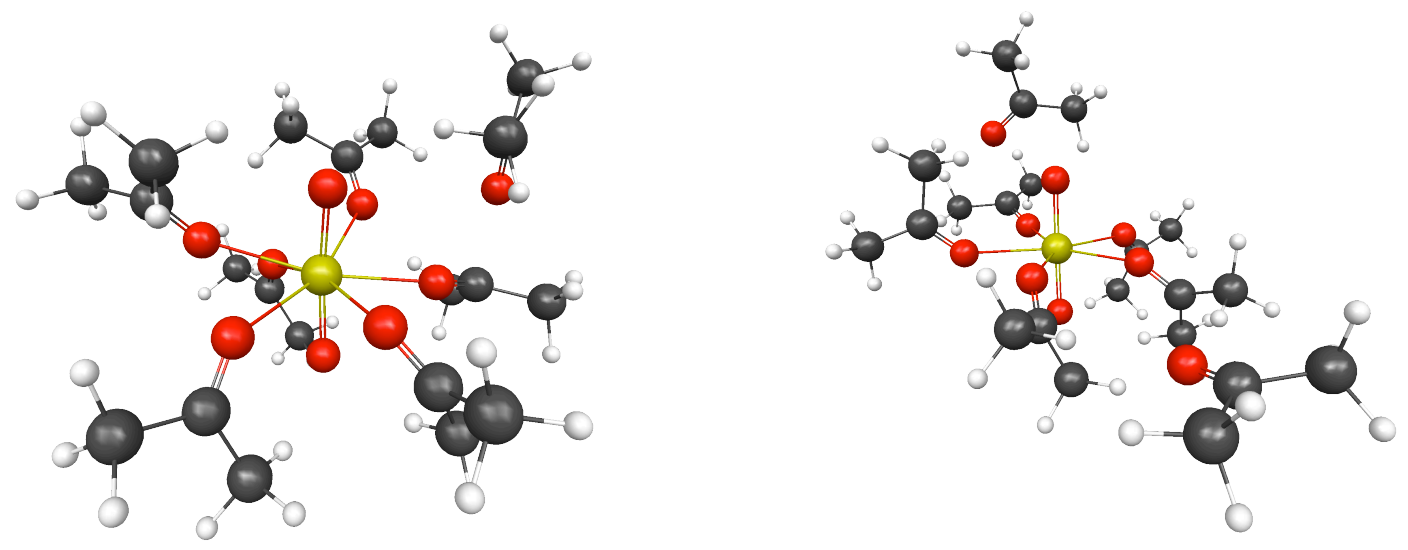

2A

2B
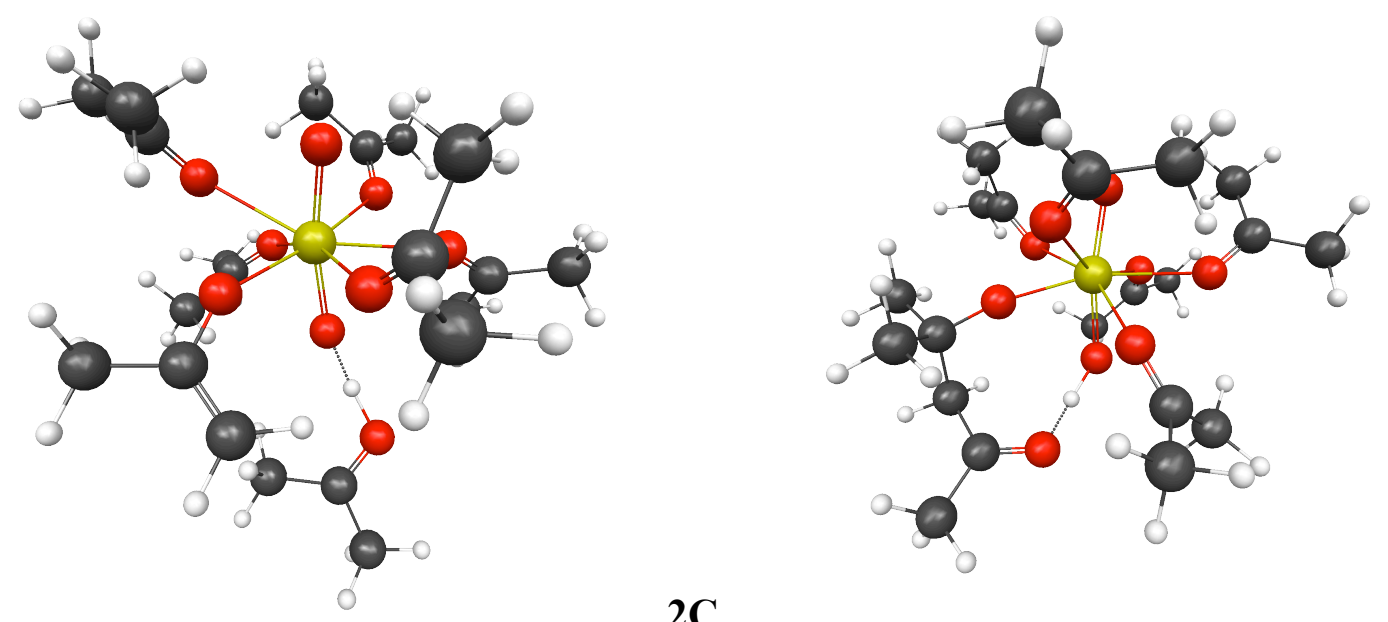
Figure 3. Complexes of $\mathrm{UO}_{2}{ }^{2+}$ with eight bound species. Complex 3A has eight acetones, complex 3B involves proton transfer between acetones and one enol tautomer, and complex $\mathbf{3 C}$ has two enol tautomers of acetone bound to the axial oxygens from uranyl via hydrogen bonds.
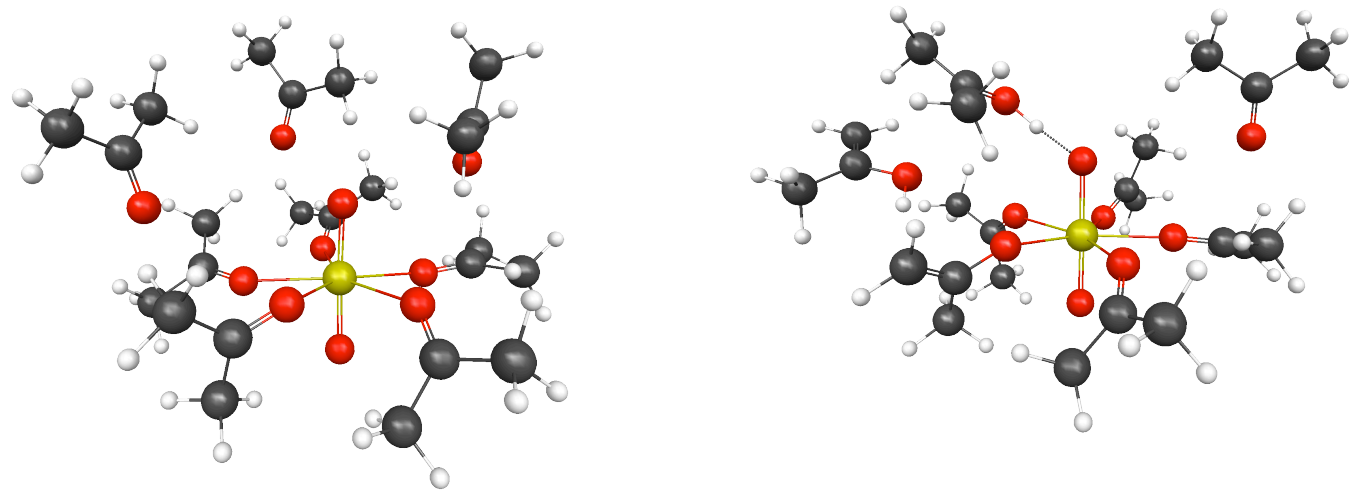

3A

3B

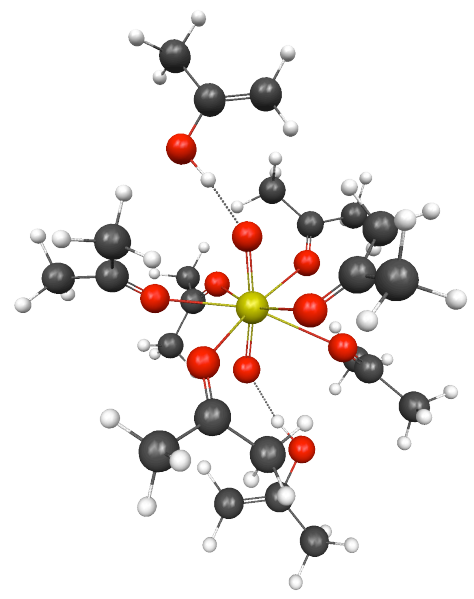

3C 
Table 2. Binding energies $(\mathrm{kcal} / \mathrm{mol})$ for the additions of the sixth, seventh, and eighth acetones. Binding energies are computed for the reactions $\left[\mathrm{UO}_{2}(\text { Ace })_{5}\right]^{2+}+\mathrm{Ace} \rightarrow\{\mathbf{1} \mathbf{A}$, $1 \mathrm{~B}\}, \mathbf{1 A}$ or $(\mathbf{1 B})+$ Ace $\rightarrow\{2 \mathrm{~A}, \mathbf{2 B}, \mathbf{2 C}$, or $\mathbf{2 D}\}$ and $\mathbf{2 B}+\mathrm{Ace} \rightarrow\{\mathbf{3 A}, \mathbf{3 B}$, or $\mathbf{3 C}\}$. The binding energies in parentheses are from acetone additions to $1 \mathbf{B}$. All binding energies include the zero point energy correction.

\begin{tabular}{|c|c|c|c|c|c|c|}
\hline & \multicolumn{5}{|c|}{ DFT } & MP2 \\
\cline { 2 - 7 } & LDA & B2PLYP & B3LYP & CAM-B3LYP & SSB-D & \\
\hline 1A & -25.0 & -9.9 & -3.9 & -7.5 & -10.5 & -8.6 \\
\hline 1B & -22.3 & -13.9 & -11.5 & -13.6 & -17.4 & -5.9 \\
\hline 2A & -8.1 & 2.3 & 7.8 & 4.6 & -4.7 & 2.1 \\
& $(-10.9)$ & $(6.3)$ & $(15.3)$ & $(10.7)$ & $(2.1)$ & $(-0.6)$ \\
\hline 2B & -13.4 & -8.6 & -8.1 & -9.4 & -15.4 & -3.3 \\
& $(-16.1)$ & $(-4.6)$ & $(-0.5)$ & $(-3.3)$ & $(-8.5)$ & $(-6.0)$ \\
\hline 2C & -5.6 & 16.4 & 17.1 & 14.0 & -0.1 & 4.5 \\
& $(-8.7)$ & $(20.4)$ & $(27.9)$ & $(27.8)$ & $(18.6)$ & $(16.8)$ \\
\hline 2D & -20.2 & 7.6 & 20.4 & 21.7 & 11.8 & 19.5 \\
& $(-22.9)$ & $(11.6)$ & $(24.7)$ & $(20.0)$ & $(6.7)$ & $(1.8)$ \\
\hline 3A & -12.1 & -6.1 & -1.3 & -5.6 & -11.5 & -5.1 \\
\hline 3B & -1.3 & 26.6 & 36.3 & 34.9 & 28.4 & 32.3 \\
\hline 3C & 2.9 & 31.5 & -0.7 & 29.0 & 21.1 & 28.9 \\
\hline
\end{tabular}




\section{References}

${ }^{1}$ Van Stipdonk, M. J.; Chien, W.; Anbalagan, V.; Bulleigh, K.; Hanna, D.; Groenewold, G. S., J. Phys. Chem. A 2004, 108, 10448.

${ }^{2}$ Schoendorff, G.; Windus, T. L.; de Jong, W. A., J. Phys. Chem. A 2009, 113, 12525.

${ }^{3}$ Rios, D.; Rutkowski, P. X.; Van Stipdonk, M. J.; Gibson, J. K., Inorg. Chem. 2011, 50, 4781.

${ }^{4}$ Valiev, M.; Bylaska, E. J.; Govind, N.; Kowalski, K.; Straatsma, T. P.; van Dam, H. H. J.; Wang, D.; Nieplocha, J.; Apra, E.; Windus, T. L.; de Jong, W. A., "NWChem: a comprehensive and scalable open-source solution for large scale molecular simulations" Comput. Phys. Commun. 2010, 181, 1477.

${ }^{5}$ Kendall, R. A.; Aprà, E.; Bernholdt, D. E.; Bylaska, E. J.; Dupuis, M.; Fann, G. I.;

Harrison, R. J.; Ju, J.; Nichols, J. A.; Nieplocha, J.; Straatsma, T. P.; Windus, T. L.;

Wong, A. T., Computer Phys. Comm. 2000, 128, 260.

${ }^{6}$ de Jong, W. A.; Harrison, R. J.; Nichols, J. A.; Dixon, D. A., Theor. Chem. Acc. 2001, $107,22$.

${ }^{7}$ Slater, J. C., Phys. Rev. 1951, 81 (3), 1287.

${ }^{8}$ Vosko, S. H.; Wilk, L.; Nusiar, M., Can. J. Phys. 1980, 58 (8), 1200.

${ }^{9}$ Becke, A. D., J. Chem. Phys. 1993, 98, 5648.

${ }^{10}$ Lee, C.; Yang, W.; Parr, R. G., Phys. Rev. B 1988, 37, 785.

${ }^{11}$ Grimme, S., J. Chem. Phys. 2006, 124, 034108.

${ }^{12}$ Yanai, T.; Tew, D.; Handy, N., Chem. Phys. Lett. 2004, 393, 51.

${ }^{13}$ Swart, M.; Solà, M.; Bickelhaupt, F. M., J. Chem. Phys. 2009, 131, 094103.

${ }^{14}$ Swart, M.; Solà, M.; Bickelhaupt, F. M., J. Comp. Meth. Sci. Engin. 2009, 9, 69. 
${ }^{15}$ Bergner, A.; Dolg, M.; Küchle, W.; Stoll, H.; Preuss, H., Mol. Phys. 1993, 80 (6), 1431.

${ }^{16}$ Küchle, W.; Dolg, M.; Stoll, H., Mol. Phys. 1991, 74 (6), 1245.

${ }^{17}$ Küchle, W.; Dolg, M.; Stoll, H.; Preuss, H., J. Chem. Phys. 1994, 100 (10), 7535.

${ }^{18}$ Godbout, N.; Salahub, D. R.; Andzelm, J.; Wimmer, E., Can. J. Chem. 1992, 70 (2), 560.

${ }^{19}$ Bode, B. M.; Gordon, M. S., J. Mol. Graphics Modell. 1998, 16, 133.

${ }^{20}$ Goerigk, L.; Grimme, S. Phys. Chem. Chem. Phys. 2011, 13, 6670.

${ }^{21}$ Karton, A.; Daon, S.; Martin, J. M. L. Chem. Phys. Lett. 2011, 510, 165.

${ }^{22}$ Akinaga, Y.; Ten-no, S. Chem. Phys. Lett. 2008, 462, 348.

${ }^{23}$ Rutkowski, P. X.; Michelini, M. C.; Bray, T. H.; Russo, N.; Marçalo, J.; Gibson, J. K., Theor. Chem. Acc. 2011, 129, 575. 


\title{
Solving the Riddles of Uranyl Acetone Complexes: Water-elimination and
}

\section{"Hypercoordination"}

George Schoendorff $\hat{t}^{*}$ Daniel Rios ${ }^{t}$,Wibe A. de Jong ${ }^{\S}$, Michael J. Van Stipdonk ${ }^{*}$, John K. Gibson $^{*}$, Mark S. Gordon ${ }^{\dagger}$, Theresa L. Windus ${ }^{\dagger}$

${ }^{\dagger}$ Department of Chemistry, Iowa State University and Ames Laboratory, Ames IA 50011

${ }^{+}$Chemical Sciences Division, The Glenn T. Seaborg Center, Lawrence Berkeley National Laboratory, Berkeley, CA 94720

${ }^{\S}$ Environmental Molecular Sciences Laboratory, Pacific Northwest National Laboratory, P.O. Box 999, Richland, WA 99352

*Department of Chemistry, Wichita State University, Wichita, KS 67260-0051

\begin{abstract}
Uranyl complexes with acetone (ACO) and diacetone alcohol (DAA) ligands are examined. Diacetone alcohol can account for the experimentally observed "hypercoordinated" uranyl complexes with acetone ligands. DAA can be bidentate, allowing more than 6 apparent acetones to bind to the equatorial sites on uranyl. The formation of DAA is supported by collision induced dissociation (CID) experiments in which either DAA or ACO is isotopically labeled. In addition to the formation of DAA, CID experiments demonstrate that DAA can decompose to mesityl oxide (MOX) via loss of $\mathrm{H}_{2} \mathrm{O}$, dissociate to become two acetones, or be deprotonated to form an alkoxide ligand.
\end{abstract}




\section{Introduction}

The coordination chemistry of the uranyl ion $\left(\mathrm{UO}_{2}{ }^{2+}\right)$ has been studied extensively, both experimentally and computationally. It is generally accepted that a maximum of five ligands coordinate with uranyl in the equatorial plane. A few exceptions are the strongly binding carbonate, nitrate, and acetate ions that form complexes in the solid phase and solution where six oxygen atoms coordinate with uranium in the equatorial plane ${ }^{1}$. Infrared multiphoton dissociation (IRMPD) experiments combined with density functional theory (DFT) calculations on tris-nitrate complexes of $\mathrm{UO}_{2}{ }^{2+}$ were able to show that six-coordinate anion species can also be produced in the gas phase $^{2}$. In contrast, recent IRMPD experiments and DFT calculations on tris-carboxylate complexes of $\mathrm{UO}_{2}{ }^{2+}$ with acetate and benzoate showed that two of the acetate and benzoate ligands bind in a bidentate manner, while the third acetate and benzoate are monodentate ${ }^{3}$. These results are more in line with the apparent pentacoordinate preference of the uranyl ion.

Hexacoordination in the equatorial plane of $\mathrm{UO}_{2}{ }^{2+}$ is not known, or expected, for monodentate neutral ligands such as acetone. Recent mass spectrometry experimental work has hinted at the potential of "hypercoordinated" species in which uranyl is coordinated by up to eight acetone ligands ${ }^{4}$. Subsequent computational studies definitively showed that a first coordination shell (or inner-sphere) with six or more acetones is energetically not feasible ${ }^{5}$. The same experiments revealed water-elimination processes, but as the dehydration of acetone is implausible the nature of the dehydration product is unknown ${ }^{4}$. 
Electrospray ionization mass-spectrometry experiments can identify species and reaction products by the mass to charge ratio, but the exact molecular structure of the coordinating ligands is not necessarily resolved. This work describes the culmination of an integrated experimental and computational effort that is able to identify the coordinating ligands and solve both the "hypercoordination" and water-elimination riddles.

\section{Experimental Details}

The uranyl(VI) solutions for electrospray ionization (ESI) were prepared using a stock aqueous acidic solution of ${ }^{238} \mathrm{U}^{\mathrm{VI}} \mathrm{O}_{2}\left(\mathrm{ClO}_{4}\right)_{2}$. The compositions of the ESI solutions were as follows: $180 \mu \mathrm{M} \mathrm{UO}_{2}{ }^{2+} / 0.1 \% \mathrm{H}_{2} \mathrm{O} / 99.9 \% \mathrm{ACO}$ (acetone); $180 \mu \mathrm{M} \mathrm{UO}_{2}{ }^{2+}$ / $0.1 \% \mathrm{H}_{2} \mathrm{O} / 0.2 \%$ DAA (diacetone alcohol) / 99.7\% $\mathrm{d}^{6} \mathrm{ACO}$ (perdeuterated acetone); and $180 \mu \mathrm{M} \mathrm{UO}_{2}{ }^{2+} / 0.1 \% \mathrm{H}_{2} \mathrm{O} / 0.2 \% \mathrm{~d}^{12} \mathrm{DAA}$ (perdeuterated DAA) / 99.7\% ACO. The " $\mathrm{d}$ "" notation indicates the number of deuterium isotopes in the compound. All handling of the uranium solutions ( $>99 \% \mathrm{U}-238)$ was performed in a radiological laboratory. ESI and ion-molecule reactions were studied using an Agilent 6340 Quadrupole Ion Trap Mass Spectrometer (QIT/MS) with the ion source located inside of a radiological containment glove box, as described in detail elsewhere. ${ }^{1,45}$ The sequential multi-stage mass spectrometry $\left(\mathrm{MS}^{\mathrm{n}}\right)$ collision-induced dissociation CID capabilities of the QIT/MS allow for isolation of ions with a particular mass-to-charge ratio, $\mathrm{m} / \mathrm{z}$, followed by resonant variable-energy excitation, which results in multiple energetic collisions of the selected ion with the He bath gas and ultimately in ion decomposition/fragmentation by one or more pathways. CID fragmentation products are determined by mass-selective ion 
ejection from the trap into an electron multiplier detector. The effective ion temperature in the trap prior to CID is estimated as $\sim 300 \mathrm{~K}^{6}$

In high resolution mode the QIT/MS has a detection range of $50-2200 \mathrm{~m} / \mathrm{z}$ and a resolution of $\sim 0.25 \mathrm{~m} / \mathrm{z}$ (full width, half maximum). Mass spectra were acquired in the positive ion accumulation and detection mode using the following typical ESI, desolvation, ion transport/focusing, and ion trapping parameters: nebulizer gas pressure, $12 \mathrm{psi}$; capillary voltage and current, $-4500 \mathrm{~V}, 1.221 \mathrm{nA}$; end plate voltage offset and current, $-500 \mathrm{~V}, 22.5 \mathrm{nA}$; dry gas flow rate, $5 \mathrm{l} / \mathrm{min}$; dry gas temperature, $100{ }^{\circ} \mathrm{C}$; capillary exit, $75 \mathrm{~V}$; skimmer, $29.2 \mathrm{~V}$; octopole 1 and $2 \mathrm{DC}, 11.46 \mathrm{~V}$ and $7.40 \mathrm{~V}$; octopole RF amplitude, 50.0 Vpp; lens 1 and 2, -2.3 V and -77.5 V; trap drive, 49.9. The parameters were somewhat different for selected spectra, where the conditions were optimized to enhance a particular low-intensity species. Solutions were injected into the electrospray capillary via a syringe pump at a rate of $60 \mu \mathrm{L} \mathrm{min}{ }^{-1}$. Nitrogen gas for nebulization and drying in the ion transfer capillary was supplied from the boil-off of a liquid nitrogen dewar. CID experiments were performed using the He buffer gas. The ion tickling voltages ranged between $0.35 \mathrm{~V}$ and $0.50 \mathrm{~V}$ applied for $40 \mathrm{~ms}$; the applied voltage was selected to provide a suitable depletion of the precursor and adequate abundances of the CID products. Pressures in the trap were $\sim 10^{-4}$ Torr helium buffer gas and $\sim 10^{-6}$ Torr background water. ${ }^{7}$ For the preparation of $\left[\mathrm{UO}_{2}(\mathrm{ACO})_{4}\right]^{2+}$ from $\left[\mathrm{UO}_{2}(\mathrm{ACO})_{3}\left(\mathrm{H}_{2} \mathrm{O}\right)\right]^{2+}$, the ACO reagent was introduced from a liquid reservoir into the same gas inlet through which the He buffer gas was injected into the ion trap; the ACO pressure was controlled by a variable leak valve. 
All organic reagents were commercial products with a purity of $99.9 \%$, except for $99 \%$ diacetone alcohol. The isotopic purity of the $\mathrm{d}^{6} \mathrm{ACO}$ was reported as 99.97 atom \% D; that of the $\mathrm{d}^{12} \mathrm{DAA}$ was 98 atom \% D. The ACO introduced into the ion trap as a gas was subjected to freeze-vacuum-thaw cycles of the ACO source liquid prior to use to eliminate volatile impurities.

As DAA is indistinguishable from $(\mathrm{ACO})_{2}$ by mass spectrometry, a key aspect of the experiments was to assure the identity of the ligands by using deuterated $\mathrm{d}^{6} \mathrm{ACO}$ and $\mathrm{d}^{12} \mathrm{DAA}$. The isolated $\quad\left[\mathrm{UO}_{2}(\mathrm{DAA})\left(\mathrm{d}^{6} \mathrm{ACO}\right)_{2}\right]^{2+}, \quad\left[\mathrm{UO}_{2}(\mathrm{DAA})_{2}\left(\mathrm{~d}^{6} \mathrm{ACO}\right)\right]^{2+}$, $\left[\mathrm{UO}_{2}(\mathrm{DAA})_{2}\right]^{2+}$ and $\left[\mathrm{UO}_{2}(\mathrm{DAA})_{3}\right]^{2+}$ complex ions were prepared from the DAA $/ \mathrm{d}^{6} \mathrm{ACO}$ solution. The $\left[\mathrm{UO}_{2}\left(\mathrm{~d}^{11} \mathrm{DAA}\right)(\mathrm{ACO})_{3}\right]^{2+}$ complex ion was prepared from the $\mathrm{d}^{12} \mathrm{DAA} / \mathrm{ACO}$ solution; gas-phase exchange of the alcohol $\mathrm{D}$ atom in $\mathrm{d}^{12} \mathrm{DAA}$ accounts for complete conversion to $\mathrm{d}^{11} \mathrm{DAA}$. The $\left[\mathrm{UO}_{2}(\mathrm{ACO})_{4}\right]^{2+}$ complex ion was prepared using the pure ACO solution: the isolated $\left[\mathrm{UO}_{2}(\mathrm{ACO})_{3}\left(\mathrm{H}_{2} \mathrm{O}\right)\right]^{2+}$ complex ion was exposed to $\sim 10^{-6}$ Torr ACO gas in the ion trap for $500 \mathrm{~ms}$ such that the $\mathrm{H}_{2} \mathrm{O}$ ligand was replaced by the stronger base $\mathrm{ACO}$; the $\left[\mathrm{UO}_{2}(\mathrm{ACO})_{4}\right]^{2+}$ product was then isolated and subjected to CID.

\section{Computational Details}

All calculations were performed using the NWChem computational chemistry software (version 6.1$).{ }^{8}$ Geometry optimizations were performed using density functional theory (DFT) with the local density approximation (LDA) $)^{9,10}$ and the fine grid. Hessians were also calculated with LDA to verify that the structures obtained are minima on the potential energy surface and to provide zero point energy (ZPE) corrections to the 
calculated energies. Single point energy calculations at the LDA optimized geometries were performed using the SSB- ${ }^{11,12}$ functional to account for dispersion effects and at the MP2 level of theory to assess the accuracy of the DFT calculations. All calculations employed the Stuttgart small core relativistic effective core potential (RECP) $)^{13,14,15}$ for uranium and the DFT optimized triple- $\zeta$ plus polarization (TZVP) ${ }^{16}$ basis set for all other atoms $(\mathrm{H}, \mathrm{C}$, and $\mathrm{O})$. Spherical Gaussian basis sets were used for all calculations.

\section{Results and Discussion}

\section{Revealing the compositions of "uranyl acetone" complexes by CID}

Among the enigmatic results of our earlier studies of uranyl acetone complexes prepared by ESI from "pure acetone" was the appearance of dehydration (Equation 1) where the nature of the dehydration product was unknown. ${ }^{4}$

$$
\left[\mathrm{UO}_{2}(\mathrm{ACO})_{4}\right]^{2+} \rightarrow\left[\mathrm{UO}_{2}(\mathrm{ACO})_{4}\left(-\mathrm{H}_{2} \mathrm{O}\right)\right]^{2+}+\mathrm{H}_{2} \mathrm{O}
$$

Dehydration of acetone by CID is implausible, but Shvartsburg and Wilkes ${ }^{17}$ have demonstrated that CID of dipositive metal ion complexes comprising DAA ligands can induce aldol dehydration to produce MOX. As one DAA ligand has the same mass as two ACO ligands, mass identification alone does not distinguish between (DAA) and $(\mathrm{ACO})_{2}$ in coordination complexes. Accordingly, the presence of DAA in purportedly uranyl/ACO complexes could account for the observed dehydration CID processes, with the dehydration products comprising a MOX (mesityl oxide) ligand. 
Another seemingly inexplicable experimental result was the appearance of the apparently "hypercoordinated" uranyl acetone complexes, $\left[\mathrm{UO}_{2}(\mathrm{ACO})_{\mathrm{n}}\right]^{2+}$ where $\mathrm{n}=6,7$ or $8 .^{4}$ A subsequent computational study of uranyl acetone complexes revealed that at most five acetones are accommodated in the inner sphere coordination shell, with secondsphere ACO bound only very weakly ${ }^{5}$. Hydration experiments employing the same conditions as those in which "hypercoordinated" uranyl acetone complexes were produced revealed that only inner sphere coordination complexes are observed ${ }^{7}$. The presence of DAA ligands in the supposedly "hypercoordinated" uranyl acetone complexes could account for the experimental observations; for example, as DAA can exhibit either monodentate or bidentate coordination, a complex assigned as $\left[\mathrm{UO}_{2}(\mathrm{ACO})_{8}\right]^{2+}$ could instead be isobaric $\left[\mathrm{UO}_{2}(\mathrm{DAA})_{4}\right]^{2+}$ or $\left[\mathrm{UO}_{2}(\mathrm{ACO})_{2}(\mathrm{DAA})_{3}\right]^{2+}$ in which the coordination of the uranium metal center is less than eight. Several uranyl complexes comprising normal or deuterium-labeled ACO and/or DAA ligands were prepared and subjected to CID. Comparison of the CID results with those for ESI complexes from pure ACO can provide an assessment of the role of DAA in the dehydration processes, as well as in "hypercoordination" complexes.

In evaluating the CID results, aldol dehydration and dissociation of DAA are considered as possible processes. DAA dehydration to MOX is given by Equation 2a and dissociation to two ACO species by Equation 2b, where deuterium labeling is employed to track the alcohol $\mathrm{H}$-atom in $\mathrm{d}^{11} \mathrm{DAA}-\mathrm{d}^{10} \mathrm{MOX}$ is the product in Equation $2 \mathrm{a}$.

$$
\begin{aligned}
& \mathrm{CD}_{3} \mathrm{C}(\mathrm{O}) \mathrm{CD}_{2} \mathrm{C}(\mathrm{OH})\left(\mathrm{CD}_{3}\right)_{2} \rightarrow \mathrm{CD}_{3} \mathrm{C}(\mathrm{O}) \mathrm{CD}=\mathrm{C}\left(\mathrm{CD}_{3}\right)_{2}+\mathrm{HDO} \\
& \mathrm{CD}_{3} \mathrm{C}(\mathrm{O}) \mathrm{CD}_{2} \mathrm{C}(\mathrm{OH})\left(\mathrm{CD}_{3}\right)_{2} \rightarrow \mathrm{CD}_{3} \mathrm{C}(\mathrm{O}) \mathrm{CD}_{2} \mathrm{H}+\mathrm{CD}_{3} \mathrm{C}(\mathrm{O}) \mathrm{CD}_{3}
\end{aligned}
$$


In CID of coordination complexes such as $\left[\mathrm{UO}_{2}(\mathrm{ACO})_{\mathrm{n}}\right]^{2+}$, the predominant process is typically ligand-elimination: loss of an ACO ligand in this case. If the $\left[\mathrm{UO}_{2}(\mathrm{ACO})_{\mathrm{n}-1}\right]^{2+}$ product is sufficiently under-coordinated, addition of background water in the gas phase can occur to produce $\left[\mathrm{UO}_{2}(\mathrm{ACO})_{\mathrm{n}-1}\left(\mathrm{H}_{2} \mathrm{O}\right)\right]^{2+}$. The results below show ligand elimination and hydration as the dominant processes for elementary uranyl ACO coordination complexes. Other processes reveal the presence of other types of ligands, and more complex fragmentation processes.

The inexplicable phenomena of water-elimination from, and "hypercoordination" in, purportedly uranyl acetone complexes were observed in species produced by ESI of uranyl from supposedly "pure acetone". To explore the nature of these phenomena, gasphase species obtained from ESI of uranyl in "pure acetone" were compared with species prepared in such a manner that the ligand compositions (ACO, DAA, and their deuterated isomers) were known. Throughout the discussion of the experimental results, species in quotation marks refer to those prepared by ESI from "pure acetone", with indeterminate compositions; species identified without quotation marks were prepared as described in the Experimental Details and have the indicated ligand compositions.

In Figure 1 spectra are shown for uranyl complexes in which the presumed coordination number is four: " $\left[\mathrm{UO}_{2}(\mathrm{ACO})_{4}\right]^{2+"}$ prepared by ESI from "pure acetone", $\left[\mathrm{UO}_{2}(\mathrm{ACO})_{4}\right]^{2+},\left[\mathrm{UO}_{2}(\mathrm{DAA})\left(\mathrm{d}^{6} \mathrm{ACO}\right)_{2}\right]^{2+}$ and $\left[\mathrm{UO}_{2}(\mathrm{DAA})_{2}\right]$, where the last three of these were prepared as described in the Experimental Details section. Comparison of the CID spectrum of "[ $\left.\mathrm{UO}_{2}(\mathrm{ACO})_{4}\right]^{2+"}$ (Fig. 1a) with that of $\left[\mathrm{UO}_{2}(\mathrm{ACO})_{4}\right]^{2+}$ clearly reveals that the identification of the former as a uranyl acetone complex is inaccurate. In particular, 
$\left[\mathrm{UO}_{2}(\mathrm{ACO})_{4}\right]^{2+}$ (Fig. 1b) exhibits almost exclusively ACO ligand loss, with rapid addition of background water to hypocoordinated $\left[\mathrm{UO}_{2}(\mathrm{ACO})_{3}\right]^{2+}$ to produce $\left[\mathrm{UO}_{2}(\mathrm{ACO})_{3}\left(\mathrm{H}_{2} \mathrm{O}\right)\right]^{2+}$ according to Equations 3a and 3a'. No $\mathrm{H}_{2} \mathrm{O}$-elimination appears in Fig. $1 \mathrm{~b}$, the absence of which confirms that the precursor ion, $\left[\mathrm{UO}_{2}(\mathrm{ACO})_{4}\right]^{2+}$, is truly the $\left[\mathrm{UO}_{2}(\mathrm{ACO})_{4}\right]^{2+}$ complex. It should be remarked that the small peak in Figure 1(b) that is assigned as $\left[\mathrm{UO}_{2}(\mathrm{ACO})_{5}\right]^{2+}$ results from $\mathrm{ACO}$ addition rather CID since the precursor ions is mass selected for the ion trap. As gaseous ACO was present in the trap for this experiment to prepare pure $\left[\mathrm{UO}_{2}(\mathrm{ACO})_{4}\right]^{2+}$, the precursor ion was presumably regenerated according to Equation 3b, with the result that the apparent CID yields in Figure $1 \mathrm{~b}$ under-represent the contribution from ACO-elimination.

$$
\begin{aligned}
& {\left[\mathrm{UO}_{2}(\mathrm{ACO})_{4}\right]^{2+} \rightarrow\left[\mathrm{UO}_{2}(\mathrm{ACO})_{3}\right]^{2+}+\mathrm{ACO}} \\
& {\left[\mathrm{UO}_{2}(\mathrm{ACO})_{3}\right]^{2+}+\mathrm{H}_{2} \mathrm{O} \rightarrow\left[\mathrm{UO}_{2}(\mathrm{ACO})_{3}\left(\mathrm{H}_{2} \mathrm{O}\right)\right]^{2+}} \\
& {\left[\mathrm{UO}_{2}(\mathrm{ACO})_{3}\right]^{2+}+\mathrm{ACO} \rightarrow\left[\mathrm{UO}_{2}(\mathrm{ACO})_{4}\right]^{2+}}
\end{aligned}
$$

$\mathrm{CID}$ of $\left[\mathrm{UO}_{2}(\mathrm{DAA})\left(\mathrm{d}^{6} \mathrm{ACO}\right)_{2}\right]^{2+}$ (Fig. 1c) resulted almost exclusively in dehydration to produce $\left[\mathrm{UO}_{2}(\mathrm{MOX})(\mathrm{ACO})_{2}\right]^{2+}$ according to Equation 4.

$$
\left[\mathrm{UO}_{2}(\mathrm{DAA})\left(\mathrm{d}^{6} \mathrm{ACO}\right)_{2}\right]^{2+} \rightarrow\left[\mathrm{UO}_{2}(\mathrm{MOX})\left(\mathrm{d}^{6} \mathrm{ACO}\right)_{2}\right]^{2+}+\mathrm{H}_{2} \mathrm{O}
$$

It is evident that $\left[\mathrm{UO}_{2}(\mathrm{DAA})(\mathrm{ACO})_{2}\right]^{2+}$ would account for the appearance of the $\left[\mathrm{UO}_{2}(\mathrm{ACO})_{4}\left(-\mathrm{H}_{2} \mathrm{O}\right)\right]^{2+}$ decomposition product - i.e., $\left[\mathrm{UO}_{2}(\mathrm{MOX})(\mathrm{ACO})_{2}\right]^{2+}-$ from 
" $\left[\mathrm{UO}_{2}(\mathrm{ACO})_{4}\right]^{2+}$ ". The CID spectrum for $\left[\mathrm{UO}_{2}(\mathrm{DAA})_{2}\right]^{2+}$ (Figure 1d) indicates that the predominant process is dehydration as given by Equation 5 .

$$
\left[\mathrm{UO}_{2}(\mathrm{DAA})_{2}\right]^{2+} \rightarrow\left[\mathrm{UO}_{2}(\mathrm{MOX})(\mathrm{DAA})\right]^{2+}+\mathrm{H}_{2} \mathrm{O}
$$

The CID spectrum of $\left[\mathrm{UO}_{2}(\mathrm{DAA})_{2}\right]^{2+}$ also includes smaller but distinct peaks corresponding to $\left[\mathrm{UO}_{2}(\mathrm{DAA})_{2}\left(\mathrm{H}_{2} \mathrm{O}\right)\right]^{2+}$ and $\left[\mathrm{UO}_{2}(\mathrm{MOX})\right]^{+}$, which do not appear in the " $\left[\mathrm{UO}_{2}(\mathrm{ACO})_{4}\right]^{2+,} \mathrm{CID}$ mass spectrum. We thus conclude that " $\left[\mathrm{UO}_{2}(\mathrm{ACO})_{4}\right]^{2+}$ " produced by ESI from "pure acetone" is primarily comprised of $\left[\mathrm{UO}_{2}(\mathrm{ACO})_{4}\right]^{2+}$ and $\left[\mathrm{UO}_{2}(\mathrm{DAA})(\mathrm{ACO})_{2}\right]^{2+}$.

The source of DAA ligands in complexes prepared from purportedly pure ACO is uncertain. Although the coupling of two ACO ligands in gas-phase uranyl complexes is a feasible source of DAA, perhaps a more plausible source is DAA as an inherent "impurity" in acetone, ${ }^{18,19}$ the concentration of which should be enhanced upon the addition of acidic aqueous uranyl solution to acetone. ${ }^{20}$ The yields of DAA complexes from ESI of acetone solutions to which $0.2 \%$ DAA or $\mathrm{d}^{12} \mathrm{DAA}$ had been added suggest that a concentration of $\sim 0.1 \%$ DAA in acetone would be adequate to account for the observed ESI yield of $\left[\mathrm{UO}_{2}(\mathrm{DAA})(\mathrm{ACO})_{2}\right]^{2+}$, as well as the other DAA complexes discussed below. The appearance of DAA in ESI complexes at such low solution concentrations is attributed to the high basicity of DAA, and its ability to exhibit bidentate coordination.

Having established the presence of DAA in " $\left[\mathrm{UO}_{2}(\mathrm{ACO})_{4}\right]^{2+"}$, it could be presumed that DAA ligands appear in other purportedly uranyl acetone complexes and 
could account for the appearance of dehydration and "hypercoordination". The presence of DAA in "[ $\left.\mathrm{UO}_{2}(\mathrm{ACO})_{5}\right]^{2+,}$ produced by ESI from "pure acetone" is consistent with the CID results shown in Figure 2. In contrast to $\left[\mathrm{UO}_{2}(\mathrm{ACO})_{4}\right]^{2+}$, there is no convenient route to produce pure gas-phase $\left[\mathrm{UO}_{2}(\mathrm{ACO})_{5}\right]^{2+}$, which may not be stable in the ion trap under the experimental conditions; accordingly, only the two DAA-substituted complexes with atomic compositions corresponding to " $\left[\mathrm{UO}_{2}(\mathrm{ACO})_{5}\right]^{2+"}$ were studied. The dominant CID pathways for $\left[\mathrm{UO}_{2}\left(\mathrm{~d}^{11} \mathrm{DAA}\right)(\mathrm{ACO})_{3}\right]^{2+}$ (Figure $2 \mathrm{~b}$ ) are given by Equations $6 a-6 c$, where $6 a^{\prime}$ is hydration of the ligand-loss product in $6 a$; minor channels resulted in the monopositive MOX products identified in Figure $2 b$.

$$
\begin{aligned}
& {\left[\mathrm{UO}_{2}\left(\mathrm{~d}^{11} \mathrm{DAA}\right)(\mathrm{ACO})_{3}\right]^{2+} \rightarrow\left[\mathrm{UO}_{2}\left(\mathrm{~d}^{11} \mathrm{DAA}\right)(\mathrm{ACO})_{2}\right]^{2+}+\mathrm{ACO}} \\
& {\left[\mathrm{UO}_{2}\left(\mathrm{~d}^{11} \mathrm{DAA}\right)(\mathrm{ACO})_{2}\right]^{2+}+\mathrm{H}_{2} \mathrm{O} \rightarrow\left[\mathrm{UO}_{2}\left(\mathrm{~d}^{11} \mathrm{DAA}\right)(\mathrm{ACO})_{2}\left(\mathrm{H}_{2} \mathrm{O}\right)\right]^{2+}} \\
& {\left[\mathrm{UO}_{2}\left(\mathrm{~d}^{11} \mathrm{DAA}\right)(\mathrm{ACO})_{3}\right]^{2+} \rightarrow\left[\mathrm{UO}_{2}\left(\mathrm{~d}^{6} \mathrm{ACO}\right)(\mathrm{ACO})_{3}\right]^{2+}+\mathrm{d}^{5} \mathrm{ACO}} \\
& {\left[\mathrm{UO}_{2}\left(\mathrm{~d}^{11} \mathrm{DAA}\right)(\mathrm{ACO})_{3}\right]^{2+} \rightarrow\left[\mathrm{UO}_{2}\left(\mathrm{~d}^{10} \mathrm{MOX}\right)(\mathrm{ACO})_{2}\right]^{2+}+\mathrm{ACO}+\mathrm{HDO}}
\end{aligned}
$$

The appearance of exclusively $\mathrm{d}^{10} \mathrm{MOX}$ with elimination of HDO (Equation 6c) is consistent with the presumed composition of $\mathrm{d}^{11} \mathrm{DAA}$ as $\mathrm{CD}_{3}(\mathrm{O}) \mathrm{CD}_{2} \mathrm{C}(\mathrm{OH})\left(\mathrm{CD}_{3}\right)_{2}$ (Equation 2a). The exclusive appearance of $\left[\mathrm{UO}_{2}\left(\mathrm{~d}^{6} \mathrm{ACO}\right)(\mathrm{ACO})_{3}\right]^{2+}$ with $\mathrm{d}^{5} \mathrm{ACO}$ elimination (Equation 6b) indicates a particular coordination to the uranium metal center during DAA dissociation (Equation 2b). Some CID pathways seen for $\left[\mathrm{UO}_{2}(\mathrm{DAA})_{2}\left(\mathrm{~d}^{6} \mathrm{ACO}\right)\right]^{2+}$ in Figure $2 \mathrm{c}$ are given by Equations $7 \mathrm{a}-7 \mathrm{~d}$, where Equation $7 \mathrm{a}$ ' is hydration of the ligand-loss product from Equation $7 \mathrm{a}$. 


$$
\begin{aligned}
& {\left[\mathrm{UO}_{2}(\mathrm{DAA})_{2}\left(\mathrm{~d}^{6} \mathrm{ACO}\right)\right]^{2+} \rightarrow\left[\mathrm{UO}_{2}(\mathrm{DAA})_{2}\right]^{2+}+\mathrm{d}^{6} \mathrm{ACO}} \\
& {\left[\mathrm{UO}_{2}(\mathrm{DAA})_{2}\right]^{2+}+\mathrm{H}_{2} \mathrm{O} \rightarrow\left[\mathrm{UO}_{2}(\mathrm{DAA})_{2}\left(\mathrm{H}_{2} \mathrm{O}\right)\right]^{2+}} \\
& {\left[\mathrm{UO}_{2}(\mathrm{DAA})_{2}\left(\mathrm{~d}^{6} \mathrm{ACO}\right)\right]^{2+} \rightarrow\left[\mathrm{UO}_{2}(\mathrm{DAA})(\mathrm{ACO})\left(\mathrm{d}^{6} \mathrm{ACO}\right)\right]^{2+}+\mathrm{ACO}} \\
& {\left[\mathrm{UO}_{2}(\mathrm{DAA})_{2}\left(\mathrm{~d}^{6} \mathrm{ACO}\right)\right]^{2+} \rightarrow\left[\mathrm{UO}_{2}(\mathrm{DAA})(\mathrm{MOX})\right]^{2+}+\mathrm{d}^{6} \mathrm{ACO}+\mathrm{H}_{2} \mathrm{O}} \\
& {\left[\mathrm{UO}_{2}(\mathrm{DAA})_{2}\left(\mathrm{~d}^{6} \mathrm{ACO}\right)\right]^{2+} \rightarrow\left[\mathrm{UO}_{2}(\mathrm{DAA})(\mathrm{MOX})\left(\mathrm{d}^{6} \mathrm{ACO}\right)\right]^{2+}+\mathrm{H}_{2} \mathrm{O}} \\
& {\left[\mathrm{UO}_{2}(\mathrm{DAA})_{2}\left(\mathrm{~d}^{6} \mathrm{ACO}\right)\right]^{2+}+\mathrm{H}_{2} \mathrm{O} \rightarrow\left[\mathrm{UO}_{2}(\mathrm{DAA})(\mathrm{DAA}-\mathrm{H})\right]^{+}+\mathrm{d}^{6} \mathrm{ACO}+\left[\mathrm{H}_{3} \mathrm{O}\right]^{+}}
\end{aligned}
$$

The postulated $\left[\mathrm{H}_{3} \mathrm{O}\right]^{+}$product ion in Equation $7 \mathrm{e}$ would not be detected due to the lowmass cutoff of the mass spectrometer. The $\left[\mathrm{UO}_{2}(\mathrm{MOX})(\mathrm{ACO})_{2}\right]^{2+}$ product in Figure $2 \mathrm{a}$ corresponds to $\left[\mathrm{UO}_{2}\left(\mathrm{~d}^{10} \mathrm{MOX}\right)(\mathrm{ACO})_{2}\right]^{2+}$ in Figure $2 \mathrm{~b}$ and $\left[\mathrm{UO}_{2}(\mathrm{DAA})(\mathrm{MOX})\right]^{2+}$ in Figure 2c, indicating that " $\left[\mathrm{UO}_{2}(\mathrm{ACO})_{5}\right]^{2+"}$ " prepared from "pure acetone" comprises $\left[\mathrm{UO}_{2}(\mathrm{DAA})(\mathrm{ACO})_{3}\right]^{2+}$ and/or $\left[\mathrm{UO}_{2}(\mathrm{DAA})_{2}(\mathrm{ACO})\right]^{2+}$. The comparable yields in Figures $2 \mathrm{a}$ and $2 \mathrm{c}$ of $[\mathrm{MOX}+\mathrm{H}]^{+}$and $\left[\mathrm{UO}_{2}(\mathrm{MOX})\right]^{+}$— which result from CID processes which are less obvious than those presented in Equations $7 \mathrm{a}-7 \mathrm{~d}-$ suggest a significant amount of $\left[\mathrm{UO}_{2}(\mathrm{DAA})_{2}(\mathrm{ACO})\right]^{2+}$ in " $\left[\mathrm{UO}_{2}(\mathrm{ACO})_{5}\right]^{2+"}$. As all of the peaks in the " $\left[\mathrm{UO}_{2}(\mathrm{ACO})_{5}\right]^{2+}$ " CID spectrum can be attributed to the DAA-containing complexes, it is feasible that little, if any, of the true penta-acetone complex, $\left[\mathrm{UO}_{2}(\mathrm{ACO})_{5}\right]^{2+}$, is present in " $\left[\mathrm{UO}_{2}(\mathrm{ACO})_{5}\right]^{2+}$. Both direct ligand loss (Equations 6a and 7a) and retro-aldol DAA dissociation followed by ligand loss (Equations $6 \mathrm{~b}$ and $7 \mathrm{~b}$ ) could account for the observed elimination of ACO from " $\left[\mathrm{UO}_{2}(\mathrm{ACO})_{5}\right]^{2+\text { ", }}$

The appearance of " $\left[\mathrm{UO}_{2}(\mathrm{ACO})_{6}\right]^{2+}$ " from "pure acetone", as seen in Figure 3a,

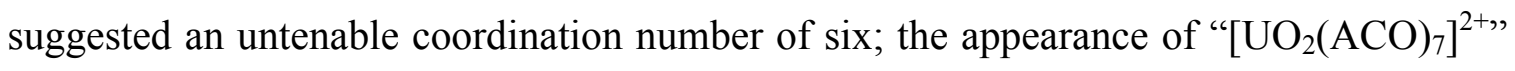
and " $\left[\mathrm{UO}_{2}(\mathrm{ACO})_{8}\right]^{2+,, 3}$ were even more problematic". With the knowledge that DAA 
was present in other complexes, DAA ligands also accounted for these apparently "hypercoordinated" complexes. In Figure 3 are shown the CID spectra for " $\left[\mathrm{UO}_{2}(\mathrm{ACO})_{6}\right]^{2+»}$ and $\left[\mathrm{UO}_{2}(\mathrm{DAA})_{3}\right]^{2+}$. The CID processes in Figure $3 \mathrm{~b}$ are given by Equations $8 \mathrm{a}$ and $8 \mathrm{~b}$, where (DAA-H) ${ }^{-}$is an alkoxide formed by deprotonation of DAA. Hydration of $[\mathrm{MOX}+\mathrm{H}]^{+}$from Equation $8 \mathrm{~b}$ results in $\left[(\mathrm{MOX}+\mathrm{H})\left(\mathrm{H}_{2} \mathrm{O}\right)\right]^{+}$.

$$
\begin{aligned}
& {\left[\mathrm{UO}_{2}(\mathrm{DAA})_{3}\right]^{2+} \rightarrow\left[\mathrm{UO}_{2}(\mathrm{DAA})_{2}(\mathrm{ACO})\right]^{2+}+\mathrm{ACO}} \\
& {\left[\mathrm{UO}_{2}(\mathrm{DAA})_{3}\right]^{2+} \rightarrow\left[\mathrm{UO}_{2}(\mathrm{DAA})(\mathrm{DAA}-\mathrm{H})\right]^{+}+[\mathrm{MOX}+\mathrm{H}]^{+}+\mathrm{H}_{2} \mathrm{O}}
\end{aligned}
$$

It was possible to prepare only a small amount of $\left[\mathrm{UO}_{2}(\mathrm{DAA})_{2}\left(\mathrm{~d}^{6} \mathrm{ACO}\right)_{2}\right]^{2+}$ to isolate for CID. The resulting CID spectrum was poor quality, but the processes in Equations 9a and $9 \mathrm{~b}$ were identified; a small peak corresponding to $\left[\mathrm{UO}_{2}(\mathrm{OH})(\mathrm{DAA})(\mathrm{ACO})\right]^{+}$also appeared, but the process leading to this product is speculative.

$$
\begin{aligned}
& {\left[\mathrm{UO}_{2}(\mathrm{DAA})_{2}\left(\mathrm{~d}^{6} \mathrm{ACO}\right)_{2}\right]^{2+} \rightarrow\left[\mathrm{UO}_{2}(\mathrm{DAA})(\mathrm{ACO})\left(\mathrm{d}^{6} \mathrm{ACO}\right)_{2}\right]^{2+}+\mathrm{ACO}} \\
& {\left[\mathrm{UO}_{2}(\mathrm{DAA})_{2}\left(\mathrm{~d}^{6} \mathrm{ACO}\right)_{2}\right]^{2+} \rightarrow\left[\mathrm{UO}_{2}(\mathrm{DAA})_{2}\left(\mathrm{~d}^{6} \mathrm{ACO}\right)\right]^{2+}+\mathrm{d}^{6} \mathrm{ACO}}
\end{aligned}
$$

The appearance of monopositive MOX products from " $\left[\mathrm{UO}_{2}(\mathrm{ACO})_{6}\right]$ " indicate the presence of a DAA ligand in some complexes. Substantial retro-aldol dissociation of DAA to two ACO, concomitant with ACO ligand loss, appeared in the CID of both $\left[\mathrm{UO}_{2}(\mathrm{DAA})_{3}\right]^{2+}$ (Equation 8a) and $\left[\mathrm{UO}_{2}(\mathrm{DAA})_{2}\left(\mathrm{~d}^{6} \mathrm{ACO}\right)_{2}\right]$ (Equation 9a). The abundance of the ACO-loss product from $\left[\mathrm{UO}_{2}(\mathrm{DAA})_{3}\right]^{2+}$ was less than that from " $\left[\mathrm{UO}_{2}(\mathrm{ACO})_{6}\right]^{2+"}$, indicating the presence in the latter of $\left[\mathrm{UO}_{2}(\mathrm{DAA})_{2}(\mathrm{ACO})_{2}\right]^{2+}$ and/or 
$\left[\mathrm{UO}_{2}(\mathrm{DAA})(\mathrm{ACO})_{4}\right]^{2+}$. No dipositive uranyl MOX complexes appeared for " $\left[\mathrm{UO}_{2}(\mathrm{ACO})_{6}\right]^{2+",}, \quad\left[\mathrm{UO}_{2}(\mathrm{DAA})_{3}\right]^{2+}$ or $\left[\mathrm{UO}_{2}(\mathrm{DAA})_{2}\left(\mathrm{~d}^{6} \mathrm{ACO}\right)_{2}\right]^{2+}$, rather only monopositive MOX products such as seen in Figure 3. Aldol dehydration of DAA to MOX in high-coordination complexes evidently results in charge separation with elimination of protonated MOX; deprotonation of DAA results in an alkoxide ligand such that the U(VI) oxidation state is retained. The key conclusion is that "hypercoordinated" "[ $\left.\mathrm{UO}_{2}(\mathrm{ACO})_{6}\right]$ " is instead a complex which comprises one or more DAA ligands, and does not comprise weakly bound outer-sphere ACO molecules. We further infer that the previously identified " $\left[\mathrm{UO}_{2}(\mathrm{ACO})_{7}\right]$ " and " $\left[\mathrm{UO}_{2}(\mathrm{ACO})_{8}\right]$ " complexes prepared from ESI of "pure acetone" ${ }^{4}$ are not "hypercoordinated" but rather comprise DAA ligands, some of which may be monodentate.

\section{A DFT study of uranyl DAA complexes-comparing experiment and theory}

Geometries and raw energetic information is available in the Supplementary Information. Binding energies for successive ACO and DAA additions are presented in Figures 4 and 5 using the lowest energy structure found for any given compound. Figure 4 displays binding energies obtained at the DFT level of theory with the SSB-D functional, and Figure 5 displays the binding energies obtained at the MP2 level of theory. Arrows going down the left side of the formation diagram correspond to addition of an acetone ligand (Equation 10), and arrows going down the right side correspond to DAA addition (Equation 11). Arrows from left to right correspond to acetone addition and dimerization (Equation 12). 


$$
\begin{aligned}
& {\left[\mathrm{UO}_{2}(\mathrm{ACO})_{\mathrm{n}}(\mathrm{DAA})_{\mathrm{m}}\right]^{2+}+\mathrm{ACO} \rightarrow\left[\mathrm{UO}_{2}(\mathrm{ACO})_{\mathrm{n}+1}(\mathrm{DAA})_{\mathrm{m}}\right]^{2+}} \\
& {\left[\mathrm{UO}_{2}(\mathrm{ACO})_{\mathrm{n}}(\mathrm{DAA})_{\mathrm{m}}\right]^{2+}+\mathrm{DAA} \rightarrow\left[\mathrm{UO}_{2}(\mathrm{ACO})_{\mathrm{n}}(\mathrm{DAA})_{\mathrm{m}+1}\right]^{2+}} \\
& {\left[\mathrm{UO}_{2}(\mathrm{ACO})_{\mathrm{n}}(\mathrm{DAA})_{\mathrm{m}}\right]^{2+}+\mathrm{ACO} \rightarrow\left[\mathrm{UO}_{2}(\mathrm{ACO})_{\mathrm{n}-1}(\mathrm{DAA})_{\mathrm{m}+1}\right]^{2+}}
\end{aligned}
$$

Compared to the MP2 binding energies, the SSB-D functional results in a slight over-binding of many of the acetone additions. The largest over-binding effects occur for the first acetone addition. When the number of oxygens available for coordination to uranyl reaches 4 or more, SSB-D consistently over-binds the acetone additions albeit to a lesser degree than is observed with unsaturated complexes. Conversely, SSB-D predicts under-binding of DAA with respect to MP2 in every case. Despite these differences in binding energy, both SSB-D and MP2 energies are relatively close and the general trends are the same.

Addition of either ACO or DAA is an exoergic process with the DAA addition thermodynamically favored. The increased exoergicity of the DAA additions with respect to ACO additions is a result of DAA forming two $\mathrm{U}-\mathrm{O}$ bonds rather than one $\mathrm{U}-\mathrm{O}$ bond. The DAA binding energy drops off faster than the ACO binding energy since two coordination sites are usually used with each DAA addition, and uranyl becomes saturated much faster by DAA additions than by ACO additions. Eventually, the bulky nature of DAA forces one or more DAA ligand to be monodentate rather than bidentate. This can be seen in Table 1. The total number of coordinating oxygens in the equatorial plane never exceeds 5. All ligand oxygens bind to uranyl when the total number of oxygens from both ACO and DAA ligands is less than five. However, if the number of ligand oxygens exceeds 5, then one or more DAA ligands becomes monodentate. 
Correlation of the number of coordinating oxygens to the binding energy shows that the binding energies for the formation of "hypercoordinated" species is on the order of $10-$ $15 \mathrm{kcal} / \mathrm{mol}$ for acetone additions or $\sim 30 \mathrm{kcal} / \mathrm{mol}$ (SSB-D) for DAA additions. Even a monodentate DAA still has a significantly exoergic binding energy as long as the precursor ion has no more than four coordinating oxygens in the equatorial plane.

Acetone additions result in one of two products. One product is simply an acetone ligand added to the precursor ion (Equation 10) and the other product undergoes dimerization to produce a DAA ligand when the acetone is added (Equation 12). In nearly every case, simple acetone addition results in the thermodynamically favored product based on calculated energies, e.g. 1 DAA addition is energetically equivalent to $\sim 1.5 \mathrm{ACO}$ additions for unsaturated precursors. The difference in energy between the two products is on the order of $15-20 \mathrm{kcal} / \mathrm{mol}$ when uranyl is unsaturated. Once the equatorial coordination number reaches five, the competing reactions become nearly isoenergetic with an energy difference of $\sim 3 \mathrm{kcal} / \mathrm{mol}$. However, "hypercoordinated" products require the presence of DAA ligands since ACO addition beyond 6 ligands is an endoergic process 5 .

Calculated DFT/SSB-D and MP2 (in parentheses) $\Delta \mathrm{E}_{\text {reaction }}$ for CID processes are shown in Table 2. Below the energies is an indication if the reaction is observed experimentally and whether it is a major or minor product. Calculations for the formation of the monocationic $\mathrm{H}_{2} \mathrm{O}$ loss products are beyond the scope of this work. MOX product formation, formed by dehydration of a DAA ligand, is always an endoergic process. The lowest energy process corresponding to MOX production is from the $\left[\mathrm{UO}_{2}(\mathrm{DAA})_{3}\right]^{2+}$ precursor, but the observed product is the monocationic species. The 
dicationic $\mathrm{MOX}$ product from the $\left[\mathrm{UO}_{2}(\mathrm{DAA})_{3}\right]^{2+}$ precursor is not experimentally observed. Contrary to thermodynamic predictions, the most prevalent dicationic products correspond to the MOX products that have the highest calculated $\Delta \mathrm{E}_{\text {reaction }}$ $\left[\mathrm{UO}_{2}(\mathrm{DAA})_{2}\right]^{2+}$ and $\left[\mathrm{UO}_{2}(\mathrm{ACO})_{2}(\mathrm{DAA})_{1}\right]^{2+}$. Since the formation of these products cannot be explained by thermodynamics, their observation may be driven by kinetics. The formation of MOX products may also be related to the equatorial coordination number. The precursor ions for the two cases that lead to large quantities of dicationic MOX products have an equatorial coordination number less than five.

Other dicationic products are the result of ACO loss either by ACO ligand loss (Equation 13) or by DAA decomposition with loss of ACO (Equation 14).

$$
\begin{aligned}
& {\left[\mathrm{UO}_{2}(\mathrm{ACO})_{\mathrm{n}}(\mathrm{DAA})_{\mathrm{m}}\right]^{2+} \rightarrow\left[\mathrm{UO}_{2}(\mathrm{ACO})_{\mathrm{n}-1}(\mathrm{DAA})_{\mathrm{m}}\right]^{2+}+\mathrm{ACO}} \\
& {\left[\mathrm{UO}_{2}(\mathrm{ACO})_{\mathrm{n}}(\mathrm{DAA})_{\mathrm{m}}\right]^{2+} \rightarrow\left[\mathrm{UO}_{2}(\mathrm{ACO})_{\mathrm{n}+1}(\mathrm{DAA})_{\mathrm{m}-1}\right]^{2+}+\mathrm{ACO}}
\end{aligned}
$$

In the case of $\left[\mathrm{UO}_{2}(\mathrm{DAA})_{3}\right]^{2+}$ and $\left[\mathrm{UO}_{2}(\mathrm{DAA})_{2}\right]^{2+}$, there are no ACO ligands, so loss of ACO must occur according to Equation 14. Decomposition of $\left[\mathrm{UO}_{2}(\mathrm{DAA})_{2}\right]^{2+}$ is a highly endoergic process ( $\Delta \mathrm{E}_{\text {reaction }}$ is $\sim 40 \mathrm{kcal} / \mathrm{mol}$ ), so it is not surprising that no product is observed. Likewise, ACO loss according to either Equation 13 or Equation 14 for the $\left[\mathrm{UO}_{2}(\mathrm{ACO})_{2}(\mathrm{DAA})_{1}\right]^{2+}$ precursor are also highly endoergic processes, and no product corresponding to ACO loss is observed. Experimentally, two of the precursor ions, $\left[\mathrm{UO}_{2}(\mathrm{ACO})_{1}(\mathrm{DAA})_{2}\right]^{2+}$ and $\left[\mathrm{UO}_{2}(\mathrm{ACO})_{3}(\mathrm{DAA})_{1}\right]^{2+}$, substantially favor the ACO ligand loss mechanism (Equation 13). SSB-D reaction energies indicate that the ACO ligand loss mechanism is less favorable thermodynamically, but the processes for both 
mechanisms are within $\sim 5 \mathrm{kcal} / \mathrm{mol}$ of each other. Both of the precursor ions have an equatorial coordination number of 5. While ACO loss by either mechanism reduces the equatorial coordination number to 4 (a less favorable situation), ACO loss coupled with DAA decomposition may have a higher barrier since the bidentate nature of DAA is lost in this process. Experimentally, both species with an equatorial coordination number less than five, $\left[\mathrm{UO}_{2}(\mathrm{DAA})_{2}\right]^{2+}$ and $\left[\mathrm{UO}_{2}(\mathrm{ACO})_{2}(\mathrm{DAA})_{1}\right]^{2+}$, form no ACO loss products by either mechanism. This indicates that a threshold of five coordinating oxygens is needed for these processes to occur under the experimental conditions.

Other possible CID products involve the loss of a DAA ligand. In no case was this observed experimentally. The energy needed to lose DAA is usually quite substantial; sometimes up to $100 \mathrm{kcal} / \mathrm{mol}$ may be needed. Furthermore, DAA loss would reduce the equatorial coordination number by two in unsaturated complexes. This is not likely to occur since uranyl favors an equatorial coordination number of 5 .

The final CID product considered in this study is the formation of an alkoxide ligand from DAA. This process is illustrated in Equation 15.

$\left[\mathrm{UO}_{2}(\mathrm{ACO})_{\mathrm{n}}(\mathrm{DAA})_{\mathrm{m}}\right]^{2+} \rightarrow\left[\mathrm{UO}_{2}(\mathrm{ACO})_{\mathrm{n}}(\mathrm{DAA})_{\mathrm{m}-2}(\mathrm{DAA}-\mathrm{H})\right]^{+}+[\mathrm{MOX}+\mathrm{H}]^{+}+\mathrm{H}_{2} \mathrm{O}$

For alkoxide formation to occur, at least two DAA ligands must be present in the precursor ion. This process also involves formation of MOX which, when protonated, leaves the complex. The only major alkoxide product corresponds to the $\left[\mathrm{UO}_{2}(\mathrm{DAA})_{3}\right]^{2+}$ precursor. The $\left[\mathrm{UO}_{2}(\mathrm{DAA})_{3}\right]^{2+}$ precursor has six ligand oxygens available for 
coordination to uranyl, but one of the DAA ligands is monodentate to cap the equatorial coordination number at 5 . This precursor also exhibits no dicationic product formation for MOX ligand formation and water loss. The low $\Delta \mathrm{E}_{\text {reaction }}$ coupled with the uncoordinated oxygen may facilitate the further decomposition of the precursor to the alkoxide product, thus explaining the lack of a dicationic MOX product for the $\left[\mathrm{UO}_{2}(\mathrm{DAA})_{3}\right]^{2+}$ precursor ion.

\section{Conclusion}

Both CID experiments and computational results indicate that diacetone alcohol (DAA) is responsible for the apparent hypercoordination of uranyl. DAA binds more strongly than acetone to uranyl, partly because of its capacity to be a bidentate ligand. When the number of coordinating oxygens in the equatorial plane is less than five, DAA always adopts a bidentate arrangement. Since the number of coordinating oxygens never exceeds five, additional DAA ligands adopt a monodentate configuration that leads to the apparent hypercoordination of uranyl. In CID experiments, presence of products with a mesityl oxide ligand (MOX) is observed. MOX is the result of dehydration of DAA. Since MOX products are observed even when the precursor ion is prepared using "pure" acetone, dimerization to form DAA must occur. Similarity between CID spectra with $\left[\mathrm{UO}_{2}(\mathrm{ACO})_{6}\right]^{2+}$ and $\left[\mathrm{UO}_{2}(\mathrm{DAA})_{3}\right]^{2+}$ further confirm that acetone dimerizes to form DAA.

Computational results together with isotopic labeling allow for some degree of understanding of the CID spectra. Five processes were proposed and four of these were observed. Loss of a DAA ligand is never observed due to the large magnitude of the binding energy of DAA to uranyl. Loss of acetone is observed and can occur either by 
loss of an acetone ligand or by decomposition of DAA to form two acetones, one of which dissociates from uranyl. Isotopic labeling of either DAA or acetone allows for a distinction between these two processes. For ACO loss to occur by either process, there must be 5 coordinating oxygens in the equatorial plane. Simple acetone ligand loss is largely favored over DAA decomposition if there are exactly five coordinating oxygens and no additional oxygens from monodentate DAA. Products with a MOX ligand are also produced, but the thermodynamically favored MOX products found in the computational study are not observed experimentally. Rather, these products lose $[\mathrm{MOX}+\mathrm{H}]^{+}$to form an alkoxide ligand. Alkoxide product formation is favored over MOX product formation when the equatorial plane is saturated and at least one DAA adopts a monodentate configuration.

\section{Acknowledgements}

This research was sponsored by the U.S. Department of Energy, Office of Basic Energy Sciences, Heavy Element Chemistry Program at LBNL under Contract No. DE-AC0205CH11231. Research also was performed in part using the Molecular Science Computing Facility (MSCF) in the William R. Wiley Environmental Molecular Sciences Laboratory, a National scientific user facility sponsored by the U.S. Department of Energy's Office of Biological and Environmental Research and located at the Pacific Northwest National Laboratory, operated for the Department of Energy by Battelle. Funding has been provided by Iowa State University and an NSF grant for petascale applications. 
Figure 1. CID product spectra for precursor ions (identified in boxes) with an equatorial coordination number of 4 . Spectrum (a) is for the species with $\mathrm{m} / \mathrm{z}=251$, which corresponds to $\left[\mathrm{UO}_{2}(\mathrm{ACO})_{4}\right]^{2+}$, produced from nominally "pure acetone". Spectra (b), (c) and (d) are for the species with the same atomic composition as (a), but with known ligand compositions. Spectrum (b) is for $\left[\mathrm{UO}_{2}(\mathrm{ACO})_{4}\right]^{2+}$, spectrum $(\mathrm{c})$ is for $\left[\mathrm{UO}_{2}(\mathrm{ACO})_{2}(\mathrm{DAA})\right]^{2+}$, and spectrum $(\mathrm{d})$ is for $\left[\mathrm{UO}_{2}(\mathrm{DAA})_{2}\right]^{2+}$. The use of deuterated ACO in (c) enabled definitive ligand identification. The $\left[\mathrm{UO}_{2}(\mathrm{ACO})_{5}\right]^{2+}$ product peak in (b) results not from CID but rather from gas-phase addition of ACO, which was necessarily present in the ion trap to prepare the precursor ion. The species identified as $\left[\mathrm{UO}_{2}(\mathrm{ACO})_{4}\left(-\mathrm{H}_{2} \mathrm{O}\right)\right]^{2+}$ in $(\mathrm{a})$ is revealed to be $\left[\mathrm{UO}_{2}(\mathrm{MOX})(\mathrm{ACO})_{2}\right]^{2+}$ from these results.

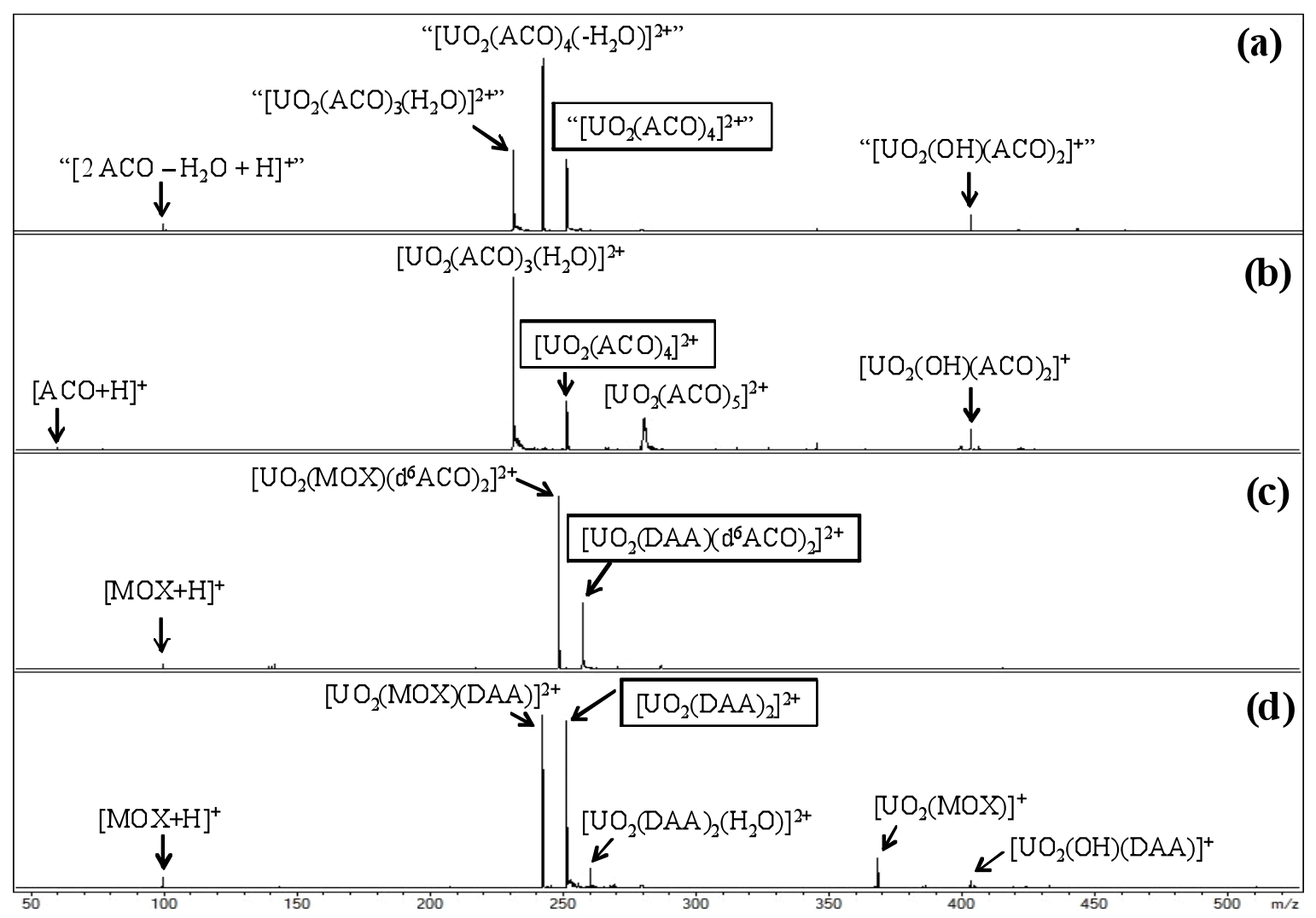


Figure 2. CID product spectra for precursor ions (identified in boxes) with an equatorial coordination number of 5 . Spectrum (a) is for the species with $\mathrm{m} / \mathrm{z}=280$, which corresponds to $\left[\mathrm{UO}_{2}(\mathrm{ACO})_{5}\right]^{2+}$, produced from nominally "pure acetone". Spectra (b) and (c) are for the species with the same atomic composition as (a), but with known ligand compositions. Spectrum (b) is for $\left[\mathrm{UO}_{2}(\mathrm{ACO})_{3}(\mathrm{DAA})\right]^{2+}$ and spectrum (c) is for $\left[\mathrm{UO}_{2}(\mathrm{ACO})(\mathrm{DAA})_{2}\right]^{2+}$. The use of deuterated DAA in (b) and deuterated ACO in (c) enabled definitive ligand identification.

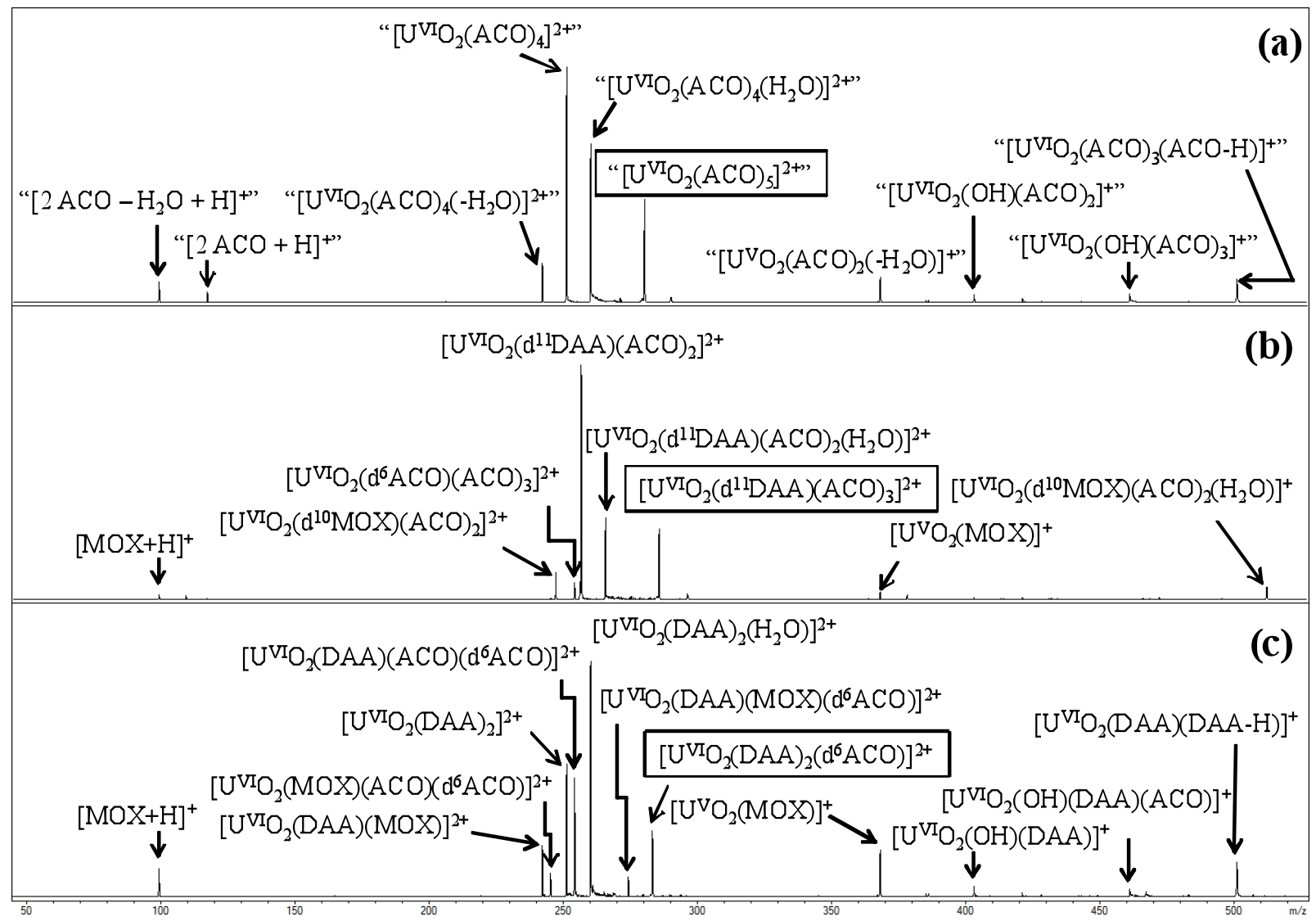


Figure 3. CID product spectra for precursor ions (identified in boxes) with a nominal equatorial coordination number of 6 . Spectrum (a) is for the species with $\mathrm{m} / \mathrm{z}=309$, which corresponds to $\left[\mathrm{UO}_{2}(\mathrm{ACO})_{6}\right]^{2+}$, produced from nominally "pure acetone".

Spectrum (b) is for the species with the same atomic composition as (a), but with the known ligand composition $\left[\mathrm{UO}_{2}(\mathrm{DAA})_{3}\right]^{2+}$.

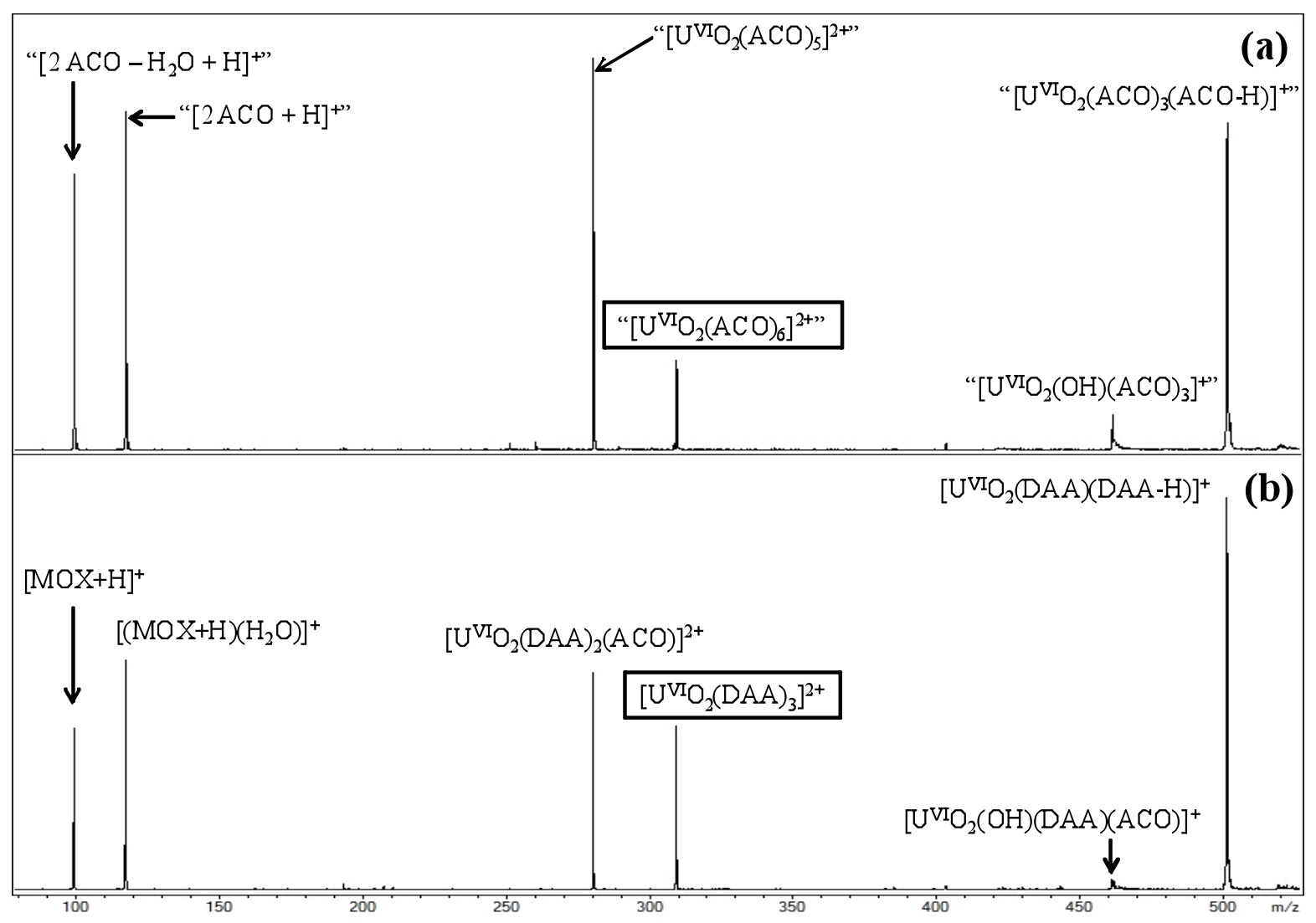


Figure 4. Relative binding energies ( $\mathrm{kcal} / \mathrm{mol}$ ) for acetone additions (down and to the left) and diacetone alcohol additions (down and to the right) according to $\left[\mathrm{UO}_{2}(\mathrm{ACO})_{\mathrm{n}}(\mathrm{DAA})_{\mathrm{m}}\right]^{2+}+\mathrm{ACO} \rightarrow\left[\mathrm{UO}_{2}(\mathrm{ACO})_{\mathrm{n}+1}(\mathrm{DAA})_{\mathrm{m}}\right]^{2+}$ and $\left[\mathrm{UO}_{2}(\mathrm{ACO})_{\mathrm{n}}(\mathrm{DAA})_{\mathrm{m}}\right]^{2+}+\mathrm{DAA} \rightarrow\left[\mathrm{UO}_{2}(\mathrm{ACO})_{\mathrm{n}}(\mathrm{DAA})_{\mathrm{m}+1}\right]^{2+}$, respectively. Going from left to right corresponds to an acetone addition plus dimerization to DAA according to $\left[\mathrm{UO}_{2}(\mathrm{ACO})_{\mathrm{n}}(\mathrm{DAA})_{\mathrm{m}}\right]^{2+}+\mathrm{ACO} \rightarrow\left[\mathrm{UO}_{2}(\mathrm{ACO})_{\mathrm{n}-1}(\mathrm{DAA})_{\mathrm{m}+1}\right]^{2+}$. Binding energies include the zero point energy correction and were calculated with the SSB-D functional at the LDA optimized geometries.

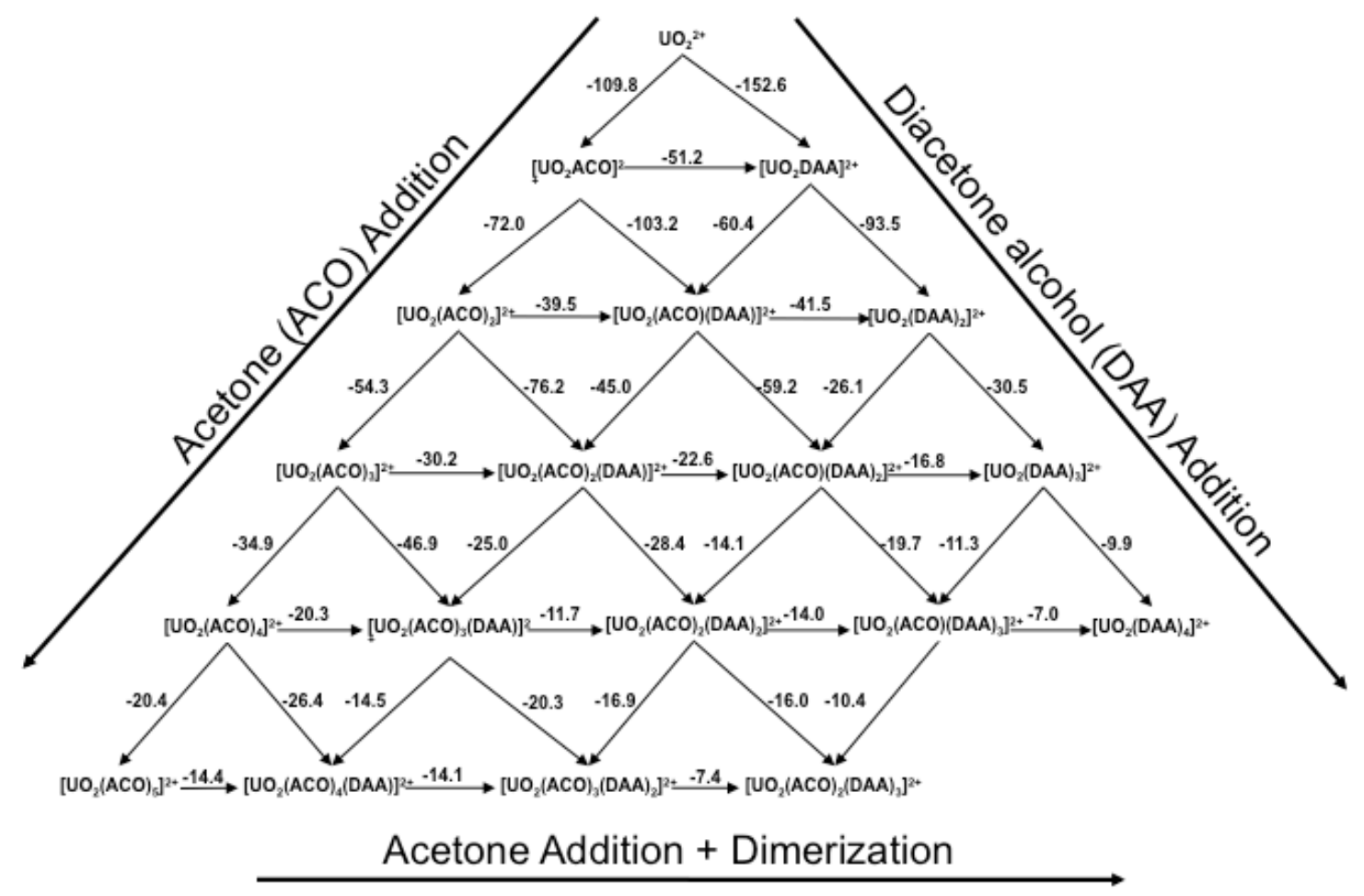


Figure 5. Relative binding energies ( $\mathrm{kcal} / \mathrm{mol}$ ) for acetone additions (down and to the left) and diacetone alcohol additions (down and to the right) according to $\left[\mathrm{UO}_{2}(\mathrm{ACO})_{\mathrm{n}}(\mathrm{DAA})_{\mathrm{m}}\right]^{2+}+\mathrm{ACO} \rightarrow\left[\mathrm{UO}_{2}(\mathrm{ACO})_{\mathrm{n}+1}(\mathrm{DAA})_{\mathrm{m}}\right]^{2+}$ and $\left[\mathrm{UO}_{2}(\mathrm{ACO})_{\mathrm{n}}(\mathrm{DAA})_{\mathrm{m}}\right]^{2+}+\mathrm{DAA} \rightarrow\left[\mathrm{UO}_{2}(\mathrm{ACO})_{\mathrm{n}}(\mathrm{DAA})_{\mathrm{m}+1}\right]^{2+}$, respectively. Going from left to right corresponds to an acetone addition plus dimerization to DAA according to $\left[\mathrm{UO}_{2}(\mathrm{ACO})_{\mathrm{n}}(\mathrm{DAA})_{\mathrm{m}}\right]^{2+}+\mathrm{ACO} \rightarrow\left[\mathrm{UO}_{2}(\mathrm{ACO})_{\mathrm{n}-1}(\mathrm{DAA})_{\mathrm{m}+1}\right]^{2+}$. Binding energies include the zero point energy correction and were calculated using the MP2 level of theory at the LDA optimized geometries.

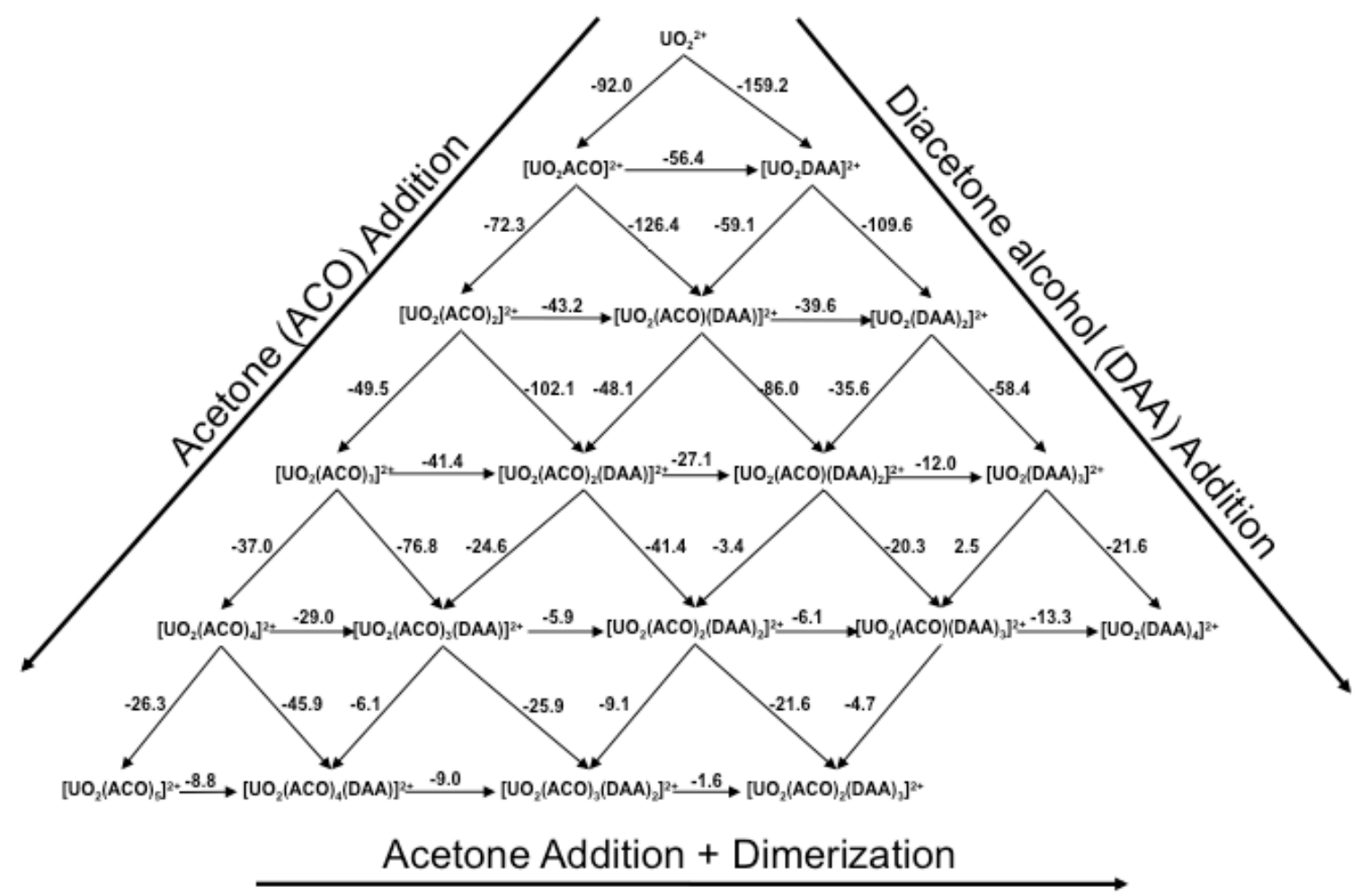


Table 1. Coordination of ligand oxygens with uranium in the equatorial plane. $\mathrm{CN}_{\mathrm{U}}$ $\mathrm{O}(\mathrm{DAA})$ is the number of DAA-oxygen atoms coordinating with uranium and $\mathrm{CN}_{\mathrm{U}}$ $\mathrm{O}$ (equatorial) is the total number of coordinating oxygen atoms in the equatorial plane.

\begin{tabular}{|l|c|c|c|}
\hline Species & $\mathbf{C N}_{\mathrm{U}-\mathbf{O}(\mathbf{D A A})}$ & $\mathbf{C N}_{\mathbf{U}-\text { O(equatorial) }}$ & $\begin{array}{l}\text { Uncoordinated } \\
\text { oxygens }\end{array}$ \\
\hline$\left[\mathrm{UO}_{2}(\mathrm{DAA})_{1}\right]^{2+}$ & 2 & 2 & 0 \\
\hline$\left[\mathrm{UO}_{2}(\mathrm{ACO})_{1}(\mathrm{DAA})_{1}\right]^{2+}$ & 2 & 3 & 0 \\
\hline$\left[\mathrm{UO}_{2}(\mathrm{ACO})_{2}(\mathrm{DAA})_{1}\right]^{2+}$ & 2 & 4 & 0 \\
\hline$\left[\mathrm{UO}_{2}(\mathrm{ACO})_{3}(\mathrm{DAA})_{1}\right]^{2+}$ & 2 & 5 & 0 \\
\hline$\left[\mathrm{UO}_{2}(\mathrm{ACO})_{4}(\mathrm{DAA})_{1}\right]^{2+}$ & 1 & 5 & 0 \\
\hline$\left[\mathrm{UO}_{2}(\mathrm{DAA})_{2}\right]^{2+}$ & 4 & 4 & 2 \\
\hline$\left[\mathrm{UO}_{2}(\mathrm{ACO})_{1}(\mathrm{DAA})_{2}\right]^{2+}$ & 4 & 5 & 1 \\
\hline$\left[\mathrm{UO}_{2}(\mathrm{ACO})_{2}(\mathrm{DAA})_{2}\right]^{2+}$ & 3 & 5 & 2 \\
\hline$\left[\mathrm{UO}_{2}(\mathrm{ACO})_{3}(\mathrm{DAA})_{2}\right]^{2+}$ & 2 & 5 & 3 \\
\hline$\left[\mathrm{UO}_{2}(\mathrm{DAA})_{3}\right]^{2+}$ & 5 & 5 & 3 \\
\hline$\left[\mathrm{UO}_{2}(\mathrm{ACO})_{1}(\mathrm{DAA})_{3}\right]^{2+}$ & 4 & 5 & 5 \\
\hline$\left[\mathrm{UO}_{2}(\mathrm{ACO})_{2}(\mathrm{DAA})_{3}\right]^{2+}$ & 3 & 5 & \\
\hline$\left[\mathrm{UO}_{2}(\mathrm{DAA})_{4}\right]^{2+}$ & 5 & & 5 \\
\hline
\end{tabular}


Table 2. CID results ${ }^{\mathrm{a}}$ and calculated $\Delta \mathrm{E}_{\text {reaction }}(\mathrm{kcal} / \mathrm{mol})$ for the decomposition of precursor species for selected uranyl complexes. The $\Delta \mathrm{E}_{\text {reaction }}$ were calculated with the SSB-D functional and MP2 (in parentheses). All reported energies include the zero point energy correction.

\begin{tabular}{|c|c|c|c|c|c|}
\hline \multirow[t]{2}{*}{ Precursor Species $^{\mathrm{a}}$} & Loss of $\mathrm{H}_{2} \mathrm{O}^{b}$ & \multicolumn{2}{|c|}{ Loss of ACO } & \multirow{2}{*}{$\begin{array}{c}\begin{array}{c}\text { Loss of } \\
\text { DAAA }\end{array} \\
\text { (DAA } \\
\text { ligand loss) }\end{array}$} & \multirow{2}{*}{$\begin{array}{c}\begin{array}{c}\text { Alkoxide } \\
\text { formation } \\
\text { (DAA-H) }\end{array} \\
(\mathrm{MOX}+\mathrm{H})^{+} \\
{\text {and } \mathrm{H}_{2} \mathrm{O} \text { loss }}^{+}\end{array}$} \\
\hline & $(\mathrm{DAA} \rightarrow \mathrm{MOX})$ & $\left(\mathrm{DAA} \rightarrow(\mathrm{ACO})_{2}\right)$ & $\begin{array}{c}\text { (ACO } \\
\text { ligand loss) }\end{array}$ & & \\
\hline$\left[\mathrm{UO}_{2}(\mathrm{DAA})_{3}\right]^{2+}$ & $\begin{array}{c}11.4(13.0) \\
Y\end{array}$ & $\begin{array}{c}16.8(12.0) \\
Y\end{array}$ & -- & $\begin{array}{c}28.4(58.4) \\
\mathrm{N}\end{array}$ & $\begin{array}{c}-6.1(10.8) \\
Y\end{array}$ \\
\hline$\left[\mathrm{UO}_{2}(\mathrm{DAA})_{2}\right]^{2+}$ & $\begin{array}{c}34.9(33.4) \\
Y\end{array}$ & $\begin{array}{c}41.5(39.6) \\
\mathrm{N}\end{array}$ & --- & $\begin{array}{c}93.5(109.6) \\
\mathrm{N}\end{array}$ & $\begin{array}{c}3.8(20.9) \\
\mathrm{N}\end{array}$ \\
\hline$\left[\mathrm{UO}_{2}(\mathrm{ACO})_{1}(\mathrm{DAA})_{2}\right]^{2+}$ & $\begin{array}{c}16.7(26.6) \\
Y\end{array}$ & $\begin{array}{c}22.6(27.1) \\
Y\end{array}$ & $\begin{array}{c}26.1(35.6) \\
Y\end{array}$ & $\begin{array}{c}59.2(86.0) \\
\mathrm{N}\end{array}$ & $\begin{array}{c}-0.4(25.2) \\
Y^{*}\end{array}$ \\
\hline$\left[\mathrm{UO}_{2}(\mathrm{ACO})_{2}(\mathrm{DAA})_{1}\right]^{2+}$ & $\begin{array}{c}26.6(31.5) \\
Y\end{array}$ & $\begin{array}{c}30.2(41.4) \\
\mathrm{N}\end{array}$ & $\begin{array}{c}45.0(48.1) \\
\mathrm{N}\end{array}$ & $\begin{array}{c}76.2(102.1) \\
\mathrm{N}\end{array}$ & --- \\
\hline$\left[\mathrm{UO}_{2}(\mathrm{ACO})_{3}(\mathrm{DAA})_{1}\right]^{2+}$ & $\begin{array}{c}13.8(23.2) \\
Y^{*}\end{array}$ & $\begin{array}{c}20.2(29.0) \\
\mathrm{Y}^{*}\end{array}$ & $\begin{array}{c}25.0(24.6) \\
Y\end{array}$ & $\begin{array}{c}46.9(76.8) \\
\mathrm{N}\end{array}$ & --- \\
\hline
\end{tabular}

a "Y" indicates that the CID channel was experimentally observed; "Y*" indicates a minor observed channel $(<10 \%)$; "N" indicates that the channel was not observed. ${ }^{b}$ The isotopic compositions of the species employed for the CID experiments are as indicated in Figures 1-3.

${ }^{c}$ The contributions from monopositive and dipositive MOX products are evident in Figs. 1-3. 


\section{References}

${ }^{1}$ de Jong, W. A.; Apra, E.; Windus, T.; Nichols, J. A.; Harrison, R. J.; Gutowski, K. E.;

Dixon, D. A. J. Phys. Chem. A 2005, 11568.

${ }^{2}$ Groenewold, G. S.; Oomens, J.; de Jong, W. A.; Gresham, G. L.; McIlwain, M. E.; Van Stipdonk, M. J. Phys. Chem. Chem. Phys. 2008, 10, 1192.

${ }^{3}$ Groenewold, G. S.; de Jong, W. A.; Oomens, J.; Van Stipdonk, M. J. Am. Soc. Mass Spec. 2010, 21, 719.

${ }^{4}$ Rios, D.; Rutkowski, P. X.; Van Stipdonk, M. J.; Gibson, J. K. Inorg. Chem. 2011, 50 (11), 4781 .

${ }^{5}$ Schoendorff, G.; de Jong, W. A.; Van Stipdonk, M. J.; Gibson, J. K.; Rios, D.; Gordon, M. S.; Windus, T. L. Inorg. Chem. 2011, 50, 8490.

${ }^{6}$ Gronert, S. J. Am. Soc. Mass Spec. 1998, 9 (8), 845.

${ }^{7}$ Rutkowski, P. X.; Michelini, M. C.; Bray, T. H.; Russo, N.; Marcalo, J.; Gibson, J. K.

Theor. Chem. Acc. 2011, 129, 575.

${ }^{8}$ Valiev, M.; Bylaska, E.; Govind, N.; Kowalski, K.; Straatsma, T.; Van Dam, H.; Wang, D.; Nieplocha, J.; Apra, E.; Windus, T.; de Jong, W. Comp. Phys. Comm. 2010, 58, 1477.

${ }^{9}$ Slater, J. C. Phys. Rev. 1951, 81, 5.

${ }^{10}$ Vosko, S. H.; Wilk, L.; Nusair, M. Can. J. Phys. 1980, 58, 1200.

${ }^{11}$ Swart, M.; Solà, M.; Bickelhaupt, F. M., J. Chem. Phys. 2009, 131, 094103.

${ }^{12}$ Grimme, S. J. Chem. Phys. 2006, 124, 16.

${ }^{13}$ Bergner, A.; Dolg, M.; Küchle, W.; Stoll, H.; Preuss, H., Mol. Phys. 1993, 80 (6), 1431.

${ }^{14}$ Küchle, W.; Dolg, M.; Stoll, H., Mol. Phys. 1991, 74 (6), 1245. 
${ }^{15}$ Küchle, W.; Dolg, M.; Stoll, H.; Preuss, H., J. Chem. Phys. 1994, 100 (10), 7535.

${ }^{16}$ Godbout, N.; Salahub, D. R.; Andzelm, J.; Wimmer, E., Can. J. Chem. 1992, 70 (2), 560.

${ }^{17}$ Shvartsburg, A. A.; Wilkes, J. G. Int. J. Mass Spec. 2003, 225, 155.

${ }^{18}$ Choetzee, J. F.; Chang, T. H. Pure and App. Chem. 1986, 58 (11), 1541.

${ }^{19}$ Wahl, J. H.; Bolz, C. D.; Wahl, K. L. Lc Gc North Am. 2010, 28 (12), 1042.

${ }^{20}$ Kim, Y. K.; Hatfield, J. D. J. Chem. Eng. Data 1985, 30 (2), 149. 
[Reprinted with permission from Pawlikowski, A. V.; Gray, T. S.; Schoendorff, G.; Baird, B.; Ellern, A.; Windus, T. L.; Sadow, A. D. Inorg. Chim. Acta 2009, 362 (12), 4517. Copyright 2009 Elsevier.]

\title{
Structure, bonding, and ligand-based reactions of zwitterionic boratoiridium(I) complexes with oxazoline-based scorpionate ligands
}

[George Schoendorff contributed the computational results. All experimental data was obtained by members of the Sadow group.]

Andrew V. Pawlikowski, Tristan S. Gray, George Schoendorff, Benjamin Baird, Arkady Ellern, Theresa L. Windus, Aaron D. Sadow*

Dedicated to S. Trofimenko

\begin{abstract}
New tris(4,4-dimethyl-2-oxazolinyl)phenylboratoiridium(I) scorpionate-type compounds $\left[\operatorname{Ir}\left(\mathrm{To}^{\mathrm{M}}\right) \mathrm{L}_{2}\right]\left(\mathrm{L}_{2}=\eta^{4}-\mathrm{C}_{8} \mathrm{H}_{12}\right.$ and $\left.(\mathrm{CO})_{2}\right)$ and electrophiles form adducts that contain a bidentate $\operatorname{IrTo}^{\mathrm{M}}$-coordination and an $N$-electrophile interaction of the third oxazoline instead of the oxidative addition product. The adduct with lithium chloride gives a unique heterobimetallic $\mathrm{Li}-$ $O$-oxazoline- $N$-Ir bridging structure that has been identified through X-ray crystallography. Density functional theory calculations provide thermodynamic data, orbital symmetries, and orbital energies that explain the formation of the observed iridium(I) products.
\end{abstract}




\section{Introduction}

Oxidative addition reactions of monovalent $\mathrm{Rh}$ and $\mathrm{Ir}$ scorpionates yield racemic $[\mathrm{M}(\mathrm{Tp}) \mathrm{R}(\mathrm{X}) \mathrm{L}]$ compounds $\left(\mathrm{Tp}=\right.$ tris(pyrazolyl)borate, Chart $1 ;{ }^{1} \mathrm{M}=\mathrm{Rh}, \mathrm{Ir} ; \mathrm{R}=$ hydrocarbyl; $\mathrm{X}$ $=$ hydride, halide; $\mathrm{L}=$ neutral ligand) that contain a stereogenic metal center. ${ }^{2}$ The configuration of the metal stereocenter and peripheral stereocenters on the hydrocarbyl $\mathrm{R}$ group could be controlled by chiral ligands. However, few diastereoselective $\mathrm{C}-\mathrm{H}$ bond activation reactions have been reported with $\operatorname{TpRh}(\mathrm{I})$ - or $\operatorname{TpIr}(\mathrm{I})$-type compounds. Notable examples include the diastereoselective activation of a fused menthylpyrazole group on an optically active Tp ligand, ${ }^{3}$ and cyclometalation of a diisopropylamine ligand that gives racemic $\left.\left[\mathrm{Tp}^{\mathrm{Me} 2 \mathrm{Cl}} \mathrm{RhH( \textrm {NH } ( { } ^ { \mathrm { i } } \mathrm { Pr } ) \mathrm { CHMeCH }}{ }_{2}\right)\right] \quad\left(\mathrm{Tp}^{\mathrm{Me} 2 \mathrm{Cl}}=\mathrm{HB}\left(4-\mathrm{Cl}-3,5 \mathrm{Me}_{2} \mathrm{~N}_{2} \mathrm{C}_{3}\right)_{3}\right)$ in high diastereoselectivity $(>95 \%){ }^{4}$ Stereoselective $\mathrm{C}-\mathrm{H}$ bond oxidative additions could be an important component of hydrocarbon functionalization mediated by scorpionate compounds, ${ }^{5}$ providing impetus for investigating oxidative addition reactions of new chiral scorpionate compounds, as well as comparing related optically active and achiral ligands.

Therefore, we recently prepared the optically active scorpionate compounds $\left[\operatorname{Ir}\left(\operatorname{To}^{\mathrm{P}}\right)\left(\mathrm{L}_{2}\right)\right]$ $\left(\mathrm{To}^{\mathrm{P}}=\operatorname{tris}\left(4 S\right.\right.$-isopropyl-2-oxazolinyl)phenylborate, Chart $1 ; \mathrm{L}_{2}=\eta^{4}-\mathrm{C}_{8} \mathrm{H}_{12}$ or $\left.(\mathrm{CO})_{2}\right)$ to study stereoselective oxidative addition reactions. ${ }^{6}$ However, reactions of $\left[\operatorname{Ir}\left(\operatorname{To}^{\mathrm{P}}\right) \mathrm{L}_{2}\right]$ and the electrophiles MeOTf and MeI provide $N$-methylated oxazolinium species $\left[\operatorname{Ir}\left(\kappa^{2}-\mathrm{To}^{\mathrm{P}}-\mathrm{Me}\right) \mathrm{L}_{2}\right]^{+}$ rather than oxidative addition products. Interestingly, reactions of Group 9 Tp-type scorpionates with protons show either metal- or ligand-based reactivity. ${ }^{7}$ For example, mixtures of $\left[\mathrm{TpRh}(\mathrm{CO})_{2}\right]$ and $\left[\mathrm{HOEt}_{2}\right]\left[\mathrm{BF}_{4}\right]$ give a pyrazolyl-protonated rhodium(I) product, whereas the heavier iridium congener forms an iridium(III)-hydride. ${ }^{7}$ Additionally, a tetrahedral 
tris(carbene)boratocobalt(II) chloride complex reacts with $\mathrm{H}^{+}$to give a protonated carbene. ${ }^{8}$ In contrast, $\left[\mathrm{Tp} * \mathrm{Rh}(\mathrm{CO})_{2}\right]\left(\mathrm{Tp}^{*}=\mathrm{HB}\left(\mathrm{N}_{2} \mathrm{C}_{3} \mathrm{HMe}_{2}\right)_{3}\right)$ and MeI react to give the acetyl compound $[\mathrm{Tp} * \mathrm{Rh}(\mathrm{CO})(\mathrm{COMe}) \mathrm{I}]$ via the unobserved $\mathrm{Rh}(\mathrm{III})$ oxidative addition product. ${ }^{9}$ Likewise, the cationic compound $\left[\mathrm{Rh}(\operatorname{tris}-\mathrm{ox})\left(\eta^{4}-\mathrm{C}_{8} \mathrm{H}_{12}\right)\right]^{+}$is oxidized by $\mathrm{CsBr}_{3}$ to give $\left[\mathrm{RhBr}_{3}(\operatorname{tris}-\mathrm{ox})\right]$ (trisox $=1,1,1$-tris $\left(4 S\right.$-isopropyl-2-oxazolinyl)ethane) ${ }^{10}$

Tris(oxazolinyl)boratoiridium(I) compounds were further explored to clarify their reactivity in the context of this Group 9 scorpionate chemistry. In this contribution, achiral tris(4,4-dimethyl-2-oxazolinyl)phenylboratoiridium(I) compounds and their interactions with electrophiles are reported. Although enantiopure $\operatorname{IrTo}^{\mathrm{P}}$-based compounds are amorphous as determined by line-widths of solid state CPMAS NMR experiments ${ }^{6}$, the achiral $\operatorname{IrTo}^{\mathrm{M}}$ compounds described here are crystalline and therefore amenable to X-ray diffraction studies for structural analysis. Interestingly, the reaction of $\operatorname{Li}\left[\mathrm{To}^{\mathrm{M}}\right]$ and $\left[\operatorname{Ir}(\mu-\mathrm{Cl})\left(\eta^{4}-\mathrm{C}_{8} \mathrm{H}_{12}\right)\right]_{2}$ produces an unusual heterobimetallic complex that contains a $\left[\mathrm{Li}-\left(\mu-\mathrm{To}^{\mathrm{M}}\right)-\mathrm{Ir}\right]$ interaction through N-Ir, N$\mathrm{Li}$, and $\mathrm{O}-\mathrm{Li}$ bonds. The $\mathrm{N}-\mathrm{Ir}$ and $\mathrm{N}-\mathrm{Li}$ interactions are persistent in solution, as verified by ${ }^{15} \mathrm{~N}$ NMR chemical shift data obtained using ${ }^{1} \mathrm{H}-{ }^{15} \mathrm{~N}$ heteronuclear multiple bond correlation (HMBC) experiments. Additionally, the X-ray data is compared with model structures obtained from density functional theory (DFT) calculations. These computational studies indicate that the observed $\mathrm{N}$-methylated and $\mathrm{N}$-protonated oxazolinium species are the thermodynamic products and thus favored in comparison to the oxidative addition products $\left[\operatorname{Ir}(E)\left(\mathrm{To}^{\mathrm{M}}\right) \mathrm{L}_{2}\right]^{+}(\mathrm{E}=\mathrm{H}, \mathrm{Me})$.

\section{Results and Discussion}

\section{Synthesis and characterization of tris(2-oxazolinyl)boratoiridium(I) compounds}


The compound $\left[\left(\eta^{4}-\mathrm{C}_{8} \mathrm{H}_{12}\right) \operatorname{Ir}\left(\mu-\kappa^{2}-N 1, N 2-\mathrm{To}^{\mathrm{M}}-\kappa^{2}-N 3, O 2\right) \operatorname{Li}(\mu-\mathrm{Cl})\right]_{2}(\mathbf{1} ; N 1, N 2, N 3$, and O2 designate nitrogen- and oxygen-centers in oxazoline rings 1, 2, and 3) is obtained upon heating a benzene solution of $\mathrm{Li}\left[\mathrm{To}^{\mathrm{M}}\right]^{11}$ and 0.5 equiv of $\left[\operatorname{Ir}(\mu-\mathrm{Cl})\left(\eta^{4}-\mathrm{C}_{8} \mathrm{H}_{12}\right)\right]_{2}$ to reflux for $18 \mathrm{~h}$ (Equation 1).

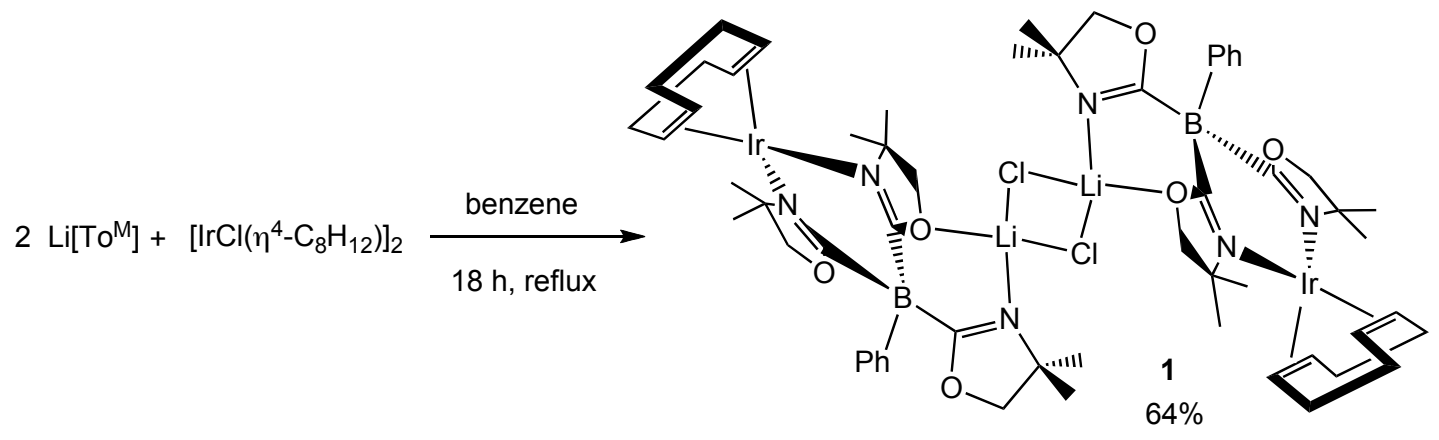

The solid state structure of $\mathbf{1}$ was established by X-ray crystallography as an interesting heterobimetallic dimer in which the $\left[\mathrm{To}^{\mathrm{M}}\right]$ anion is a bridging bidentate ligand for one iridium and one lithium center (Figure 1). The pseudo-square planar iridium centers are coordinated by nitrogen from two oxazoline rings and by 1,5-cyclooctadiene. The nitrogen of the third oxazoline ring interacts with a lithium cation, and that four-coordinate lithium center is also bonded to the oxygen of the second oxazoline ring. Thus, that oxazoline interacts with both iridium and lithium in a $\mathrm{Li}-O$-oxazoline- $N$-Ir bridging structure. The final two coordination sites of the lithium cation are taken by two inversion-related chloride ions that bridge to the symmetry-equivalent lithium cation in the other half of the dimer. This configuration gives a $(\mathrm{LiCl})_{2}$ planar parallelogram (Li1-Cl1-Li1 ${ }^{\#}, 78.0(4)^{\circ}$; Cl1-Li1-Cl1 ${ }^{\#}, 102.0(4)^{\circ}$; the Li1-Cl1-Li1 ${ }^{\#-C 11^{\#}}$ dihedral angle is $0^{\circ}$ ), and the crystallographic inversion center that relates the two halves of the dimer is located at the center of the parallelogram. The Ir-N distances are identical within error (Ir1-N1, 2.107(5) and Ir1-N2, 2.107(6) $\AA$ ) indicating that the lithium-oxygen interaction does not affect the iridium-nitrogen bond distances. In this crystalline phase, all three oxazoline groups are 
unique and $\mathbf{1}$ is $C_{1}$-symmetric, whereas in solution two oxazoline rings are related by a mirror plane (see NMR discussion below).

The structure of $\mathbf{1}$ contains the first crystallographically characterized $O$-coordinated oxazoline, and it is further highlighted by a unique heterobimetallic $\mathrm{M}-\mathrm{N}$-oxazoline- $O-\mathrm{M}^{\prime}$ bridging interaction. A few examples of $O$-coordinated oxazole-metal interactions (particularly benzoxazole, $\mathbf{A}$ in Figure 2) have been proposed, and a europium(III) compound $O$-coordinated by 2-(2'-pyridyl)-1,3-benzoxazole has been crystallographically characterized. ${ }^{12}$ The configuration of divalent cobalt, nickel, copper, and zinc $O$-coordinated benzoxazole compounds was assigned using their metal-oxygen stretching frequency $\left(v_{\mathrm{M}-\mathrm{O}}\right)$ in the far infrared, ${ }^{13}$ and EPR studies supported oxygen binding in a related copper(II) complex. ${ }^{14}$ The dimeric $\left[\operatorname{Pd}(\text { oxalato)(benzoxazole) }]_{2}\right.$ apparently involves a unique $\mathrm{Pd}-N$-benzoxazole- $O-\mathrm{Pd}$ bridging structure (structure $\mathbf{B}$ in Figure 2) based on its $v_{\mathrm{M}-\mathrm{O}}$ and $v_{\mathrm{M}-\mathrm{N} .}{ }^{15}$ In oxazoline coordination chemistry, oxygen-metal interactions are less common. A trimeric lithium compound 2-(2'lithiophenyl)-4,4-dimethyl-2-oxazoline was proposed to contain an oxygen-lithium interaction, although $\mathrm{N}$-coordination was not excluded. ${ }^{16}$ Recently, a zirconium(IV)-mediated oxazoline ring opening was suggested to involve a $\mathrm{Zr}-\mathrm{O}$ interaction. ${ }^{17} \mathrm{We}$ have not found analogous examples of $M-(\mu-T p)-M^{\prime}$ or $M-(\mu$-pyrazolyl)-M' structures from intact classic scorpionates in the literature, although functionalized scorpionates have recently provided heterobimetallic structures useful for building coordination networks, investigating $\mathrm{M} \cdots \mathrm{M}^{\prime}$ electronic interactions, and developing new catalytic reactions. ${ }^{18}$

The structure of $\mathbf{1}$ is particularly interesting in the context of salt metathesis reactions of polydentate anionic ligands. Presumably the reaction of optically active $\mathrm{Li}\left[\mathrm{To}^{\mathrm{P}}\right]$ and $0.5\left[\operatorname{IrCl}\left(\eta^{4}-\right.\right.$ 
$\left.\left.\mathrm{C}_{8} \mathrm{H}_{12}\right)\right]_{2}$ that yields LiCl-free $\left[\operatorname{Ir}\left(\mathrm{To}^{\mathrm{P}}\right)\left(\eta^{4}-\mathrm{C}_{8} \mathrm{H}_{12}\right)\right]^{6}$ proceeds through structures in which oxazoline groups bond simultaneously with both metal centers before the eventual extrusion of LiCl. Likewise, reactions of KTp and metal halides likely involve unobserved heterobimetallic intermediates. Thus, compound $\mathbf{1}$ may be viewed as an intermediate in salt metathesis reactions of polydentate ligand anions and metal halides. In the case of achiral $\mathrm{Li}\left[\mathrm{To}^{\mathrm{M}}\right]$, the salt elimination is not completed under the reaction conditions, in refluxing tetrahydrofuran, by heating in non-polar solvents (to precipitate $\mathrm{LiCl}$ ), or by Soxhlet extraction. However, ligand substitution reactions and stronger electrophiles than $\mathrm{Li}^{+}$will induce $\mathrm{LiCl}$ extrusion (see below).

Although 1 is $C_{1}$-symmetric in the solid state, solution state NMR data (in benzene- $d_{6}$, methylene chloride- $d_{2}$, and tetrahydrofuran- $d_{8}$ ) are consistent with $C_{\mathrm{s}}$-symmetry. In the ${ }^{1} \mathrm{H}$ NMR spectrum of $\mathbf{1}$ in tetrahydrofuran- $d_{8}$, the oxazoline methyl resonances appeared as three singlet resonances at 1.18, 1.24 and $1.46 \mathrm{ppm}$, and three resonances assigned to ring methylene moieties were observed as a singlet $(3.5 \mathrm{ppm}, 2 \mathrm{H})$ and two coupled diastereotopic doublets (4.18 and $4.26 \mathrm{ppm}, 4 \mathrm{H},{ }^{2} \mathrm{~J}_{\mathrm{HH}}=7.7 \mathrm{~Hz}$ ) from one unique and two equivalent oxazoline rings, respectively. The spectrum for a $C_{1}$-symmetric structure (not observed in solution) would contain six singlet resonances and six doublets for oxazoline $\mathrm{CH}_{3}$ and $\mathrm{CH}_{2}$ groups. Thus, two of the three oxazolines are related by a mirror plane that is coincident with the third oxazoline ring. $\mathrm{A}^{1} \mathrm{H}^{1}{ }^{15} \mathrm{~N}$ HMBC experiment helped identify the solution state coordination mode of the $\left[\mathrm{To}^{\mathrm{M}}\right]$ ligand in $\mathbf{1}$; two ${ }^{15} \mathrm{~N}$ NMR resonances at -145.9 and $-181.4 \mathrm{ppm}$ (referenced to nitromethane and acquired in tetrahydrofuran- $d_{8}$ ) correspond to one unique and two equivalent oxazoline nitrogen, respectively. The latter resonance was assigned to the iridium-coordinated oxazoline nitrogen based on its crosspeaks with the two diastereotopic doublets in the ${ }^{1} \mathrm{H}$ NMR spectrum. The chemical shift of the former ${ }^{15} \mathrm{~N}$ NMR resonance (-145.9 ppm) is $18 \mathrm{ppm}$ upfield from that of 
uncoordinated 4,4-dimethyl-2-oxazoline (-127.9 ppm) and substantially downfield from the two oxazoline nitrogen that are coordinated to iridium (-182 ppm, $36 \mathrm{ppm}$ difference).

These NMR data contrast the solution structures of $\mathbf{1}$ and the optically active, LiCl-free derivative $\left[\operatorname{Ir}\left(\operatorname{To}^{\mathrm{P}}\right)\left(\eta^{4}-\mathrm{C}_{8} \mathrm{H}_{12}\right)\right]$; in the latter, the three $4 S$-isopropyloxazoline groups are equivalent due to a rapid exchange process(es). ${ }^{6}$ However, the CPMAS ${ }^{15} \mathrm{~N}$ NMR spectrum (Cross-polarization Magic Angle Spinning) of the chiral iridium compound revealed it is composed of a mixture of $\kappa^{2}$ - and $\kappa^{3}$-isomers in the solid state. The ${ }^{15} \mathrm{~N}$ chemical shift of the uncoordinated oxazoline nitrogen in the $\kappa^{2}$-isomer of $\left[\operatorname{Ir}\left(\operatorname{To}^{\mathrm{P}}\right)\left(\eta^{4}-\mathrm{C}_{8} \mathrm{H}_{12}\right)\right](-147 \mathrm{ppm})$ is similar to that of uncoordinated $4 S$-isopropyl-2-oxazoline (-150 ppm).

The $\mathrm{Li}-O$-oxazoline interaction of $\mathbf{1}$ in solution is either completely disrupted or the two oxazoline rings are exchanging rapidly on the ${ }^{1} \mathrm{H}$ NMR timescale. The low temperature ${ }^{1} \mathrm{H}$ NMR spectrum of 1 (toluene- $d_{8}, 190 \mathrm{~K}$ ) is broad but the resonances do not coalesce at or above this temperature. Thus, the lithium-oxygen interaction is labile at least to $190 \mathrm{~K}$.

Given its lithium-oxazoline interactions, we were curious to investigate reactivity of $\mathbf{1}$ with electrophiles and toward ligand substitution. We speculated that oxidative addition would be more likely with 1 because the third oxazoline is blocked by coordination to a cationic lithium center. Nonetheless, addition of MeOTf to $\mathbf{1}$ at room temperature results in oxazoline $\mathrm{N}$ methylation and loss of $\mathrm{LiCl}$ producing $\left[\operatorname{Ir}\left(\kappa^{2}-\mathrm{To}^{\mathrm{M}}-\mathrm{N} 3-\mathrm{CH}_{3}\right)\left(\eta^{4}-\mathrm{C}_{8} \mathrm{H}_{12}\right)\right][\mathrm{OTf}](\mathbf{2})$ (N3 designates bonding to the nitrogen on the third oxazoline ring, Equation 2) rather than formation of an iridium-carbon bond. 


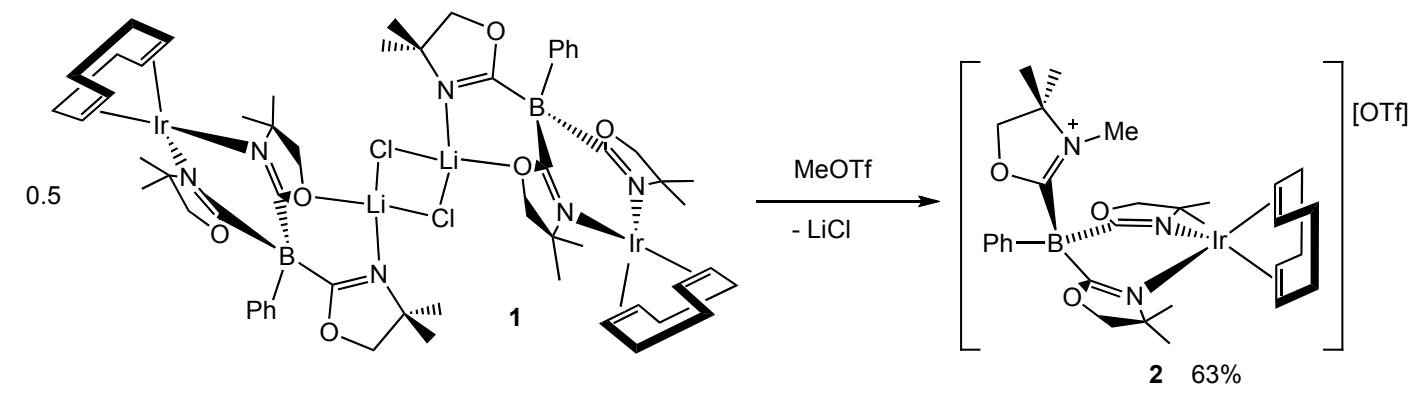

In benzene- $d_{6}$, a small amount of precipitate (likely $\mathrm{LiCl}$ ) formed upon addition of MeOTf to $\mathbf{1}$, and $C_{\mathrm{s}}$-symmetric 2 was the only product detected by ${ }^{1} \mathrm{H}$ NMR spectroscopy. A new resonance at $3.12 \mathrm{ppm}(3 \mathrm{H})$ was assigned to an $N$-methyl oxazoline moiety based on its integrated intensity and its downfield chemical shift. Furthermore, an intense crosspeak in the ${ }^{1} \mathrm{H}_{-}{ }^{15} \mathrm{~N}$ HMBC spectrum showed coupling between the methyl moiety and an oxazoline nitrogen $\left({ }^{15} \mathrm{~N}\right.$ NMR: 208.0 ppm). This ${ }^{15} \mathrm{~N}$ NMR chemical shift for the $N$-Me in 2 is far upfield from 4,4-dimethyloxazoline $(-127.5 \mathrm{ppm})$, the lithium-coordinated oxazoline in $\mathbf{1}(-145.9 \mathrm{ppm})$, as well as the iridium-coordinated oxazoline nitrogen of 2 and $\mathbf{1}$ at -175.0 and $-181.4 \mathrm{ppm}$, respectively.

Oxazoline $N$-methylation in $\mathbf{2}$ was confirmed by a single crystal X-ray diffraction study that also verified bidentate $\operatorname{IrTo}^{\mathrm{M}}$ coordination (Figure 3). The two iridium-nitrogen bond distances are identical within $3 \sigma(\operatorname{Ir} 1-\mathrm{N} 1,2.105(6)$; Ir1-N2, 2.140(6)) and identical to the Ir-N distances in 1. Although the phenyl group and the iridium center are disposed syn, the ipso carbon of the phenyl group is approximately $3.43 \AA$ from the iridium center, well outside the sum of covalent radii $(2.17 \AA),{ }^{19}$ and the aryl C-C bond distances are all identical within error. Likewise, addition of HOTf to a benzene solution of $\mathbf{1}$ provides $\left[\operatorname{Ir}\left(\kappa^{2}-\mathrm{To} \mathrm{M}^{\mathrm{M}}-N 3-\mathrm{H}\right)\left(\eta^{4}-\right.\right.$ $\left.\left.\mathrm{C}_{8} \mathrm{H}_{12}\right)\right][\mathrm{OTf}]$ (3) in $81 \%$ yield. X-ray quality crystals were obtained from evaporation of a concentrated tetrahydrofuran solution, and the solid state structure shows that the conformation of the $\left[\kappa^{2}-\mathrm{To}^{\mathrm{M}}-\mathrm{N} 3-\mathrm{E}\right](\mathrm{E}=\mathrm{H}, \mathrm{Me})$ ligands in $\mathbf{2}$ and $\mathbf{3}$ are very similar (compare Figures 3 and 4 ). 
The Ir-N bond distances are identical (within $3 \sigma$ ) for $\mathbf{1}, \mathbf{2}$, and $\mathbf{3}$ showing that the identity of the electrophile bonded to a pendent oxazoline does not affect the iridium-oxazoline bonding. Protonated $\mathbf{3}$ is $C_{\mathrm{s}}$-symmetric, and sharp resonances were observed in the ${ }^{1} \mathrm{H}$ NMR spectrum (benzene- $d_{6}$ ). Thus, the $\mathrm{H}-$ and Ir-coordinated oxazolines do not exchange on the ${ }^{1} \mathrm{H}$ NMR timescale. Additionally, the reaction of 3 and $\mathrm{KH}$ in THF- $d_{8}$ results in deprotonation of the pendent oxazolinium acid, giving a $C_{\mathrm{s}}$-symmetric product. Resonances in the ${ }^{1} \mathrm{H}$ NMR spectrum of this compound are assigned to inequivalent oxazoline groups and a cyclooctadiene ligand, and the chemical shifts are different from those of the lithium chloride adduct $\mathbf{1}$.

The reaction of $\mathbf{1}$ and $\mathrm{CO}$ could provide additional information about substitution chemistry of iridium in this bimetallic system. We considered that the lithium-, proton-, or methyl-oxazoline interactions might facilitate $\left[\mathrm{To}^{\mathrm{M}}\right.$-E] substitution rather than $\mathrm{C}_{8} \mathrm{H}_{12}$ replacement, since the charge-neutral $\left[\mathrm{To}^{\mathrm{M}}\right.$-E] could be a better leaving group than anionic ancillary ligands such as $\left[\mathrm{To}^{\mathrm{M}}\right]$ or $\mathrm{Tp}$. Conversely, cyclooctadiene substitution might affect the oxazoline-lithium interaction by increasing the electrophilicity of the iridium center. The $v_{\mathrm{CO}}$ of the desired $\left[\operatorname{Ir}\left(\mathrm{To}^{\mathrm{M}}\right)(\mathrm{CO})_{2}\right]$ product are valuable for identifying the coordination geometry of the $\left[\mathrm{To}^{\mathrm{M}}\right]$ ligand. In analogy to $\left[\mathrm{TpM}(\mathrm{CO})_{2}\right]$ systems $^{2}$, photochemical carbonyl dissociation from $\left[\operatorname{Ir}\left(\mathrm{To}^{\mathrm{M}}\right)(\mathrm{CO})_{2}\right]$ will access reactive species. Finally, the smaller $\mathrm{CO}$ compounds are easier to model computationally, and frequency calculations can be used to compare calculated structures with experimental spectroscopic properties (see below).

When a benzene- $d_{6}$ solution of $\mathbf{1}$ was exposed to carbon monoxide, the resulting ${ }^{1} \mathrm{H}$ NMR spectrum contained broad singlets for the methyl $(1.10 \mathrm{ppm})$ and methylene groups (3.50 ppm). We were surprised to find that degassing this mixture after short reaction times (ca. $1 \mathrm{~h}$ ) resulted in regeneration of compound $\mathbf{1}$. However, when $\mathbf{1}$ was stirred for $18 \mathrm{~h}$ under a CO 
atmosphere, a precipitate formed (presumably $\mathrm{LiCl}$ ) and irreversible substitution of 1,5cyclooctadiene provided the pale yellow LiCl-free dicarbonyl compound $\left[\operatorname{Ir}\left(\mathrm{To}^{\mathrm{M}}\right)(\mathrm{CO})_{2}\right](4)$ in $77 \%$ yield. In contrast to 1 , the $\left[\mathrm{To}^{\mathrm{M}}\right]$ ligand of 4 appeared $C_{3}$-symmetric in its ${ }^{1} \mathrm{H},{ }^{13} \mathrm{C}$ and ${ }^{15} \mathrm{~N}$ NMR spectra. For example, only one ${ }^{15} \mathrm{~N}$ signal is detected at $-167.3 \mathrm{ppm}$ in a ${ }^{1} \mathrm{H}^{15}{ }^{15} \mathrm{HMBC}$ experiment. The infrared spectrum of $\mathbf{4}$ (methylene chloride) contains two sets of $v_{\mathrm{CO}}$; an intense pair (2066 and $\left.1989 \mathrm{~cm}^{-1}\right)$ and a low intensity pair (2029 and $\left.1933 \mathrm{~cm}^{-1}\right)$, which are assigned to the bidentate and tridentate $\left[\mathrm{To}^{\mathrm{M}}\right]$ coordination modes, respectively. Bidentate and tridentate coordination of related tris- $N$-coordinating ligands, particularly tris(pyrazolyl)borates, to $d^{8}$ metal centers has been investigated using a range of spectroscopic techniques, ${ }^{20}$ including $v_{\mathrm{CO}}$ values, ${ }^{20 a} \mathrm{~N} 1 / \mathrm{N} 2$ chemical shift differences observed by ${ }^{15} \mathrm{~N}$ NMR spectroscopy, ${ }^{20 a}{ }^{11} \mathrm{~B}$ NMR chemical shift values, ${ }^{20 \mathrm{~b}}$ relative energies of $v_{\mathrm{BH}},{ }^{20 c, \mathrm{~d}}$ as well as solid state and solution ${ }^{15} \mathrm{~N}$ NMR spectroscopy. ${ }^{6,21}$ For comparison $\left[\operatorname{Tp} * \operatorname{Ir}(\mathrm{CO})_{2}\right]$, the most closely related pyrazolyl borate complex to 4 , contains a tridentate tris(pyrazolyl)borate as suggested by its $v_{\mathrm{CO}}$ (2039 and 1960 $\left.\mathrm{cm}^{-1}\right) .^{7 \mathrm{a}}$ However, the unsubstituted $\left[\operatorname{Tp} \operatorname{Ir}(\mathrm{CO})_{2}\right]$ is a mixture of four- and five-coordinate species. $^{7 \mathrm{a}}$

Compound 4 reacts with the electrophiles MeOTf and HOTf in benzene to form $\left[\operatorname{Ir}\left(\kappa^{2}-\right.\right.$ $\left.\left.\mathrm{To}^{\mathrm{M}}-\mathrm{N} 3-\mathrm{E}\right)(\mathrm{CO})_{2}\right][\mathrm{OTf}](\mathrm{E}=\mathrm{Me}(\mathbf{5}), 53 \% ; \mathrm{E}=\mathrm{H}(\mathbf{6}), 63 \%)$. The ${ }^{1} \mathrm{H}$ NMR and ${ }^{1} \mathrm{H}_{-}{ }^{15} \mathrm{~N}$ HMBC spectra are consistent with formation of electrophile-oxazoline bonds and overall $C_{\mathrm{s}}$-symmetric molecules as described above for the cyclooctadiene compounds 2 and 3. An X-ray crystal structure of 5 was obtained from a concentrated benzene solution (Figure 5). In contrast to the structures of $\mathbf{2}$ (and 3), the methylated oxazoline ring is syn with respect to the iridium center, and the phenyl group is located anti to iridium. 
Both iridium dicarbonyl compounds $\mathbf{5}$ and $\mathbf{6}$ can be prepared by reaction of carbon monoxide with $\mathbf{2}$ and $\mathbf{3}$, respectively. Thus, cyclooctadiene is preferentially replaced for $\mathrm{CO}$, and the overall non-charged (though zwitterionic) $\left[\mathrm{To}^{\mathrm{M}}-\mathrm{E}\right]$ ligands are not displaced.

\section{Computational model structures based on dicarbonyl tris(oxazolin-2-yl)boratoiridium(I).}

DFT calculations on a model system $\left[\operatorname{Ir}\left(\mathrm{To}^{\mathrm{X}}\right)(\mathrm{CO})_{2}\right]\left(\mathrm{To}^{\mathrm{X}}=\right.$ tris(oxazolin-2-yl)borate) provide insight into the structures and selectivity observed in the reactions described above. The optimized model compound $\left[\operatorname{Ir}\left(\mathrm{To}^{\mathrm{X}}\right)(\mathrm{CO})_{2}\right] \mathbf{C}\left(\mathrm{B} 3 \mathrm{LYP},{ }^{22}\right.$ in the gas phase) is a four-coordinate, square planar iridium compound with bidentate $N, N-\left[\mathrm{To}^{\mathrm{X}}\right]$ coordination (Ir-N, 2.106 and 2.107 $\AA$ ). The third oxazoline is not coordinated to iridium (Ir-N3, $5.250 \AA$ ). The Ir-N bond distances in this $\left[\operatorname{Ir}\left(\kappa^{2}-\mathrm{To}^{\mathrm{X}}\right)(\mathrm{CO})_{2}\right]$ structure are identical (within error) to the distances in $\mathbf{1}$ determined by X-ray diffraction. Based on a Hessian calculation, this structure is a local minimum; in contrast, no minimum energy structure could be located for five-coordinate geometries in which the $\left[\operatorname{To}^{\mathrm{X}}\right]$ ligand is tridentate. The calculated $v_{\mathrm{CO}}$ for $\left[\operatorname{Ir}\left(\kappa^{2}-\mathrm{To}^{\mathrm{X}}\right)(\mathrm{CO})_{2}\right](\text { corrected })^{23}$ are 2065 and 1993 $\mathrm{cm}^{-1}$, which compare extremely well with $\left[\operatorname{Ir}\left(\mathrm{To}^{\mathrm{M}}\right)(\mathrm{CO})_{2}\right]$ (4) $\left(2066\right.$ and $\left.1989 \mathrm{~cm}^{-1}\right)$ and $\left[\operatorname{Ir}\left(\operatorname{To}^{\mathrm{P}}\right)(\mathrm{CO})_{2}\right] \quad(2065$ and $1987 \mathrm{~cm}-1){ }^{23}$ This IR data comparison suggests that the tris(oxazolinyl)borate ligands are bidentate in $\mathbf{4}$ and $\left[\operatorname{Ir}\left(\operatorname{To}^{\mathrm{P}}\right)(\mathrm{CO})_{2}\right]$. However, structural conclusions from these DFT calculations are in conflict with our solid state CPMAS ${ }^{13} \mathrm{C}$ and ${ }^{15} \mathrm{~N}$ NMR spectroscopic data that suggest the coordination mode in $\left[\operatorname{Ir}\left(\mathrm{To}^{\mathrm{P}}\right)(\mathrm{CO})_{2}\right]$ is tridentate. ${ }^{6} \mathrm{We}$ made multiple attempts to locate a stationary point corresponding to a five-coordinate iridium complexes by starting with tridentate $\operatorname{To}{ }^{\mathrm{X}} \operatorname{Ir}(\mathrm{I})$ species, but none are found. A constrained geometry optimization of one five coordinate model compound, in which Ir-N distances were 
fixed at $2.111,2.020$, and $2.080 \AA$, is $14.2 \mathrm{kcal} / \mathrm{mol}$ higher in energy than the four-coordinate minimum described above. When these Ir-N distance constraints are removed, the structure optimized to the four-coordinate structure described above. Crystal forces could be responsible for the structural difference, since $\mathbf{C}$ is modeled in the gas phase.

The Kohn-Sham orbitals and their relative energies in this model system suggest that the iridium(I) center is (1) not sufficiently electrophilic to form a five-coordinate structure and (2) less nucleophilic than the uncoordinated oxazoline group. Notably, the highest occupied (KohnSham) molecular orbital (HOMO) is the $\mathrm{C}=\mathrm{N} \pi$-bond located on the non-coordinated oxazoline. The next highest occupied orbitals are the iridium $d_{\mathrm{z2}}$-like orbital $12.1 \mathrm{kcal} / \mathrm{mol}(0.52 \mathrm{eV})$ below the HOMO, and the non-coordinated oxazoline $N$-lone pair $15.9 \mathrm{kcal} / \mathrm{mol}(0.691 \mathrm{eV})$ below the HOMO. The lowest unoccupied molecular orbital (LUMO) is a mixture of $d_{\mathrm{xy}}$ and $p_{\mathrm{y}}$ orbitals on the metal center, as well as some $\mathrm{CO} \pi^{*}$ character, that is available to bond to the nonbonding electron pair on the uncoordinated oxazoline. Although this orbital is directed toward the 'free' oxazoline, this bonding is discouraged because the LUMO is high in energy $(97.2 \mathrm{kcal} / \mathrm{mol}$ or $4.2 \mathrm{eV}$ above the HOMO) and the highest filled orbital on the oxazoline ( $\pi_{\mathrm{CN}}$ character) has the wrong symmetry for bonding to the LUMO $(\sigma)$. Clearly, the HOMO and HOMO-2 on the oxazoline, as well as the HOMO-1 on iridium, are available for bonding to external electrophiles.

Additionally, the charges on atoms in the $\mathrm{To}^{\mathrm{M}}$ Ir-system can provide insight into its electronic properties, and these have been evaluated with Mulliken charges determined for the model compound $\mathbf{C}$. In $\mathbf{C}$, the boron center is negatively charged (-0.38 electrons) as expected, and the nitrogen in the pendent oxazoline also has some anionic character (-0.19 electrons). The iridium center contains significant positive character $(+0.59$ electrons $)$, so the description of $\left[\operatorname{Ir}\left(\kappa^{2}-\mathrm{To}^{\mathrm{X}}\right)(\mathrm{CO})_{2}\right]$ as a zwitterionic boratoiridium(I) complex is reasonable. 
To better understand the selectivity for oxazoline $N$-methylation versus oxidative addition to iridium, the model compounds $\left[\operatorname{Ir}\left(\kappa^{2}-\mathrm{To}^{\mathrm{X}}-\mathrm{Me}\right)(\mathrm{CO})_{2}\right]^{+}(\mathbf{D})$ and $\left[\operatorname{IrMe}\left(\kappa^{3}-\mathrm{To}^{\mathrm{X}}\right)(\mathrm{CO})_{2}\right]^{+}(\mathbf{E})$ were optimized. The calculated structure of the model oxazoline-methylated compound $\left[\operatorname{Ir}\left(\kappa^{2}-\right.\right.$ $\left.\left.\mathrm{To}^{\mathrm{X}}-\mathrm{Me}\right)(\mathrm{CO})_{2}\right]^{+}$successfully reproduces the bond lengths and angles of the crystallographically characterized 5. The Ir-N distances $(2.12 \AA)$, Ir-C distances $(1.87 \AA)$, the $\mathrm{N}_{\text {oxazoline- }}-\mathrm{C}_{\text {methyl }}$ distance (1.46), and the $\mathrm{C}=\mathrm{O}$ distances $(1.14 \AA)$ in the calculated structure are all identical with 5 within error. The square planar geometry of iridium is observed in this calculated structure and in the X-ray data, and the N-Ir-N angle $\left(87.1^{\circ}\right)$ is only slightly larger than the experimental value of 85.9(3) ${ }^{\circ}$ and the N-Ir-C are slightly smaller (calculated $91.4^{\circ}$ versus experimental 94.0(4) and 93.2(4) ${ }^{\circ}$ ). Thus, there is good structural agreement between calculated structure $\mathbf{D}$ and compound 5. Structural comparisons of the optimized geometry for the oxidative addition product $\mathbf{E}$ were not possible since corresponding methyliridium(III) species could not be prepared. Importantly, $\mathbf{D}$ is $12.4 \mathrm{kcal} / \mathrm{mol}$ lower in energy than $\mathbf{E}$ (electronic and zero point energy correction). Thus, these gas phase model compounds predict that the observed oxazolinemethylation product is thermodynamically favored over the oxidative addition product.

The (corrected) $v_{\mathrm{CO}}$ for $\mathbf{D}\left(2089\right.$ and $\left.2022 \mathrm{~cm}^{-1}\right)$ are higher than the experimental values for 5 (2069 and $\left.1997 \mathrm{~cm}^{-1}\right)$, and we attribute this difference to the approximation of 5 by a gas phase counterion-free cationic species. Although experimental and calculated $v_{\mathrm{CO}}$ deviated slightly, the $v_{C O}$ differences for calculated structures $\left[\operatorname{Ir}\left(\kappa^{2}-\operatorname{To}^{X}\right)(C O)_{2}\right]$ and $\left[\operatorname{Ir}\left(\kappa^{2}-\operatorname{To}^{X}-\right.\right.$ $\left.\mathrm{Me})(\mathrm{CO})_{2}\right]^{+}\left(\Delta v_{\mathrm{COsym}}=25 \mathrm{~cm}^{-1}\right.$; and $\left.\Delta v_{\mathrm{COasym}}=30 \mathrm{~cm}^{-1}\right)$, calculated structures $\left[\operatorname{Ir}\left(\kappa^{2}-\mathrm{To}^{\mathrm{X}}\right)(\mathrm{CO})_{2}\right]$ and $\left[\operatorname{IrMe}\left(\kappa^{3}-\mathrm{To}^{\mathrm{X}}\right)(\mathrm{CO})_{2}\right]^{+}\left(\Delta v_{\mathrm{CO} \text { sym }}=69 \mathrm{~cm}^{-1}\right.$; and $\left.\Delta v_{\mathrm{COasym}}=87 \mathrm{~cm}^{-1}\right)$, and the experimental compounds $\left[\operatorname{Ir}\left(\mathrm{To}^{\mathrm{M}}\right)(\mathrm{CO})_{2}\right](4)$ and $\left[\operatorname{Ir}\left(\mathrm{To}^{\mathrm{M}}-\mathrm{Me}\right)(\mathrm{CO})_{2}\right][\mathrm{OTf}](\mathbf{5})\left(\Delta v_{\mathrm{COsym}}=3 \mathrm{~cm}^{-1}\right.$; and $\Delta v_{\mathrm{COasym}}$ $=8 \mathrm{~cm}^{-1}$ ) are worth considering. In the calculations, oxazoline $N$-methylation produces a smaller 
effect on the $v_{\mathrm{CO}}$ than the change upon oxidative addition to iridium. The change in the IR spectrum upon methylation is even smaller for the experimental $\left[\operatorname{Ir}\left(\mathrm{To}^{\mathrm{M}}\right)(\mathrm{CO})_{2}\right]$ compounds.

The oxazoline-protonated structure $\left[\operatorname{Ir}\left(\kappa^{2}-\mathrm{To}^{\mathrm{X}}-\mathrm{H}\right)(\mathrm{CO})_{2}\right]^{+}(\mathbf{F})$ is a model for the observed product $\left[\operatorname{Ir}\left(\kappa^{2}-\mathrm{To}^{\mathrm{M}}-\mathrm{H}\right)(\mathrm{CO})_{2}\right][\mathrm{OTf}](\mathbf{6})$, and the optimized structure of $\mathbf{F}$ is a minimum on the potential energy surface. Direct structural comparisons between calculated $\mathbf{F}$ and compound $\mathbf{6}$ were not made because X-ray data was not available for $\mathbf{6}$. However the relative energies obtained from the calculations are consistent with our experimental observations favoring oxazoline protonation, since the minimum for the iridium(III)-hydride species $\left[\operatorname{Ir}\left(\kappa^{3}-\right.\right.$ $\left.\left.\mathrm{To}^{\mathrm{X}}\right) \mathrm{H}(\mathrm{CO})_{2}\right]^{+}(\mathbf{G})$ is $7.46 \mathrm{kcal} / \mathrm{mol}$ higher in energy than protonated-oxazoline structure $\mathbf{F}$. Thus, $\mathbf{6}$ is most likely the thermodynamically favored product.

\section{Concluding remarks}

Tris(oxazolinyl)boratoiridium(I) scorpionates clearly differ from isoelectronic tris(pyrazolyl)borates in their interactions with electrophiles. Protonation of $\mathrm{TpML}_{2}$-type compounds provides metal hydrides in several cases, ${ }^{7}$ whereas three electrophiles $\mathrm{EX}(\mathrm{EX}=$ HOTf, MeOTf, and $\mathrm{LiCl})$ interact with $\left[\operatorname{Ir}\left(\mathrm{To}^{\mathrm{M}}\right) \mathrm{L}_{2}\right]$ to give $\left[\operatorname{Ir}\left(\kappa^{2}-\mathrm{To}^{\mathrm{M}}-\mathrm{E}\right) \mathrm{L}_{2}\right]^{+}$compounds. These oxazoline-electrophile interactions have been established by ${ }^{15} \mathrm{~N}$ NMR HMBC experiments through chemical shift comparisons and through-bond coupling, as well as through X-ray crystallography. Our computational results indicate that the highest energy electron pair resides in a non-coordinated $\pi_{\mathrm{CN}}$ bond, and this HOMO is consistent with our observed reactivity. Additionally, the calculations show that oxazoline-methylation (and likely oxazolineprotonation) is thermodynamically favored over iridium-based oxidative addition in these 
compounds. In contrast to these results, $\left[\mathrm{Tp} * \mathrm{Rh}(\mathrm{CO})_{2}\right]$ and MeI react via oxidative addition ${ }^{9}$, although $\left[\mathrm{Tp} * \mathrm{Rh}(\mathrm{CO})_{2}\right]$ also reacts with $\mathrm{HBF}_{4} \cdot \mathrm{OEt}_{2}$ via pyrazolyl protonation. ${ }^{7 \mathrm{a}}$ Additionally, a cationic rhodium compound containing the neutral tris-ox ligand $\left[\mathrm{Rh}(\operatorname{tris}-\mathrm{ox})\left(\mathrm{C}_{8} \mathrm{H}_{12}\right)\right]^{+}$has been oxidized by $\mathrm{CsBr}_{3}$ to $\left[\mathrm{RhBr}_{3}\right.$ (tris-ox)]. ${ }^{10}$ These contrasting results could be attributed to differences in ligand (neutral versus anionic), metal center (rhodium versus iridium), or oxidant $\left(\mathrm{CsBr}_{3}\right.$ versus $\left.\mathrm{H}^{+}, \mathrm{Me}^{+}\right)$. Regardless, the $v_{\mathrm{CO}}$ for 4 and $\left[\operatorname{Ir}\left(\mathrm{To}^{\mathrm{P}}\right)(\mathrm{CO})_{2}\right]$ suggest that the tris(oxazolinyl)borate ligands are sufficiently electron donating to mediate oxidative addition of nonpolar bonds under photolytic conditions. Our investigations of stereoselective oxidative additions will be disclosed in due course.

Acknowledgement We thank the U.S. DOE office of Basic Energy Sciences, through the Catalysis Science Grant No. AL-03-380-011, the Roy J. Carver Charitable Trust, and the National Science Foundation (Award number OCI-0749156) for support. We gratefully acknowledge Ames Laboratory and Iowa State University for computational resources. Dr. Bruce Fulton is thanked for assistance collecting ${ }^{15} \mathrm{~N}$ NMR spectral data.

Supplemental material Details of DFT optimized atomic coordinates and normal modes, and $\mathrm{X}$-ray diffraction collection, atomic coordinates, and refined bond lengths and angles. 


\section{Experimental}

General Procedures All manipulations were performed under a dry argon atmosphere using standard Schlenk techniques, or under a nitrogen atmosphere in a glovebox unless otherwise indicated. Dry, oxygen-free solvents were used throughout. Benzene, toluene, pentane, methylene chloride, and tetrahydrofuran were degassed by sparging with nitrogen, filtered through activated alumina columns, and stored under $\mathrm{N}_{2}$. Benzene- $d_{6}$ and tetrahydrofuran- $d_{8}$ were vacuum transferred from $\mathrm{Na} / \mathrm{K}$ alloy and stored under $\mathrm{N}_{2}$ in the glovebox. Lithium tris $(4,4-$ dimethyl-2-oxazolinyl)phenylborate $\left(\mathrm{Li}\left[\mathrm{To}^{\mathrm{M}}\right]\right)^{11}$ and $\left[\operatorname{Ir}(\mu-\mathrm{Cl})\left(\eta^{4}-\mathrm{C}_{8} \mathrm{H}_{12}\right)\right]_{2}{ }^{24}$ were synthesized as previously reported. All other reagents were purchased from Aldrich and used as received.

${ }^{1} \mathrm{H},{ }^{11} \mathrm{~B}$, and ${ }^{13} \mathrm{C}\left\{{ }^{1} \mathrm{H}\right\}$ solution NMR spectra were collected on Bruker DRX-400 or Avance II 700 spectrometers. ${ }^{15} \mathrm{~N}$ chemical shifts were determined by ${ }^{1} \mathrm{H}^{-}{ }^{15} \mathrm{~N}$ HMBC experiments on a Bruker Avance II 700 spectrometer with a Bruker Z-gradient inverse TXI ${ }^{1} \mathrm{H} /{ }^{13} \mathrm{C} /{ }^{15} \mathrm{~N} 5 \mathrm{~mm}$ cryoprobe. ${ }^{15} \mathrm{~N}$ chemical shifts were originally recorded with respect to liquid $\mathrm{NH}_{3}$ (machine calibration) and recalculated to the $\mathrm{CH}_{3} \mathrm{NO}_{2}$ chemical shift scale by adding -381.9 ppm. Elemental analysis was performed using a Perkin-Elmer 2400 Series II CHN/S by the Iowa State Chemical Instrumentation Facility.

\section{$\left[\left(\eta^{4}-\mathrm{C}_{8} \mathrm{H}_{12}\right) \operatorname{Ir}\left(\mu-\kappa^{2}-N 1, N 2-\mathrm{To}^{\mathrm{M}}-\kappa^{2}-N 3, O 2\right) \operatorname{Li}(\mu-\mathrm{Cl})\right]_{2}(1)$.}

A $100 \mathrm{~mL}$ Teflon-sealed flask was charged with $\left[\operatorname{Ir}(\mu-\mathrm{Cl})\left(\eta^{4}-\mathrm{C}_{8} \mathrm{H}_{12}\right)\right]_{2}(0.50 \mathrm{~g}, 0.74 \mathrm{mmol}), 2$ equiv of $\mathrm{Li}\left[\mathrm{To}^{\mathrm{M}}\right](0.58 \mathrm{~g}, 1.5 \mathrm{mmol})$, and $50 \mathrm{~mL}$ of benzene. This mixture was heated at $80{ }^{\circ} \mathrm{C}$ for $18 \mathrm{~h}$. The resulting suspension was filtered and the solvent removed from the filtrate under vacuum to give a red solid. Methylene chloride $(20 \mathrm{~mL})$ was added to the residue, the volume was reduced to $10 \mathrm{~mL}$, and the mixture was filtered to wash away the red component of the 
material. The remaining yellow solid was washed with pentane $(20 \mathrm{~mL})$ and dried under vacuum to afford $0.69 \mathrm{~g}$ of 1 as a yellow powder $(0.48 \mathrm{mmol}, 64 \%$ yield). X-ray quality crystals were obtained by slow evaporation of a tetrahydrofuran solution of isolated 1. ${ }^{1} \mathrm{H}$ NMR (tetrahydrofuran- $\left.d_{8}, 700 \mathrm{MHz}\right): \delta 0.85\left(\mathrm{~m}, 2 \mathrm{H}, \mathrm{C}_{8} \mathrm{H}_{12}\right), 1.11\left(\mathrm{~m}, 2 \mathrm{H}, \mathrm{C}_{8} \mathrm{H}_{12}\right), 1.18(\mathrm{~s}, 6 \mathrm{H}$, $\left.\mathrm{NCMe}_{2} \mathrm{CH}_{2} \mathrm{OC}\right), 1.24\left(\mathrm{~s}, 6 \mathrm{H}, \overparen{\mathrm{NCMe}_{2} \mathrm{CH}_{2} \mathrm{OC}}\right), 1.31\left(\mathrm{~m}, 2 \mathrm{H}, \mathrm{C}_{8} \mathrm{H}_{12}\right), 1.46(\mathrm{~s}, 6 \mathrm{H}$,

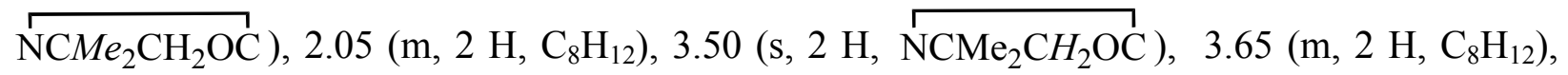
$4.18\left(\mathrm{~d}, 2 \mathrm{H},{ }^{2} J_{\mathrm{HH}}=7.7 \mathrm{~Hz}, \mathrm{NCMe}_{2} \mathrm{CH}_{2} \mathrm{OC}\right), 4.22\left(\mathrm{~m}, 2 \mathrm{H}, \mathrm{C}_{8} \mathrm{H}_{12}\right), 4.26\left(\mathrm{~d}, 2 \mathrm{H},{ }^{2} J_{\mathrm{HH}}=7.7 \mathrm{~Hz}\right.$, $\left.\mathrm{NCMe}_{2} \mathrm{CH}_{2} \mathrm{OC}\right), 7.07\left(\mathrm{t}, 1 \mathrm{H},{ }^{3} J_{\mathrm{HH}}=7.0 \mathrm{~Hz}\right.$, para- $\left.\mathrm{C}_{6} \mathrm{H}_{5}\right), 7.17\left(\mathrm{t}, 2 \mathrm{H},{ }^{3} J_{\mathrm{HH}}=7.0 \mathrm{~Hz}\right.$, meta$\left.\mathrm{C}_{6} \mathrm{H}_{5}\right), 7.25\left(\mathrm{~d}, 2 \mathrm{H},{ }^{3} J_{\mathrm{HH}}=7.0 \mathrm{~Hz}\right.$, ortho- $\left.\mathrm{C}_{6} \mathrm{H}_{5}\right) .{ }^{13} \mathrm{C}\left\{{ }^{1} \mathrm{H}\right\}$ NMR (tetrahydrofuran- $d_{8}, 150 \mathrm{MHz}$ ):

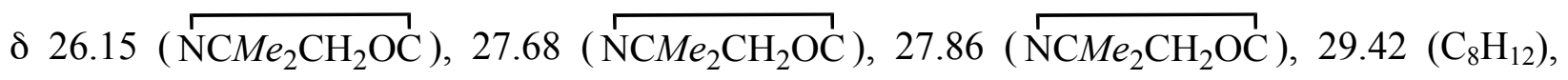

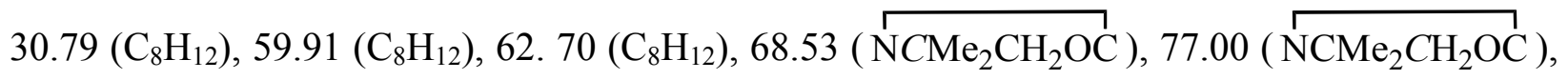

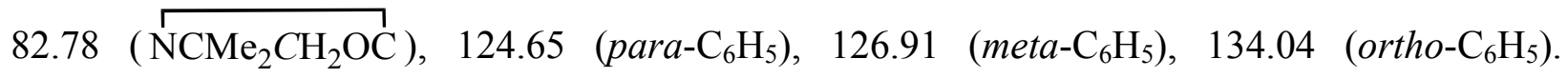
${ }^{15} \mathrm{~N}\left\{{ }^{1} \mathrm{H}\right\}$ NMR (tetrahydrofuran- $\left.d_{8}, 71 \mathrm{MHz}\right): \delta$-145.9 (N-Li), -181.4 (N-Ir). ${ }^{11} \mathrm{~B}$ NMR (benzene$\left.d_{6}, 128 \mathrm{MHz}\right): \delta$-15.7. IR (KBr, $\left.\mathrm{cm}^{-1}\right): v 3064(\mathrm{w}), 2999(\mathrm{w}), 2964(\mathrm{~s}), 2929(\mathrm{~m}), 2881(\mathrm{~m})$, $2835(\mathrm{w}), 1610$ (s), 1573 (s), 1463 (m), 1431 (w), 1363 (w), $1280(\mathrm{~s}), 1199$ (s), 1158 (m), 996 (m), 970 (s), 894 (w), 819 (w), 781 (w), 730 (m). Anal. Calcd. for $\mathrm{C}_{29} \mathrm{H}_{41} \mathrm{BClIrLiN}_{3} \mathrm{O}_{3}$ : C, 48.04; H, 5.70; N, 5.80. Found: C, 48.14; H, 5.78; N, 5.46. mp 250-254 ${ }^{\circ} \mathrm{C}$, dec.

$\left[\operatorname{Ir}\left(\kappa^{2}-N 1, N 2-\mathrm{To}^{\mathrm{M}}-N 3-\mathrm{Me}\right)\left(\eta^{4}-\mathrm{C}_{8} \mathrm{H}_{12}\right)\right][\mathrm{OTf}](2)$.

$\mathrm{CH}_{3} \mathrm{OTf}(1.0 \mathrm{~mL}, 0.152 \mathrm{M}$ in benzene) was added to a benzene solution of compound $\mathbf{1}(0.10 \mathrm{~g}$, $0.069 \mathrm{mmol})$. The solution was stirred overnight, and the color changed from pale orange to yellow-green. The volatile materials were removed under reduced pressure to give a powder, and 
the resulting solid $2(0.075 \mathrm{~g}, 0.087 \mathrm{mmol}, 63 \%)$ was washed with pentane $(10 \mathrm{~mL})$. Slow evaporation of a concentrated tetrahydrofuran solution of $\mathbf{2}$ at room temperature provided X-ray quality crystals. ${ }^{1} \mathrm{H}$ NMR (tetrahydrofuran- $\left.d_{8}, 700 \mathrm{MHz}\right): \delta 0.92\left(\mathrm{~m}, 2 \mathrm{H}, \mathrm{C}_{8} \mathrm{H}_{12}\right), 1.06(\mathrm{~m}, 2 \mathrm{H}$, $\left.\mathrm{C}_{8} \mathrm{H}_{12}\right), 1.24$ (s, $\left.6 \mathrm{H}, \widehat{\mathrm{NCMe}_{2} \mathrm{CH}_{2} \mathrm{OC}}\right), 1.34\left(\mathrm{~m}, 2 \mathrm{H}, \mathrm{C}_{8} \mathrm{H}_{12}\right), 1.47$ (s, $\left.6 \mathrm{H}, \widehat{\mathrm{NCMe}_{2} \mathrm{CH}_{2} \mathrm{OC}}\right), 1.58$ (s, $6 \mathrm{H}, \overparen{\mathrm{NCMe}_{2} \mathrm{CH}_{2} \mathrm{OC}}$ ), $2.11\left(\mathrm{~m}, 2 \mathrm{H}, \mathrm{C}_{8} \mathrm{H}_{12}\right), 3.12(\mathrm{~s}, 3 \mathrm{H}, \mathrm{NCH}), 3.67\left(\mathrm{~m}, 2 \mathrm{H}, \mathrm{C}_{8} \mathrm{H}_{12}\right), 4.19$

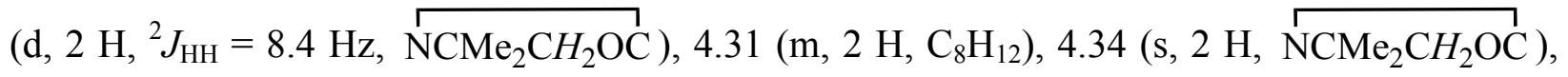
$4.37\left(\mathrm{~d}, 2 \mathrm{H},{ }^{2} J_{\mathrm{HH}}=8.4 \mathrm{~Hz}, \mathrm{NCMe}_{2} \mathrm{CH}_{2} \mathrm{OC}\right), 7.14\left(\mathrm{~d}, 2 \mathrm{H},{ }^{3} J_{\mathrm{HH}}=7.0 \mathrm{~Hz}\right.$, ortho- $\left.\mathrm{C}_{6} \mathrm{H}_{5}\right), 7.21$ (t, 1 $\mathrm{H},{ }^{3} J_{\mathrm{HH}}=7.0 \mathrm{~Hz}, \quad$ para $\left.-\mathrm{C}_{6} \mathrm{H}_{5}\right), 7.17\left(\mathrm{t}, 2 \mathrm{H},{ }^{3} J_{\mathrm{HH}}=7.0 \mathrm{~Hz}\right.$, meta $\left.-\mathrm{C}_{6} \mathrm{H}_{5}\right) .{ }^{13} \mathrm{C}\left\{{ }^{1} \mathrm{H}\right\} \mathrm{NMR}$ (tetrahydrofuran- $\left.d_{8}, 125 \mathrm{MHz}\right): \delta 24.19\left(\widehat{\mathrm{NCMe}_{2} \mathrm{CH}_{2} \mathrm{OC}}\right), 26.21\left(\stackrel{\mathrm{NCMe}_{2} \mathrm{CH}_{2} \mathrm{OC}}{)}\right), 28.15$ ( $\left.\mathrm{NCMe}_{2} \mathrm{CH}_{2} \mathrm{OC}\right), 30.52\left(\mathrm{C}_{8} \mathrm{H}_{12}\right), 31.51\left(\mathrm{C}_{8} \mathrm{H}_{12}\right), 32.41\left(\mathrm{NCH}_{3}\right), 61.57\left(\mathrm{C}_{8} \mathrm{H}_{12}\right), 64.57\left(\mathrm{C}_{8} \mathrm{H}_{12}\right)$,

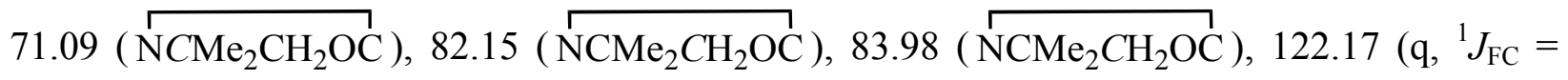
$319 \mathrm{~Hz}, \mathrm{OSO}_{2} \mathrm{CF}_{3}$ ), 127.01 (para- $\mathrm{C}_{6} \mathrm{H}_{5}$ ), 128.62 (meta- $\mathrm{C}_{6} \mathrm{H}_{5}$ ), 134.66 (ortho- $\left.\mathrm{C}_{6} \mathrm{H}_{5}\right) .{ }^{15} \mathrm{~N}\left\{{ }^{1} \mathrm{H}\right\}$ NMR (tetrahydrofuran- $\left.d_{8}, 71 \mathrm{MHz}\right): \delta$-174.7 ( $N$-Ir), -208.8 (N-Me). ${ }^{11} \mathrm{~B}$ NMR (tetrahydrofuran$\left.d_{8}, 128 \mathrm{MHz}\right): \delta-16.1 .{ }^{19} \mathrm{~F}$ NMR (tetrahydrofuran- $\left.d_{8}, 376 \mathrm{MHz}\right): \delta-81.8 \mathrm{IR}\left(\mathrm{KBr}, \mathrm{cm}^{-1}\right): v 3036$ (w), 2969 (m), 2934 (m), 2881 (m), 2836 (w), 1599 (m sh), 1577 (s), 1465 (m), 1434 (w), 1389 (w), 1374 (m), 1322 (s), 1299 (s), 1266 (s), 1183 (s), 1169 (s), 1057 (m), 1043 (s), 1032 (s), 957 (m), 897 (w), 804 (w). Anal. Calcd. for $\mathrm{C}_{31} \mathrm{H}_{44} \mathrm{BF}_{3} \mathrm{IrN}_{3} \mathrm{O}_{6} \mathrm{~S}: \mathrm{C}, 43.97 ; \mathrm{H}, 5.24 ; \mathrm{N}, 4.96$. Found: C, 43.89; H, 5.18; N, 5.38. mp 173- $175^{\circ} \mathrm{C}$, dec.

\section{$\left[\operatorname{Ir}\left(\kappa^{2}-\mathrm{To}^{\mathrm{M}}-\mathrm{N} 3-\mathrm{H}\right)\left(\eta^{4}-\mathrm{C}_{8} \mathrm{H}_{12}\right)\right][\mathrm{OTf}](3)$.}

Compound $1(0.20 \mathrm{~g}, 0.14 \mathrm{mmol})$ was dissolved in benzene $(25 \mathrm{~mL})$, and a benzene solution of triflic acid $(1.8 \mathrm{~mL}, 0.15 \mathrm{M})$ was added. As the mixture was stirred overnight, the color changed 
from pale orange to yellow-green. The solvent was then removed in vacuo, and the resulting solid was washed with pentane $(10 \mathrm{~mL})$ and dried under vacuum to yield $3(0.19 \mathrm{~g}, 0.22 \mathrm{mmol}$, $81 \%)$. X-ray quality crystals were obtained by slow evaporation of a tetrahydrofuran solution at room temperature. ${ }^{1} \mathrm{H}$ NMR (benzene- $\left.d_{6}, 400 \mathrm{MHz}\right): \delta 0.80\left(\mathrm{~s}, 6 \mathrm{H}, \widehat{\mathrm{NCMe}_{2} \mathrm{CH}_{2} \mathrm{OC}}\right.$ ), $0.88(\mathrm{~m}, 2$ $\left.\mathrm{H}, \mathrm{C}_{8} \mathrm{H}_{12}\right), 1.12\left(\mathrm{~m}, 2 \mathrm{H}, \mathrm{C}_{8} \mathrm{H}_{12}\right), 1.16\left(\mathrm{~s}, 6 \mathrm{H}, \overparen{\mathrm{NCMe}_{2} \mathrm{CH}_{2} \mathrm{OC}}\right), 1.19\left(\mathrm{~m}, 2 \mathrm{H} \mathrm{C}_{8} \mathrm{H}_{12}\right), 1.40(\mathrm{~s}, 6$

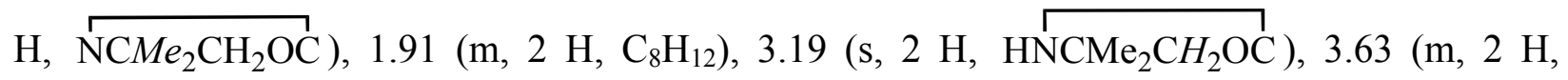
$\left.\mathrm{C}_{8} \mathrm{H}_{12}\right), 3.78\left(\mathrm{~d}, 2 \mathrm{H},{ }^{2} J_{\mathrm{HH}}=8.0 \mathrm{~Hz}, \mathrm{IrNCMe} \mathrm{CH}_{2} \mathrm{OC}\right), 4.10\left(\mathrm{~m}, 2 \mathrm{H}, \mathrm{C}_{8} \mathrm{H}_{12}\right), 4.74\left(\mathrm{~d}, 2 \mathrm{H},{ }^{2} J_{\mathrm{HH}}\right.$ $\left.=8.0 \mathrm{~Hz}, \underset{\mathrm{IrNCMe}}{2} \mathrm{CH}_{2} \mathrm{OC}\right), 7.22\left(\mathrm{t}, 1 \mathrm{H}\right.$, para $\left.-\mathrm{C}_{6} \mathrm{H}_{5}\right), 7.31\left(\mathrm{t}, 2 \mathrm{H}\right.$, meta $\left.-\mathrm{C}_{6} \mathrm{H}_{5}\right), 7.38(\mathrm{~d}, 2 \mathrm{H}$, ${ }^{3} J_{\mathrm{HH}}=7.2 \mathrm{~Hz}$, ortho- $\left.\mathrm{C}_{6} \mathrm{H}_{5}\right), 11.73($ br s, $1 \mathrm{H}, \mathrm{N} H) .{ }^{13} \mathrm{C}\left\{{ }^{1} \mathrm{H}\right\}$ NMR (tetrahydrofuran- $d_{8}, 125$

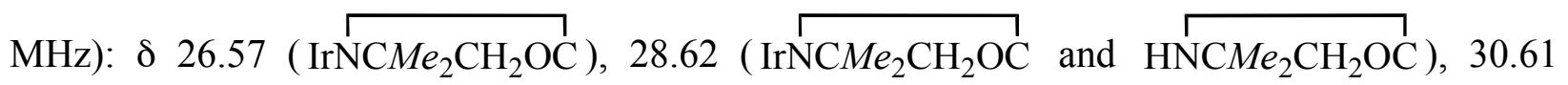
$\left(\mathrm{C}_{8} \mathrm{H}_{12}\right), 31.63\left(\mathrm{C}_{8} \mathrm{H}_{12}\right), 33.01\left(\stackrel{\mathrm{NCMe}_{2} \mathrm{CH}_{2} \mathrm{OC}}{)}\right), 61.28\left(\mathrm{C}_{8} \mathrm{H}_{12}\right), 63.75\left(\stackrel{\mathrm{NCMe}_{2} \mathrm{CH}_{2} \mathrm{OC}}{)}\right), 64.43$

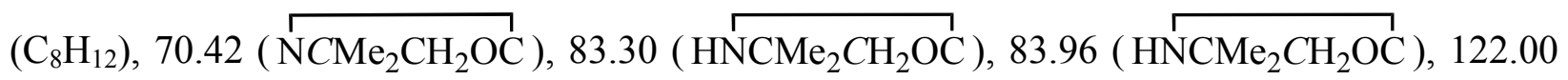
$\left(\mathrm{SO}_{3} \mathrm{CF}_{3}\right), 126.93\left(\mathrm{C}_{6} \mathrm{H}_{5}\right), 128.53\left(\mathrm{C}_{6} \mathrm{H}_{5}\right), 134.66\left(\mathrm{C}_{6} \mathrm{H}_{5}\right) .{ }^{15} \mathrm{~N}\left\{{ }^{1} \mathrm{H}\right\}$ NMR (tetrahydrofuran- $d_{8}, 71$ MHz): $\delta-206.3(N-\mathrm{H}),-180.0\left(N\right.$-Ir). ${ }^{11} \mathrm{~B}$ NMR (benzene- $\left.d_{6}, 128 \mathrm{MHz}\right): \delta-16.3 .{ }^{19} \mathrm{~F}$ NMR (benzene- $\left.d_{6}, 376 \mathrm{MHz}\right): \delta$-78.30. IR $\left(\mathrm{KBr}, \mathrm{cm}^{-1}\right): v 3220$ (br w), 3091 (w), 3007 (m), 2973 (m), 2929 (m), 2878 (m), 2834 (w), 1603 (m sh), 1581 (s), 1463 (m), 1433 (w), 1390 (w), 1373 (m), 1294 (s), 1250 (s), 1225 (m), 1153 (s), 1032 (s), 1005 (m), 961 (m), 727 (m). mp 173-178 C, dec. Anal. Calcd. for $\mathrm{C}_{30} \mathrm{H}_{42} \mathrm{BF}_{3} \mathrm{IrN}_{3} \mathrm{O}_{6} \mathrm{~S}: \mathrm{C}, 43.27 ; \mathrm{H}, 5.08 ; \mathrm{N}, 5.05$. Found: C, 43.12; H, 5.37; N, 4.31 .

\section{$\left[\operatorname{Ir}\left(\operatorname{To}^{\mathrm{M}}\right)(\mathrm{CO})_{2}\right](4)$.}


A Teflon-sealed flask was charged with $1(0.35 \mathrm{~g}, 0.24 \mathrm{mmol})$ dissolved in benzene $(50 \mathrm{~mL})$. The solution was degassed with freeze-pump-thaw cycles, the headspace was evacuated, and carbon monoxide was added. The reaction mixture was stirred vigorously for $18 \mathrm{~h}$ during which time the color changed to pale yellow-green. The volatile materials were removed in vacuo to afford $\left[\operatorname{Ir}\left(\mathrm{To}^{\mathrm{M}}\right)(\mathrm{CO})_{2}\right]$ as a pale yellow powder $(0.23 \mathrm{~g}, 0.37 \mathrm{mmol}, \quad 77 \%) .{ }^{1} \mathrm{H}$ NMR (tetrahydrofuran- $\left.d_{8}, 700 \mathrm{MHz}\right): \delta 1.27\left(\mathrm{~s}, 18 \mathrm{H}, \stackrel{\mathrm{NCMe}_{2} \mathrm{CH}_{2} \mathrm{OC}}{)}\right), 3.93\left(\mathrm{~s}, 6 \mathrm{H}, \stackrel{\mathrm{NCMe}_{2} \mathrm{CH}_{2} \mathrm{OC}}{\mathrm{N}^{2}}\right.$, $6.91\left(\mathrm{t}, 1 \mathrm{H},{ }^{3} J_{\mathrm{HH}}=7.7 \mathrm{~Hz}\right.$, para $\left.-\mathrm{C}_{6} \mathrm{H}_{5}\right), 6.97\left(\mathrm{t}, 2 \mathrm{H},{ }^{3} J_{\mathrm{HH}}=7.7 \mathrm{~Hz}\right.$, meta $\left.-\mathrm{C}_{6} \mathrm{H}_{5}\right), 7.29(\mathrm{~d}, 2 \mathrm{H}$, ${ }^{3} J_{\mathrm{HH}}=7.0 \mathrm{~Hz}$, ortho- $\left.\mathrm{C}_{6} \mathrm{H}_{5}\right) .{ }^{13} \mathrm{C}\left\{{ }^{1} \mathrm{H}\right\} \quad \mathrm{NMR}$ (tetrahydrofuran-d8, $150 \mathrm{MHz}$ ): $\delta \quad 25.68$

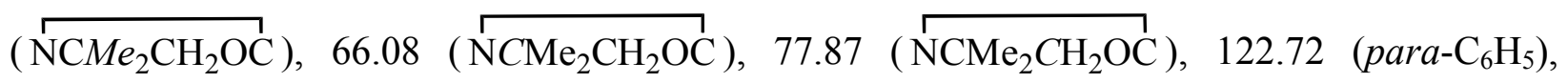
$124.05\left(\right.$ meta $\left.-\mathrm{C}_{6} \mathrm{H}_{5}\right), 132.50\left(\right.$ ortho $\left.-\mathrm{C}_{6} \mathrm{H}_{5}\right) .{ }^{15} \mathrm{~N} \mathrm{NMR}$ (tetrahydrofuran- $\left.d_{8}, 71 \mathrm{MHz}\right): \delta-167.1 .{ }^{11} \mathrm{~B}$ NMR (tetrahydrofuran- $\left.d_{8}, 128 \mathrm{MHz}\right): \delta$-18.7. IR $\left(\mathrm{CH}_{2} \mathrm{Cl}_{2}, \mathrm{~cm}^{-1}\right): v 2970(\mathrm{~m}), 2931(\mathrm{w}), 2898$ (w), 2066 (s), 2029 (w), 1989 (s), 1934 (w), 1613 (w), 1566 (m), $1461(w), 1391(w), 1364$ (m), 1291 (m), 1205 (m), 1166 (w), 989 (m). Anal. Calcd. for $\mathrm{C}_{23} \mathrm{H}_{31} \mathrm{BIrN}_{3} \mathrm{O}_{5}: \mathrm{C}, 43.67 ; \mathrm{H}, 4.94 ; \mathrm{N}$,

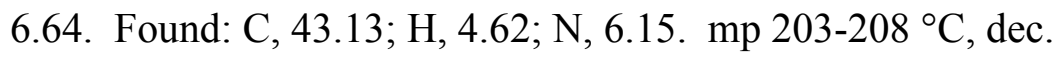

\section{$\left[\operatorname{Ir}\left(\kappa^{2}-T^{M}-N 3-M e\right)(\mathrm{CO})_{2}\right][O T f](5)$.}

A $50 \mathrm{~mL}$ Schlenk flask was charged with $4(0.10 \mathrm{~g}, 0.16 \mathrm{mmol})$, benzene $(25 \mathrm{~mL})$, and $1.0 \mathrm{~mL}$ of MeOTf (0.152 $\mathrm{M}$ in benzene). After the solution was stirred overnight, the color changed from pale orange to yellow-green. The volatile materials were removed in vacuo, and the resulting solid was washed with pentane $(10 \mathrm{~mL})$ to give $0.068 \mathrm{~g}$ of $5(0.09 \mathrm{mmol}, 53 \%) .{ }^{1} \mathrm{H}$ NMR (tetrahydrofuran- $\left.d_{8}, 400 \mathrm{MHz}\right): \delta 1.45\left(\mathrm{~s}, 6 \mathrm{H}, \underset{\operatorname{IrNCMe}}{2} \mathrm{CH}_{2} \mathrm{OC}\right), 1.51(\mathrm{~s}, 6 \mathrm{H}$,

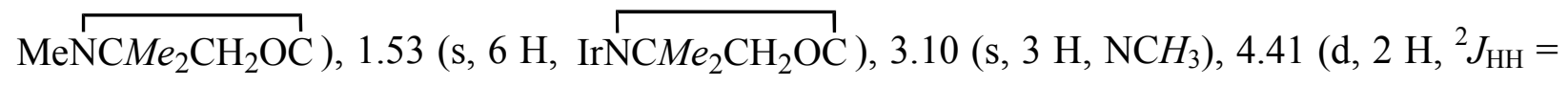




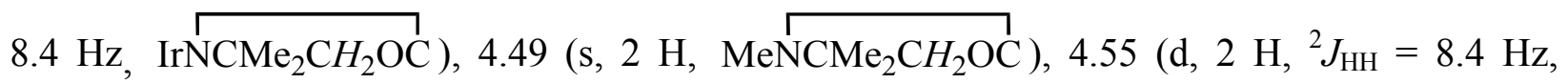
IrNCMe $\left.{ }_{2} \mathrm{CH}_{2} \mathrm{OC}\right), 7.10\left(\mathrm{~d}, 2 \mathrm{H},{ }^{3} J_{\mathrm{HH}}=6.4 \mathrm{~Hz}\right.$, ortho- $\left.\mathrm{C}_{6} \mathrm{H}_{5}\right), 7.15-7.22(\mathrm{~m}, 3 \mathrm{H}$, para- and meta$\left.\mathrm{C}_{6} \mathrm{H}_{5}\right) .{ }^{13} \mathrm{C}\left\{{ }^{1} \mathrm{H}\right\} \quad \mathrm{NMR}$ (tetrahydrofuran- $\left.d_{8}, 125 \mathrm{MHz}\right): \delta 24.12\left(\stackrel{\mathrm{NCMe}_{2} \mathrm{CH}_{2} \mathrm{OC}}{)}\right), 27.91$ $\left(\stackrel{\mathrm{NCMe}_{2} \mathrm{CH}_{2} \mathrm{OC}}{)}, 28.18\left(\stackrel{\mathrm{NCMe}_{2} \mathrm{CH}_{2} \mathrm{OC}}{\mathrm{O}}\right), 31.14\left(\mathrm{NCH}_{3}\right), 71.17\left(\stackrel{\mathrm{NCMe}_{2} \mathrm{CH}_{2} \mathrm{OC}}{ }\right), 82.46\right.$

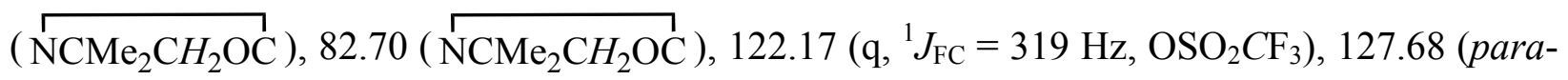
$\left.\mathrm{C}_{6} \mathrm{H}_{5}\right), 128.74$ (meta- $\left.\mathrm{C}_{6} \mathrm{H}_{5}\right), 133.85$ (ortho $\left.-\mathrm{C}_{6} \mathrm{H}_{5}\right), 173.65(C \mathrm{O}) .{ }^{15} \mathrm{~N}\left\{{ }^{1} \mathrm{H}\right\}$ NMR (tetrahydrofuran$\left.d_{8}, 71 \mathrm{MHz}\right):-211.0(N-\mathrm{Me}),-181.0(N-\mathrm{Ir}) .{ }^{11} \mathrm{~B}$ NMR (tetrahydrofuran- $\left.d_{8}, 128 \mathrm{MHz}\right): \delta-16.5$. ${ }^{19}$ F NMR (tetrahydrofuran- $\left.d_{8}, 376 \mathrm{MHz}\right): \delta$-81.8. IR $\left(\mathrm{KBr}, \mathrm{cm}^{-1}\right): v 3072(\mathrm{w}), 3006(\mathrm{w}), 2976$ (m), 2937 (w), 2069 (s), 1997 (s), 1602 (m), 1575 (s), 1541 (w), 1479 (w), 1461 (m), 1435 (w), 1392 (w), 1297 (s), 1279 (s), 1257 (s), 1224 (w), 1208 (w), 1154 (s), 1031 (s), 956 (m). Anal. Calcd. for $\mathrm{C}_{28} \mathrm{H}_{35} \mathrm{BF}_{3} \mathrm{IrN}_{3} \mathrm{O}_{9} \mathrm{~S}: \mathrm{C}, 39.58 ; \mathrm{H}, 4.15 ; \mathrm{N}, 4.95$. Found: C, 39.74; H, 4.17; N, 4.89. mp $145-147^{\circ} \mathrm{C}$.

\section{$\left[\operatorname{Ir}\left(\kappa^{2}-T^{M}-N 3-H\right)(C O)_{2}\right][O T f](6)$}

A flask was charged with $\left[\operatorname{Ir}\left(\mathrm{To}^{\mathrm{M}}\right)(\mathrm{CO})_{2}\right](0.1 \mathrm{~g}, 0.16 \mathrm{mmol})$ dissolved in benzene $(25 \mathrm{~mL})$. A benzene solution of triflic acid $(1.0 \mathrm{~mL}, 0.15 \mathrm{M})$ was added in a dropwise fashion. The solution was stirred overnight, and the color became yellow-green. All volatile materials were removed in vacuo to provide a yellow solid, which was washed with pentane $(10 \mathrm{~mL})$ and dried under vacuum. Compound 6 was isolated in $63 \%$ yield $(0.080 \mathrm{~g}, 0.10 \mathrm{mmol}) .{ }^{1} \mathrm{H}$ NMR (tetrahydrofuran- $\left.d_{8}, 500 \mathrm{MHz}\right): \delta 1.43 \quad\left(\mathrm{~s}, \quad 6 \quad \mathrm{H}, \quad \underset{\operatorname{IrNCMe}}{2 \mathrm{CH}_{2} \mathrm{OC}}\right), \quad 1.50 \quad(\mathrm{~s}, \quad 6 \quad \mathrm{H}$,

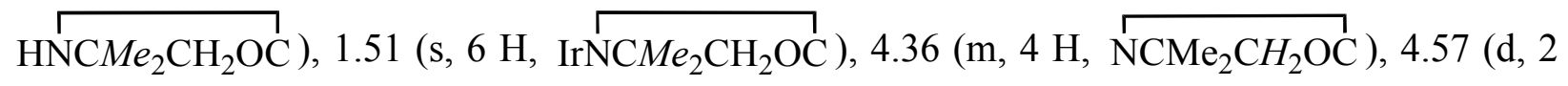


$\left.\mathrm{H}, \underset{\mathrm{NCMe}_{2} \mathrm{CH}_{2} \mathrm{OC}}{ }\right), 7.09\left(\mathrm{~d}, 2 \mathrm{H},{ }^{3} J_{\mathrm{HH}}=8.8 \mathrm{~Hz}\right.$, ortho- $\left.\mathrm{C}_{6} \mathrm{H}_{5}\right), 7.13-7.20(\mathrm{~m}, 3 \mathrm{H}$, para- and meta- $\mathrm{C}_{6} \mathrm{H}_{5}$ ), $11.92(\mathrm{~s}, 1 \mathrm{H}, \mathrm{N} H) .{ }^{13} \mathrm{C}\left\{{ }^{1} \mathrm{H}\right\}$ NMR (tetrahydrofuran- $d_{8}, 125 \mathrm{MHz}$ ): $\delta 26.57$ $\left(\stackrel{\mathrm{NCMe}_{2} \mathrm{CH}_{2} \mathrm{OC}}{)}, 27.92\left(\stackrel{\mathrm{NCMe}_{2} \mathrm{CH}_{2} \mathrm{OC}}{)}, 28.50\left(\stackrel{\mathrm{NCMe}_{2} \mathrm{CH}_{2} \mathrm{OC}}{)}, 63.89\left(\stackrel{\mathrm{NCMe}_{2} \mathrm{CH}_{2} \mathrm{OC}}{)}\right)\right.\right.\right.$, $70.54\left(\stackrel{\mathrm{NCMe}_{2} \mathrm{CH}_{2} \mathrm{OC}}{)}\right), 82.58\left(\widehat{\mathrm{NCMe}_{2} \mathrm{CH}_{2} \mathrm{OC}}\right), 83.48\left(\widehat{\mathrm{NCMe}_{2} \mathrm{CH}_{2} \mathrm{OC}}\right), 121.93\left(\mathrm{q},{ }^{1} J_{\mathrm{FC}}=\right.$ $320 \mathrm{~Hz}, \mathrm{OSO}_{2} \mathrm{CF}_{3}$ ), $127.46\left(\right.$ para $\left.-\mathrm{C}_{6} \mathrm{H}_{5}\right), 128.57$ (meta- $\mathrm{C}_{6} \mathrm{H}_{5}$ ), 133.78 (ortho- $\mathrm{C}_{6} \mathrm{H}_{5}$ ), 174.20 (CO). ${ }^{15} \mathrm{~N}\left\{{ }^{1} \mathrm{H}\right\}$ NMR (tetrahydrofuran- $\left.d_{8}, 71 \mathrm{MHz}\right): \delta-207.1(N-\mathrm{H}),-161.4(N-\mathrm{Ir}) .{ }^{11} \mathrm{~B}$ NMR (tetrahydrofuran- $d_{8}, 128 \mathrm{MHz}$ ): $\delta-16.6 .{ }^{19} \mathrm{~F}$ NMR (tetrahydrofuran- $d_{8}, 376 \mathrm{MHz}$ ): $\delta-79.8$. IR (KBr, cm ${ }^{-1}$ ): v 3237 (br w), 2974 (m), 2933 (w), 2880 (w sh), 2067 (s), 1990 (s), 1584 (br s), 1464 (m), 1434 (w), 1392 (w), 1373 (w), 1295 (s), 1248 (s), 1208 (w), 1164 (m), 1043 (m), 1030 (m), 967 (w). Anal. Calcd. for $\mathrm{C}_{24} \mathrm{H}_{32} \mathrm{BF}_{3} \mathrm{IrN}_{3} \mathrm{O}_{8} \mathrm{~S}: \mathrm{C}, 36.83 ; \mathrm{H}, 4.12$; N, 5.37. Found: C, 36.61; H, 4.10; N, 5.14. mp $76-85^{\circ} \mathrm{C}$, dec.

\section{Details of the Density Functional Theory Calculations}

All calculations were performed with the NWChem software suite. ${ }^{25}$ Density functional theory (DFT) was employed using the $\mathrm{B}^{2} \mathrm{LYP}^{22}$ hybrid functional to obtain optimized geometries and frequencies (see supplementary material). Energies were also calculated using DFT with the B3LYP functional and include the zero point energy correction. The Los Alamos double- $\zeta$ ECP $\left(\right.$ LANL2DZ) ${ }^{26}$ was used for iridium and the $6-311+\mathrm{G}^{* 27}$ basis set was used for all other atoms. Linear dependencies were determined using a tolerance of $5 \times 10^{-7}$ for the orbital overlap. Orbitals with overlap values greater than this threshold were deemed linearly dependent and subsequently removed. Additionally, the energy convergence was tightened to $10^{-11}$ hartree. All structures reported have positive second derivatives with respect to coordinates, indicating that 
they are all minima on the potential energy surface. The corrections for the $v_{\mathrm{CO} 23}$ are similar to those found for other similar B3LYP calculations. ${ }^{28}$ 


\section{Chart 1}

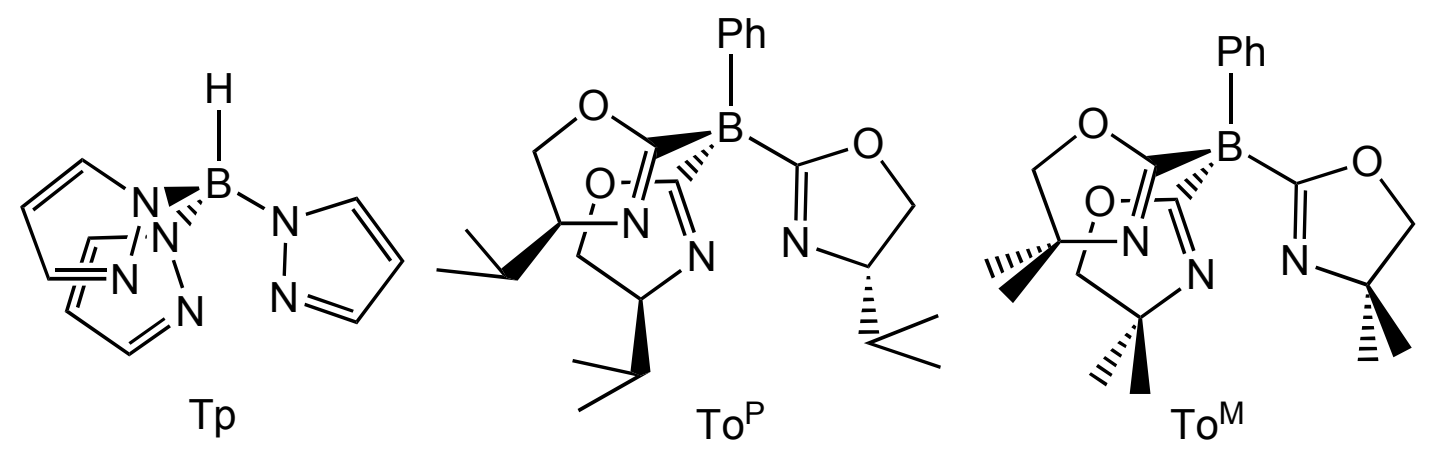


Figure 1. ORTEP diagram of $\left[\left(\eta^{4}-\mathrm{C}_{8} \mathrm{H}_{12}\right) \operatorname{Ir}\left(\mu-\kappa^{2}-N 1, N 2-\mathrm{To}^{\mathrm{M}}-\kappa^{2}-N 3, O 2\right) \mathrm{Li}(\mu-\mathrm{Cl})\right]_{2}(\mathbf{1})$. Hydrogen atoms and a co-crystallized tetrahydrofuran molecule are not shown (for clarity), and the ellipsoids are drawn at 50\% probability. Bond distances: Ir1-N1, 2.107(5) and Ir1-N2, 2.107(6) $\AA$.

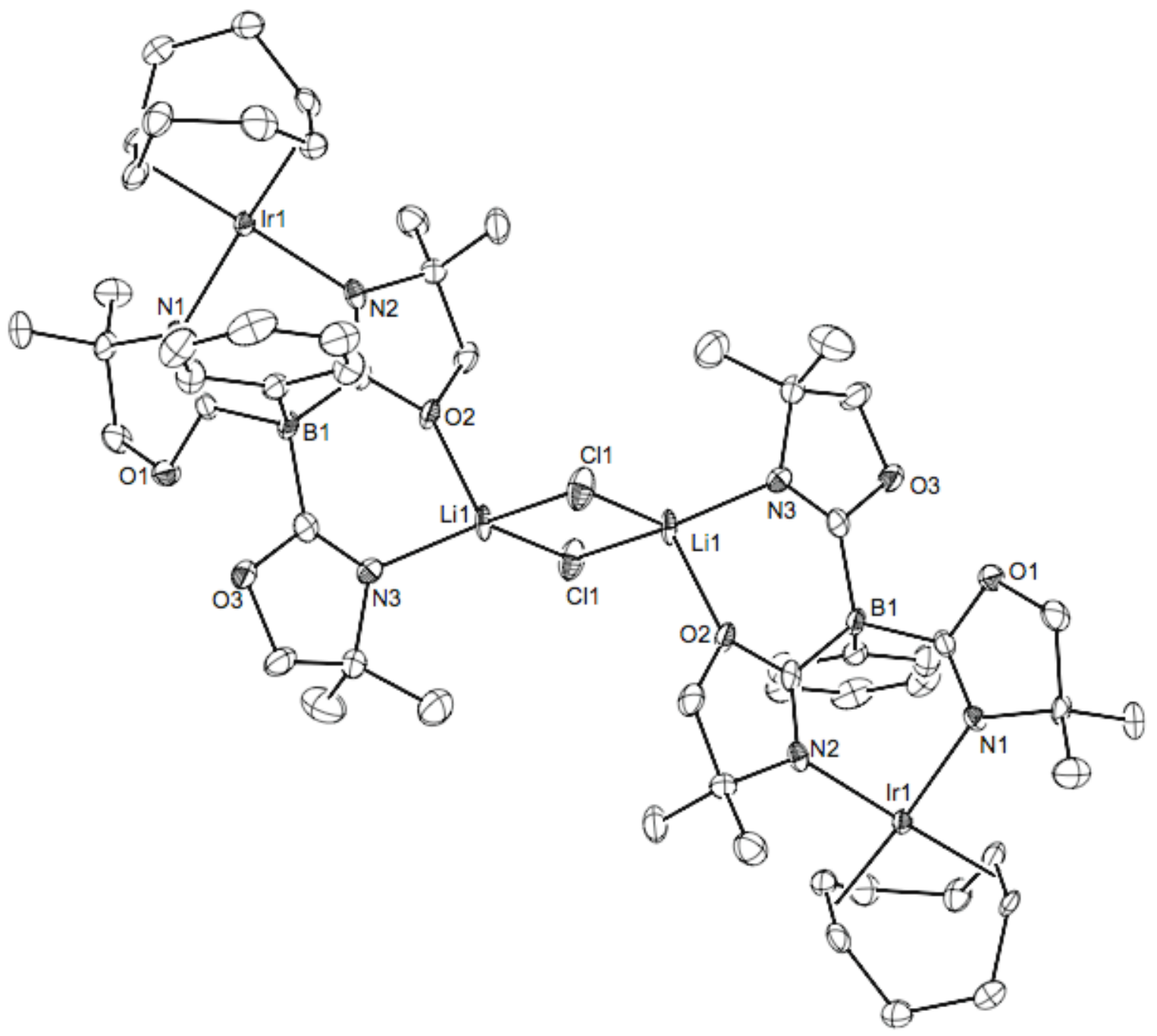


Figure 2. A: $O$-coordinated benzoxazole, oxazole, or oxazoline, and B: bridging $\mathrm{M}-\mathrm{Ox}-\mathrm{M}^{\prime}$ benzoxazole/oxazole/oxazoline structures.<smiles></smiles><smiles>[M]Oc1cccccc1=[N+]=[N-]</smiles>

Figure 3. ORTEP diagram of $\left[\operatorname{Ir}\left(\kappa^{2}-\mathrm{To}^{\mathrm{M}}-\mathrm{Me}\right)\left(\eta^{4}-\mathrm{C}_{8} \mathrm{H}_{12}\right)\right][\mathrm{OTf}](2)$. Centroids are drawn at 50\% probability. Hydrogen atoms, OTf ${ }^{-}$counterion, and a co-crystallized tetrahydrofuran molecule are omitted for clarity. Distances ( $\AA)$ : Ir1-N1, 2.105(6); Ir1-N2, 2.140(6); N3-C15, 1.45(1).

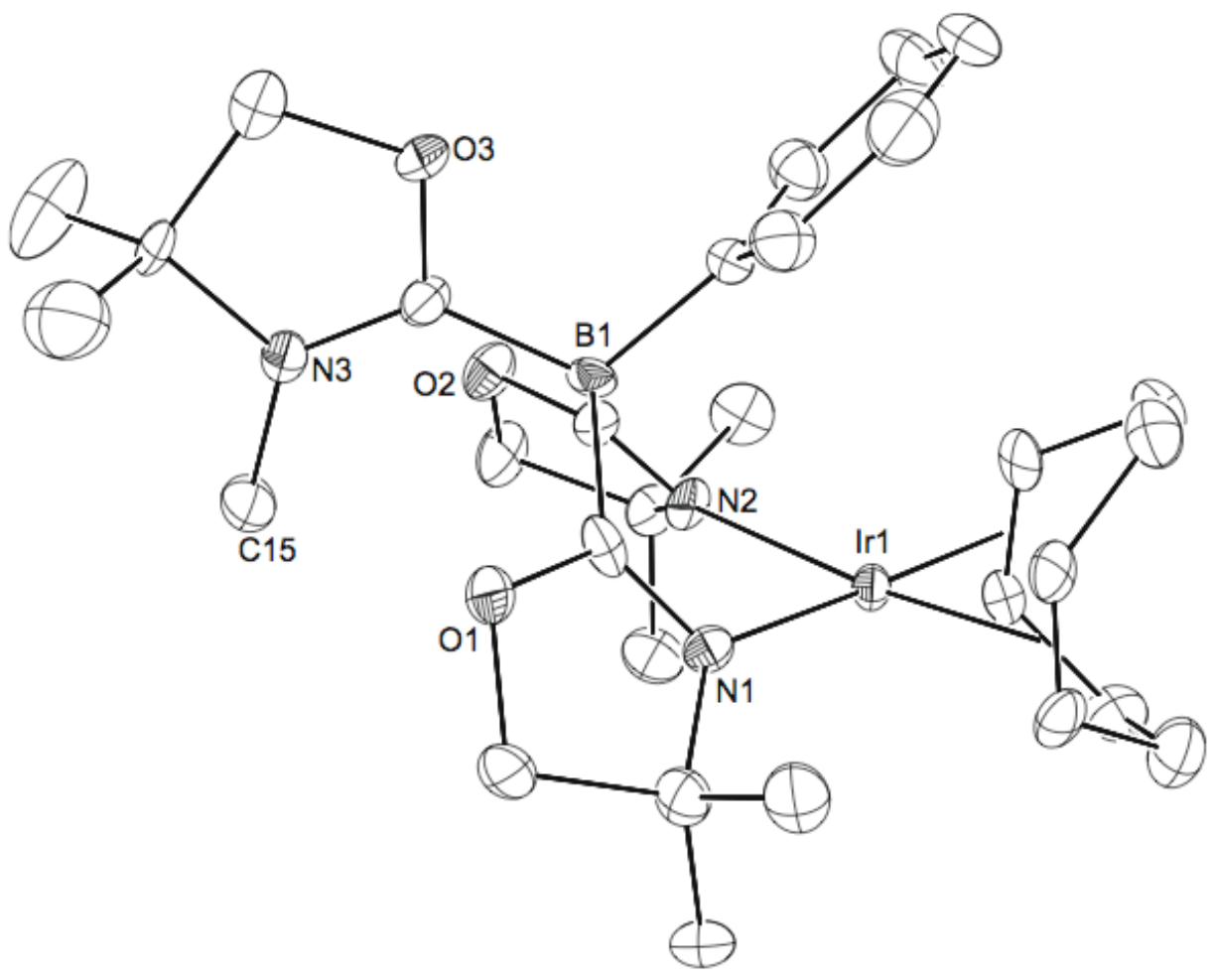


Figure 4. ORTEP diagram of $\left[\operatorname{Ir}\left(\kappa^{2}-\mathrm{To}^{\mathrm{M}}-\mathrm{H}\right)\left(\eta^{4}-\mathrm{C}_{8} \mathrm{H}_{12}\right)\right][\mathrm{OTf}](\mathbf{3})$. Centroids are drawn at $50 \%$ probability. Hydrogen atoms (except for the hydrogen on the protonated oxazoline), the OTf counterion, and a co-crystallized tetrahydrofuran molecule are hidden for clarity. Distances (given in $\AA$ ): Ir1-N1, 2.098(8); Ir1-N2, 2.120(6); N3-H3 was not refined.

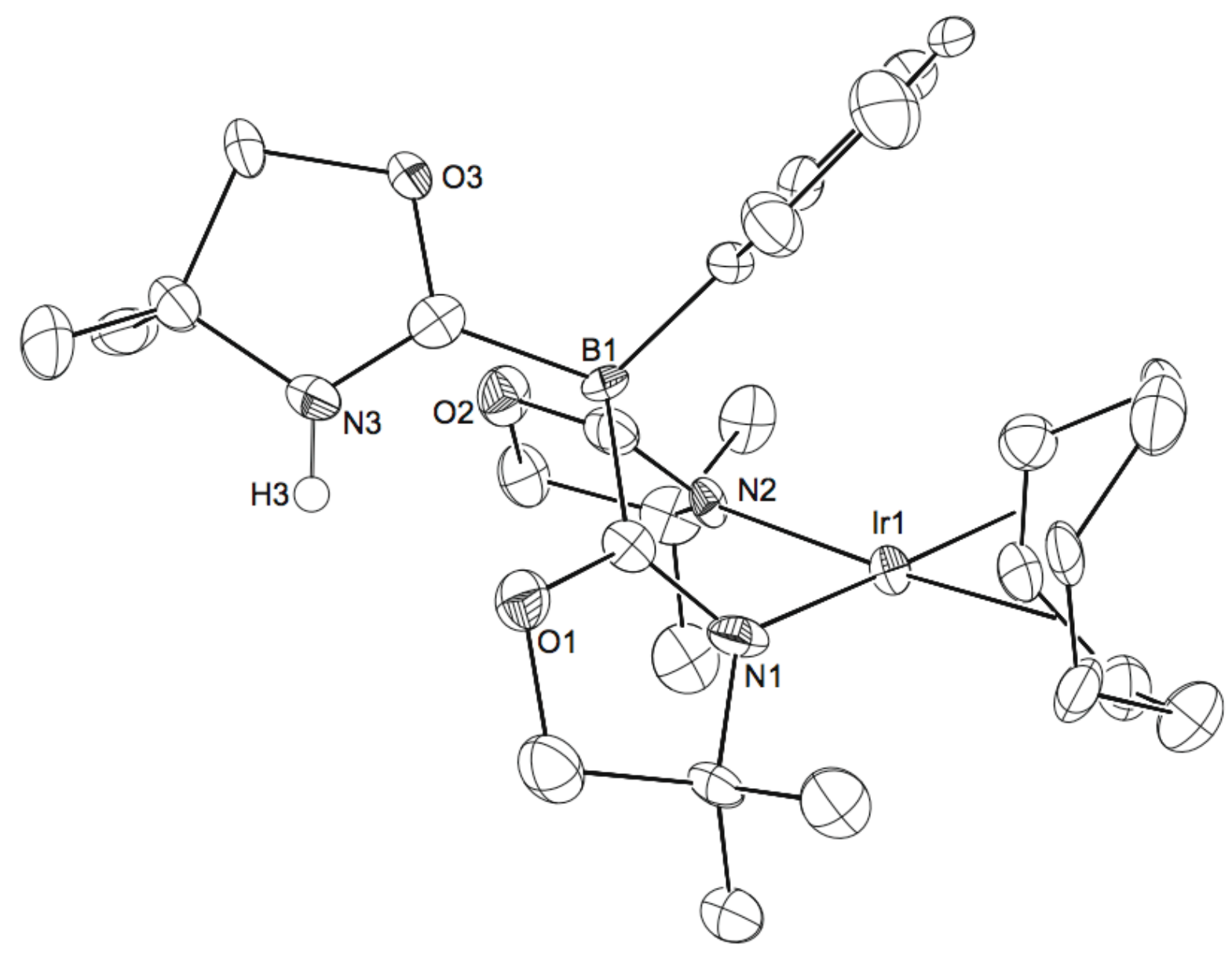


Figure 5. ORTEP diagram of $\left[\operatorname{Ir}\left(\kappa^{2}-\mathrm{To}^{\mathrm{M}}-\mathrm{Me}\right)(\mathrm{CO})_{2}\right][\mathrm{OTf}](\mathbf{5})$. Centroids are drawn at 50\% probability. Hydrogen atoms, the OTf- counterion, and a co-crystallized benzene molecule are hidden for clarity. Distances (given in Å): Ir1-N1, 2.090(8); Ir1-N2, 2.074(8); Ir1-C23, 1.82(2); Ir1-C24, 1.87(1); C23-O4, 1.17(2); C24-O5, 1.12(1); N3-C16, 1.46(1). Angles given in ${ }^{\circ}$ : C23Ir1-C24, 87.1(5); N1-Ir1-N2, 85.9(3); N1-Ir1-C23, 93.2(4); N2-Ir1-C24 94.0(4).

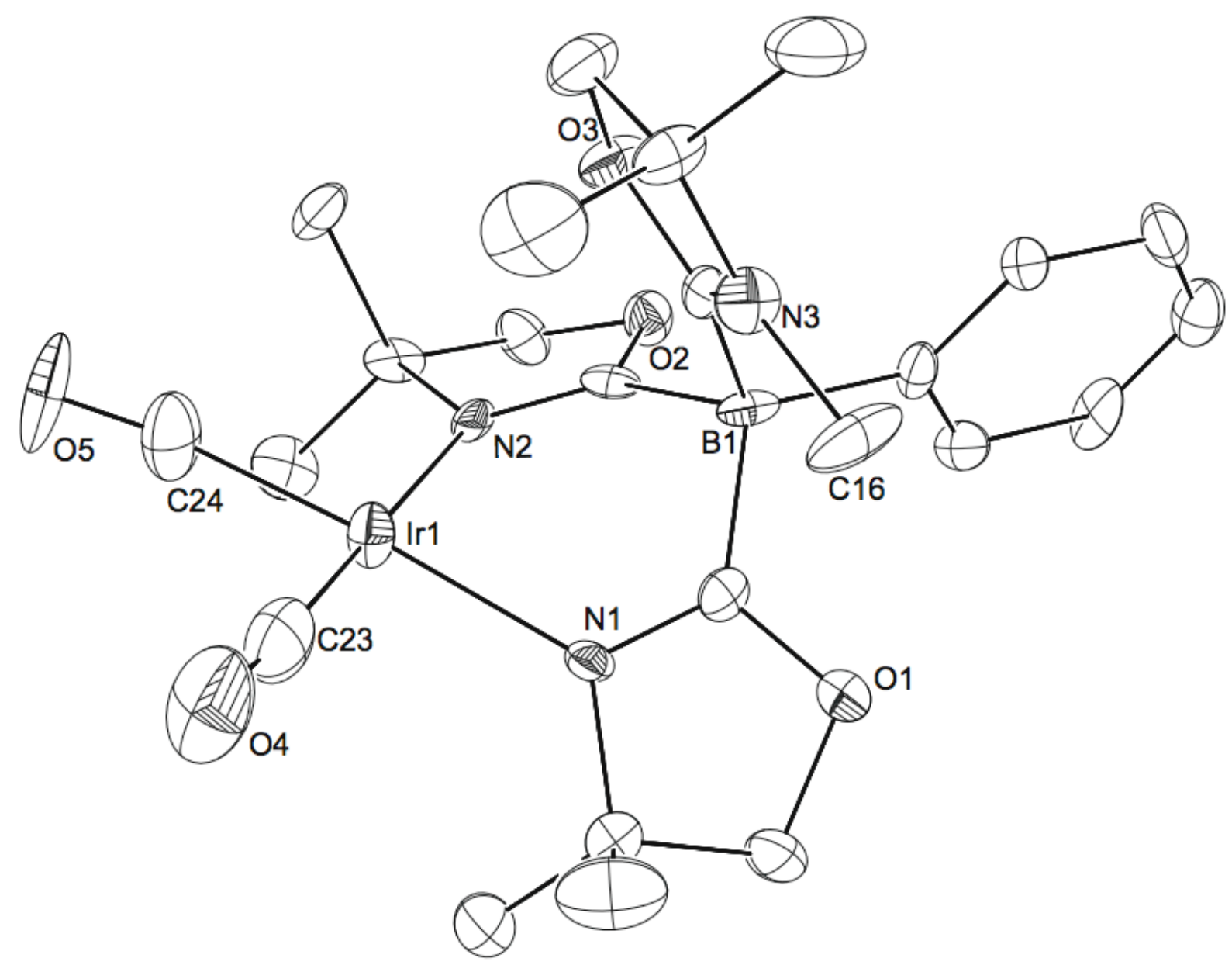


Figure 6. Rendered structures of $\left[\operatorname{Ir}\left(\kappa^{2}-\mathrm{To}^{\mathrm{X}}\right)(\mathrm{CO})_{2}\right]$ (A) illustrating the Kohn-Sham orbitals for a) HOMO-2, b) HOMO-1, c) HOMO, and d) LUMO. The relative energies for each orbital are given in $\mathrm{eV}$.

a) HOMO-2 (-0.252 eV)

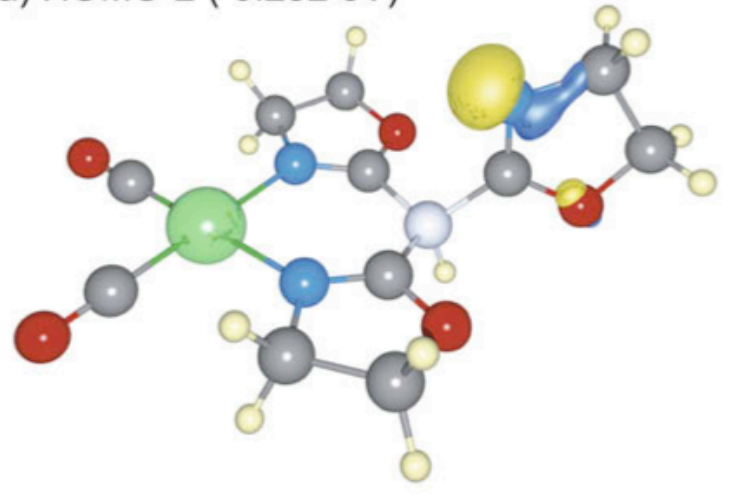

c) $\mathrm{HOMO}(-0.226 \mathrm{eV})$

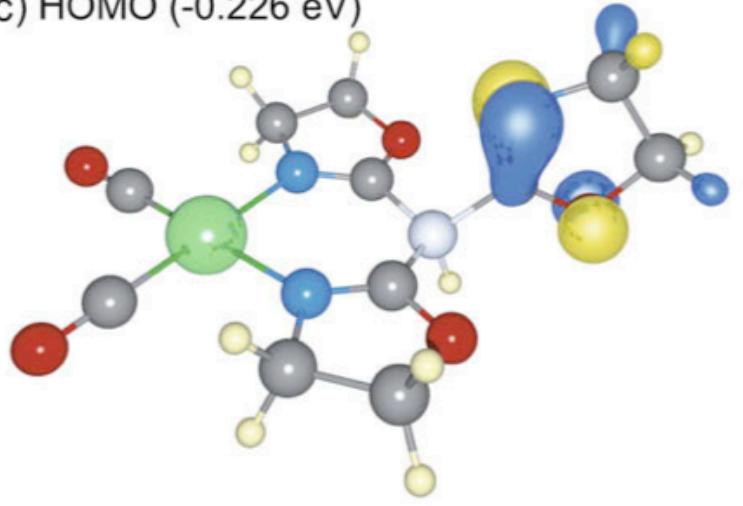

b) $\mathrm{HOMO}-1(-0.246 \mathrm{eV})$

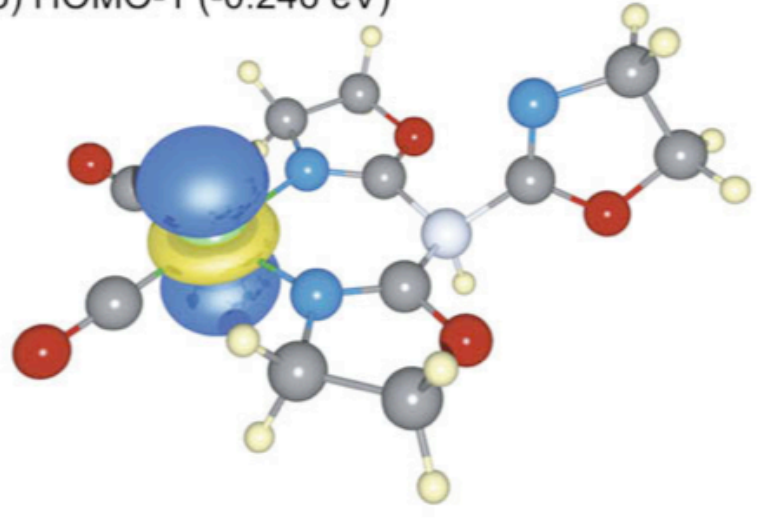

d) LUMO (-0.071 eV)

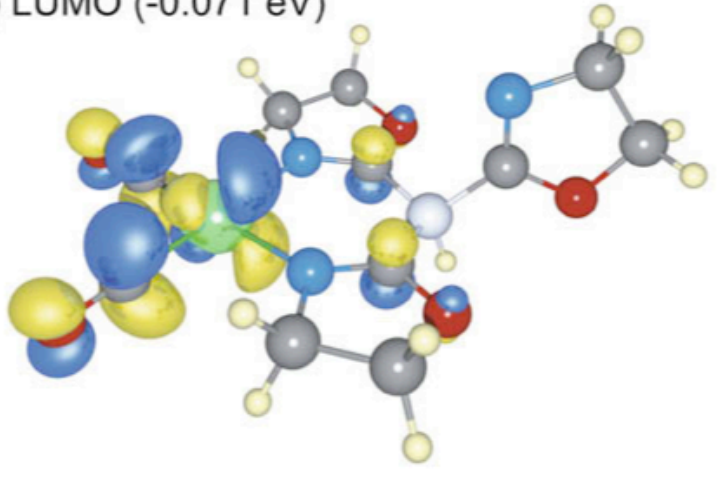




\section{References}

${ }^{1}$ Trofimenko, S. Scorpionates: The Coordination Chemistry of Polypyrazolylborate Ligands, 1999, Imperial College Press.

${ }^{2}$ Ghosh, C. K.; Graham, W. A. G. J. Am. Chem. Soc. 1987, 109, 4726.

${ }^{3}$ Keyes, M. C.; Young Jr., V. G.; Tolman,W. B. Organometallics 1996, 15, 4133.

${ }^{4}$ Teuma, E.; Malbosc, F.; Pons, V.; Serra-Le Berre, C.; Jaud, J.; Etienne, M.; Kalck, P. J. Chem. Soc., Dalton Trans. 2001, 2225.

${ }^{5}$ Ghosh, C. K.; Graham, W. A. G. J. Am. Chem. Soc. 1989, 111, 375.

${ }^{6}$ Baird, B.; Pawlikowski, A. V.; Su, J.; Wiench, J. W.; Pruski, M.; Sadow, A. D. Inorg. Chem. 2008, 47, 10208.

${ }^{7}$ Ball, R. G.; Ghosh, C. K.; Hoyano, J. K.; McMaster, A. D.; Graham, W. A. G. J. Chem. Soc., Chem. Commun. 1989, 341. Bovens, M.; Gerfin, T.; Gramlich, V.; Petter, W.; Venanzi, L. M.; Haward, M. T.; Jackson, S. A.; Eisenstein, O. New J. Chem. 1992, 16, 337. Wiley, J. S.; Heinekey, D. M. Inorg. Chem. 2002, 41, 4961 .

${ }^{8}$ Cowley, R. E.; Bontchev, R. P.; Duesler, E. N.; Smith, J. M. Inorg. Chem. 2006, 45, 9771.

${ }^{9}$ Chauby, V.; Daran, J. C.; Serra-Le Berre, C.; Malbosc, F.; Kalck, P.; Gonzalez, O. D.; Haslam, C. E.; Haynes, A. Inorg. Chem. 2002, 41, 3280.

${ }^{10}$ Gade, L. H.; Marconi, G.; Dro, C.; Ward, B. D.; Poyatos, M.; Bellemin-Laponnaz, S.;

Wadepohl, H.; Sorace, L.; Poneti, G. Chem.- Eur. J. 2007, 13, 3058. 
${ }^{11}$ Dunne, J. F.; Su, J. C.; Ellern, A.; Sadow, A. D. Organometallics 2008, 27, 2399.

${ }^{12}$ Gao, L. H.; Guan, M.; Wang, K. Z.; Jin, L. P.; Huang, C. H. Eur. J. Inorg. Chem. 2006, 3731.

${ }^{13}$ Duff, E. J.; Hughes, M. N.; K. Rutt, J. J. Chem. Soc. A 1969, 2126. Duff, E. J.; Hughes, M. N. J. Chem. Soc. A 1969, 477.

${ }^{14}$ Ponticelli, G.; Massacesi, M.; Sastry, B. A.; Balaiah, B.; Subramanian, R.; Chary, M. M. Indian J. Pure Appl. Phys. 1986, 24, 206.

${ }^{15}$ Devoto, G.; Biddau, M.; Massacesi, M.; Pinna, R.; Ponticelli, G.; Tat'yanenko, L. V.; Zakharova, I. A. J. Inorg. Biochem. 1983, 19, 311.

${ }^{16}$ Wehman, E.; Van Koten, G.; Jastrzebski, J. T. B. H.; Rotteveel, M. A.; Stam, C. H. Organometallics 1988, 7, 1477.

${ }^{17}$ Gott, A. L.; Clarkson, G. J.; Deeth, R. J.; Hammond, M. L.; Morton, C.; Scott, P. J. Chem. Soc., Dalton Trans. 2008, 2983.

${ }^{18}$ van Assema, S. G. A.; Tazelaar, C. G. J.; Bas de Jong, G.; van Maarseveen, J. H.; Schakel, M.; Lutz, M.; Spek, A. L.; Slootweg, J. C.; Lammertsma, K. Organometallics 2008, 27, 3210.

Reger, D. L.; Gardinier, J. R.; Grattan, T. C.; Smith, M. D. J. Organomet. Chem. 2005, 690, 1901. Mueller, H.; Bauer-Siebenlist, B.; Csapo, E.; Dechert, S.; Farkas, E.; Meyer, F. Inorg. Chem. 2008, 47, 5278. Krummenacher, I.; Rueegger, H.; Breher, F. J. Chem. Soc., Dalton Trans. 2006, 1073.

${ }^{19}$ Cordero, B.; Gomez, V.; Platero-Prats, A. E.; Reves, M.; Echeverria, J.; Cremades, E.; Barragan, F.; Alvarez, S. J. Chem. Soc., Dalton Trans. 2008, 2832. 
${ }^{20}$ Bucher, U. E.; Currao, A.; Nesper, R.; Ruegger, H.; Venanzi, L. M.; Younger, E. Inorg. Chem. 1995, 34, 66. Northcutt, T. O.; Lachicotte, R. J.; Jones, W. D. Organometallics 1998, 17, 5148. Akita, M.; Ohta, K.; Takahashi, Y.; Hikichi, S.; Moro-oka, Y. Organometallics 1997, 16, 4121. Akita, M.; Hashinoto, M.; Hikichi, S.; Moro-oka, Y. Organometallics 2000, 19, 3744.

${ }^{21}$ Foltz, C.; Enders, D.; Bellemin-Laponnaz, S.; Wadepohl, H.; Gade, L. H. Chem.-Eur. J. 2007, $13,5994$.

${ }^{22}$ Becke, A. D. J. Chem. Phys. 1993, 98, 5648. Lee, C. T.; Yang, W. T.; Parr, R. G. Phys. Rev. B 1988, $37,785$.

${ }^{23}$ Scaling factors of 0.969 (symmetric) and 0.965 (asymmetric), determined by comparison of calculated and experimental $v_{\mathrm{CO}}$ for $\left[\mathrm{Cp} * \operatorname{Ir}(\mathrm{CO})_{2}\right]$ were used to correct the raw values.

${ }^{24}$ Herde, J. L.; Lambert, J. C.; Senoff, C. V. Inorg. Synth. 1974, 15, 18.

${ }^{25}$ Kendall, R. A.; Apra, E.; Bernholdt, D. E.; Bylaska, E. J.; Dupuis, M.; Fann, G. I.; Harrison, R. J.; Ju, J.; Nichols, J. A.; Nieplocha, J.; Straatsma, T. P.; Windus, T. L.; Wong, A. T. Computer Phys. Comm. 2000, 128, 260. Bylaska, E. J.; de Jong, W. A.; Govind, N.; Kowalski, K.;

Straatsma, T. P.; Valiev, M.; Wang, D.; Apra, E.; Windus, T. L.; Hammond, J.; Nichols, P.; Hirata, S.; Hackler, M. T.; Zhao, Y.; Fan, P. D.; Harrison, R. J.; Dupuis, M.; Smith, D. M. A.; Nieplocha, J.; Tipparaju, V.; Krishnan, M.; Wu, Q.; Voorhis, T. V.; Auer, A. A.; Nooijen, M.; Brown, E.; Cisneros, G.; Fann, G. I.; Fruchtl, H.; Garza, J.; Hirao, K.; Kendall, R.; Nichols, J. A.; Tsemekhman, K.; Wolinski, K.; Anchell, J.; Bernholdt, D.; Borowski, P.; Clark, T.; Clerc, D.; Dachsel, H.; Deegan, M.; Dyall, K.; Elwood, D.; Glendening, E.; Gutowski, M.; Hess, A.; Jaffe, J.; Johnson, B.; Ju, J.; Kobayashi, R.; Kutteh, R.; Lin, Z.; Littlefield, R.; Long, X.; Meng, 
B.; Nakajima, T.; Niu, S.; Pollack, L.; Rosing, M.; Sandrone, G.; Stave, M.; Taylor, H.; Thomas, G.; Lenthe, J. V.; Wong, A.; Zhang, A. Pacific Northwest National Laboratory Richland, Washington 99352, USA, 2007.

${ }^{26}$ Hay, P. J.; Wadt, W. R. J. Chem. Phys. 1985, 82, 270.

${ }^{27}$ Frisch, M. J.; Pople, J. A.; Binkley, J. S. J. Chem. Phys. 1984, 80, 3265.

${ }^{28}$ Merrick, J. P.; Moran, D.; Radom, L. J. Phys. Chem. A 2007, 111, 11683. 


\title{
Catalytic hydroamination/cyclization of $\operatorname{PhB}\left(\mathrm{C}_{5} \mathrm{H}_{4}\right)\left(\mathrm{Ox}^{\mathrm{R}_{2}}\right)_{2} \mathrm{Zr}\left(\mathrm{NR} \mathrm{R}^{\prime}\right)(\mathrm{NR}$ ”)
}

George Schoendorff, Mark S. Gordon, Aaron D. Sadow, Theresa L. Windus

Department of Chemistry, Iowa State University and Ames Laboratory, Ames IA 50011

\begin{abstract}
The reaction mechanism for catalytic hydroamination/cyclization of a truncated zirconium is studied using density functional theory (DFT) and second-order perturbation theory (MP2). Ligands include oxazoline, an aminoalkane as the hydrogen donor, and a primary aminoalkene as the hydrogen receptor. The rate-limiting step proposed by Sadow et al. is examined for a model complex. Substituents are added incrementally toward the experimental system to determine the substituent effects on the reaction barriers. Thermodynamics and reaction barriers are presented using both DFT and MP2 levels of theory at the DFT optimized structures. Approximate transmission coefficients from the Wigner approximation are also presented.
\end{abstract}

\section{Introduction}

Hydroamination is the process of $\mathrm{NH}$ addition across an unsaturated (double or triple) C-C bond ${ }^{1}$. Direct addition of amines to olefins generally does not produce detectable quantities of products, so catalysts are necessary to aid the hydroamination process. The catalytic hydroamination considered in this work occurs in concert with cyclization of an aminoalkene. Numerous organometallic complexes with early transition metal, rare earth, and actinide metal centers have been found that are highly 
reactive for the intramolecular cyclization of aminoalkenes. Until recently, it was believed that catalytic hydroamination occurs by one of two mechanisms -1,2-insertion of an olefin ligand into a M-N bond ${ }^{2}$ (Figure 1) or $\alpha$-abstraction followed by [2 $\left.2 \pi+2 \pi\right]$ cycloaddition of an olefin and a $\mathrm{M}=\mathrm{N}$ double bond ${ }^{3}$ (Figure 2). Both of these mechanisms have since been ruled out. It has been shown that an isolated characterized magnesium amido compound does not undergo 1,2-insertion on its own. ${ }^{4}$ In another study, a chiral zirconium complex was found to cyclize aminoalkenes to give enantioenriched pyrrolidines. ${ }^{5}$ It was observed that enantioselectivity is affected by isotopic $\left({ }^{2} \mathrm{H}\right)$ substitution of the amino group on the substrate, ruling out both the 1,2insertion and the $[2 \pi+2 \pi]$ cycloaddition mechanisms.

Based on the observed isotopic effects, a third mechanism has been proposed (Figure 3). This mechanism involves proton transfer from one amino ligand to another aminoalkene ligand with a simultaneous cyclization of the aminoalkene ligand via a 6center transition state. When the metal center is zirconium the $\mathrm{R}$ product is favored, while the S product is favored when the metal is changed to yttrium ${ }^{6}$. The computational studies presented here examine the mechanism shown in Figure 3 for the zirconiumbased catalyst. Due to the computational expense of such a large chemical system, the donor ligand was simplified to $\mathrm{NHCH}_{3}$ (Figure 4).

It should be noted that one more potential mechanism has been proposed, although a computational study of this mechanism with a zirconium metal center is not discussed here. This additional mechanism requires only a single aminoalkene ligand wherein the hydroamination of the terminal alkene and cyclization occur in a single step. 
Barriers as low as $5 \mathrm{kcal} / \mathrm{mol}$ have been reported for this mechanism with a magnesium metal center.

\section{Computational Details}

Geometry optimizations and Hessians were calculated with the NWChem software suite $;{ }^{8,9}$ intrinsic reaction coordinate ${ }^{10}$ (IRC) calculations were performed with the GAMESS software suite ${ }^{11}$ to ensure that the transition states connect to the relevant minima. Density functional theory (DFT) with the $\mathrm{B} 3 \mathrm{LYP}^{12,13}$ functional was employed, as well as second order perturbation theory (MP2) calculations.

Geometry optimizations, Hessians, and IRC calculations were all performed using the LANL2DZ relativistic effective core potential (RECP) and associated orbital basis $\mathrm{set}^{14}$ for zirconium and the $3-21 \mathrm{G}^{15}$ basis set for all other atoms $(\mathrm{H}, \mathrm{B}, \mathrm{C}, \mathrm{N}$, and $\mathrm{O})$. All minima and transition states were verified based on the Hessian calculations. This basis set was chosen to minimize the number of basis functions due to the large complexes studied. DFT/B3LYP and MP2 single point energies using the Stuttgart RECP and associated Stuttgart orbital basis set ${ }^{16,17,18}$ for zirconium and the $6-311 \mathrm{G}(\mathrm{d}, \mathrm{p})$ basis set for all other atoms ${ }^{19}$ were performed at the optimized structures to improve the calculated energies.

The rate-determining step in the mechanism illustrated in Figure 3 was studied. A model complex was chosen as a reference point in order to establish trends based on the size, type, and location of functional groups in the zirconium-based catalyst. A transition state with an imaginary mode corresponding to the proton transfer reaction was used as a starting point for IRC calculations. The minimum energy path obtained via the IRC 
calculation confirms that this transition state is connected to the appropriate minima on the potential energy surface. ZPE (zero point vibrational energy)-corrected energies, enthalpies, and Gibbs free energies, based on the harmonic oscillator/rigid rotor approximation, were used to determine the barrier height. Since experimental data suggests that there is a significant isotope effect, an estimate of the transmission coefficient can be used to determine the validity of the proposed mechanism. The magnitude of the imaginary mode and the temperature (298.15 K in this case) was used to determine approximate transmission coefficients, $\kappa(\mathrm{T})$, via the Wigner approximation (Eq. 1$)^{20}$

$$
\kappa(\mathrm{T})=1+\frac{1}{24}\left(\frac{\hbar \mid \omega^{\ddagger}}{\mathrm{RT}}\right)^{2}
$$

where $\hbar$ is Plank's constant divided by $2 \pi,\left|\omega^{\ddagger}\right|$ is the magnitude of the imaginary mode in $\mathrm{Hz}$, and $\mathrm{R}$ is the ideal gas constant.

All reported energies include the zero point energy correction obtained from Hessian calculations. Enthalpy and entropy corrections were obtained from the harmonic oscillator approximation. The magnitude of the imaginary frequencies of the transition state complexes was used to calculate Wigner transmission coefficients ${ }^{6}$ in order to obtain an estimation of tunneling effects. In some cases the $\mathrm{COSMO}^{21}$ implicit solvation model with a dielectric constant of 2.27 was used to simulate a benzene solvent. 


\section{Results and Discussion}

The model transition state complex used in this study is shown in Figure 4. To minimize the computational cost, substituents were added incrementally. $R_{1}$ is either a hydrogen or a phenyl group; $\mathrm{R}_{2}$ is either a hydrogen or a cyclohexyl group. Substituents (methyl groups in this study) at either $\mathrm{R}_{3}$ or $\mathrm{R}_{4}$ introduce chirality into the oxazoline ligand. When $\mathrm{R}_{3}$ is $\mathrm{CH}_{3}$ and $\mathrm{R}_{4}$ is $\mathrm{H}$, the methylated oxazoline has the $\mathrm{R}$ configuration. Likewise, when $\mathrm{R}_{3}$ is $\mathrm{H}$ and $\mathrm{R}_{4}$ is $\mathrm{CH}_{3}$, the methylated oxazoline has the $\mathrm{S}$ configuration. Upon cyclization, the aminoalkene also has a chiral center. In this study, both the $\mathrm{R}$ and the S configurations of oxazoline are considered, but only the S configuration of the cyclized aminoalkene ligand is presented. It is the chirality of the cyclized aminoalkene that determines the chirality of the final product. The S-aminoalkene ligands in the transition state complexes examined in this study lead to products with the $\mathrm{R}$ configuration. It is known from experiments that the R products are favored experimentally when zirconium is the metal center. ${ }^{5}$ Transition states with the Raminoalkene configuration have not been found.

Minimum energy paths connecting the reactant and product through the transition state were obtained from IRC calculations. IRC calculations were performed for complexes with the following substituents: $\mathrm{R}_{1}=\mathrm{R}_{2}=\mathrm{R}_{3}=\mathrm{R}_{4}=\mathrm{H} ; \mathrm{R}_{1}=\mathrm{R}_{3}=\mathrm{R}_{4}=\mathrm{H}$ and $\mathrm{R}_{2}=\mathrm{C}_{6} \mathrm{H}_{11} ; \mathrm{R}_{1}=\mathrm{R}_{4}=\mathrm{H}, \mathrm{R}_{2}=\mathrm{C}_{6} \mathrm{H}_{11}$, and $\mathrm{R}_{3}=\mathrm{CH}_{3}$; and $\mathrm{R}_{1}=\mathrm{R}_{3}=\mathrm{H}, \mathrm{R}_{2}=\mathrm{C}_{6} \mathrm{H}_{11}$, and $\mathrm{R}_{4}=\mathrm{CH}_{3}$. In all of these cases, it was found that the transition state does indeed connect to the appropriate minima on the potential energy surface. Since the transition states for complexes with other substituents are similar to the transition states used in the IRC 
calculations, it was assumed that these all connect to the desired minima. In these cases, geometry optimizations were performed and no IRC calculations were performed.

Thermodynamic data for the reactions are displayed in Table $1 . \Delta \mathrm{E}_{\text {reaction }}$ is the difference between product and reactant energies, where $\mathrm{E}$ is the electronic energy corrected for the zero point energy. Likewise, $\Delta \mathrm{H}_{\text {reaction }}$ and $\Delta \mathrm{G}_{\text {reaction }}$ are also displayed and correspond to reactions occurring at $298.15 \mathrm{~K}$. In nearly all cases the reactions are endothermic, but the energy difference between products and reactants is small $(<8$ $\mathrm{kcal} / \mathrm{mol}$ ). In the only case where the reaction is exothermic, the reactant and product are nearly isoenergetic.

Reaction barriers based on the ZPE-corrected energy, enthalpy, and Gibbs free energy are shown in Table 2. In all cases the barriers are much higher than one would expect, based on the experimental kinetics ${ }^{5}$. Corrections for the enthalpy temperature effects generally lower the barrier by $1-5 \mathrm{kcal} / \mathrm{mol}$ and inclusion of entropic effects via the free energy generally raise the reaction barrier by $\sim 2-3 \mathrm{kcal} / \mathrm{mol}$. However, the harmonic oscillator approximation tends to produce unreliable results for the entropy if low frequency modes are present. ${ }^{22}$ This, in turn, will have an impact on the calculated free energies. Since the structures presented have low-frequency modes $\left(<100 \mathrm{~cm}^{-1}\right)$, the free energies likely contain errors due to the harmonic oscillator approximation. In all cases, barriers based on the free energies are greater than $35 \mathrm{kcal} / \mathrm{mol}$ and as much as $48.5 \mathrm{kcal} / \mathrm{mol}$. These barriers may be prohibitively high if the reaction is run at room temperature or colder.

The $\Delta \mathrm{E}_{\text {reaction }}$ and barriers reported in Tables 1 and 2 were obtained with a small basis set (3-21G and LANL2DZ). Single point energy calculations on the optimized 
geometries were performed with a larger basis set $(6-311 \mathrm{G}(\mathrm{d}, \mathrm{p})$ and Stuttgart RECP) to determine if the choice of basis set influences the thermodynamics and barrier heights of the systems studied. Comparison of $\Delta \mathrm{E}_{\text {reaction }}$ in Tables 1 and 3 shows that an effect of the larger, supposedly more accurate, basis set is to make the reactions more endoergic. Furthermore, the calculated barriers consistently are increased by $1-2 \mathrm{kcal} / \mathrm{mol}$ when the larger basis set is used (Tables 2 and 3). The differences in $\Delta \mathrm{E}_{\text {reaction }}$ and barrier heights are almost negligible; the calculated energies are relatively insensitive to the choice of basis set.

Solvent effects were examined for the model complex and for the complex with $\mathrm{R}_{2}=\mathrm{C}_{6} \mathrm{H}_{11}$. Single point energy calculations were performed at the gas phase optimized geometries with the COSMO implicit solvation model. A dielectric constant of 2.27 was used to simulate solvation in benzene. Values for $\Delta \mathrm{E}_{\text {reaction }}$ and for the barrier are in parentheses in Table 3. Based on these calculations, solvation lowers $\Delta \mathrm{E}_{\text {reaction }}$ as well as the barrier. However, the reactions are both still endoergic. Notably, the barriers are lowered by $1-4 \mathrm{kcal} / \mathrm{mol}$. Thus, solvation helps lower the barrier compared with the gas phase data, but the barrier is not sufficiently lowered to explain how these reactions occur under experimental conditions (room temperature or colder).

$\mathrm{C}_{6} \mathrm{H}_{5}$ substitution at $\mathrm{R}_{1}$ substantially lowers the barrier by $\sim 10 \mathrm{kcal} / \mathrm{mol}$ compared with the unsubstituted complex. However, substitution at $\mathrm{R}_{1}$ increases the barrier relative to complexes with methyl substitution at the $\mathrm{R}_{3}$ or $\mathrm{R}_{4}$ positions by $2-5$ $\mathrm{kcal} / \mathrm{mol}$. Thus, substitution at the $\mathrm{R}_{1}$ position may have a negligible impact on the full system used in experimental studies. $\mathrm{C}_{6} \mathrm{H}_{11}$ substitution at the $\mathrm{R}_{2}$ position also lowers the barrier by up to $8 \mathrm{kcal} / \mathrm{mol}$ relative to the unsubstituted model complex. This is 
consistent with experimental observations that substitution at the $\mathrm{R}_{2}$ position increases the reaction rate. However, as with substitution at the $\mathrm{R}_{1}$ position, $\mathrm{R}_{2}$ substitution slightly increases the barrier height when chirality is introduced into the oxazoline ligand by methyl substitution at either $\mathrm{R}_{3}(\mathrm{R})$ or $\mathrm{R}_{4}(\mathrm{~S})$. In all cases, methyl substitution at $\mathrm{R}_{4}$ results in a slightly lower barrier compared with methyl substitution at $\mathrm{R}_{3}$, but the difference in barrier height is only $\sim 2-3 \mathrm{kcal} / \mathrm{mol} . \Delta \mathrm{E}_{\text {reaction }}$ is also lower for $\mathrm{R}_{4}$ substitution versus $R_{3}$ substitution, but the difference is small (less than $5 \mathrm{kcal} / \mathrm{mol}$ ).

Table 4 shows relative MP2 energies for each of the reactants, transition states, and products calculated at the DFT/B3LYP optimized geometries. In each case, the ZPEcorrected energy of the reactant is used as a reference. Thus, the relative transition state energies correspond to barrier heights and the relative product energies correspond to $\Delta \mathrm{E}_{\text {reaction. }}$. The MP2 data predicts all the reactions to be exoergic in contrast to the results obtained with DFT. Furthermore, the MP2 barriers are substantially lower than the barriers obtained via DFT. The MP2 barriers range from $22.9-34.1 \mathrm{kcal} / \mathrm{mol}$, on the order of $7-15 \mathrm{kcal} / \mathrm{mol}$ lower than the corresponding DFT barriers. The trends in the MP2 barriers are still the same as the trends in the DFT barriers, but the large decrease in barrier height with MP2 together with the change from endoergicity to exoergicity when going from DFT to MP2 indicate that these systems are a colossal failure of density functional theory.

Approximate transmission coefficients are presented in Table 5. The Wigner approximation was used with a temperature of $298.15 \mathrm{~K}$. The transmission coefficients are all quite small corrections to the rate constant, indicating only a small contribution to the rate from tunneling effects (on the order of $3-4 \%$ ). This is in contrast with the 
isotope effect observed in the experimental studies. However, the Wigner approximation uses only the temperature and the magnitude of the imaginary frequency. The Wigner approximation is a very rough approximation since no consideration of the barrier height or width is included. Thus, this is only an initial estimate of tunneling effects. Since the transition states are quite similar in the reactive region, the associated imaginary frequencies are also similar and little distinction is made between $\mathrm{R}$ and $\mathrm{S}$ configurations of the cyclized aminoalkene ligand. A more rigorous calculation of the transmission coefficient is necessary to adequately quantify tunneling effects on the reaction rate.

\section{Conclusion}

Calculated thermodynamic data and barrier heights have been presented for the catalytic hydroamination/cyclization by a zirconium based catalyst. A model complex was proposed and substituents were added incrementally. Density functional theory predicts the reactions to be endoergic with high $(\sim 40 \mathrm{kcal} / \mathrm{mol})$ barriers. These results are in conflict with experimental observations. However, MP2 predicts exoergic processes and barriers on the order of $\sim 30 \mathrm{kcal} / \mathrm{mol}$. While the MP2 barriers are still high, it is not inconceivable that the full complex used experimentally has barriers that are even lower than those reported. Furthermore, the Wigner approximation predicts a small isotope effect contrary to experimental observations. However, the failure of density functional theory and the inadequacy of the Wigner approximation do not allow for a conclusive statement on the validity of the proposed reaction mechanism at this time. Further calculations are needed with additional substituents to recover complexes used experimentally. The trends in barrier height with substitution suggest that it may be 
possible that barriers for the fully substituted complexes that were studied experimentally may have barriers low enough to be practical at room temperature or lower. It is also possible that "spectator" substituents play an as yet unknown role in these reactions.

\section{Acknowledgements}

This research was supported by an allocation of advanced computing resources provided by the National Science Foundation. The computations were performed on Kraken at the National Institute for Computational Sciences (TG-CHE110011). Funding has been provided by Iowa State University and an NSF grant for petascale applications. 
Figure 1. 1,2-insertion of an olefin ligand into a $\mathrm{M}-\mathrm{N}$ bond.

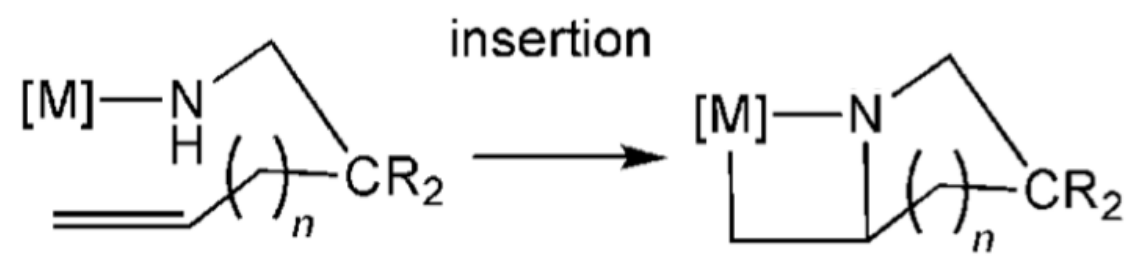

Figure 2. $\alpha$-abstraction followed by $[2 \pi+2 \pi]$ cycloaddition.

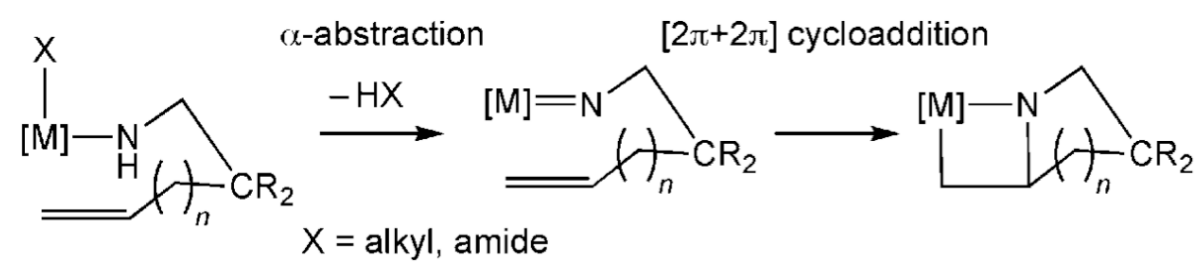

Figure 3. Proposed mechanism controlling absolute configuration in zirconium catalyzed aminoalkene cyclization. The chiral center for each transition state is designated with an asterisk. The $\mathrm{S}$ transition state results in the $\mathrm{R}$ product, and the $\mathrm{R}$ transition state results in the $\mathrm{S}$ product.

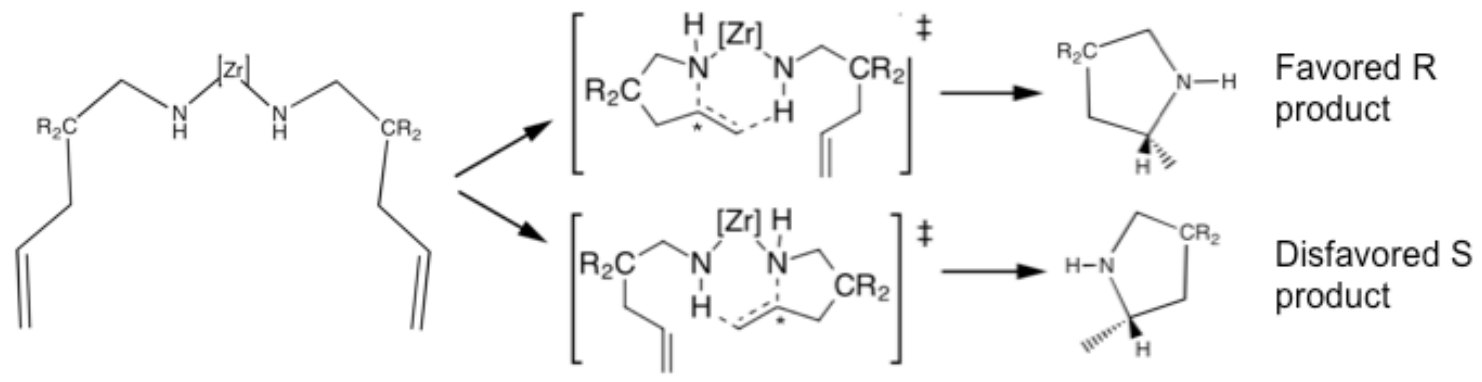


Figure 4. The model $\mathrm{Zr}$ transition state complex. The H-donor ligand has been shortened to $\mathrm{NHCH}_{3} . \mathrm{R}_{1}=\mathrm{H}$ or $\mathrm{C}_{6} \mathrm{H}_{5} ; \mathrm{R}_{2}=\mathrm{H}$ or $\mathrm{C}_{6} \mathrm{H}_{11} ; \mathrm{R}_{3}=\mathrm{H}$ or $\mathrm{CH}_{3} ; \mathrm{R}_{4}=\mathrm{H}$ or $\mathrm{CH}_{3}$. Substitution at $\mathrm{R}_{3}$ produces the $\mathrm{R}$ oxazoline isomer and substitution at $\mathrm{R}_{4}$ produces the $\mathrm{S}$ oxazoline isomer.

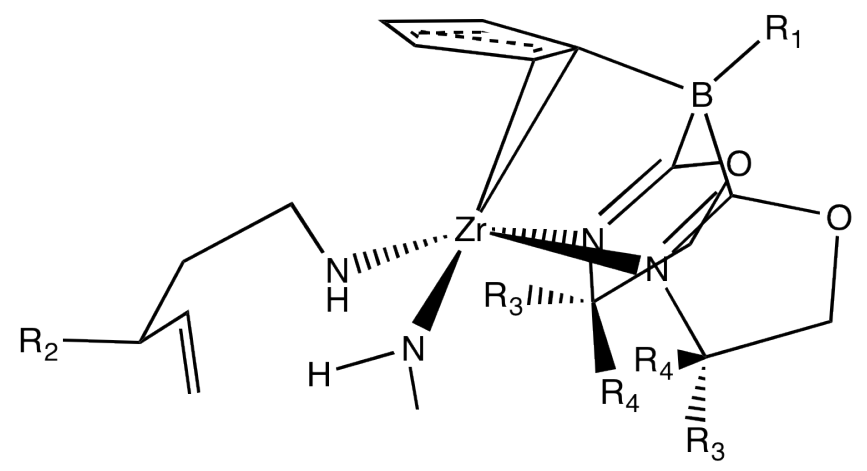

Table 1. $\Delta \mathrm{E}_{\text {reaction, }} \Delta \mathrm{H}_{\text {reaction, }}$ and $\Delta \mathrm{G}_{\text {reaction }}$ calculated with DFT/B3LYP for the model system with substituents at the $\mathrm{R}_{1}, \mathrm{R}_{2}, \mathrm{R}_{3}$ or $\mathrm{R}_{4}$ positions. The LANL2DZ RECP was used for $\mathrm{Zr}$ and the 3-21G basis set was used for all other atoms. All energies are in $\mathrm{kcal} / \mathrm{mol}$ and include the zero point correction to the energy. Enthalpies and entropies were obtained with the harmonic oscillator/rigid rotor approximation. Substituents placed on $R_{3}$ form the $R$ oxazoline isomer, and substituents placed on $R_{4}$ form the $S$ oxazoline isomer.

\begin{tabular}{|l|l|l|l|c|c|c|}
\hline \multicolumn{2}{|l|}{ Substituents } & \multicolumn{1}{c|}{$\Delta \mathbf{E}_{\text {reaction }}$} & $\Delta \mathbf{H}_{\text {reaction }}$ & $\Delta \mathbf{G}_{\text {reaction }}$ \\
\cline { 1 - 3 } $\mathbf{R}_{\mathbf{1}}$ & $\mathbf{R}_{\mathbf{2}}$ & $\mathbf{R}_{\mathbf{3}}$ & $\mathbf{R}_{\mathbf{4}}$ & & & 7.6 \\
\hline $\mathrm{H}$ & $\mathrm{H}$ & $\mathrm{H}$ & $\mathrm{H}$ & 4.3 & 4.6 & 3.6 \\
\hline $\mathrm{H}$ & $\mathrm{C}_{6} \mathrm{H}_{11}$ & $\mathrm{H}$ & $\mathrm{H}$ & 2.4 & 1.7 & 6.0 \\
\hline $\mathrm{C}_{6} \mathrm{H}_{5}$ & $\mathrm{H}$ & $\mathrm{H}$ & $\mathrm{H}$ & 5.3 & 4.7 & 3.4 \\
\hline $\mathrm{H}$ & $\mathrm{H}$ & $\mathrm{CH}_{3}$ & $\mathrm{H}$ & 2.4 & 1.6 & -0.8 \\
\hline $\mathrm{H}$ & $\mathrm{H}$ & $\mathrm{H}$ & $\mathrm{CH}_{3}$ & -1.2 & -1.4 & 7.5 \\
\hline $\mathrm{C}_{6} \mathrm{H}_{5}$ & $\mathrm{H}$ & $\mathrm{CH}_{3}$ & $\mathrm{H}$ & 6.9 & 6.2 & 5.0 \\
\hline $\mathrm{C}_{6} \mathrm{H}_{5}$ & $\mathrm{H}$ & $\mathrm{H}$ & $\mathrm{CH}_{3}$ & 4.3 & 3.7 & 5.9 \\
\hline $\mathrm{H}$ & $\mathrm{C}_{6} \mathrm{H}_{11}$ & $\mathrm{CH}_{3}$ & $\mathrm{H}$ & 5.0 & 4.3 & 2.3 \\
\hline $\mathrm{H}$ & $\mathrm{C}_{6} \mathrm{H}_{11}$ & $\mathrm{H}$ & $\mathrm{CH}$ & 1.3 & 0.7 & \\
\hline
\end{tabular}


Table 2. Reaction barriers calculated with DFT/B3LYP for the model system with substituents at the $\mathrm{R}_{1}, \mathrm{R}_{2}, \mathrm{R}_{3}$ or $\mathrm{R}_{4}$ positions. The LANL2DZ RECP was used for Zr and the 3-21G basis set was used for all other atoms. All energies are in $\mathrm{kcal} / \mathrm{mol}$ and include the zero point correction to the energy. Enthalpies and entropies were obtained with the harmonic oscillator/rigid rotor approximation.

\begin{tabular}{|l|l|l|l|c|c|c|}
\hline \multicolumn{2}{|l|}{ Substituents } & \multicolumn{2}{|c|}{$\mathbf{E}^{\ddagger}-\mathbf{E}$} & $\mathbf{H}^{\ddagger}-\mathbf{H}$ & $\mathbf{G}^{\ddagger}-\mathbf{G}$ \\
\hline $\mathbf{R}_{\mathbf{1}}$ & $\mathbf{R}_{\mathbf{2}}$ & $\mathbf{R}_{\mathbf{3}}$ & $\mathbf{R}_{\mathbf{4}}$ & & & 42.3 \\
\hline $\mathrm{H}$ & $\mathrm{H}$ & $\mathrm{H}$ & $\mathrm{H}$ & 44.6 & 39.2 & 38.5 \\
\hline $\mathrm{H}$ & $\mathrm{C}_{6} \mathrm{H}_{11}$ & $\mathrm{H}$ & $\mathrm{H}$ & 36.6 & 35.6 & 35.7 \\
\hline $\mathrm{C}_{6} \mathrm{H}_{5}$ & $\mathrm{H}$ & $\mathrm{H}$ & $\mathrm{H}$ & 34.9 & 33.8 & 44.7 \\
\hline $\mathrm{H}$ & $\mathrm{H}$ & $\mathrm{CH}_{3}$ & $\mathrm{H}$ & 42.3 & 41.2 & 40.8 \\
\hline $\mathrm{H}$ & $\mathrm{H}$ & $\mathrm{H}$ & $\mathrm{CH}_{3}$ & 39.1 & 38.6 & 48.5 \\
\hline $\mathrm{C}_{6} \mathrm{H}_{5}$ & $\mathrm{H}$ & $\mathrm{CH}_{3}$ & $\mathrm{H}$ & 46.8 & 45.9 & 46.4 \\
\hline $\mathrm{C}_{6} \mathrm{H}_{5}$ & $\mathrm{H}$ & $\mathrm{H}$ & $\mathrm{CH}_{3}$ & 44.6 & 43.7 & 45.7 \\
\hline $\mathrm{H}$ & $\mathrm{C}_{6} \mathrm{H}_{11}$ & $\mathrm{CH}_{3}$ & $\mathrm{H}$ & 41.2 & 42.5 & 43.2 \\
\hline $\mathrm{H}$ & $\mathrm{C}_{6} \mathrm{H}_{11}$ & $\mathrm{H}$ & $\mathrm{CH}_{3}$ & 41.2 & 40.2 & \\
\hline
\end{tabular}


Table 3. Reaction barriers and $\Delta \mathrm{E}_{\text {reaction }}$ calculated with DFT/B3LYP for the model system with substituents at the $\mathrm{R}_{1}, \mathrm{R}_{2}, \mathrm{R}_{3}$ or $\mathrm{R}_{4}$ positions. The Stuttgart RECP was used for $\mathrm{Zr}$ and the 6-311G(d,p) basis set was used for all other atoms. All energies are in $\mathrm{kcal} / \mathrm{mol}$ and include the zero point correction to the energy. Values in parentheses correspond to COSMO solvation with a dielectric constant of 2.27.

\begin{tabular}{|l|l|l|l|c|c|}
\hline \multicolumn{3}{|l|}{ Substituents } & \multirow{2}{*}{$\mathbf{E}^{\ddagger}-\mathbf{E}$} & $\Delta \mathbf{E}_{\text {reaction }}$ \\
\cline { 1 - 4 } $\mathbf{R}_{\mathbf{1}}$ & $\mathbf{R}_{\mathbf{2}}$ & $\mathbf{R}_{\mathbf{3}}$ & $\mathbf{R}_{\mathbf{4}}$ & & \\
\hline $\mathrm{H}$ & $\mathrm{H}$ & $\mathrm{H}$ & $\mathrm{H}$ & $45.8(41.3)$ & $6.5(6.0)$ \\
\hline $\mathrm{H}$ & $\mathrm{C}_{6} \mathrm{H}_{11}$ & $\mathrm{H}$ & $\mathrm{H}$ & $38.4(37.3)$ & $4.3(1.4)$ \\
\hline $\mathrm{C}_{6} \mathrm{H}_{5}$ & $\mathrm{H}$ & $\mathrm{H}$ & $\mathrm{H}$ & 35.9 & 7.4 \\
\hline $\mathrm{H}$ & $\mathrm{H}$ & $\mathrm{CH}_{3}$ & $\mathrm{H}$ & 44.2 & 5.2 \\
\hline $\mathrm{H}$ & $\mathrm{H}$ & $\mathrm{H}$ & $\mathrm{CH}_{3}$ & 40.6 & 1.3 \\
\hline $\mathrm{C}_{6} \mathrm{H}_{5}$ & $\mathrm{H}$ & $\mathrm{CH}_{3}$ & $\mathrm{H}$ & 47.6 & 8.6 \\
\hline $\mathrm{C}_{6} \mathrm{H}_{5}$ & $\mathrm{H}$ & $\mathrm{H}$ & $\mathrm{CH}_{3}$ & 45.8 & 6.5 \\
\hline $\mathrm{H}$ & $\mathrm{C}_{6} \mathrm{H}_{11}$ & $\mathrm{CH}_{3}$ & $\mathrm{H}$ & 44.0 & 6.4 \\
\hline $\mathrm{H}$ & $\mathrm{C}_{6} \mathrm{H}_{11}$ & $\mathrm{H}$ & $\mathrm{CH}_{3}$ & 41.9 & 3.0 \\
\hline
\end{tabular}


Table 4. Relative MP2 energies for the model system with substituents at the $R_{1}, R_{2}, R_{3}$ or $\mathrm{R}_{4}$ positions. The reactant energies are set to zero, to the transition state energies correspond to the barriers and the product energies correspond to $\Delta \mathrm{E}_{\text {reaction. }}$ The donor amino ligand is shortened to $\mathrm{NHCH}_{3}$, while the receptor ligand is unmodified compared with the full system. ZPE corrected MP2 energies $(\mathrm{kcal} / \mathrm{mol})$ are display with the reactant as the reference energy. The Stuttgart RECP was used for Zr, and the 6$311 \mathrm{G}(\mathrm{d}, \mathrm{p})$ basis set was used for all other atoms.

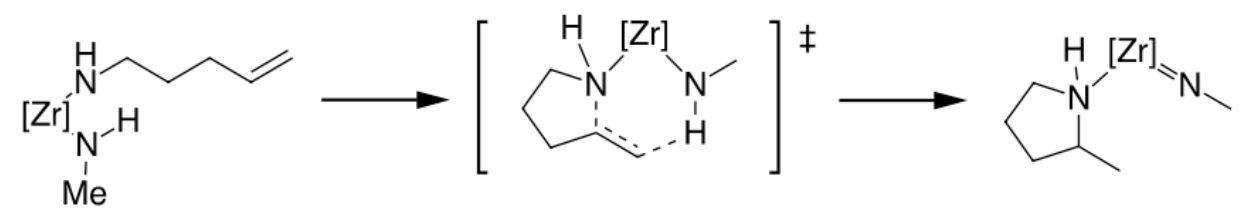

$\begin{array}{lll}\text { Reactant } & \text { Transition state Product }\end{array}$

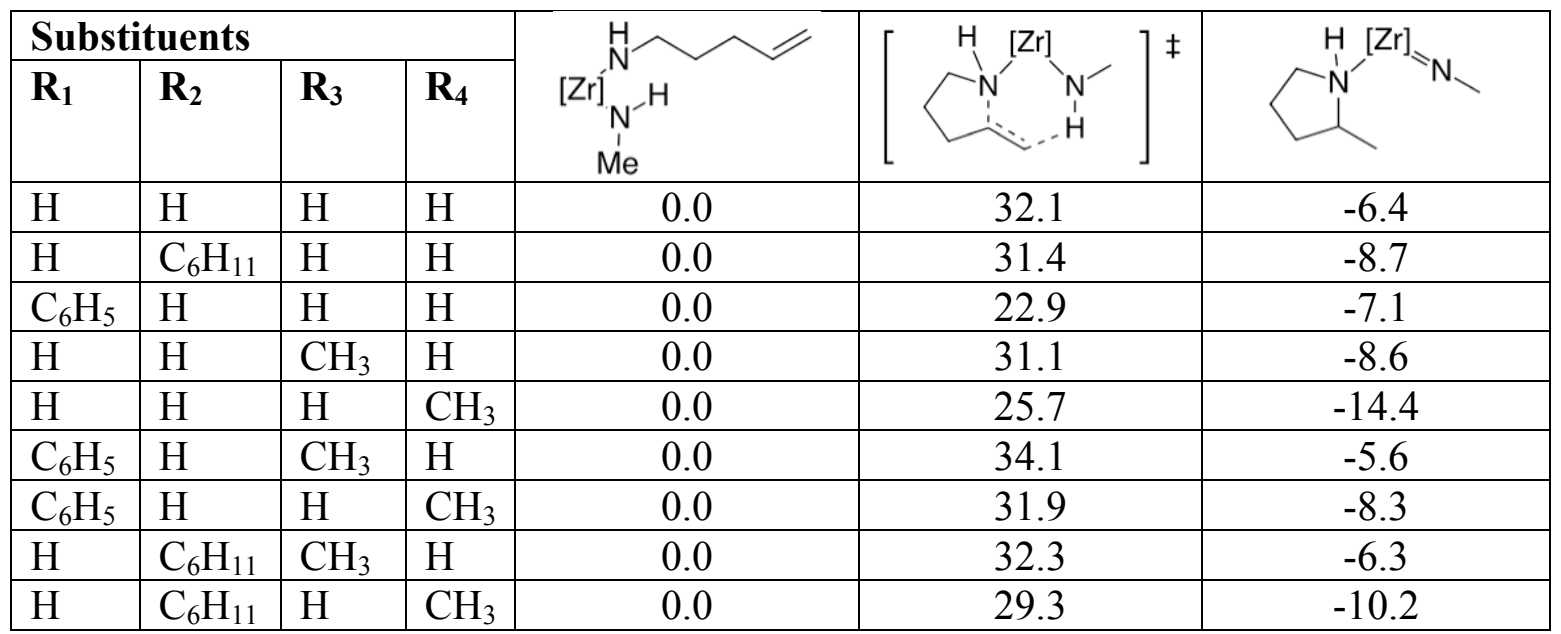


Table 5. Wigner transmission coefficients for each reaction at $298 \mathrm{~K}$.

\begin{tabular}{|l|l|l|l|c|}
\hline \multicolumn{3}{|l|}{ Substituents } & \multirow{2}{*}{$\kappa_{\mathbf{w}}(\mathbf{2 9 8} \mathbf{K})$} \\
\hline $\mathbf{R}_{\mathbf{1}}$ & $\mathbf{R}_{\mathbf{2}}$ & $\mathbf{R}_{\mathbf{3}}$ & $\mathbf{R}_{\mathbf{4}}$ & \\
\hline $\mathrm{H}$ & $\mathrm{H}$ & $\mathrm{H}$ & $\mathrm{H}$ & 1.031 \\
\hline $\mathrm{H}$ & $\mathrm{C}_{6} \mathrm{H}_{11}$ & $\mathrm{H}$ & $\mathrm{H}$ & 1.031 \\
\hline $\mathrm{C}_{6} \mathrm{H}_{5}$ & $\mathrm{H}$ & $\mathrm{H}$ & $\mathrm{H}$ & 1.028 \\
\hline $\mathrm{H}$ & $\mathrm{H}$ & $\mathrm{CH}_{3}$ & $\mathrm{H}$ & 1.041 \\
\hline $\mathrm{H}$ & $\mathrm{H}$ & $\mathrm{H}$ & $\mathrm{CH}_{3}$ & 1.041 \\
\hline $\mathrm{C}_{6} \mathrm{H}_{5}$ & $\mathrm{H}$ & $\mathrm{CH}_{3}$ & $\mathrm{H}$ & 1.041 \\
\hline $\mathrm{C}_{6} \mathrm{H}_{5}$ & $\mathrm{H}$ & $\mathrm{H}$ & $\mathrm{CH}_{3}$ & 1.041 \\
\hline $\mathrm{H}$ & $\mathrm{C}_{6} \mathrm{H}_{11}$ & $\mathrm{CH}_{3}$ & $\mathrm{H}$ & 1.041 \\
\hline $\mathrm{H}$ & $\mathrm{C}_{6} \mathrm{H}_{11}$ & $\mathrm{H}$ & $\mathrm{CH}_{3}$ & 1.041 \\
\hline
\end{tabular}




\section{References}

${ }^{1}$ Müller, T. E.; Hultzsch, K. C.; Yus, M.; Foubelo, F.; Tada, M. Chem. Rev. 2008, 108, 3795.

${ }^{2}$ Gagne, M. R.; Stern, C. L.; Marks, T. J. J. Am. Chem. Soc. 1992, 114, 275.

${ }^{3}$ Wood, M. C.; Leitch, D. C.; Yeung, C. S.; Kozak, J. A.; Schafer, L. L Angew. Chem., Int. Ed. 2007, 46, 354. Gott, A. L.; Clarke, A. J.; Clarkson, G. J.; Scott, P. Chem.

Commun. 2008, 1422. Pawlikowski, A. V.; Ellern, A.; Sadow, A. D. Inorg. Chem. 2009, 48, 8020. Neal, S. R.; Ellern, A.; Sadow, A. D. J. Organomet. Chem. 2011, 696, 228.

${ }^{4}$ Dunne, J. F.; Fulton, D. B.; Ellern, A.; Sadow, A. D. J. Am. Chem. Soc. 2010, 132, 17680.

${ }^{5}$ Manna, K.; Xu, S.; Sadow, A. D. Angew. Chem., Int. Ed. 2011, 501865.

${ }^{6}$ Manna, K.; Kruse, M. L.; Sadow, A. D. ACS Catalysis 2011, 1, 1637.

${ }^{7}$ Tobisch, S. Chem. Eur. J. 2011.

${ }^{8}$ Valiev, M.; Bylaska, E. J.; Govind, N.; Kowalski, K.; Straatsma, T. P.; van Dam, H. H. J.; Wang, D.; Nieplocha, J.; Apra, E.; Windus, T. L.; de Jong, W. A., "NWChem: a comprehensive and scalable open-source solution for large scale molecular simulations" Comput. Phys. Commun. 2010, 181, 1477.

${ }^{9}$ Kendall, R.A.; Apra, E.; Bernholdt, D.E.; Bylaska, E.J.; Dupuis, M.; Fann, G.I.;

Harrison, R.J.; Ju, J.; Nichols, J.A.; Nieplocha, J.; Straatsma, T.P.; Windus, T.L.; Wong, A.T. Computer Phys. Comm. 2000, 128, 260.

${ }^{10}$ Ishida, K.; Morokuma, K.; Komornicki, A. J. Chem. Phys. 1977, 66, 2153. 
${ }^{11}$ Schmidt, M. W.; Baldridge, K. K.; Boatz, J. A.; Elbert, S. T.; Gordon, M. S.; Jensen, J.

H.; Koseki, S.; Matsunaga, N.; Nguyen, K. A.; Su, S.; Windus, T. L.; Dupuis, M.;

Montgomery, J. A. J. Comput. Chem. 1993, 14, 1347.

${ }^{12}$ Becke, A. D., J. Chem. Phys. 1993, 98, 5648.

${ }^{13}$ Lee, C.; Yang, W.; Parr, R. G., Phys. Rev. B 1988, 37, 785.

${ }^{14}$ Hay, P. J.; Wadt, W. R. J. Chem. Phys. 1985, 82, 270. Hay, P. J.; Wadt, W. R. J.

Chem. Phys. 1985, 82, 284. Hay, P. J.; Wadt, W. R. J. Chem. Phys. 1985, 82, 299.

${ }^{15}$ Binkley, J. S.; Pople, J. A.; Hehre, W. J. J. Am. Chem. Soc. 1980, 102, 939.

${ }^{16}$ Bergner, A.; Dolg, M.; Küchle, W.; Stoll, H.; Preuss, H., Mol. Phys. 1993, 80 (6), 1431.

${ }^{17}$ Küchle, W.; Dolg, M.; Stoll, H., Mol. Phys. 1991, 74 (6), 1245.

${ }^{18}$ Küchle, W.; Dolg, M.; Stoll, H., Mol. Phys. 1991, 74 (6), 1245.

${ }^{19}$ Krishnan, R.; Binkley, J. S.; Seeger, R.; Pople, J. A. J. Chem. Phys. 1980, 72, 650.

${ }^{20}$ Wigner, E. P Z. Phys. Chem., Abt. B 1932, 19, 203.

${ }^{21}$ Klamt, A.; Schüürmann, G. J. Chem. Soc. Perkin Trans. 1993, 2, 799.

${ }^{22}$ Njegic, B.; Gordon, M. S. J. Chem. Phys. 2006, 125, 224102. Njegic, B.; Gordon, M.

S. J. Chem. Phys. 2008, 129, 164107. 


\title{
An Overview of GPU Coding Techniques with PGI Fortran
}

\author{
George Schoendorff, Mark S. Gordon, Theresa L. Windus
}

\section{Introduction}

Graphical processing units (GPUs) are an emerging technology that has the potential to increase the performance of a parallel code. Early GPU models supported only single precision arithmetic, so the usefulness of GPUs in scientific computing was limited. In the field of chemistry, early GPU technology was primarily used for molecular dynamics simulations in packages such as $\mathrm{AMBER}^{1,2}, \mathrm{GROMACS}^{3}$, LAMMPS $^{4}$, and HOOMD ${ }^{5}$. One of the earliest attempts to implement quantum chemistry code on GPUs was with the development of TeraChem ${ }^{6}$, an ab initio software package that relies on adaptive precision to circumvent the limitations imposed by the GPU architecture.

Double precision GPUs were introduced with the Tesla GPU architecture ${ }^{7}$. Since then other quantum chemists have taken advantage of the double precision capability and implemented GPU code into existing software packages. Currently, the UK version of the General Atomic and Molecular Electronic Structure System (GAMESS-UK) uses a GPU implementation of the Hehre-Pople rotated axis integral code for $\mathrm{s}$ and $\mathrm{p}$ functions ${ }^{8}$, and the GAMESS-US GPU code is based on an implementation of Rys quadrature integrals for $\mathrm{s}, \mathrm{p}, \mathrm{d}, \mathrm{f}$, and $\mathrm{g}$ functions ${ }^{9}$. There is a growing interest in the implementation of quantum chemistry codes on GPUs, with developers for NWChem ${ }^{10}$, Q-Chem ${ }^{11}$, and Gaussian $^{12}$ also investigating the possibility of incorporating GPU code into their software packages. 
Since early 2011, the Portland Group has included NVidia's compute unified device architecture (CUDA) extensions to Fortran as part of the pgfortran compiler suite (versions 11 and above). CUDA is NVidia's parallel computing architecture designed to give programmers access to the GPU and is also available for $\mathrm{C}$ and $\mathrm{C}++$. The CUDA Fortran language extensions require the use of the cudafor module, and thus the Fortran 90 standard must be employed to allow for the use of modules.

In addition to allowing programmers to write explicit CUDA GPU kernels (subroutines or functions) in Fortran, pgfortran also supports the use of directives. Directives are specialized comment lines that tell the compiler how to adapt a portion of CPU code for execution on the GPU. Directives are intended to simplify the process of coding for GPUs while enabling developers to maintain a single code base for both CPU and GPU architectures. Since the development of the PGI directives, directives have been generalized with the OpenAcc standard, ${ }^{13}$ a standard meant to work on multiple platforms with multiple languages and be vendor neutral.

The programming models presented here are compatible with the Fermi architecture and backward compatible with the Tesla architecture. A brief overview of the Fermi architecture is presented in addition to three programming models. A discussion of explicit GPU code is presented, followed by a discussion of GPU directives. For the directives discussion, the PGI style directives are presented as opposed to OpenACC since OpenACC is a relatively recent development. GPU code can also be implemented by calls to GPU libraries provided by NVidia or other third parties. In particular, use of the CUBLAS library ${ }^{14}$ is discussed. Finally, specific issues that arise 
as a result of the GPU architecture are presented. A Glossary is provided at the end of the chapter to help with the terminology of GPU architecture and code.

\section{Fermi Architecture}

A schematic of a Fermi GPU is shown in Figure 1. The Fermi GPU consists of 16 streaming multiprocessors (SM) that are arranged around a shared L2 cache. The L2 cache provides the multiprocessors with fast access to reusable data. Longer-term storage of data on the GPU makes use of up to 6 GB of DDR5 DRAM. The Fermi GPU also has a gigathread scheduler that assigns work to each of the SMs. Data transfers between the GPU and the host are handled by a $2^{\text {nd }}$ generation PCI express connection.

A schematic of an individual Fermi SM is shown in Figure 2. A single SM has a shared L1 cache for all 32 cores that allows data sharing between cores. Each of the 32 cores operates in a single instruction multiple data (SIMD) manner. Thus, every core executes the same instruction with different data elements. The 32 cores in a Fermi SM each have a single precision floating point unit and an integer unit (Figure 3). Two cores can be tied together for double precision, so the effective number of cores becomes 16 . Use of double precision arithmetic incurs a $2 \mathrm{x}$ penalty compared with single precision due to the reduction in the effective number of cores. Each pair of cores also has a load/store unit for moving the necessary data to/from the core. Special operations such as trigonometric function and the square root are handle by four dedicated special function units (SFU). Since there are only four SFUs per SM, use of the special function units incurs a $4 x$ performance penalty compared with double precision arithmetic. 
Since each SM operates in a SIMD manner, every core must evaluate the same instruction. Divergence can occur when a conditional statement (if-then-else) occurs in the GPU code. When this happens, the SM first evaluates the true condition on all core followed by the false condition on all cores. Thus, there is a $2 \mathrm{x}$ performance penalty for each if statement. The GPU architecture also imposes limitations on the dimensions of a data structure. Each thread maps on to a single core in an SM, and 32 single precision or 16 double precision threads are needed to fill the cores in an SM. Thus, optimal performance is achieved when a data structure is a multiple of 16 elements. The programmer is allowed to divide the threads into 1,2, or 3-dimension groups of threads. These groups of threads can be further grouped into 1, 2, or 3-dimensional thread blocks. Each group of threads or blocks must have rectangular dimensions to enable efficient mapping of the treads onto the individual cores in a SM. This hardware limitation leads restrictions on the type of code that can be implemented on the GPU.

\section{Explicit Model}

The explicit programming model for GPUs leaves all decisions on implementation to the programmer. The programmer must take care to properly manage all data movement and thread mapping. CUDA Fortran language extensions using the cudafor module are used to aid in this process. The basic elements of explicit GPU code are contained in Figure 4.

The GPU kernel, add_kernel, is contained in the module gpumod. Included in this module is the "use cudafor" statement to include the cudafor module, which contains the CUDA language extensions. Without cudafor, the compiler will see all GPU-specific 
code as syntax errors. The module, gpumod, also contains a single subroutine (add_kernel) that adds two matrices, A_dev and B_dev, and stores the result in C_dev. Note that "_dev" is used in this example to indicate that a variable or matrix is stored in GPU memory. This distinction is not necessary for the program to execute properly, but it serves to remind the programmer where the data resides and is a good programming practice to avoid unnecessary confusion.

The device subroutine, add_kernel, is declared in a manner similar to what one would use to declare a subroutine that runs on a CPU (also known as a host) with the addition of "attributes (global)" to indicate that this subroutine executes on a GPU (device). Subroutines can have three different types of attributes - global, device, and host. The global attribute indicates that the subroutine is called from the host and executes on the GPU, the device attribute indicates that the subroutine is called from the device and executes on the GPU, and the host attribute indicates that the subroutine is called from the host and executes on the CPU. If no attribute is specified, then the host attribute is assumed. A host subroutine functions as any other subroutine on the CPU and is callable only from other host subroutines. A global subroutine can be called from a host or device subroutine (kernel), and a device subroutine can be called only from a global or device subroutine.

In the add_kernel subroutine are two integers, I and J. These are used as the indices of the matrices. On a CPU, the matrix addition would be performed inside a nested do loop, but on the GPU each thread executes C_dev $=$ A_dev + B_dev for a single value of both I and J. So a total of $\mathrm{I}^{*} \mathrm{~J}$ threads are simultaneously executed to add all matrix elements. I and $\mathrm{J}$ are defined as threadIdx $\% \mathrm{x}$ and threadIdx $\% \mathrm{y}$, respectively, 
where the latter are built-in variables that identify the $\mathrm{x}$ and $\mathrm{y}$ values of a thread block. Likewise, blockIdx $\% \mathrm{x}$ and blockIdx $\% \mathrm{y}$ are built-in variables that identify the $\mathrm{x}$ and $\mathrm{y}$ values of blocks of thread blocks. In the current example, however, only one block of threads is used, so the block indices are 1 for all threads. After the execution of $\mathrm{C}_{-} \mathrm{dev}=$ A_dev + B_dev in the kernel, control returns to the calling subroutine on the host.

The host subroutine in this example is called add_matrix and includes the gpumod module that in turn includes the cudafor module. Thus, cudafor does not need to be explicitly included in the add_matrix subroutine. However, if one is uncertain whether cudafor has been included in the modules, it is permissible to include it again.

The host subroutine has matrices A and B passed to it in this example. However, these matrices need to be copied to GPU memory. The GPU matrices are declared and allocated with the following lines:

double precision, device, allocatable, dimension(:,:) $A \_d e v, B \_d e v, C \_d e v$ allocate $\left(A \_\operatorname{dev}(L D, L D), B \_\operatorname{dev}(L D, L D), C \_\operatorname{dev}(L D, L D)\right)$

The device attribute indicates that matrices A_dev, B_dev, and C_dev reside in GPU memory, and the variable LD is the leading dimension of the matrices. Square matrices are used for this example.

GPU kernels are launched with the threads arranged as 1, 2, or 3 dimensional arrays of threads. Each array of threads can also be arranged in a 1, 2, or 3 dimensional thread block. A three-dimensional integer variable type is needed to specify the thread and block dimensions. The data type, dim3, fulfills this role. Dim3 is a 3 dimensional variable, each dimension having a data type of integer*4. In the example, the variables Grid and Block are declared as type dim3 with the following line: 
type(dim3) $::$ Grid, Block

The Grid and Block variables are then initialized with the following lines:

$$
\begin{aligned}
& \text { Grid }=\operatorname{dim} 3(L D, L D, 1) \\
& \text { Block }=\operatorname{dim} 3(1,1,1)
\end{aligned}
$$

In this case, the grid of threads is defined to be a LDxLD two dimensional grid, and the thread block is defined such that only one thread block exists. If LDxLD exceeds the maximum number of threads that the GPU can handle, then an alternative is to split up the thread block into multiple thread blocks, e.g. Grid $=\operatorname{dim} 3(\mathrm{LD} / \mathrm{N}, \mathrm{LD} / \mathrm{N}, 1)$ where $\mathrm{N}$ is an integer. The Grid and Block variables are used later on when the add_kernel device subroutine is called.

Before add_kernel is called, the A and B matrices need to be copied from host memory to device memory. With pgfortran, the memory copies can be achieved by simple assignment statements. In this case, the following lines perform the memory copy:

$$
\begin{aligned}
& A \_d e v=A(1: L D, 1: L D) \\
& B \_d e v=B(1: L D, 1: L D)
\end{aligned}
$$

Alternatively, the limits can be implied and the memory copies can be simplified to the following:

$$
\begin{aligned}
& A \_d e v=A \\
& B \_d e v=B
\end{aligned}
$$

In either case, the memory copies are synchronous. The B_dev memory copy will not start until the A_dev memory copy is complete. 
Now that the A_dev and B_dev matrices reside in GPU memory, the GPU kernel can be called. The general form of a kernel call is the following:

call kernel $<<<$ Grid, Block, Bytes, StreamID $>>>$ (variables to be passed)

The chevron syntax $(<<<>>>)$ is used to indicate how the kernel is to be executed on the GPU. Grid and Block need to have a data type of either integer*4 or dim3. In the current example, both are type dim3 but Block could just as easily be set to 1 (as opposed to $(1,1,1))$. The Bytes and StreamID variables are optional arguments. Bytes is an integer that indicates how much shared memory should be set aside for the kernel, and StreamID is an integer that indicates in which execution stream the kernel call is queued and executed. If no value is given fro the Bytes argument, then the compiler determines an appropriate value. An execution stream is a queue for the GPU resources. Often, a kernel does not use the full capacity of the GPU, so another kernel in a different execution stream can be run concurrently to maximize the use of the GPU. If no value is given for StreamID, then the StreamID defaults to stream 0. Kernels in each stream are executed in the order they are called. Multiple streams can be used if additional parallelism is available in the algorithm. When multiple streams are used, kernels can be executed simultaneously if sufficient GPU resources are available. In the current example (Figure 4), the GPU kernel is called with the following line:

$$
\text { call add_kernel }<<<\text { Grid,Block }>>>\left(A \_d e v, B \_d e v, C \_d e v, L D \_d e v\right)
$$

This launches a kernel in a single thread block on stream 0 . The threads are arranged in a two-dimensional grid with dimensions LDxLD. After execution of the kernel, control returns to the host subroutine that calls the kernel, in this case the add_matrix subroutine. 
The result of the matrix addition still resides in GPU memory, so this must be copied back to CPU memory in an analogous manner to the previous memory copies with the following line:

$$
C=C \_\operatorname{dev}(1: L D, 1: L D)
$$

Again, this memory copy is synchronous and it is not executed until the kernel returns control to the host subroutine.

The code example presented here illustrates the major aspects of explicit GPU code. Another useful tool that was not necessary in this example is a call to syncthreads(). The syncthreads() subroutine waits for all threads in a kernel to reach the syncthreads() line before execution continues. This is useful to ensure that there are no race conditions, especially when threads diverge due to an "if" statement inside the GPU kernel.

Multiple streams can be used to run concurrent kernels to improve the overall parallel performance of an algorithm. In the above example, the stream was not specified, so it defaults to stream 0 . Additional streams can be created and destroyed with the cudaStreamCreate( $v a l)$ and cudaStreamDestroy(val), respectively, where val is an integer that uniquely identifies the stream. Analogous to the syncthreads () subroutine, all processes in a stream (both memory copies and kernels) can be synced with cudaStreamSynchronize( $v a l)$.

In the example illustrated above, the memory copies were performed implicitly by assignment statements, but memory copies can also be performed with the CUDA application programming interface (API) routines. There are numerous API routines for the memory copies depending on the data type that is to be copied, but a generic API 
routine for data transfers is cudaMemcpy(dst, src, count, kdir), where $d s t$ is the destination variable name, src is the source variable name, count is the number of bytes to be copied, and kdir is the direction. The direction can be "hosttodevice" or "devicetohost". Arguments to other more specialized data transfer routines are analogous to those used with cudaMemcpy(). Unless specified in the name of the routine, all data transfer routines execute synchronously.

Asynchronous data transfers can also be performed. These have the form APInameAsync(), e.g. Async is added to the name of the API routine. Since the copy is asynchronous, there is also an additional argument that is an integer specifying a particular execution stream. Asynchronous data transfers are possible with pgfortran version 12 and later. However, as of version 12.3 their implementation is still buggy and requires extra care to ensure that the memory transfer occurs as expected.

\section{Directives}

Directives are specialized comment statements that let the compiler know how a code segment is to be implemented on a GPU. This allows a programmer to write CPU code that is "easily" ported to a GPU. In principle, only a rudimentary knowledge of the GPU architecture is needed to use directives, but a more thorough understanding of the GPU architecture can help the programmer resolve problems with parallelization and performance. Because the directives appear as comments, software developers need to maintain only one version of the code for both CPU and GPU based systems. Compiling code with directives requires the "-ta=nvidia" flag to inform the compiler of the target architecture for the accelerator code. Additional information can be obtained at compiler 
time with the "-Minfo" flag, which provides information on what was implemented on the GPU and what was ignored. In some cases, "-Minfo" may even provide clues as to why an accelerator region was ignored.

Directives have the general form $! \$ a c c$ followed by additional options that indicate how the parallelization is tooccur. For a directive to have any affect, it must occur at points in the code that are parallelizable. In Fortran, compiler directives are often used in conjunction with do loops. If there is a single do loop that will be executed on the GPU, then the appropriate directive is ! \$acc do followed by the do loop as shown in Figure 5. The compiler handles the memory copies to and from GPU memory, constructs the appropriate kernel, and determines the mapping of the individual threads and thread blocks. More complicated parallel regions such as nested loops are enclosed between two directive lines - !\$acc region and !\$acc end region Figure 6. Once again, the compiler handles the memory copies, kernel generation, and thread mapping. Accelerator regions can also enclose larger parts of the code as shown in Figure 7. Both sets of nested do loops are implemented as GPU kernels, but the call to my_subroutine is not implemented on the GPU. Thus, serial code and calls to other subroutines can occur in the accelerator region, but these are not parallelized. By default, if the compiler cannot determine how to implement the parallelization, then the code is left to run on the CPU in serial.

Use of directives as illustrated above frequently results in inefficient code. The reason for this is that data is copied to the GPU memory when the accelerator region is entered and copied back to host memory when the accelerator region is exited. This can result in numerous, unnecessary memory copies. A solution to this problem is to have 
the accelerator regions enclosed in data regions. Consider the example in Figure 8. In this case, only the inner loop becomes a GPU kernel and it is called 1000 times. If the code is left as is, then there will be 1000 copies of the A, B, and C matrices between the host and GPU memory. However, if the outer loop is contained within a data region as illustrated in Figure 9, then the data is copied once to GPU memory when the data region is entered and once back to the host memory when the data region exits.

Accelerator directives can also be augmented with optional clauses. Clauses can be included in the initial directive line for an accelerator region or a data region, e.g.

!\$acc region clause1, clause1, etc.

or

!\$acc data region clause1, clause2, etc.

Alternatively, clauses can be inserted at appropriate points within an accelerator region or data region, e.g.

!\$acc clause

Clauses are used to provide the compiler with additional instructions on how to handle data movement and parallelization.

One of the most common clauses is the "copy" clause. This is used to specify when to copy data to the GPU memory. For example,

$\$ \$ \operatorname{acc} \operatorname{copy}(A[1: 100],[1: 100])$

will copy only the first $100 \times 100$ elements of A to the GPU memory. This can be useful if only a portion of the data contained in matrix A is needed on the GPU. Without this 
clause, the compiler will assume that every element of A is needed. So the copy clause can help eliminate unnecessary data transfers. The "local" clause can also be used to eliminate unnecessary data transfers. This is particularly useful if a variable holds temporary data. The "local" clause tells the compiler that the specified data is generated on the GPU and is not needed once the GPU kernel finishes execution. The format of the "local" clause is similar to the "copy" clause. The following statement indicates that the vector, temp, is temporary storage on the GPU with 1000 elements.

!\$acc local(temp[1:1000])

The "mirror" clause is useful when dealing with arrays that are defined in a module or passed between subroutines. Mirrored arrays can only be used with allocatable arrays. When a mirrored array is allocated on the host, it is simultaneously allocated on the GPU. All computations on the host will use the original host copy of the array, and all computations on the GPU use the GPU copy of the array. At the time of allocation, no data transfer between the host and the GPU occurs. Data transfers occur only when "updatein" (memory copy from host to device) and "updateout" (memory copy from device to host) directives occur. (Alternatively, these clauses can also be "update device" and "update host", respectively.) The vector B in Figure 10 is allocated on the host and GPU at the same time. At some point in another subroutine, B can be modified. If the modification occurs on the CPU without an updatein clause, then the GPU copy is undefined. Likewise, if B is modified on the GPU without an updateout clause, then the host copy is undefined. In the latter case, the sample code above is unaffected since the computation occurs in an accelerator region. So it is only necessary to have the GPU copy of B defined. Suppose that the vector B is filled by CPU code. 
Then the example in Figure 10 would require an updatein clause as illustrated in Figure 11. In Figure 11, B is copied only once to the GPU at the beginning of the accelerator region. The array, $\mathrm{C}$, is not treated as a mirrored array, so by default the GPU copy of C is copied back to the host memory at the end of the accelerator region.

\section{Restrictions}

Directives can be a powerful tool to aid in the implementation of GPU code. However, there are a number of restrictions that the programmer must adhere to in order to successfully implement code with directives. The restrictions arise partly as a result of the GPU architecture, but also because compiler directives are still a relatively new development. It is expected that some of the restrictions may be lifted with improvements in later releases of pgfortran.

One significant restriction on the use of directives relates to assumed size arrays. Since the compiler generally cannot determine the actual dimensions of the array at compile time, knowledge of the array sizes is needed in order to construct appropriately dimensioned thread blocks. Likewise, upper limits of do loops must also be defined. Performing a loop from 1 to $\mathrm{N}$ is not allowed with directives since $\mathrm{N}$ can vary at run time. The GPU code, however, is generated at compile time and the upper limit must be known in order to map the do loop onto a thread block. Both assumed size arrays and variable upper limits for do loops are prevalent throughout the GAMESS-US source code. In order to effectively use directives in these situations, a substantial effort to recode portions of GAMESS-US is necessary to adhere to the restrictions imposed by the use of directives. 
Another difficult situation for directives arises when a variable is used more than once within an accelerator region. Consider the example in Figure 12. The array C appears on different sides of the equations in this loop. The operations involving $\mathrm{C}$ are not independent of each other unless they are run in the correct order. However, each thread in the GPU code operates on different elements of $\mathrm{C}$, and the compiler does not understand how to handle such a dependancy. Furthermore, there is a reduction of D stored in the variable Sum. Sum appears to the compiler to be dependent on the thread in this case. A solution to both of these problems is presented in the code segment in Figure 13. The nested loop is divided into three sets of loops; each set of loops then becomes a GPU kernel. In the first kernel $\mathrm{C}$ is computed. The next kernel uses $\mathrm{C}$ to determine $\mathrm{D}$. Finally, a reduction is performed on D and stored in Sum. The first two loops remove the dependency on C. The last loop appears to have a dependency on Sum, but this is just a reduction. Recent versions of pgfortran can recognize a reduction and generate an appropriate kernel. However, if Sum was not used for a reduction, then the dependency would be real and use of directives would be ineffective.

Finally, accelerator regions cannot be nested since an accelerator region causes the compiler to implement as much as possible on the GPU. Nested accelerator regions are redundant and will cause the compiler to return an error. However, as was the case with the previous example, multiple loops can be included in a single accelerator region. When this is done, the compiler generates a separate kernel for each set of loops (nested or otherwise). 


\section{Libraries}

The simplest way to insert GPU code into existing CPU code is by making use of GPU libraries provided by NVidia or other third party developers. These libraries include subroutines for signal processing, fast Fourier transforms, and linear algebra ${ }^{14}$. In particular, linear algebra is handled by the CUBLAS and CULA libraries. The latest releases of CUBLAS (versions 4.0 and 4.1) include all the standard BLAS routines.

Implementation of CUBLAS is relatively straightforward. NormalBLAS routine names are preceded by cublas_to change them into CUBLAS routines. For example, a dgemm() call would become cublas_dgemm(). The arguments passed to the CUBLAS routine are exactly the same as the arguments passed to a CPU implementation of BLAS with one exception - the data must reside in GPU memory. Data transfers can be performed by assignment if the cudafor library is used. This method also requires compiling with the "-Mcuda" flag. Alternatively, accelerator data directives can be used to manage the data transfers. If directives are used, then "-ta=nvidia" is needed at compile time. Alternatively, helper functions included in the cublas library can be used for the data transfers. The helper functions currently use synchronous memory transfers, so there is no advantage to this method over the assignment method with cudafor.

The use of CUBLAS requires an extra function call before any other CUBLAS call is made. A call to cublas_init() is needed to initialize the GPU. As with the data transfers this is an expensive operation. A call to cublas_init() generally takes $\sim 1$ second. Multiple CUBLAS calls usually are needed to hide the cost of cublas_init() in addition to hiding the cost of the data transfers. 
Fortran wrapper functions for the CUBLAS routines are contained in fortran.c provided by NVidia. Fortran.c must be compiled and linked in order for the CUBLAS calls to function properly. PGI also provides Fortran wrappers to CUBLAS. However, the PGI CUBLAS is generally a few months out of date compared with the code provided by NVidia.

\section{Specific issues}

Aside from the challenges outlined in earlier sections, there remain a few specific issues that a programmer may need to overcome in order to produce an efficient GPU code. The primary concern, alluded to earlier, has to do with data transfers. The Fermi architecture uses a second generation PCI express bus for data transfers to and from the $\mathrm{GPU}^{15, *}$ and has a theoretical peak transfer rate of $8 \mathrm{~Gb} / \mathrm{sec}$. While the speed of the PCI bus is quite fast for $\mathrm{I} / \mathrm{O}$ operations, it is roughly 2 orders of magnitude slower than DRAM access. Thus, the bottleneck in any GPU code is the data transfer. Ideally, one would like to move data to the GPU and perform the entire computation on the GPU before copying the result to the CPU. However, most algorithms will have many parts that are not parallelizable. Furthermore, if statements can lead to branch divergence, reducing the parallizability of the code. Serial regions of the code must run on the CPU, incurring a penalty for any resultant data transfers. Alternatively, serial sections could in principle be executed on the GPU. This also incurs a penalty since only a single thread on a single core is operational and the other 200 - 500 cores remain idle.

\footnotetext{
* The exception is the NVidia ION architecture. This architecture features integrated graphics with shared memory for the CPU and GPU.
} 
Another challenge faced by GPU programmers is how to maximize use of the GPU if the kernels are small. Fermi GPUs have up to 512 cores, and an efficient use of the GPU needs to maximize use of all the available cores. A solution is to launch multiple kernels in different streams so that as many cores as possible are used. In principle this is simple. However, the programmer is again left with the problem of moving sufficient amounts of data to the GPU memory in order to keep the cores active. The ideal situation is to use an algorithm that maximizes the reuse of data. This could minimize the data transfers and maximize the use of the available cores.

Another challenging problem when porting legacy code to a GPU is best illustrated by a code excerpt from the Douglas-Kroll code in GAMESS (Figure 14). Memory used to be much more expensive than it is today, so programmers found ways to minimize memory use. In this example of triangular mapping, only half of a symmetric, square matrix (PVP) is stored in memory. However, GPU code needs rectangular mapping. Enclosing this region in an accelerator region will not work. The upper limits are not fixed values, the two loops do not map onto a rectangular grid of threads, and there is a dependence on the variable IJ that prevents parallelization.

The best method of implementing the code in Figure 14 on a GPU would be to use the explicit model to turn these nested loops into a single GPU kernel. The PVP array is currently a vectorized triangular matrix. A new copy of PVP is needed that is a square matrix. Next, the loops need to map rectangularly. So the IJ index must be replaced with $(\mathrm{I}, \mathrm{J})$, where $\mathrm{I}$ and $\mathrm{J}$ map to the $\mathrm{x}$ and $\mathrm{y}$ thread indices. A suitable kernel to replace the original GAMESS code in is shown in Figure 15. The GPU copies of the temporary matrices TWRK2A and TWRK2B are simply called A and B. PVP has been 
recast as a square matrix (on the $\mathrm{CPU}$, but not shown here). I and $\mathrm{J}$, formerly the indices of the do loops, are now related to the $\mathrm{x}$ and $\mathrm{y}$ thread indices. To make this general, a factor of $\mathrm{N}$ is included to account for multiple launches of the kernel mapped to a grid of threads with dimensions NxN. After these modifications, the computation per thread is reduced to only two lines. The drawback to this method is that the PVP matrix must be recast and copied to the GPU. In addition, the VAO matrix and the AP and RP vectors must be copied to the GPU. At the end of the kernel execution, the A and B matrices must be copied back to the CPU. The only way for this to outperform the CPU is if additional GPU kernels are used that construct the matrices on the GPU and reuse this data in as many kernels as possible. Unfortunately, in the case of the Douglas-Kroll code, implementation of all the necessary kernels on the GPU performs on par with the original CPU code due to the inefficiency of the data transfers. This is still true despite the reuse of data through multiple cublas_Dgemm calls.

\section{Conclusion}

Use of graphical processors as a massively parallel coprocessor is still a developing technology. Multiple programming models have been developed to provide programmers with choices on how to implement the code. The explicit model, while the most powerful, is also the most difficult to use. Alternatively, the use of directives seems straightforward, but often requires a substantial rewrite of the CPU code in order to deal with restrictions associated with directives. Calls to GPU libraries can also be used, but, unless these are used in conjunction with either the explicit model or directives, the cost of the data transfers frequently outweighs the gains in computational performance. In all 
cases effective management and movement of data should be the programmer's primary concern. Given the current GPU architecture, limited by the PCI express bandwidth, and the ever-evolving coding styles, GPU programming is best left to the most ambitious, patient, and creative programmers, at least until the technology is better standardized.

\section{Acknowledgements}

Assistance has been provided by NVidia (Mark Berger, Jonathan Bentz, and Carl Ponder) and The Portland Group (Mathew Colgrove and Dave Norton). Funding has been provided by Iowa State University and an NSF grant for petascale applications.

\section{Additional Information}

The information provided here is current as of the time of writing, but GPU technology is a quickly evolving field. The following sources are recommended for the most up-to-date information.

www.pgroup.com/cudafortran

www.pgroup.com/accelerate

www.developer.nvidia.com/category/zone/cuda-zone

www.openacc-standard.org 


\section{Glossary}

Accelerator - A general term for GPUs or other off-chip processors

Block - A group of threads to be executed simultaneously in a SIMD fashion

Cache - On-chip memory used for fast access to reusable data

CPU - Central processing unit

CUDA - "Compute Unified Device Architecture"; used to refer to any GPU code

Device - Related to GPU architecture, e.g. anything on the GPU board

Directive - A specialized comment line that indicates to the compiler how to adapt CPU code for execution on a GPU

GPU - Graphical processing unit

Host - Related to CPU architecture, e.g. anything connected to the motherboard

Kernel - Subroutine or function that is executed on a GPU

NVidia - Company responsible for the development of GPU technology

PGI - The Portland Group; responsible for the development and maintenance of CUDA Fortran

SIMD - Single Instruction Multiple Data; this is the parallel model used in GPU code

Thread - A single piece of code executed in serial. Multiple threads are executed simultaneously on a GPU.

Thread block - SIMD execution of multiple threads on a GPU

Warp - Simultaneous execution of 16 or 32 threads depending on the GPU model 
Figure 1. The Fermi GPU architecture ${ }^{16}$

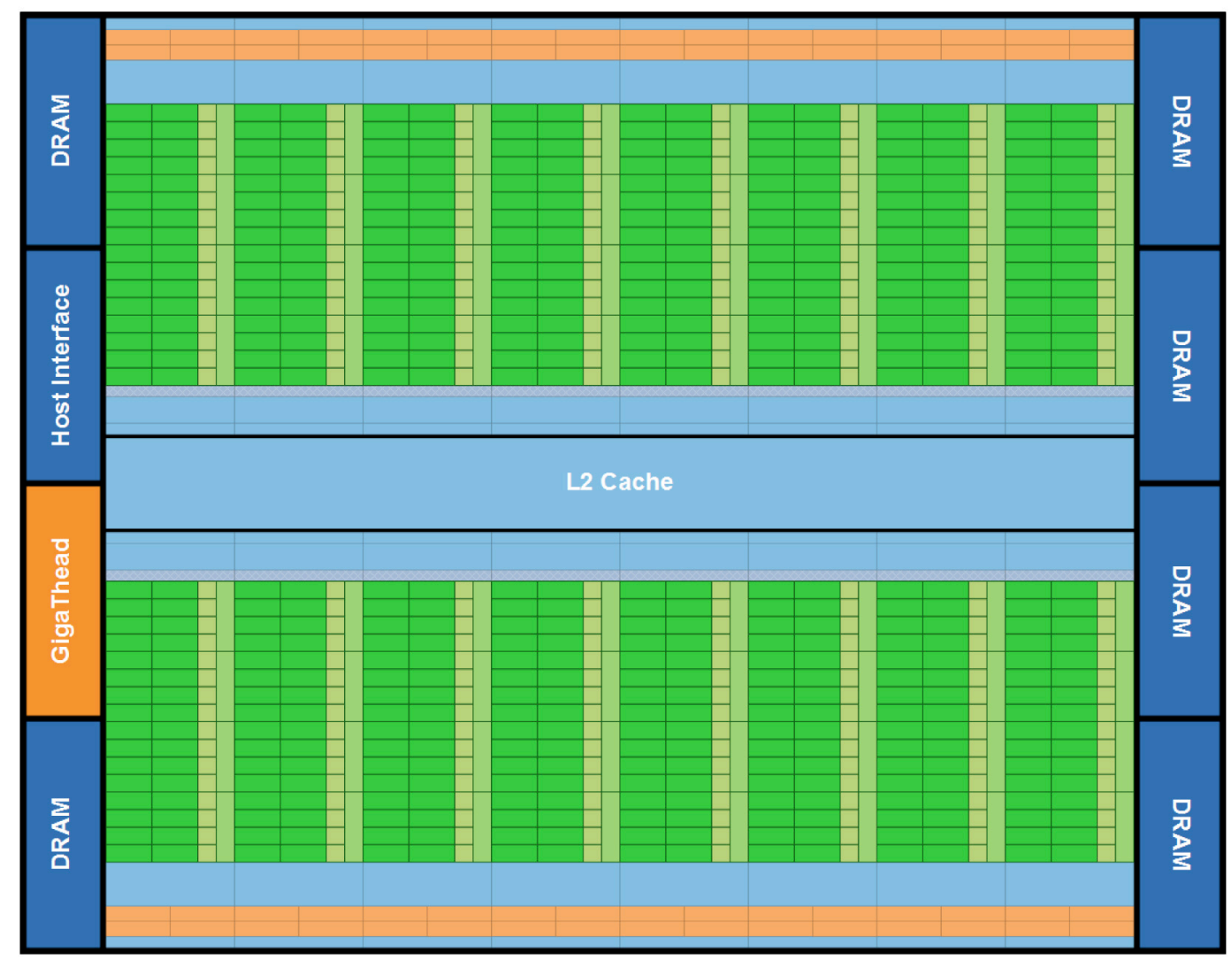

Fermi's 16 SM are positioned around a common L2 cache. Each SM is a vertical rectangular strip that contain an orange portion (scheduler and dispatch), a green portion (execution units), and light blue portions (register file and L1 cache). 
Figure 2. A Fermi streaming multiprocessor (SM). ${ }^{16}$ Each multiprocessor has its own cache, shared memory, registers, and warp scheduler. There are 32 cores per SM, 16 load/store units, and 4 special function units.

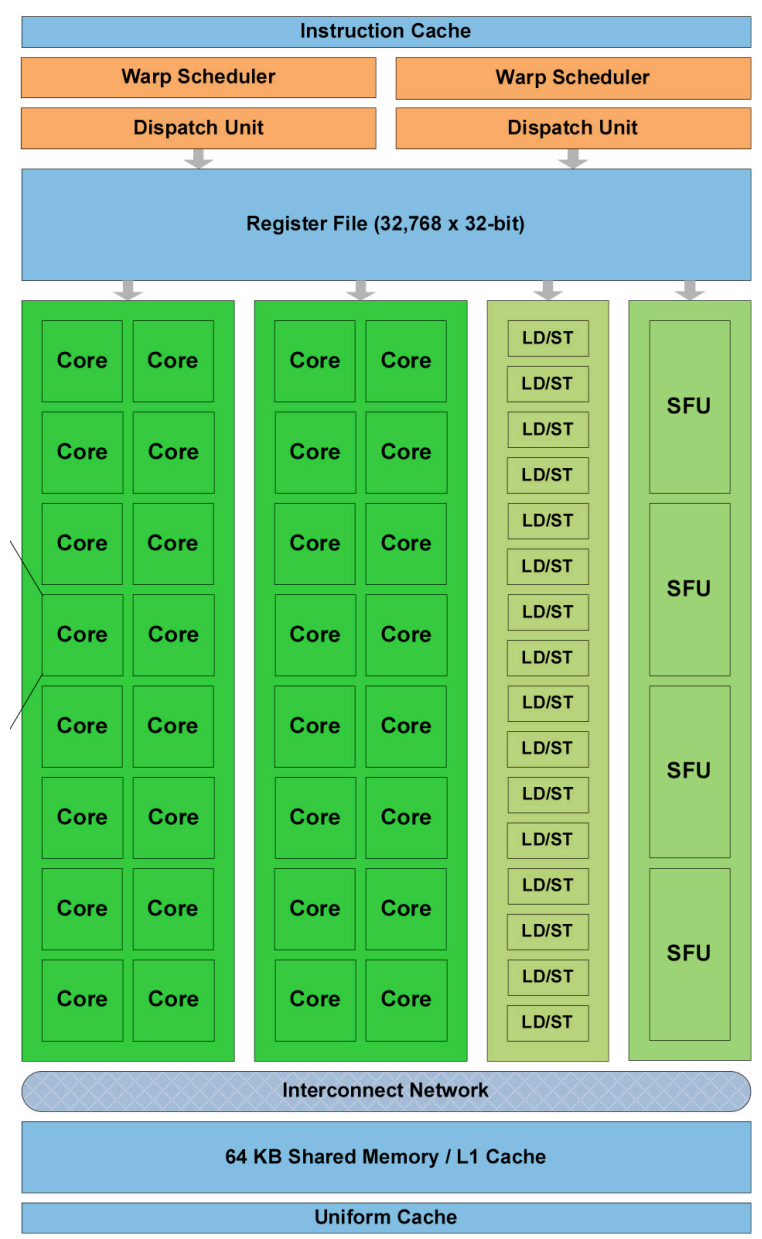

Fermi Streaming Multiprocessor (SM)

Figure 3. A single core in a Fermi streaming multiprocessor (SM). ${ }^{16}$ The core handles both floating point and integer operations.

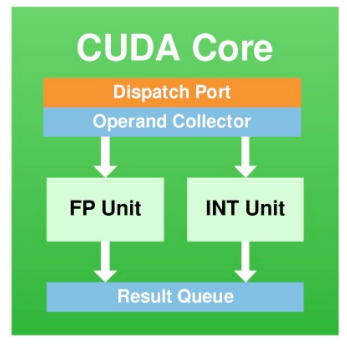


Figure 4. A sample code excerpt using the explicit method

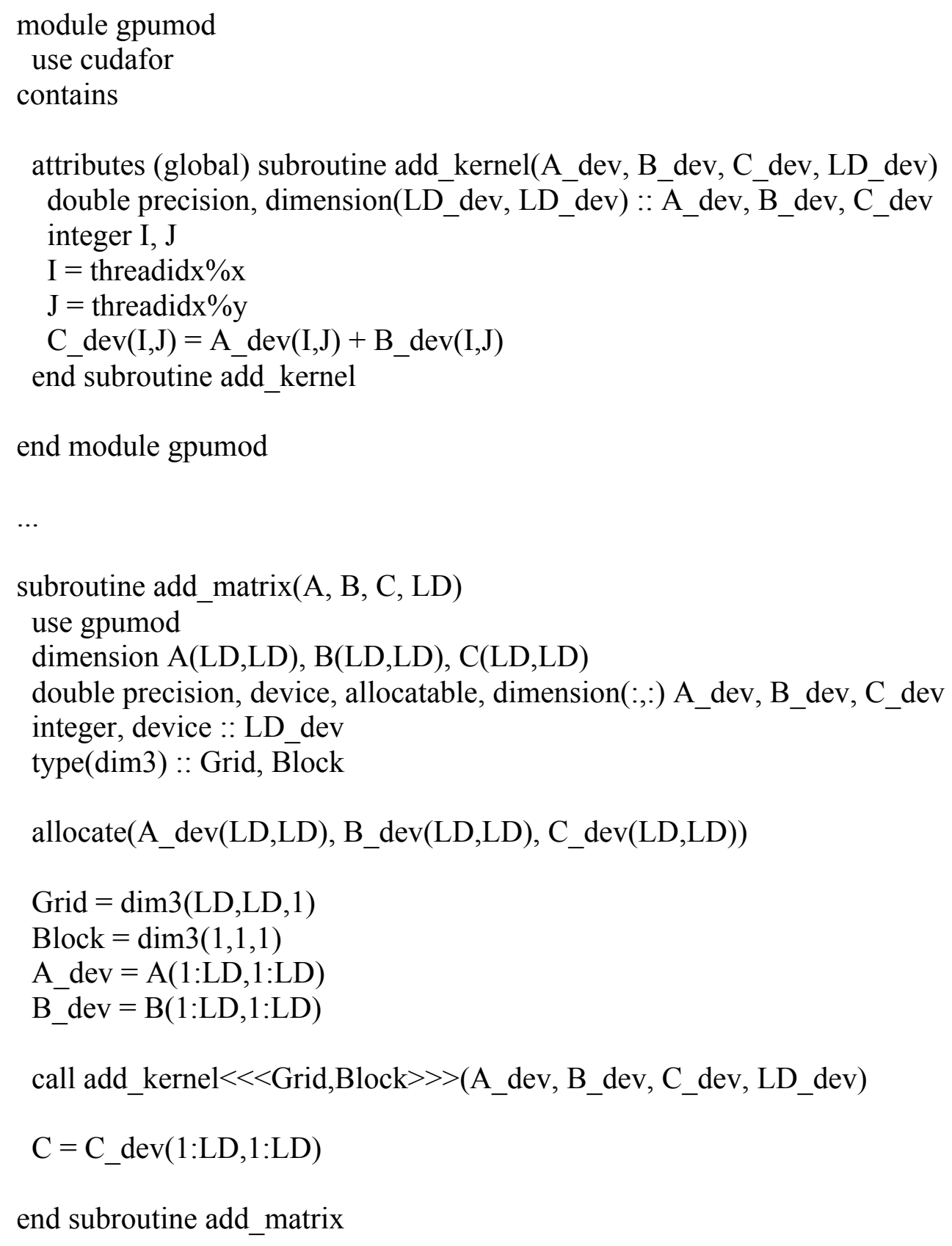


Figure 5. ! \$acc directive used to implement a single do loop on a GPU

$$
\begin{aligned}
& \text { !\$acc do } \\
& \text { do } \mathrm{i}=1,1000 \\
& \mathrm{C}(\mathrm{i})=\mathrm{A}(\mathrm{i})+0.5 * \mathrm{~B}(\mathrm{i}) \\
& \text { end do }
\end{aligned}
$$

Figure 6. An alternative method for parallelizing loops with directives

$$
\begin{aligned}
& \text { !\$acc region } \\
& \text { do } i=1,1000 \\
& \text { do } j=1,1500 \\
& \quad C(i, j)=A(i, j)+0.5 * B(i, j) \\
& \text { end do } \\
& \text { end do } \\
& \text { !\$acc end region }
\end{aligned}
$$

Figure 7. Multiple nested do loops inside an accelerator region. Each set of loops becomes a GPU kernel.

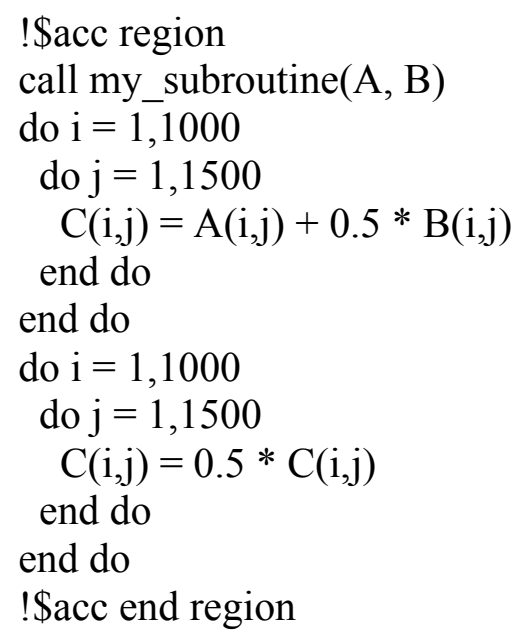


Figure 8. Looping over an accelerator region results in memory copies for each iteration.

$$
\begin{aligned}
& \text { do } i=1,1000 \\
& \text { !\$acc region } \\
& \text { do } j=1,1500 \\
& C(i, j)=A(i, j)+0.5 * B(i, j) \\
& \text { end do } \\
& \text { !\$acc end region } \\
& \text { end do }
\end{aligned}
$$

Figure 9. A data region enclosing the loop prevents data copies at every iteration.

$$
\begin{aligned}
& \text { !\$acc data region } \\
& \text { do } \mathrm{i}=1,1000 \\
& \text { !\$acc region } \\
& \text { do } \mathrm{j}=1,1500 \\
& \mathrm{C}(\mathrm{i}, \mathrm{j})=\mathrm{A}(\mathrm{i}, \mathrm{j})+0.5 * \mathrm{~B}(\mathrm{i}, \mathrm{j}) \\
& \text { end do } \\
& \text { !\$acc end region } \\
& \text { end do } \\
& \text { !\$acc end data region }
\end{aligned}
$$


Figure 10. An example of mirrored data. The vector $B$ is allocated in host and device memory simultaneously.

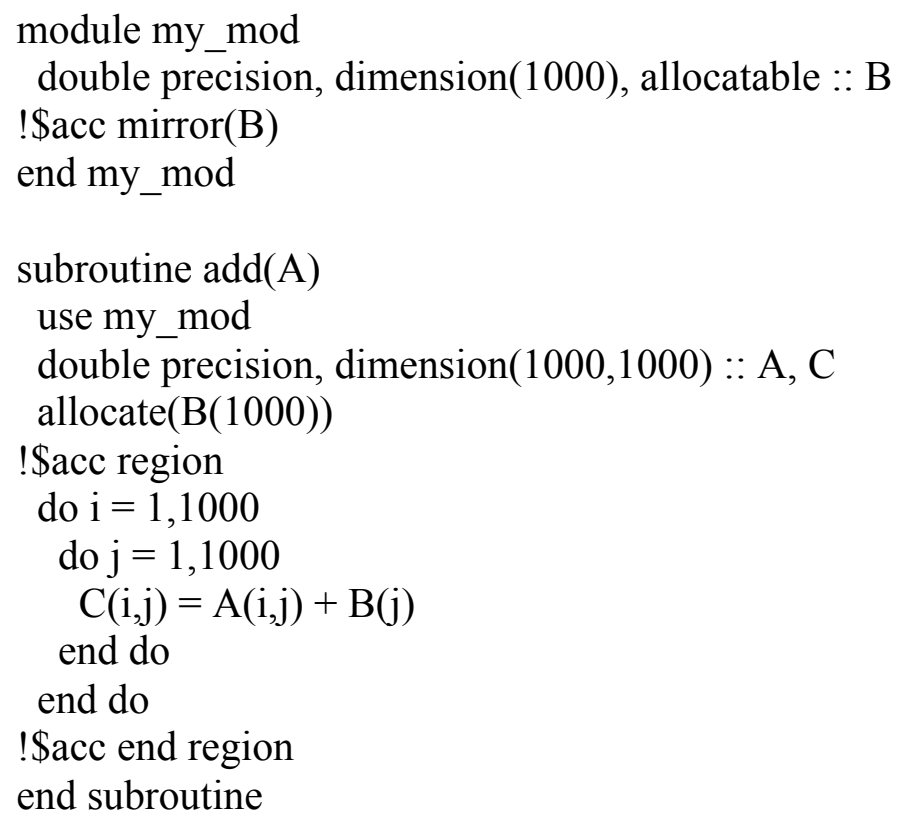

Figure 11. The updatein clause updates the device copy of the vector B.

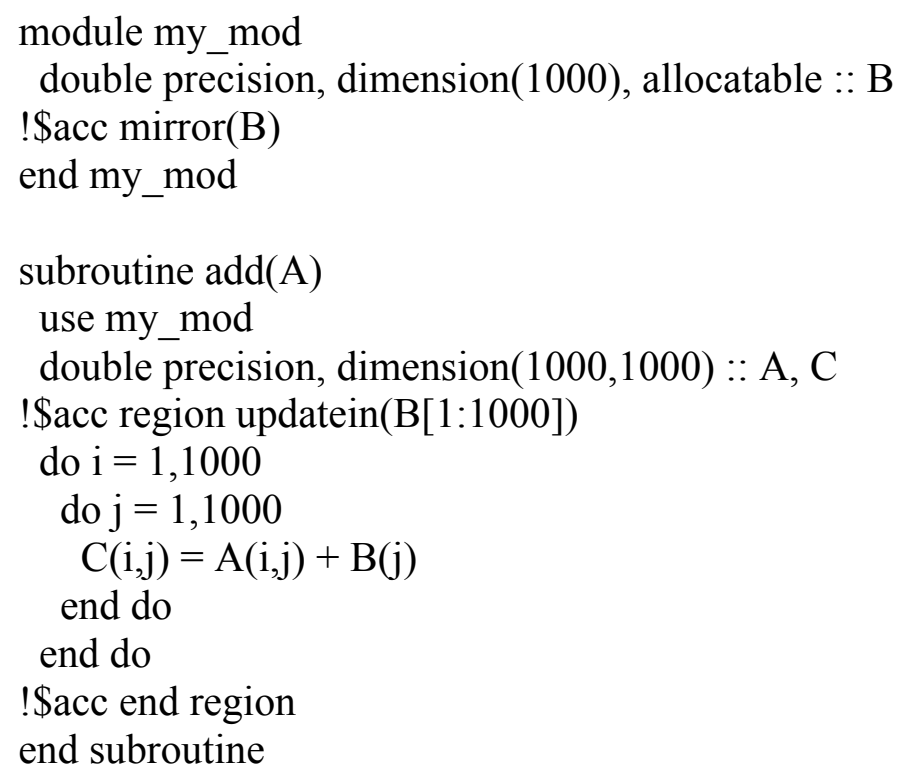


Figure 12. The accelerator region contains nested a do loop with dependencies on C, D, and Sum.

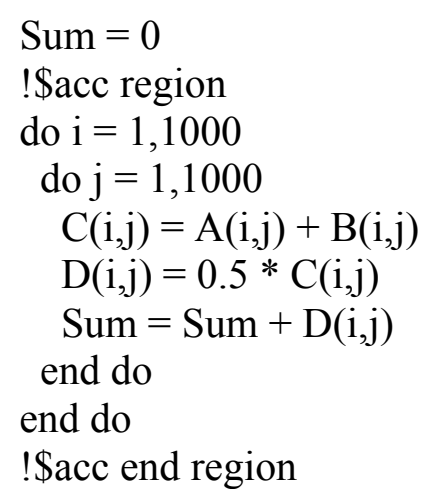

Figure 13. Dependencies on C, D, and Sum are removed by making three separate nested loops. Each of the nested loops becomes a separate GPU kernel.

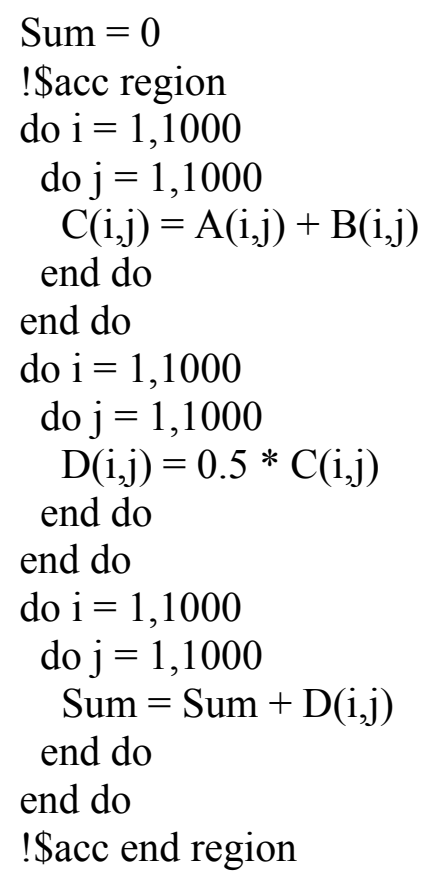


Figure 14. An excerpt from the Douglas-Kroll code in GAMESS. This part of the code uses triangular mapping, which makes implementation on a GPU difficult.

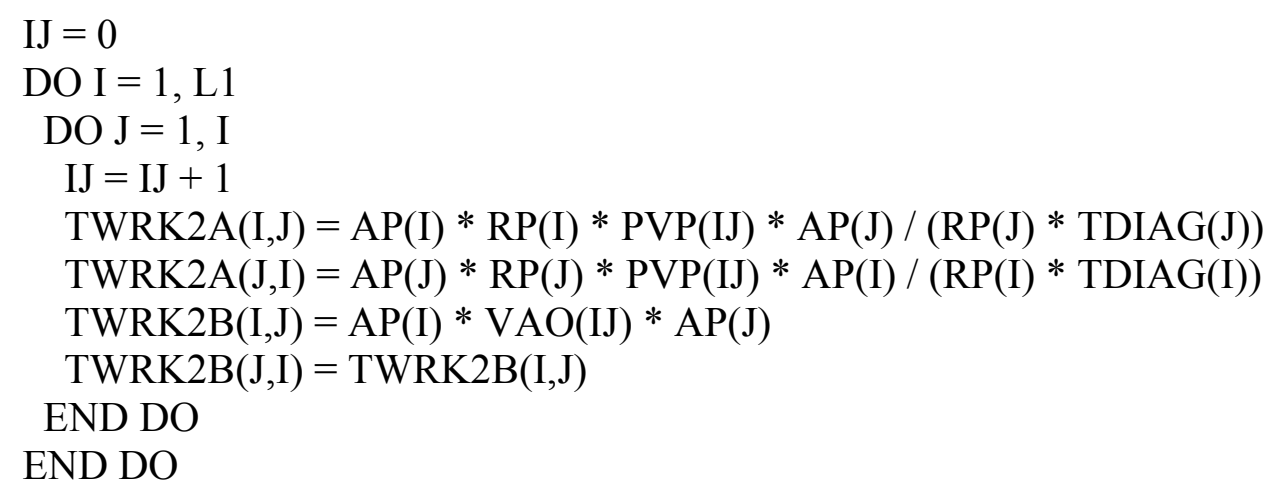

Figure 15. An explicit GPU kernel recast to have rectangular dimensions.

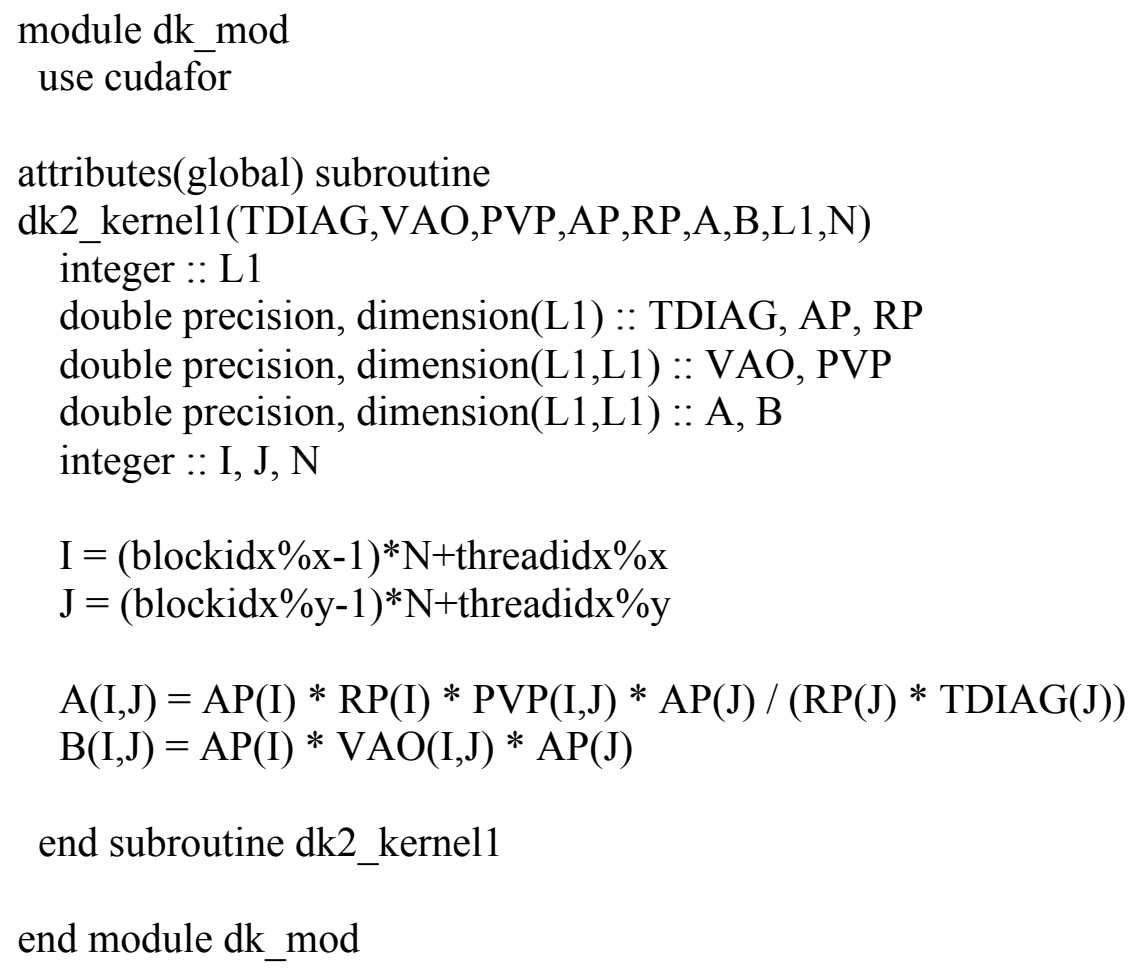




\section{References}

${ }^{1}$ Goetz, A. W.; Williamson, M. J.; Xu, D.; Poole, D.; Grand, S. L.; Walker, R. C. "Routine microsecond molecular dynamics simulations with AMBER - Part 1: Generalized Born) 2011, (in review).

${ }^{2}$ Salomon-Ferrer, R.; Goetz, A. W.; Poole, D.; Grand, S. L.; Walker, R. C “Routine microsecond molecular dynamics simulations with AMBER - Part 2: Particle Mesh Ewald” 2011, (in preparation).

${ }^{3}$ Hess, B.; Kutzner, C.; van der Spoel, D.; Lindahl, E. J. Chem. Theory Comput. 2008, 4 (3), 435 .

${ }^{4}$ Plimpton, S. J. Comp. Phys. 1995, 117, 1. http://lammps.sandia.gov

${ }^{5}$ Anderson, J. A.; Lorenz, C. D.; Travesset, A. Comp. Phys. 2008, 227 (10), 5342.

${ }^{6}$ Ufimtsev, I. S.; Martinez, T. J Comp. Sci. \& Eng. 2008, 10 (6), 26.

7 NVidia, NVidia Tesla C870 GPU Computing Processor Board 2008, www.nvidia.com/docs/IO/43395/C870-BoardSpec_BD-03399-001_v04.pdf

${ }^{8}$ Wilkinson, K. A.; Sherwood, P.; Guest, M. F.; Naidoo, K. J. J. Comp. Chem. 2011, 32 (10), 2313.

${ }^{9}$ Asadchev, A.; Allada, V.; Felder, J.; Bode, B. M.; Gordon, M. S.; Windus, T. L. J. Chem. Theory Comput. 2010, 6, 696.

${ }^{10}$ Valiev, M.; Bylaska, E.; Govind, N.; Kowalski, K.; Straatsma, T.; Van Dam, H.; Wang, D.; Nieplocha, J.; Apra, E.; Windus, T.; de Jong, W. Comp. Phys. Comm. 2010, $58,1477$.

${ }^{11}$ Shao, Y.; Fusti-Molnar, L.; Jung, Y.; Kussmann, J.; Ochsenfeld, C.; Brown, S. T.; Gilbert, A. T. B.; Slipchenko, L. V.; Levchenko, S. V.; O’Neill, D. P.; Distasio Jr., R. A.; 
Lochan, R. C.; Wang, T.; Beran, G. J. O.; Belsey, N. A.; Herbert, J. M.; Lin, C. Y.; Van Voorhis, T.; Chien, S. H.; Sodt, A.; Steele, R. P.; Rassolov, V. A.; Maslen, P. E.; Korambath, P. P.; Adamson, R. D.; Austin, B.; Baker, J.; yurd, E. F. C.; Dachsel, H.; Doerksen, R. J.; Dreuw, A.; Dunietz, D.; Dutoi, A. D.; Furlani, T. R.; Gwaltney, S. R.; Heyden, A.; Hirata, S.; Hsu, C. -P.; Kedziora, G.; Khalliulin, R. Z.; Klunzinger, P.; Lee, A. M.; Lee, M. S.; Liang, W.; Lotan, I.; Nari, N.; Peters, B.; Proynov, E. I.; Pieniazek, P. A.; Rhee, Y. M.; Ritchie, J.; Rosta, E.; Sherrill, C. D.; Simmonett, A. C.; Subotnik, J. E.; Woodcock III, H. L.; Zhang, W.; Bell, A. T.; Chakraborty, A. K.; Chipman, D. M.; Keil, F. J.; Warshel, A.; Hehre, W. J.; Schaefer III, H. F.; Kong, J.; Krylov, A. I.; Gill, P. M. W.; Head-Gordon, M. Phys. Chem. Chem. Phys. 2006, 8, 3172.

12 Frisch, M. J.; Trucks, G. W.; Schlegel, H. B.; Scuseria, G. E.; Robb, M. A.; Cheeseman, J. R.; Scalmani, G.; Barone, V.; Mennucci, B.; Petersson, G. A.; Nakatsuji, H.; Caricato, M.; Li, X.; Hratchian, H. P.; Izmaylov, A. F.; Bloino, J.; Zheng, G.; Sonnenberg, J. L.; Hada, M.; Ehara, M.; Toyota, K.; Fukuda, R.; Hasegawa, J.; Ishida, M.; Nakajima, T.; Honda, Y.; Kitao, O.; Nakai, H.; Vreven, T.; Montgomery, Jr., J. A.; Peralta, J. E.; Ogliaro, F.; Bearpark, M.; Heyd, J. J.; Brothers, E.; Kudin, K. N.; Staroverov, V. N.; Kobayashi, R.; Normand, J.; Raghavachari, K.; Rendell, A.; Burant, J. C.; Iyengar, S. S.; Tomasi, J.; Cossi, M.; Rega, N.; Millam, N. J.; Klene, M.; Knox, J. E.; Cross, J. B.; Bakken, V.; Adamo, C.; Jaramillo, J.; Gomperts, R.; Stratmann, R. E.; Yazyev, O.; Austin, A. J.; Cammi, R.; Pomelli, C.; Ochterski, J. W.; Martin, R. L.; Morokuma, K.; Zakrzewski, V. G.; Voth, G. A.; Salvador, P.; Dannenberg, J. J.; Dapprich, S.; Daniels, A. D.; Farkas, Ö.; Foresman, J. B.; Ortiz, J. V.; Cioslowski, J.; Fox, D. J. Gaussian 09, Revision A.1 2009, Gaussian Inc., Wallingford CT. 
${ }^{13}$ www.openacc-standard.org/home, OpenACC, Accessed on March 26, 2010.

${ }^{14}$ http://developer.nvidia.com/cuda-toolkit-41, CUDA Toolkit 4.1, Accessed on March 30, 2012.

${ }^{15}$ http://www.nvidia.com/object/picoatom_specifications.html, Accessed on March 20, 2012.

${ }^{16}$ NVidia, NVIDIA's Next Generation CUDA Compute Architecture: Fermi 2009. Used with permission from NVidia, Copyright 2009. 


\section{General Conclusions}

\section{Uranyl Complexes}

The complexation of gas phase $\mathrm{UO}_{2}{ }^{2+}$ with nitrile and carbonyl ligands has been examined. Both types of ligands bind to uranyl with the nitrogen or oxygen lying in the equatorial plane. However, complexes containing six ligands, as well as the five coordinate acetone complex, experience distortions due to steric effects that force them to deviate from the equatorial plane. Additionally, the plane of the nitrile ligands is parallel to $\mathrm{UO}_{2}{ }^{2+}$, while the plane of the carbonyl ligands is generally perpendicular to $\mathrm{UO}_{2}{ }^{2+}$. The carbonyls, however, have side groups closer to uranium than do the nitrile. This forces the plane of the carbonyl ligands to deviate from a $90^{\circ}$ angle with $\mathrm{UO}_{2}{ }^{2+}$ when 5 or 6 ligands are present. Additionally, while the nitrile series binds to uranyl with a U-N-C angle of $180^{\circ}$, the carbonyl series binds with a U-O-C angle less than $180^{\circ}$ in the equatorial plane when 4 or more ligands are present. Notably, formaldehyde is the only ligand studied that does not form a 6 coordinate complex with uranyl.

Both classes of ligands exhibit a strong affinity for uranyl; however, the nitrile ligands tend to bind more strongly than the carbonyls. The strength of the uranyl-ligand bonds are also influenced by the size of the ligands. Larger ligands more easily stabilize a shift in electron density, and thus are more capable of donation to the metal center. This effect is most noteworthy for the first ligand addition, and it diminishes as more ligands are added. Complexes containing up to six ligands have been modeled, and the relative binding energies predict all complexes to have five ligands with the exception of complexes containing either propionitrile or acetone ligands. This is similar to experimental results obtained van Stipdonk et al. in their ESI-MS study of nitrile 
containing complexes ${ }^{1}$. However, no complexes with six ligands were found in this experimental study.

Reactions involving dicationic uranyl complexes with both water and nitrile (acetonitrile, propionitrile, and benzonitrile) ligands have also been examined. These include charge-exchange reactions, whereby a dicationic complex is reduced to a monocationic complex, addition of ligands to the dicationic complexes, and addition of ligands to the monocationic complexes. While most of the complexes presented here have been experimentally observed, the inclusion of all the other possible products has enabled a thorough study of the processes observed experimentally. These results help shed light on some of the possible products of those reactions that have not been observed. Additionally, mass spectrometry studies are unable to distinguish between isomers. In some cases this may be a significant disadvantage. However, the computational results presented here show that, in general, the possible isomers (cis or trans) of interest are isoenergetic. Therefore, it is expected that they would be formed in nearly equal proportions.

The predominant reaction pathway in this study is ligand addition. It has been shown that ligand addition reactions are always thermodynamically favored as long as the equatorial coordination number is less than five for dicationic complexes and less than 4 for monocationic complexes. Addition of more ligands is generally either endoergic or the exoergicity of the reaction is small enough that thermodynamics alone is not enough to drive the reaction forward. The addition of a water ligand versus a nitrile ligand is influenced by the ratio of nitrile ligands to water ligands in the precursor ion. When there is a predominance of water ligands, the binding energy for the next ligand addition 
becomes more exoergic than if the precursor ion contains primarily nitrile ligands. This has a greater effect on the binding energies of nitrile additions than it does on water additions. Therefore, the tendency to add a nitrile ligand is enhanced when the precursor ion contains predominantly water ligands. This effect occurs for ligand additions to both the dicationic and the monocationic species and can explain the large number of dicationic complexes with mainly nitrile ligands observed experimentally. ${ }^{1}$

In addition to ligand addition reactions, charge-exchange or hydrolysis reactions of the form of equations 1 and 2 have been examined.

$$
\begin{aligned}
& {\left[\mathrm{UO}_{2}\left(\mathrm{H}_{2} \mathrm{O}\right)_{\mathrm{m}}(\mathrm{RCN})_{\mathrm{n}}\right]^{2+} \rightarrow\left[\mathrm{UO}_{2} \mathrm{OH}\left(\mathrm{H}_{2} \mathrm{O}\right)_{\mathrm{m}-2}(\mathrm{RCN})_{\mathrm{n}}\right]^{+}+\mathrm{H}_{3} \mathrm{O}^{+}} \\
& {\left[\mathrm{UO}_{2}\left(\mathrm{H}_{2} \mathrm{O}\right)_{\mathrm{m}}(\mathrm{RCN})_{\mathrm{n}}\right]^{2+} \rightarrow\left[\mathrm{UO}_{2} \mathrm{OH}\left(\mathrm{H}_{2} \mathrm{O}\right)_{\mathrm{m}-1}(\mathrm{RCN})_{\mathrm{n}-1}\right]^{+}+(\mathrm{H}+\mathrm{RCN})^{+}}
\end{aligned}
$$

These reactions involve at least two ligands, and water must be one of them. The reaction energies of the charge-exchange reactions indicate that they are thermodynamically competitive with the third ligand addition to dicationic precursor ions, although they are less exoergic than the third ligand addition. Charge-exchange reactions are still exoergic when the precursor ion has many ligands, but only if the reaction proceeds via equation $2\left(\operatorname{loss}\right.$ of $\left.(\mathrm{H}+\mathrm{RCN})^{+}\right)$rather than by equation 1 (loss of $\mathrm{H}_{3} \mathrm{O}^{+}$). Once the complex is reduced to a monocation, it then can proceed with subsequent ligand additions. As with ligand additions to dicationic complexes, nitrile addition is favored when ligands are added to monocationic complexes. However, the difference in binding energies between a nitrile and water - and even among the nitriles themselves - is diminished when adding to monocationic species. Thus, water becomes 
more competitive when adding to monocationic complexes than it is when adding to dicationic complexes. This tendency, along with the initial depletion of dicationic complexes that contain water through the charge-exchange process, helps explain the tendency of monocationic species to be observed with a larger proportion of water ligands than are observed with dicationic species.

Some important details can be elucidated from the data presented in Chapter 4. It has been shown that care must be taken when choosing a density functional for these systems. The results of this study suggest that the SSB-D functional provides the best binding energies compared with MP2 for complexes that have acetone directly bound to uranyl, and CAM-B3LYP provides the best agreement with MP2 for complexes that have acetones that are not directly bound to uranyl. With six acetones, only LDA gave the correct trend (although it significantly over-binds compared to MP2).

More significantly, the hypercoordinated species previously reported ${ }^{2}$ do not simply involve coordination of acetone ligands to uranyl. The seventh and eighth, and in some computational approaches even the sixth, acetone generally does not bind directly to uranyl. There simply is not sufficient room in the equatorial plane to accommodate so many bulky ligands. However, the structures with additional acetones in the second solvation sphere do appear to be possible from the binding energies. Other more exotic species involving proton transfer between acetones and species involving enol tautomers of acetone are high-energy species that are unlikely to form. Additionally, the complexes obtained exist in very shallow potential energy wells suggesting that numerous geometries might be possible, although the last few acetones will necessarily be in the second solvation shell. 
The experimental conditions under which the apparently "hypercoordinated" complexes, $\left[\mathrm{UO}_{2}(\text { Ace })_{6,7,8}\right]^{2+}$, were observed have been described in chapters 3 and 4., An ion trap gas-phase hydration study under similar conditions resulted in monopositive metal ion complexes coordinated by inner-shell waters but not second-shell waters. ${ }^{4}$ DFT computations of $\left[\mathrm{Yb}(\mathrm{OH})_{2}\left(\mathrm{H}_{2} \mathrm{O}\right)_{n}\right]^{+}(\mathrm{n}=1-5)$, for example, demonstrated that the first four waters are directly bound to the $\mathrm{Yb}$ metal center. Addition of a fifth water to the second shell was computed to be both exothermic and exoergic, but was not observed under the experimental conditions, $\mathrm{P}\left[\mathrm{H}_{2} \mathrm{O}\right] \approx 300 \mathrm{~K}$. As second shell acetones should generally be less strongly bound than hydrogen-bonded second shell waters, and the acetone pressure in the ion trap is less than that of water, experimental observations of weakly-bound second shell acetones such as in structure $\mathbf{3 A}$ (in chapter 4) are not expected. From the experimental observation of the $\left[\mathrm{UO}_{2}(\text { Ace })_{6,7,8}\right]^{2+}$ complexes, and the theory results that their energetically favored structures have outer sphere acetones, it can be concluded that the observed complexes most probably do not comprise only acetone ligands and that uranyl is not necessarily "hypercoordinated."

Both CID experiments and computational results indicate that diacetone alcohol (DAA) is responsible for the apparent hypercoordination of uranyl. DAA binds more strongly than acetone (ACO) to uranyl, partly because of its capacity to be a bidentate ligand. When the number of coordinating oxygens in the equatorial plane is less than five, DAA always adopts a bidentate arrangement. Since the number of coordinating oxygens never exceeds five, additional DAA ligands adopt a monodentate configuration that leads to the apparent hypercoordination of uranyl. In CID experiments, presence of products with a mesityl oxide ligand (MOX) is observed. MOX is the result of 
dehydration of DAA. Since MOX products are observed even when the precursor ion is prepared using "pure" acetone, dimerization to form DAA must occur. Similarity between CID spectra with $\left[\mathrm{UO}_{2}(\mathrm{ACO})_{6}\right]^{2+}$ and $\left[\mathrm{UO}_{2}(\mathrm{DAA})_{3}\right]^{2+}$ further confirm that acetone dimerizes to form DAA.

Computational results together with isotopic labeling allow for some degree of understanding of the CID spectra. Five processes were proposed and four of these were observed. Loss of a DAA ligand is never observed due to the large magnitude of the binding energy of DAA to uranyl. Loss of acetone is observed and can occur either by loss of an acetone ligand or by decomposition of DAA to form two acetones, one of which dissociates from uranyl. Isotopic labeling of either DAA or acetone allows for a distinction between these two processes. For ACO loss to occur by either process, there must be 5 coordinating oxygens in the equatorial plane. Simple acetone ligand loss is largely favored over DAA decomposition if there are exactly five coordinating oxygens and no additional oxygens from monodentate DAA. Products with a MOX ligand are also produced, but the thermodynamically favored MOX products found in the computational study are not observed experimentally. Rather, these products lose $[\mathrm{MOX}+\mathrm{H}]^{+}$to form an alkoxide ligand. Alkoxide product formation is favored over MOX product formation when the equatorial plane is saturated and at least one DAA adopts a monodentate configuration.

\section{Boratoiridium(I) Complexes}

Tris(oxazolinyl)boratoiridium(I) scorpionates clearly differ from isoelectronic tris(pyrazolyl)borates in their interactions with electrophiles. Protonation of $\mathrm{TpML}_{2}$-type 
compounds provides metal hydrides in several cases, ${ }^{5}$ whereas three electrophiles EX $(\mathrm{EX}=$ HOTf, MeOTf, and $\mathrm{LiCl})$ interact with $\left[\operatorname{Ir}\left(\mathrm{To}^{\mathrm{M}}\right) \mathrm{L}_{2}\right]$ to give $\left[\operatorname{Ir}\left(\kappa^{2}-\mathrm{To}^{\mathrm{M}}-\mathrm{E}\right) \mathrm{L}_{2}\right]^{+}$ compounds. These oxazoline-electrophile interactions have been established by ${ }^{15} \mathrm{~N}$ NMR HMBC experiments through chemical shift comparisons and through-bond coupling, as well as through X-ray crystallography. Our computational results indicate that the highest energy electron pair resides in a non-coordinated $\pi_{\mathrm{CN}}$ bond, and this HOMO is consistent with our observed reactivity. Additionally, the calculations show that oxazolinemethylation (and likely oxazoline-protonation) is thermodynamically favored over iridium-based oxidative addition in these compounds. In contrast to these results, $\left[\mathrm{Tp} * \mathrm{Rh}(\mathrm{CO})_{2}\right]$ and MeI react via oxidative addition, ${ }^{6}$ although $\left[\mathrm{Tp} * \mathrm{Rh}(\mathrm{CO})_{2}\right]$ also reacts with $\mathrm{HBF}_{4} \cdot \mathrm{OEt}_{2}$ via pyrazolyl protonation. ${ }^{5 \mathrm{a}}$ Additionally, a cationic rhodium compound containing the neutral tris-ox ligand $\left[\mathrm{Rh}(\text { tris-ox })\left(\mathrm{C}_{8} \mathrm{H}_{12}\right)\right]^{+}$has been oxidized by $\mathrm{CsBr}_{3}$ to $\left[\mathrm{RhBr}_{3}(\right.$ tris-ox $\left.)\right] .^{7}$ These contrasting results could be attributed to differences in ligand (neutral versus anionic), metal center (rhodium versus iridium), or oxidant $\left(\mathrm{CsBr}_{3}\right.$ versus $\left.\mathrm{H}^{+}, \mathrm{Me}^{+}\right)$. Regardless, the $v_{\mathrm{CO}}$ for 4 and $\left[\operatorname{Ir}\left(\mathrm{To}^{\mathrm{P}}\right)(\mathrm{CO})_{2}\right]$ suggest that the tris(oxazolinyl)borate ligands are sufficiently electron donating to mediate oxidative addition of nonpolar bonds under photolytic conditions. Our investigations of stereoselective oxidative additions will be disclosed in due course.

\section{Catalytic Hydroamination/Cyclization}

Calculated thermodynamic data and barrier heights have been presented for the catalytic hydroamination/cyclization by a zirconium based catalyst. A model complex was proposed and substituents were added incrementally. Density functional theory 
predicts the reactions to be endoergic with high $(\sim 40 \mathrm{kcal} / \mathrm{mol})$ barriers. These results are in conflict with experimental observations. However, MP2 predicts exoergic processes and barriers on the order of $\sim 30 \mathrm{kcal} / \mathrm{mol}$. While the MP2 barriers are still high, it is not inconceivable that the full complex used experimentally has barriers that are even lower than those reported. Furthermore, the Wigner approximation predicts a small isotope effect contrary to experimental observations. However, the failure of density functional theory and the inadequacy of the Wigner approximation do not allow for a conclusive statement on the validity of the proposed reaction mechanism at this time. Further calculations are needed with additional substituents to recover complexes used experimentally. The trends in barrier height with substitution suggest that it may be possible that barriers for the fully substituted complexes that were studied experimentally may have barriers low enough to be practical at room temperature or lower. It is also possible that "spectator" substituents play an as yet unknown role in these reactions.

\section{PGI Fortran for Graphical Processors}

Use of graphical processors as a massively parallel coprocessor is still a developing technology. Multiple programming models have been developed to provide programmers with choices on how to implement the code. The explicit model, while the most powerful, is also the most difficult to use. Alternatively, the use of directives seems straightforward, but often requires a substantial rewrite of the CPU code in order to deal with restrictions associated with directives. Calls to GPU libraries can also be used, but, unless these are used in conjunction with either the explicit model or directives, the cost of the data transfers frequently outweighs the gains in computational performance. In all 
cases effective management and movement of data should be the programmer's primary concern. Given the current GPU architecture, limited by the PCI express bandwidth, and the ever-evolving coding styles, GPU programming is best left to the most ambitious, patient, and creative programmers, at least until the technology is better standardized.

\section{References}

${ }^{1}$ Van Stipdonk, M.J.; Chien, W.; Bulleigh, K.; Wu, Q.; Groenewold, G.S. J. Phys. Chem. A. 2006, 110, 959 .

${ }^{2}$ Rios, D.; Rutkowski, P. X.; Van Stipdonk, M. J.; Gibson, J. K., Inorg. Chem. 2011, 50, 4781.

${ }^{3}$ Schoendorff, G.; Windus, T. L.; de Jong, W. A., J. Phys. Chem. A 2009, 113, 12525.

${ }^{4}$ Rutkowski, P. X.; Michelini, M. C.; Bray, T. H.; Russo, N.; Marçalo, J.; Gibson, J. K., Theor. Chem. Acc. 2011, 129, 575.

${ }^{5}$ Ball, R. G.; Ghosh, C. K.; Hoyano, J. K.; McMaster, A. D.; Graham, W. A. G. J. Chem. Soc., Chem. Commun. 1989, 341. Bovens, M.; Gerfin, T.; Gramlich, V.; Petter, W.; Venanzi, L. M.; Haward, M. T.; Jackson, S. A.; Eisenstein, O. New J. Chem. 1992, 16, 337. Wiley, J. S.; Heinekey, D. M. Inorg. Chem. 2002, 41, 4961.

${ }^{6}$ Chauby, V.; Daran, J. C.; Serra-Le Berre, C.; Malbosc, F.; Kalck, P.; Gonzalez, O. D.; Haslam, C. E.; Haynes, A. Inorg. Chem. 2002, 41, 3280.

${ }^{7}$ Gade, L. H.; Marconi, G.; Dro, C.; Ward, B. D.; Poyatos, M.; Bellemin-Laponnaz, S.; Wadepohl, H.; Sorace, L.; Poneti, G. Chem.- Eur. J. 2007, 13, 3058. 